\title{
WestVirginiaUniversity
}

THE RESEARCH REPOSITORY @ WVU

Graduate Theses, Dissertations, and Problem Reports

2003

\section{Evaluation of $4.75 \mathrm{~mm}$ Superpave mix criteria for West Virginia}

David Diazgranados Diaz

West Virginia University

Follow this and additional works at: https://researchrepository.wvu.edu/etd

\section{Recommended Citation}

Diazgranados Diaz, David, "Evaluation of $4.75 \mathrm{~mm}$ Superpave mix criteria for West Virginia" (2003).

Graduate Theses, Dissertations, and Problem Reports. 1370.

https://researchrepository.wvu.edu/etd/1370

This Thesis is protected by copyright and/or related rights. It has been brought to you by the The Research Repository @ WVU with permission from the rights-holder(s). You are free to use this Thesis in any way that is permitted by the copyright and related rights legislation that applies to your use. For other uses you must obtain permission from the rights-holder(s) directly, unless additional rights are indicated by a Creative Commons license in the record and/ or on the work itself. This Thesis has been accepted for inclusion in WVU Graduate Theses, Dissertations, and Problem Reports collection by an authorized administrator of The Research Repository @ WVU. For more information, please contact researchrepository@mail.wvu.edu. 


\title{
EVALUATION OF 4.75 mm SUPERPAVE MIX CRITERIA FOR WEST VIRGINIA
}

\author{
David Diazgranados Diaz \\ Thesis submitted to the \\ College of Engineering and Mineral Resources at \\ West Virginia University \\ in partial fulfillment of the requirements for the degree of:
}

Master of Science

In

Civil Engineering

John P. Zaniewski, Ph.D. Chair

Ronald Eck, Ph.D.

Gary Winn, Ph.D.

Department of Civil and Environmental Engineering

Morgantown, West Virginia

2003

Keywords: Superpave, Asphalt Mix Design, Hot mix paving mixtures, Aggregate gradation, Low volume roads, Volumetric Analysis 


\section{ABSTRACT \\ Evaluation of $4.75 \mathrm{~mm}$ Superpave Mix Criteria for West Virginia David Diazgranados Diaz}

Since its first appearance in 1993 Superpave, an acronym for Superior

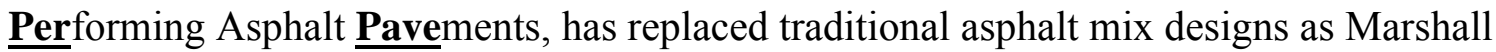
and Hveem for many applications. The West Virginia Division of Highways, WVDOH, first Superpave project was constructed in 1997. The department currently uses Superpave for National Highways System projects. Based on the success of these projects, the WVDOH is considering implementing Superpave for all projects. Under Marshall Specifications, the WVDOH commonly uses three mixes types Wearing I, Base I and Base II. These correspond to Superpave 9.5, 19 and $37.5 \mathrm{~mm}$ mixes. In addition, for rehabilitation of low volume roads the WVDOH uses a Wearing III mix. This mix has a nominal maximum aggregate size of $4.75 \mathrm{~mm}$. This type of mix is not currently available in the Superpave specifications.

The purpose of this research was to evaluate design parameters for $4.75 \mathrm{~mm}$ nominal maximum aggregate size mixes, NMAS, in West Virginia. This research was divided in two phases. During Phase I, evaluation of Superpave criteria for $4.75 \mathrm{~mm}$ NMAS mixes, a variety of $4.75 \mathrm{~mm}$ NMAS limestone mixes were developed following Superpave methodology for low traffic volume. In Phase II, natural sand evaluation for $4.75 \mathrm{~mm}$ mixes; three approved Marshall designs were obtained from the WVDOT. Two of the mixes contained natural sand and the other was a 100 percent limestone mix. The Marshall mix designs were verified and then redesigned using Superpave methodology for low volume traffic. Comparison between Marshall and Superpave mixes was performed. Additionally the Asphalt Pavement Analyzer, APA, was used to evaluate rutting performance of the Superpave mixes during both phases.

Based on the results of these evaluations, recommendations for Superpave mix design parameters for $4.75 \mathrm{~mm}$ NMAS mixes were developed. These recommendations allow the WVDOH to use Superpave in lieu of the current Marshall Wearing III mix. 


\section{ACKNOWLEDGMENTS}

I would like to express my most sincere gratitude to Dr. John Zaniewski for his guidance and encouragement throughout the research and thesis writing process. Without his support, guidance and time this work would not have been possible.

I would also like to thank Dr. Ronald Eck and Dr. Gary Winn, members of my thesis committee, for their precious time and guidance. Likewise, I extend my gratitude to Dr. George Seidel for his assistance.

Special thanks to Andy Kincell and my Lab mates at WVU Asphalt Technology Laboratory, for their support and assistance.

The support of J.F. Allen, Martin Marietta, and Marathon Ashland companies is acknowledged for the material supplied for the research. The research sponsorship of the West Virginia Division of Highways is appreciated.

Finally, I would like to thank my parents Walter, and Ada for their unconditional love and support throughout my life and college career, you are my source of strength and motivation. To my brothers Jonathan, Rommel and Willy for their guidance and example, and to my girlfriend Sandra for her unselfish love and support. To all of them my everlasting love and gratitude. 


\section{TABLE OF CONTENTS}

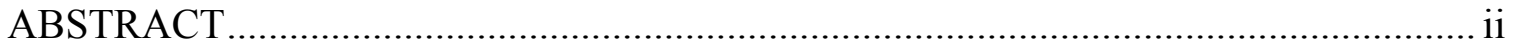

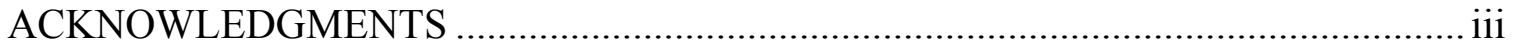

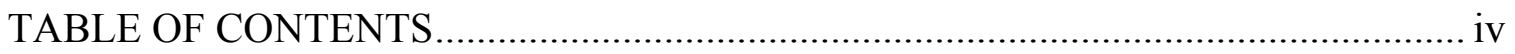

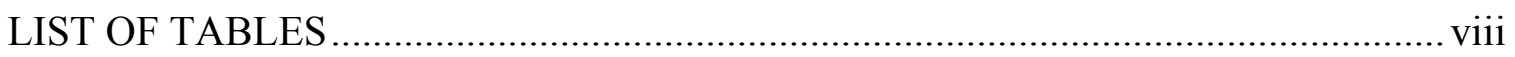

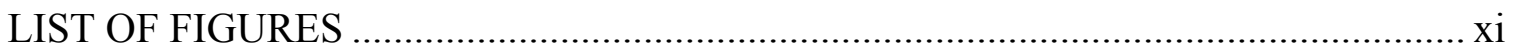

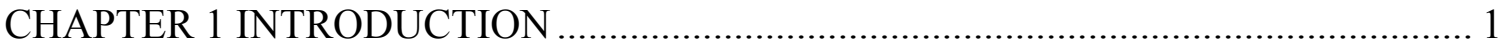

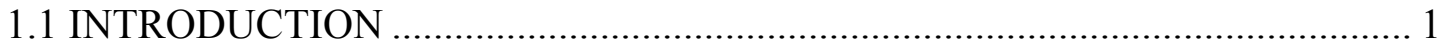

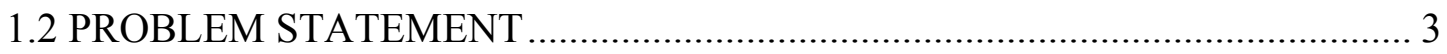

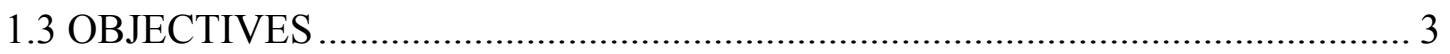

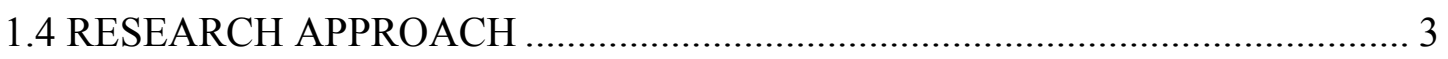

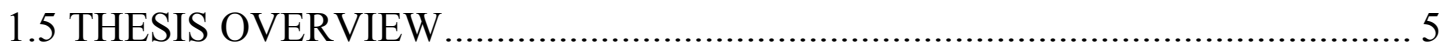

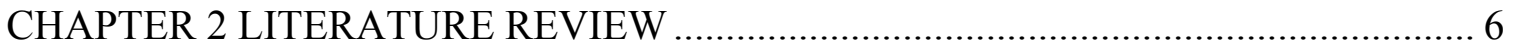

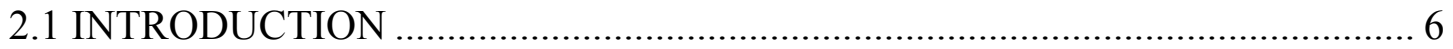

2.2 MARSHALL MIX DESIGN OVERVIEW ………………………………....... 7

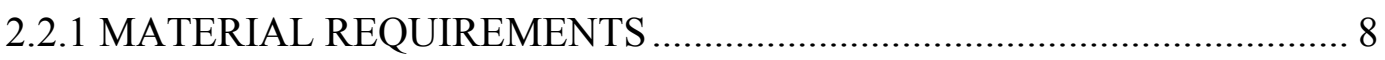

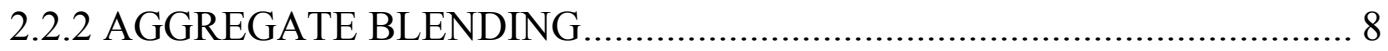

2.2.3 PREPARATION OF MARSHALL SPECIMENS ........................................ 9

2.2.4 VOLUMETRIC ANALYSIS........................................................... 10

2.2.4.1 Bulk Specific Gravity or Mix Density ............................................... 10

2.2.4.2 Maximum Specific Gravity of the Mixture. ………………………..... 11

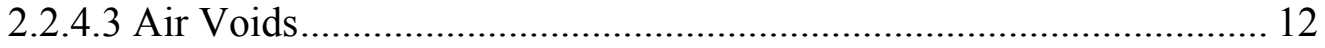

2.2.4.4 Voids in the Mineral Aggregates ......................................................... 13

2.2.4.5 Voids Filled with Asphalt ............................................................... 14

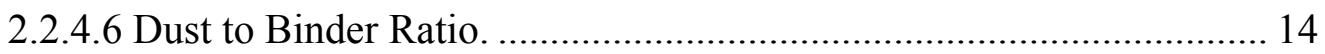

2.2.5 STABILITY AND FLOW MEASURES................................................. 15

2.2.6 OPTIMUM BINDER CONTENT DETERMINATION ……….................. 15

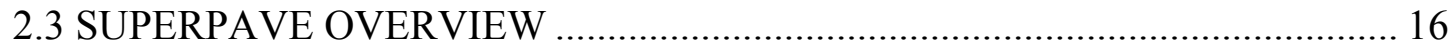

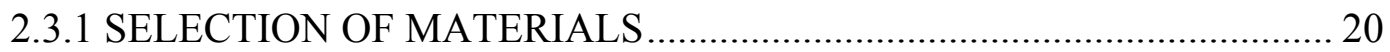


2.3.1.1 Asphalt Cement Grade.................................................................. 20

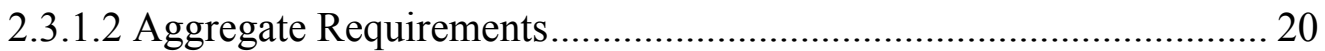

2.3.2 SELECTION OF THE DESIGN AGGREGATE STRUCTURE ................ 22

2.3.3 SELECTION OF THE DESIGN ASPHALT BINDER CONTENT........... 29

2.3.4 EVALUATION OF MOISTURE SUSCEPTIBILITY ……….................... 31

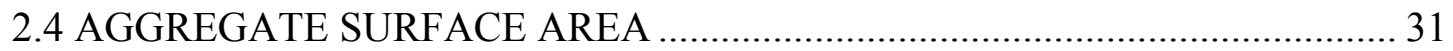

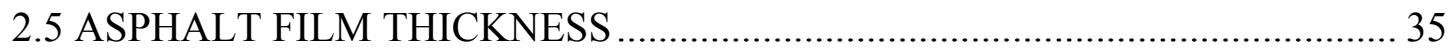

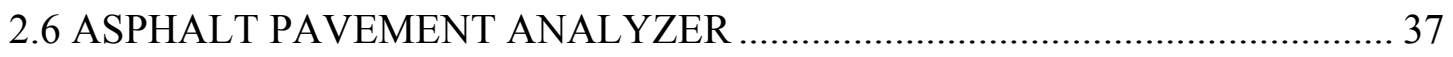

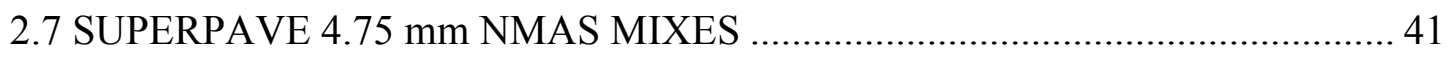

2.8 NATURAL SAND AS HMA AGGREGATE.................................................... 50

2.9 COMPARISON Of MARSHALL AND SUPERPAVE DESIGNS..................... 53

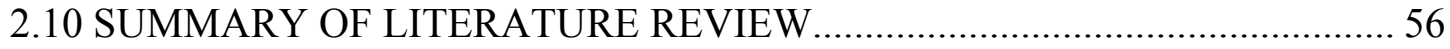

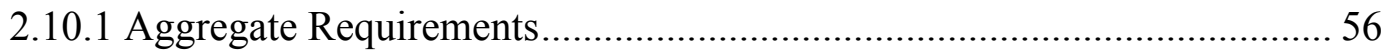

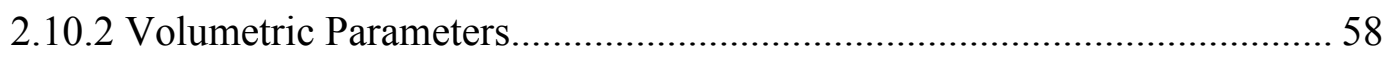

2.10.3 SGC Compaction Parameters .................................................................. 59

2.10.4 Asphalt Pavement Analyzer Parameters and Criteria ................................. 60

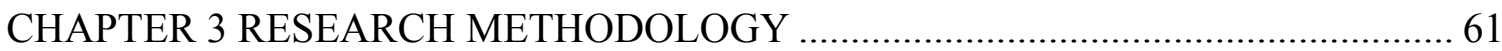

3.1 PHASE I EVALUATION OF CRITERIA FOR $4.75 \mathrm{~mm}$ MIXES........................ 61

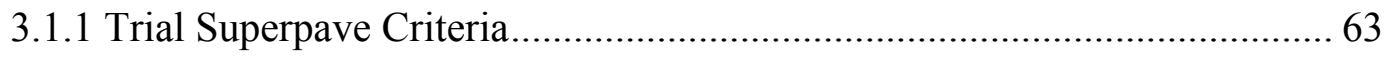

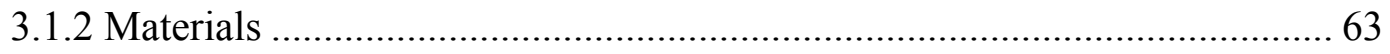

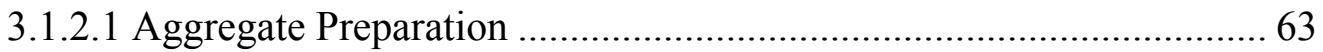

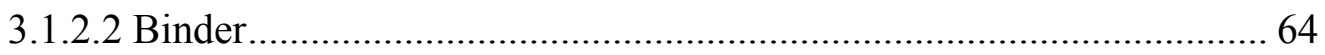

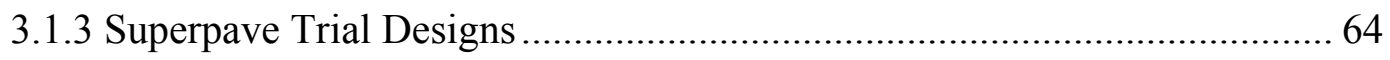

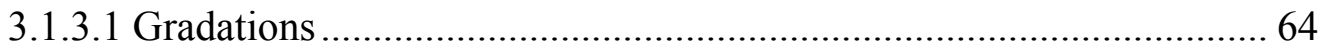

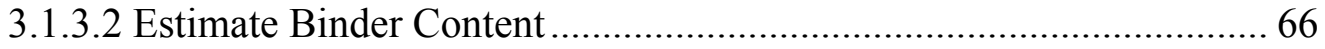

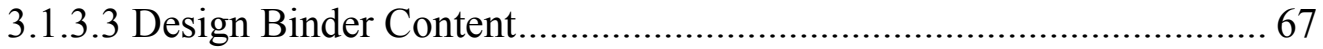

3.1.3.4 Surface Area and Thin Film Thickness Calculations .......................... 67

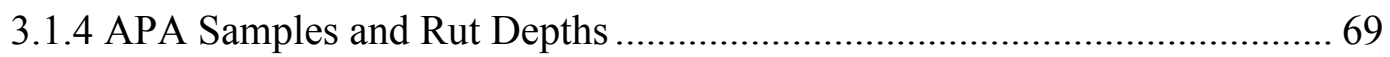

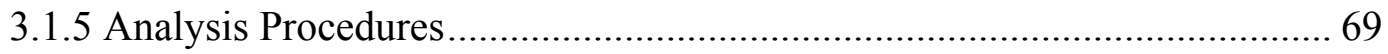




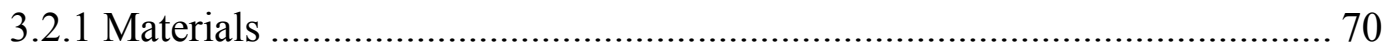

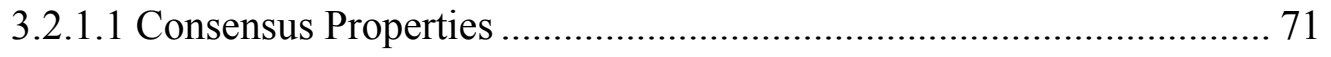

3.2.1.2 Aggregate Specific Gravity............................................................ 71

3.2.1.3 Aggregate Gradation ...................................................................... 72

3.2.2 Marshall Mix Designs............................................................................... 73

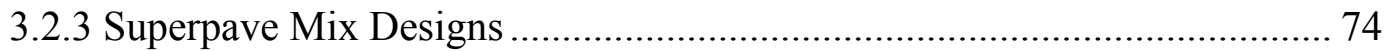

3.2.4 APA Samples and Rut Depths ................................................................... 75

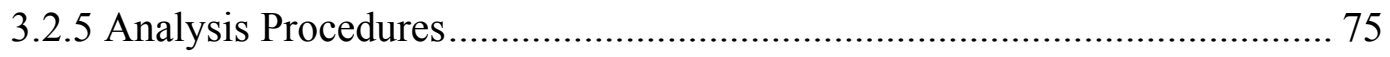

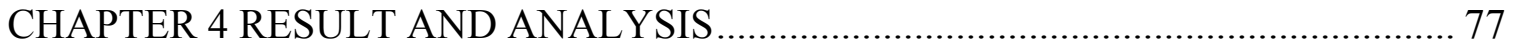

4.1 EVALUATION OF CRITERIA FOR 4.75 mm MIXES...................................... 77

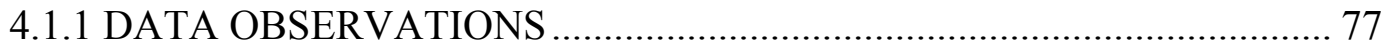

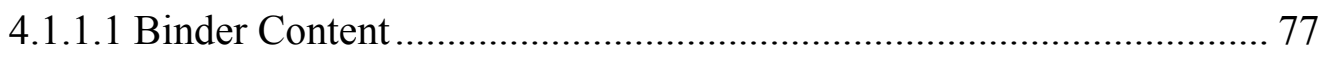

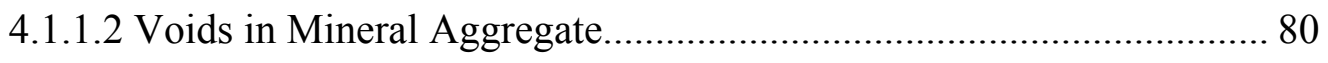

4.1.1.3 Voids Filled with Asphalt .................................................................. 82

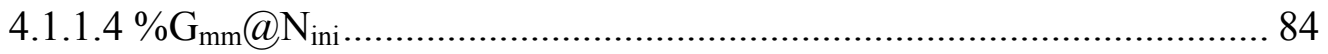

4.1.1.5 Dust to Effective Binder Ratio........................................................... 84

4.1.1.6 Asphalt Film Thickness ................................................................. 86

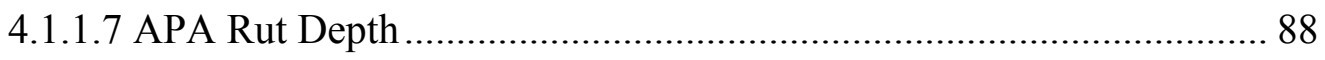

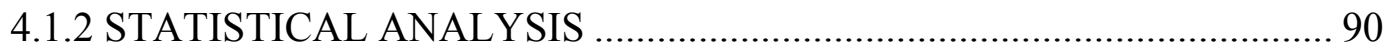

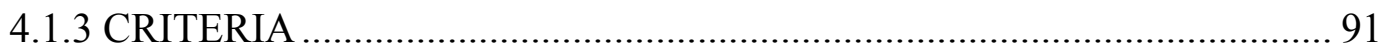

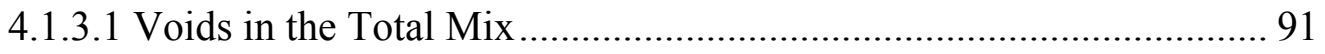

4.1.3.2 Voids in Mineral Aggregate.............................................................. 91

4.1.3.3 Voids Filled with Asphalt .................................................................... 95

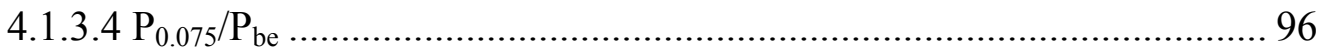

4.1.3.5 Gradation Control Points .................................................................... 97

4.1.3.6 Summary of Mix Design Recommendations ........................................ 97

4.2 COMPARISON OF MARSHALL AND SUPERPAVE 4.75 mm MIXES......... 98

CHAPTER 5 CONCLUSIONS AND RECOMMENDATIONS .................................... 104

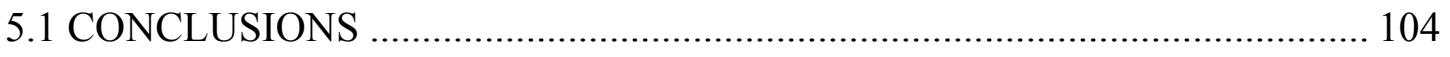




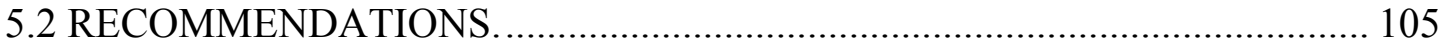

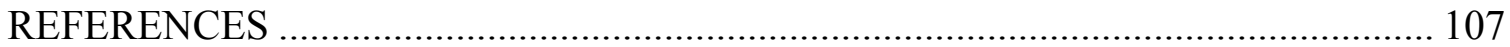

SPECIFICATIONS AND TEST METHODS …................................................... 109

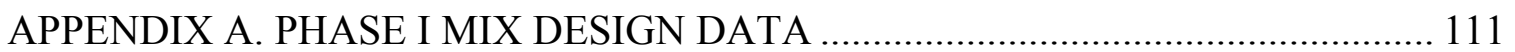

APPENDIX B. PHASE II MIX DESIGN DATA ….................................................... 133 


\section{LIST OF TABLES}

Table 1.1 Main study factors to develop $4.75 \mathrm{~mm}$ NMAS criteria................................. 4

Table 2.1 WVDOH aggregate gradation requirements for Marshall mix designs ............ 9

Table 2.2 WVDOH Marshall method mix design criteria .......................................... 17

Table 2.3 WVDOH requirements for minimum percent voids in mineral aggregate....... 18

Table 2.4 Typical roadway applications for Superpave mixes ................................... 19

Table 2.5 WVDOH gyratory compaction criteria................................................... 19

Table 2.6 Performance grades of asphalt binders ...................................................... 21

Table 2.7 WVDOH Superpave aggregate consensus property requirements .................. 23

Table 2.8 WVDOH Superpave aggregate gradation requirements.............................. 24

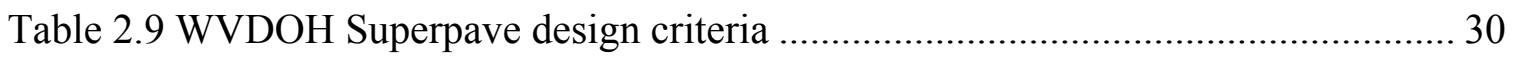

Table 2.10 Edwards-Hveem surface area factors ................................................... 33

Table 2.11 Hveem surface area calculation example.................................................. 33

Table 2.12 Craus and Ishai method surface area calculation example. ......................... 34

Table 2.13 Measured surface area for materials finer than $150 \mu \mathrm{m}$............................ 35

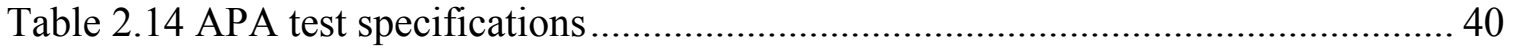

Table 2.15 Guideline for evaluating rut resistance using the APA............................... 41

Table 2.16 Gradation requirements for 4.75 mm NMAS mixes.................................. 43

Table 2.17 Design specifications for 4.75 mm NMAS mixes ...................................... 43

Table 2.18 Main experimental factors used in NCAT REPORT No 2002 - 04 .............. 45

Table 2.19 Coolley optimum binder contents and volumetric properties ...................... 46

Table 2.20 Main factors used in NCAT REPORT No 2002 - 10 .................................. 48

Table 2.21 Study gradation NCAT REPORT No 2002 - 10....................................... 49

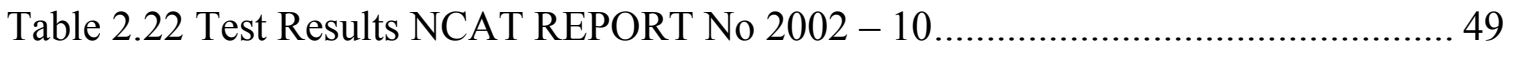


Table 2.23 Gradation of FAA samples ..................................................................... 51

Table 2.24 Marshall-Superpave optimum asphalt content, Virginia study ...................... 56

Table 3.1 Trial Superpave design criteria and parameters............................................. 63

Table 3.2 Gradations used for development of Superpave criteria................................... 65

Table 3.3 Adjusted values for estimated and effective binder contents ........................... 67

Table 3.4 Optimum binder contents and volumetric properties ....................................... 68

Table 3.5 Consensus properties of aggregates used in Phase II. .................................... 71

Table 3.6 Specific gravity of Phase II aggregates........................................................ 71

Table 3.7 WVDOH aggregate gradations, percent passing ............................................. 72

Table 3.8 West Virginia Asphalt Technology Lab Marshall results ................................ 73

Table 3.9 WVDOH Marshall mix designs................................................................. 74

Table 3.10 Phase II Superpave volumetric results..................................................... 75

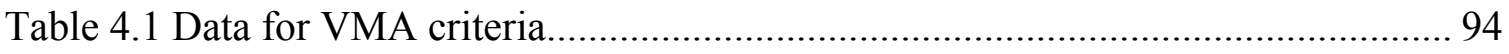

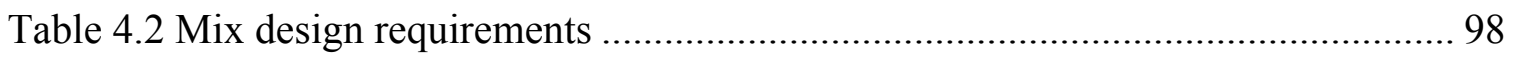

Table A1. Volumetric properties mix design 1: Superpave, coarse gradation, 4 percent

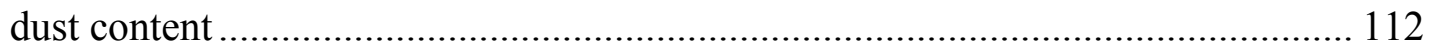

Table A2. Volumetric properties mix design 2: Superpave, coarse gradation, 8 percent

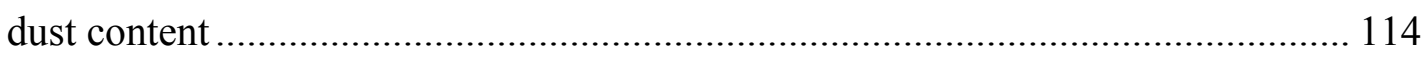

Table A3. Volumetric properties mix design 3: Superpave, coarse gradation, 12 percent

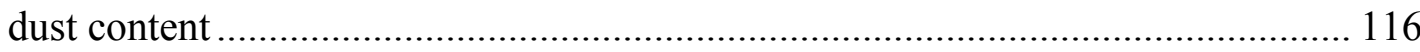

Table A4.Volumetric properties mix design 4: Superpave, medium gradation, 4 percent

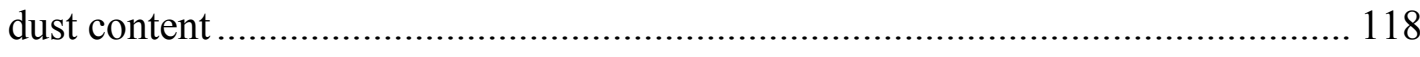

Table A5.Volumetric properties mix design 5: Superpave, medium gradation, 8 percent

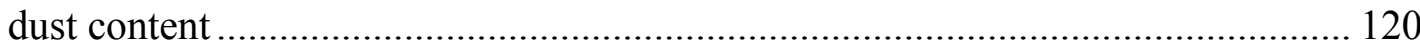

Table A6.Volumetric properties mix design 6: Superpave, medium gradation, 12 percent dust conten 
Table A7. Volumetric properties mix design 7: Superpave, fine gradation, 4 percent dust content.

Table A8.Volumetric properties mix design 8: Superpave, fine gradation, 8 percent dust content 126

Table A9. Volumetric properties mix design 9: Superpave, fine gradation, 12 percent dust content....... 128

Table A10. APA rut depths for coarse blend gradations 130

Table A11. APA rut depths for medium blend gradations

Table A12. APA rut depths for fine blend gradations

Table B1. Volumetric properties mix design 10: Marshall, 85 percent limestone - 15 percent $\# 9$.

Table B2. Volumetric properties mix design 11: Marshall, 55 percent limestone -45 percent natural sand

Table B3. Volumetric properties mix design 12: Marshall, 60 percent limestone -40 percent natural sand

Table B4. Volumetric properties mix design 13: Superpave, 85 percent limestone -15 percent \#9.

Table B5. Volumetric properties mix design 14: Superpave, 55 percent limestone -45 percent natural sand

Table B6. Volumetric properties mix design 15: Superpave, 60 percent limestone -40 percent natural sand 


\section{LIST OF FIGURES}

Figure 2.1 Performance grade binder specification implementation. ............................ 6

Figure 2.2 Superpave mix design implementation. ................................................. 7

Figure 2.3 Superpave Gyratory Compactor ........................................................ 18

Figure 2.4 Superpave Gyratory Compactor mold configuration and compaction

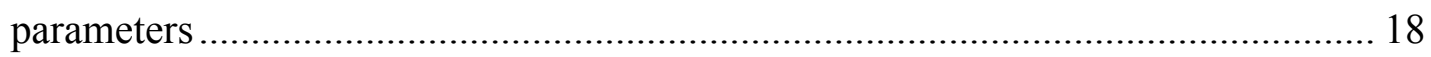

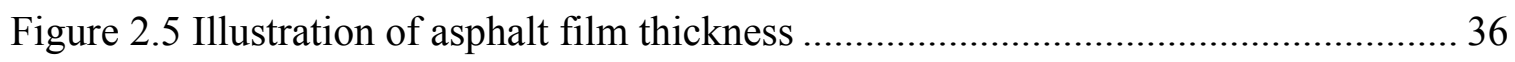

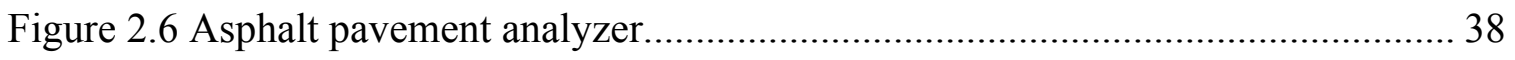

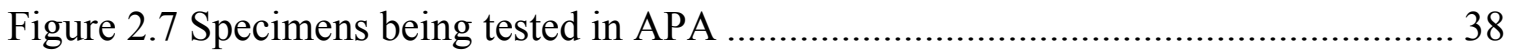

Figure 2.8 Typical gradation curves for $4.75 \mathrm{~mm}$ mixes........................................ 44

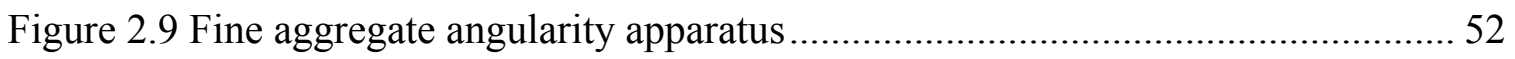

Figure 2.10 Comparison of Marshall and Superpave optimum asphalt contents, 4 percent

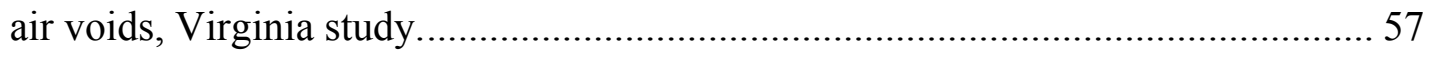

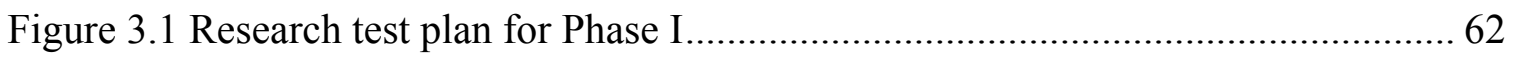

Figure 3.2 Gradations used for development of Superpave criteria .............................. 65

Figure 3.3 Research test plan for Phase II ............................................................ 70

Figure 3.4 Gradation curves for WVDOH Marshall mixes ...................................... 72

Figure 4.1 Range of optimum asphalt content ..................................................... 78

Figure 4.2 Optimum asphalt content versus voids in the mix.................................... 78

Figure 4.3 Optimum binder content versus dust content ....................................... 79

Figure 4.4 Range in binder contents, Cooley data ............................................... 79

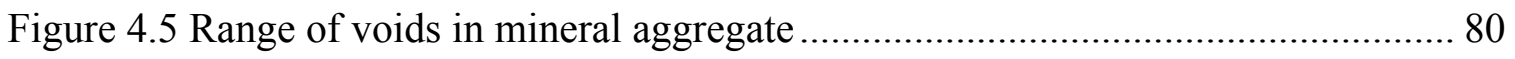

Figure 4.6 Trends in voids in the mineral aggregate with experiment variables, Cooley

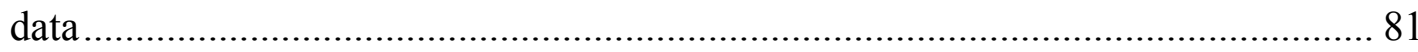


Figure 4.7 Trend lines for voids filled with asphalt versus dust content 81

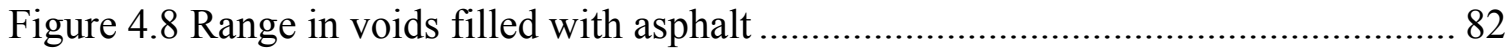

Figure 4.9 Trend of voids filled with asphalt and dust content ................................. 83

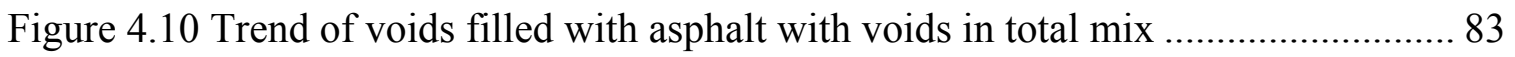

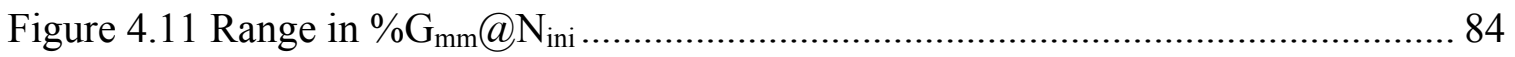

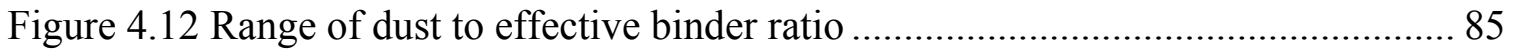

Figure 4.13 Trends in dust to effective binder ratio.................................................... 85

Figure 4.14 Trend in voids in mineral aggregate and dust to effective binder content .... 86

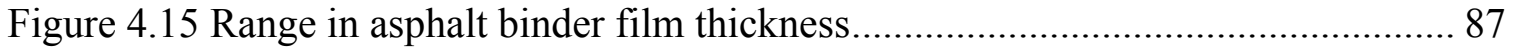

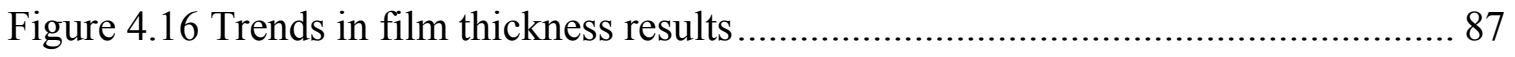

Figure 4.17 Result of Asphalt Pavement Analyzer testing ........................................ 88

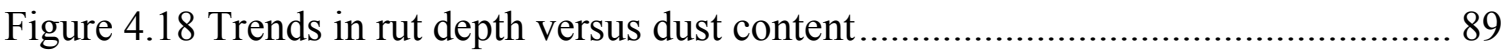

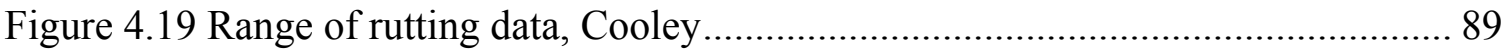

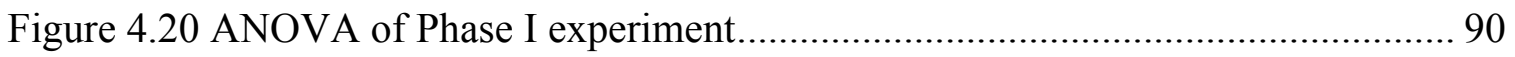

Figure 4.21 Relationship between dust to optimum content ratio and dust to effective

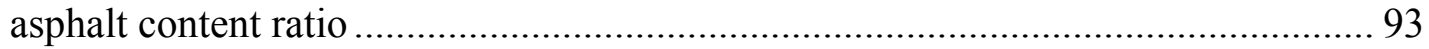

Figure 4.22 Relationship between voids in mineral aggregate, film thickness, dust to

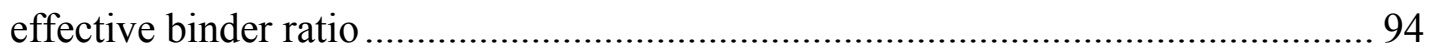

Figure 4.23 Rut depth versus voids filled with asphalt........................................... 96

Figure 4.24 Development of minimum P0.075/Pbe criteria.................................... 97

Figure 4.25 Comparison of Superpave and Marshall optimum asphalt contents ............ 99

Figure 4.26 Comparison of voids in mineral aggregate for Marshall and Superpave mixes 100

Figure 4.27 Comparison of voids filled with asphalt for Marshall and Superpave mixes 
Figure 4.28 Comparison of film thickness for Marshall and Superpave mixes.

Figure 4.29 Compaction characteristics of Phase II Superpave mixes

Figure 4.30 Typical rut depth for 100 percent limestone sample

Figure 4.31 Typical rut depth for 60 percent limestone 40 percent natural sand sample 103

Figure A.1 Volumetric properties plots mix design 1: Superpave, coarse gradation, 4 percent dust content

Figure A2. Volumetric properties plots mix design 2: Superpave, coarse gradation, 8 percent dust content

Figure A3.Volumetric properties plots mix design 3: Superpave, coarse gradation, 12 percent dust content

Figure A4.Volumetric properties plots mix design 4: Superpave, medium gradation, 4 percent dust content

Figure A5.Volumetric properties plots mix design 5: Superpave, medium gradation, 8 percent dust content

Figure A6.Volumetric properties plots mix design 6: Superpave, medium gradation, 12 percent dust content

Figure A7. Volumetric properties plots mix design 7: Superpave, fine gradation, 4 percent dust content

Figure A8.Volumetric properties plots mix design 8: Superpave, fine gradation, 8 percent dust content

Figure A9. Volumetric properties plots mix design 9: Superpave, fine gradation, 12 percent dust content

Figure B1. Volumetric properties plots mix design 10: Marshall Mix 10, 85 percent limestone -15 percent \#9

Figure B2 Volumetric properties plots mix design 11: Marshall, 55 percent limestone 45 percent natural sand 
Figure B3. Volumetric properties plots mix design 12: Marshall, 60 percent limestone -

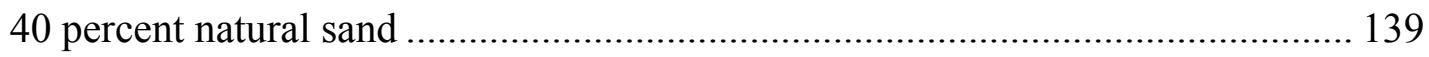

Figure B4. Volumetric properties plots mix design 13: Superpave, 85 percent limestone -

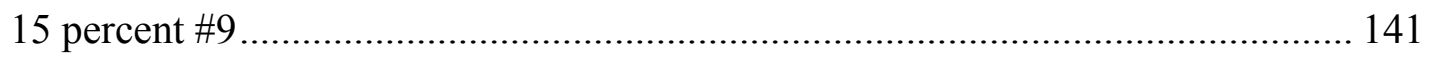

Figure B5. Volumetric properties plots mix design 14: Superpave, 55 percent limestone -

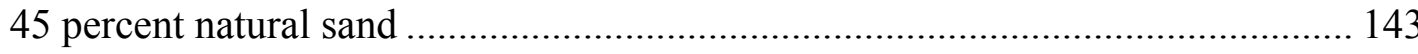

Figure B6. Volumetric properties plots mix design 15: Superpave, 60 percent limestone -

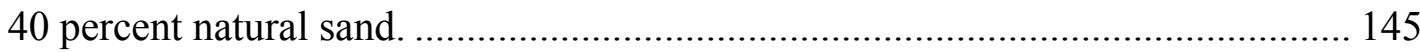




\section{CHAPTER 1 INTRODUCTION}

\subsection{INTRODUCTION}

Of the 2.3 million of miles of paved roads in the United States approximately 96 percent have asphalt surfaces (Roberts et al; 1996). During the last two decades, the amount of vehicle miles traveled per year and the amount of equivalent single axle loads, ESALs, has increased by 75 and 60 percent, respectively. As a result hot mix asphalt, HMA, pavements have struggled to perform the intended design life, presenting rutting, fatigue and thermal cracking problems. This created a need to develop an enhanced hot mix asphalt concrete design procedure (Amirkhanian, 2001).

Superpave, an acronym for Superior Performing Asphalt Pavements, was developed as a result of the Strategic Highway Research Program, SHRP, in 1993 as an improved hot mix asphalt procedure, HMA, design and analysis system (Harman, et al; 2002). Since its development, this mix design procedure has replaced the traditional Marshall and Hveem methods for many applications. The Marshall and Hveem methods were developed with empirical laboratory procedures, which required field experience and knowledge of local conditions and materials, to determine whether or not a mix would perform well. The West Virginia Department of Highways, WVDOH, used the Marshall method exclusively prior to the implementation of Superpave. Hence the Hveem method is not discussed further.

Superpave is a more comprehensive and accurate system that takes into account

all phases of mix design and performance including specification of asphalt binders and mineral aggregates. Concurrent with the development of the Superpave mix design method, Performance Grade asphalt binder specifications were introduced. The Performance Grade specifications are more comprehensive than previous asphalt cement specifications. Under the Performance Grade specification, the binder is tested at these condition levels:

- Neat or tank, as it comes from refinery, 
- Conditioned to simulate the hardening during construction, hardening that takes place as it goes through the mixing plant, and

- Conditioned to simulate the long term behavior, hardening that takes place in the road.

In addition, the binder is tested for performance with respect to these distress types

- Rutting,

- Fatigue and

- Thermal Cracking

Additionally, the Superpave specifications for aggregate are more stringent than aggregate requirement in the Marshall method, particularly for mix designs where the twenty year cumulative equivalent single axle loads, ESALs, exceeds 300,000 applications. These requirements ensure sufficient interparticle friction to provide a stable asphalt concrete mix. In most Superpave applications a "coarse" aggregate blended gradation is selected to increase the rutting resistance in the mix. However, fine aggregate blend gradations are generally, preferred for low volume roads to provide better durability.

The West Virginia Division of Highways, WVDOH, first Superpave project was constructed in 1997. The department currently uses Superpave for National Highways System projects. Based on the success of these projects, the WVDOH is considering implementing Superpave for all projects. Superpave covers five mix types based on the nominal maximum aggregate size: 9.5, 12.5, 19, 25 and $37.5 \mathrm{~mm}$. Under Marshall specifications, the WVDOH commonly uses three mixes types Wearing I, Base I and Base II. These correspond to Superpave 9.5, 19 and $37.5 \mathrm{~mm}$ mixes. In addition, for rehabilitation of low volume roads the WVDOH uses a Wearing III mix. This mix has a nominal maximum aggregate size of $4.75 \mathrm{~mm}$. This type of mix is not currently available in the Superpave specifications. 


\subsection{PROBLEM STATEMENT}

Although Superpave is recognized as a significant improvement over the Marshall method, the WVDOH continues to use the Marshall method in many projects. There are several issues which inhibit full implementation of Superpave, one of which is the lack of specifications for the equivalent of the Marshall Wearing III mix. Specifications and criteria are needed for this mix type before the WVDOH can fully replace the Marshall method with Superpave. In addition, the impact of the relaxation of aggregate specification for low volume mix designs needs to be evaluated since Superpave does not incorporate any stability test comparable to the Marshall method.

\subsection{OBJECTIVES}

The main objective of this research was to evaluate design parameters for 4.75 $\mathrm{mm}$ nominal maximum aggregate size mixes, NMAS, in West Virginia. Additionally, the effects of the use of natural sand for this mix type was studied to determine if the limitation of Superpave with respect to relaxed aggregate requirements has a detrimental effect on the expected performance of the mix.

\subsection{RESEARCH APPROACH}

In order to address project objectives, this research work was divided in two phases. Phase I addressed the evaluation of Superpave criteria for $4.75 \mathrm{~mm}$ NMAS mixes, and Phase II evaluated the use of natural sand for $4.75 \mathrm{~mm}$ mixes. During Phase I, three different gradations with $4.75 \mathrm{~mm}$ NMAS, coarse, medium and fine were studied. The literature review identified that for fine aggregate mixes, dust content, percent of material passing $0.075 \mathrm{~mm}$ sieve has a significant effect on the percent voids in mineral aggregate, VMA and rutting (Coree and Hislop, 1998). To study this effect, three dust content were analyzed for each gradation blend: 4, 8, 12 percent. The literature review also showed that for $4.75 \mathrm{~mm}$ NMAS mixes, intended for low volume traffic and leveling purposes, a design air void content, VTM, higher than 4 percent is sometimes allowed. This results in lower asphalt content without significantly affecting rutting resistance of the mix (Cooley, et al; 2002a). Thus two levels of VTM were studied: four and five 
percent. This resulted in 18 combinations of factors and levels in the Phase I experiment as shown in Table 1.1 .

Table 1.1 Main study factors to develop $4.75 \mathrm{~mm}$ NMAS criteria

\begin{tabular}{|c|c|}
\hline \multicolumn{2}{|c|}{ PHASE I } \\
\hline Factors & Levels \\
\hline Gradation blend & Coarse, Intermediate, Fine \\
\hline Percent dust & $4,8,12$ percent \\
\hline $\begin{array}{c}\text { Voids in mix } \\
\text { (VMA) }\end{array}$ & 4,5 percent \\
\hline
\end{tabular}

Crushed limestone fine aggregate from J.F. Allen Company of Elkins, WV, was used exclusively in the Phase I experiment. The standard asphalt grade in West Virginia, PG 64 -22, was used for all samples. Marathon Ashland Company of Ashland Kentucky provided all asphalt binder used during the research.

For each combination of factors and levels in the experiment, an initial estimate of the asphalt content was computed following the standard Superpave method. Samples were prepared and evaluated for volumetric properties. The estimated asphalt content was adjusted based on the volumetric results. Samples were then prepared at four asphalt contents and the volumetric data were analyzed to evaluate the evaluate designs parameters for $4.75 \mathrm{~mm}$ NMAS Superpave mixes. All mixes were compacted according Superpave specifications for less than 0.3 million ESALs; 50 gyration, using the Superpave Gyratory Compactor, SGC. Volumetric properties were determined for each mix, in order to study the degree of variation of main effects on pavement performance. In addition, the asphalt film thickness of each mix was evaluated and analyzed in determining the recommended criteria. Additional samples were compacted at $7 \pm 0.5 \%$ air voids for testing in the Asphalt Pavement Analyzer, APA, to evaluate rutting potential. These criteria were compared to the results produced by other state highway agencies and researchers.

During Phase II, three Wearing III Marshall designs were obtained from WVDOH. Two of the mixes included limestone fine aggregate, LFA, and natural sand, NS, blended as 60 percent LFA to 40 percent NS and 55 percent LFA to 45 percent NS. 
The third design was 100\% limestone containing a blend of 85 percent LFA and 15 percent \#9 limestone. These designs were verified using the Marshall method, at the West Virginia University Asphalt Technology Laboratory to ensure the properties from the mix design data results could be reproduced. Superpave mix designs were performed for each of the three Marshall blends to determine the Superpave optimum asphalt content. The performance was evaluated with the APA. The limestone aggregate was obtained from J.F. Allen Company. The natural sand was obtained from Martin Marietta Company of Wheeling, WV. PG 64-22 from Marathon Ashland was used for Phase II. Marshall designs were evaluated under WVDOH specifications using a compactive effort of 50 blows per side. Superpave samples were compacted to 50 gyrations.

The optimum asphalt content of the mixes under both the Marshall and recommended Superpave criteria were compared. This analysis was performed to determine if the asphalt content resulting from the recommended criteria from Phase I produced reasonable results relative to the existing mix design method.

\subsection{THESIS OVERVIEW}

This research work is organized into five chapters and two appendixes. After this introductory chapter, Chapter 2 discusses the literature including a review of the Marshall and Superpave methods, natural sand as HMA aggregate, research on $4.75 \mathrm{~mm}$ NMAS mixes, comparison between Marshall and Superpave methods and surface area and film thickness effects on HMA mix design. The Chapter 3 presents research approach and procedures used for both Phase I and Phase II of this research. The result and analysis are presented in Chapter 4. The conclusions and recommendations are presented in Chapter 5. The mix design data for the two phases are presented in the appendixes. 


\section{CHAPTER 2 LITERATURE REVIEW}

\subsection{INTRODUCTION}

The Marshall method of mix design has been used in United States for more than fifty years. As a consequence, knowledge and use of the Marshall method by highway agencies and the construction industry has inhibited users from abandoning the method. On the other hand, performance grade specification and the Superpave method were introduced in 1993. The Superpave Implementation Survey 2000 - 2001 (Mack, 2001) shows implementation of Performance Grade specifications by 49 states after 2001, Figure 2.1. Similarly the Superpave mix design method was implemented by 42 states, Figure 2.2.

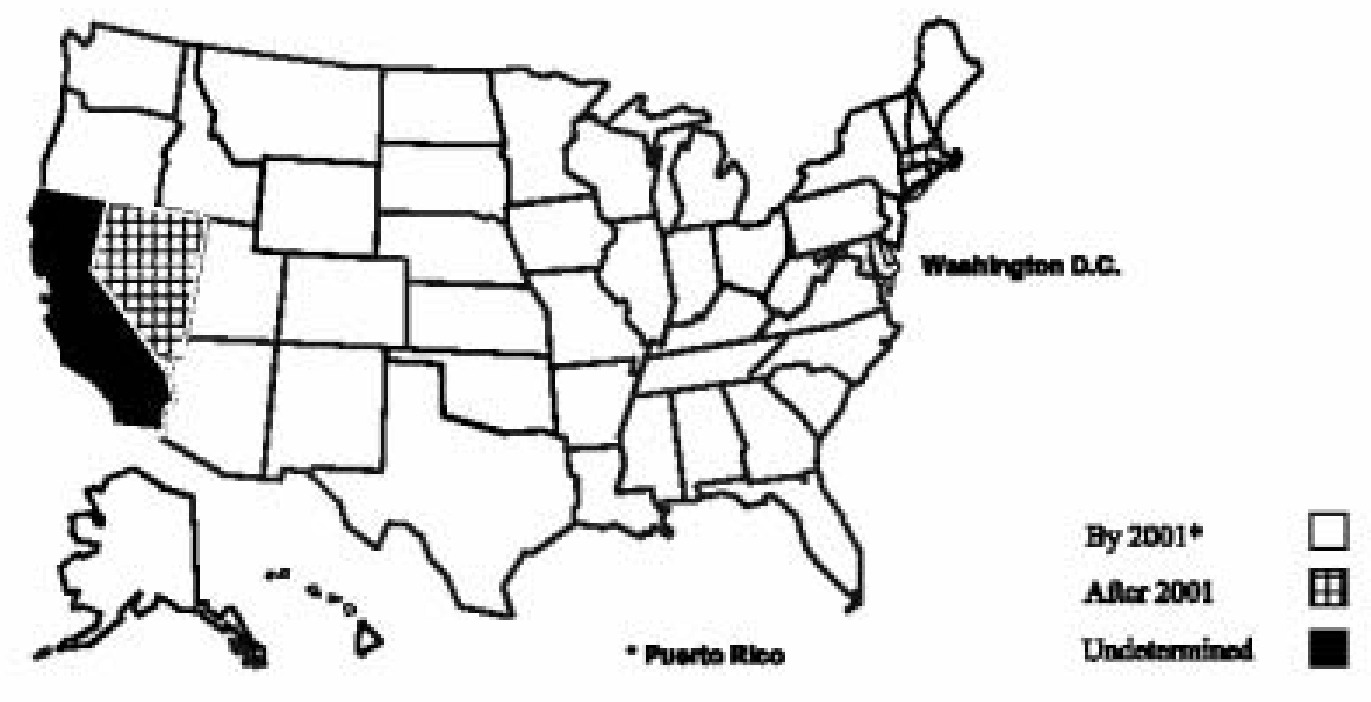

Figure 2.1 Performance grade binder specification implementation.

The purpose of this chapter is to present a summary of the Marshall and Superpave mix designs methods, and provide a review of main subjects to cover in this research, including $4.75 \mathrm{~mm}$ NMAS Superpave mixes and evaluation of natural sands as aggregate in HMA pavements. 


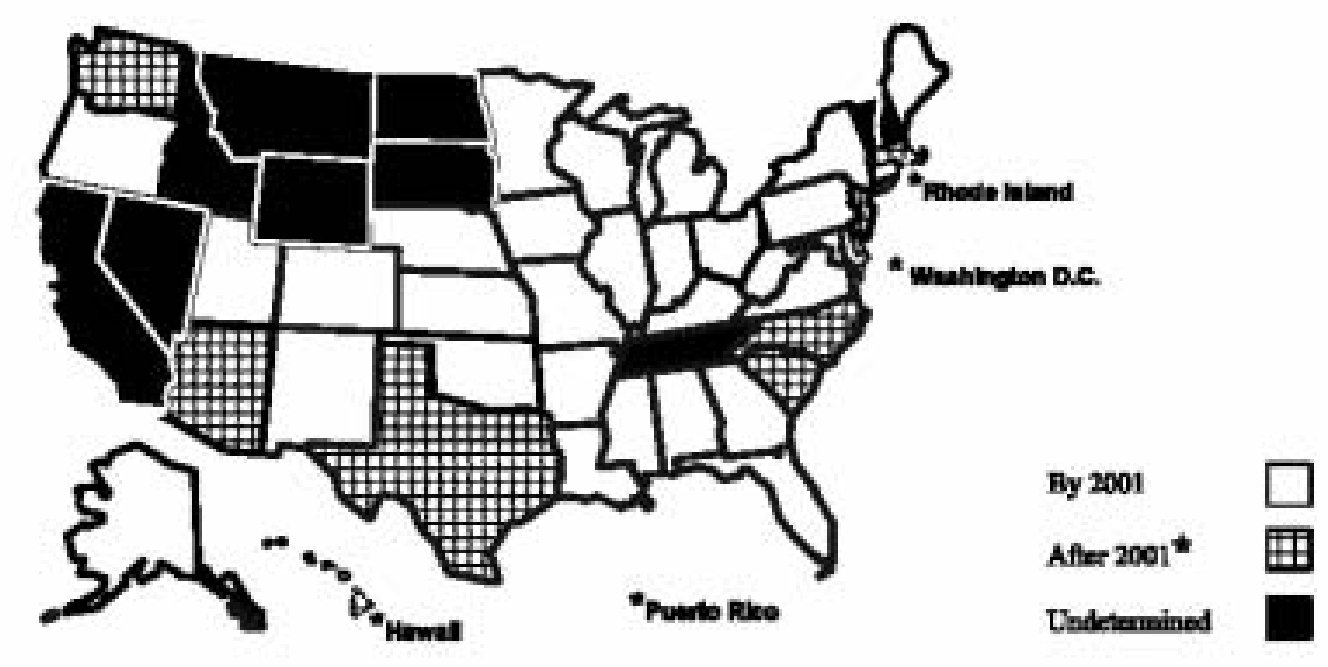

Figure 2.2 Superpave mix design implementation.

\subsection{MARSHALL MIX DESIGN OVERVIEW}

Bruce Marshall, an engineer with the Mississippi Department of Highways, formulated the concept of this method in 1939. In 1943, the U.S Army Corps of Engineers refined and adopted the Marshall method for selecting optimum asphalt content as a function of gradation and traffic conditions. A standard compaction procedure was adopted using a sliding hammer with $98.4 \mathrm{~mm}$ (3.88 inch) in diameter head, weighing $5.54 \mathrm{~kg}(10.0 \mathrm{lb})$ to deliver and specific amount of blows per side on samples with $63.5 \mathrm{~mm}$ (2.5 in.) height and $102 \mathrm{~mm}$ (4.0 inch) in diameter. In 1954 stability, flow, density, and void criteria were established. Volumetric criteria were added to the method in 1973 by the Asphalt Institute. These studies improved and added new features to Marshall's design method, resulting the present form of the mix design method. The dimensions of the standard Marshall sample limited the method to aggregate with a nominal maximum aggregate size of $19 \mathrm{~mm}$ or less. A modified procedure was later introduced using 6 inch diameter molds to accommodate aggregate up to $37.5 \mathrm{~mm}$ NMAS.

While there are national standards for the Marshall mix design method (Asphalt Institute, 1993) most state highway agencies have tailored the method to meet local conditions. The procedure is the basis for the following review of the Marshall method. 


\subsubsection{MATERIAL REQUIREMENTS}

The Marshall design process starts with the selection of aggregate and asphalt suitable for job conditions. The material requirements used by the WVDOH are set forth in their Standards Specification Manual: mineral filler and fine aggregate specification Section 702, coarse aggregate Section 703, and PG binders Section 705.

\subsubsection{AGGREGATE BLENDING}

Contractors maintain aggregate in stockpiles, sorted by size, to control segregation. The first step in the mix design process is to determine a blend of stockpiles such that the resulting gradation of the aggregate blend falls within the specifications of the contracting agency. The WVDOH Marshall gradation requirements are given in Table 2.1. The equation used to compute the blended gradation from a group of stockpiles is computed as:

$$
p=A a+B b+C c+\ldots
$$

Where,

$p=$ the percent of material passing a given sieve for the combined aggregates

$A, B, C, \ldots=$ the percent of material passing a given sieve for each aggregate.

$a, b, c, \ldots=$ proportions of aggregates $\mathrm{A}, \mathrm{B}, \mathrm{C}, \ldots$ to be used in the blend $\mathrm{a}+\mathrm{b}+\mathrm{c}$

Once the blend gradation has been chosen and after determining the specific gravity of individual aggregates according AASHTO T- 85 for coarse aggregate and AASHTO T-84 for fine aggregate, blended aggregate specific gravity is calculated as:

$$
G=\frac{P_{1}+P_{2}+\ldots+P_{n}}{\frac{P_{1}}{G_{1}}+\frac{P_{2}}{G_{2}}+\ldots \frac{P_{n}}{G_{n}}}
$$

Where,

$G=$ average specific gravity of the aggregate.

$G_{1}, G_{2}, \ldots, G_{n}=$ specific gravity values for fraction $1,2, \ldots \mathrm{n}$.

$P_{1}, P_{2}, \ldots, P_{n}=$ weight percentages of fraction $1,2, \ldots \mathrm{n}$. 
Table 2.1 WVDOH aggregate gradation requirements for Marshall mix designs

\begin{tabular}{|c|c|c|c|c|}
\hline TYPE OF MIX & Base-I & $\begin{array}{c}\text { Base-II } \\
\text { (Patch \& } \\
\text { Level) } \\
\text { Wearing-IV }\end{array}$ & $\begin{array}{l}\text { Wearing-I } \\
\text { (Scratch) }\end{array}$ & Wearing-III \\
\hline $\begin{array}{l}\text { SIEVE } \\
\text { SIZE }\end{array}$ & $\begin{array}{l}\text { Nominal } \\
\text { Max } \\
\text { Size } \\
11 / 2 \text { in } \\
(37.5 \mathrm{~mm})\end{array}$ & $\begin{array}{c}\text { Nominal } \\
\text { Max } \\
\text { Size } \\
3 / 4 \text { in } \\
(19 \mathrm{~mm})\end{array}$ & $\begin{array}{c}\text { Nominal } \\
\text { Max } \\
\text { Size } \\
3 / 8 \mathrm{in} \\
(9.5 \mathrm{~mm})\end{array}$ & $\begin{array}{c}\text { Nominal } \\
\text { Max } \\
\text { Size } \\
\text { No.4 } \\
(4.75 \mathrm{~mm})\end{array}$ \\
\hline $2 \mathrm{in}(50 \mathrm{~mm})$ & 100 & & & \\
\hline $11 / 2$ in $(37.5 \mathrm{~mm})$ & $90.0-100.0$ & & & \\
\hline $1 \mathrm{in}(25 \mathrm{~mm})$ & 90 Max & 100 & & \\
\hline $3 / 4 \mathrm{I}(19 \mathrm{~mm})$ & - & $90.0-100.0$ & & \\
\hline $1 / 2 \mathrm{in}(12.5 \mathrm{~mm})$ & - & 90 Max & 100 & \\
\hline $3 / 8$ in $(9.5 \mathrm{~mm})$ & - & - & $85-100$ & 100 \\
\hline No. $4(4.75 \mathrm{~mm})$ & - & - & $80 \max$ & $90-100$ \\
\hline No. $8(2.36 \mathrm{~mm})$ & $15.0-36.0$ & $20.0-50.0$ & $30-55$ & 90 Max \\
\hline No.16 $(1.18 \mathrm{~mm})$ & - & - & - & $40-65$ \\
\hline No.30 $(600 \mu \mathrm{m})$ & - & - & - & - \\
\hline No.50 $(300 \mu \mathrm{m})$ & - & - & - & - \\
\hline No.200 $(75 \mu \mathrm{m})$ & $1.0-6.0$ & $2.0-8.0$ & $2.0-9.0$ & $3.0-11.0$ \\
\hline
\end{tabular}

\subsubsection{PREPARATION OF MARSHALL SPECIMENS}

For determining the optimum asphalt content for a particular blend of aggregates, three compaction specimens are prepared at each asphalt content. The asphalt contents are centered about an estimated value and vary in 0.5 percent increments. At least one sample at the estimated asphalt content is mixed to determine the maximum specific gravity in accordance with ASSHTO T-209.

A specimen is prepared by heating asphalt cement and aggregate to the mixing temperature. The aggregate and binder are mixed together and the sample is conditioned for two hours at the compaction temperature to allow absorption of the asphalt into the voids of the aggregate. Conditioning in the oven is essential to determine the effective asphalt content. Some of the asphalt mixed with the aggregate is absorbed into the 
aggregate voids and therefore does not serve to bind the asphalt concrete together. The difference between the total binder added to the mix and the absorbed binder is the effective binder of the mix.

The sample is compacted using Marshall hammer to apply the appropriate number of blows per side according to the expected traffic level. The sample is allowed to cool and removed from the mold. Finally samples are cooled to room temperature and measures for thickness and bulk specific gravity are taken. The samples are then tested for stability and flow.

\subsubsection{VOLUMETRIC ANALYSIS}

Five volumetric parameters are evaluated for the Marshall procedure:

1) Mix density,

2) Air voids,

3) Voids in the mineral aggregate, VMA,

4) Voids filled with asphalt, VFA, and

5) Dust to binder ratio.

Volumetric requirements ensure the asphalt concrete has suitable proportions of aggregate, asphalt and air. Although volumetric analysis was developed in the early 1900 's, its value was not fully appreciated until the mid 1950's following the work of McLeod (1956).

\subsubsection{Bulk Specific Gravity or Mix Density}

The procedure for measuring bulk specific gravity is described in AASHTO T166. Bulk specific gravity can be used to determine the density of a specimen by multiply the specific gravity by 1000 to obtain units of $\mathrm{kg} / \mathrm{m}^{3}$. Once sample has been compacted the weight of the cool-dry sample is determined. Next, the pill is suspended in water at $25^{\circ} \mathrm{C}\left(77^{\circ} \mathrm{F}\right)$ for $4 \pm 1$ minute and its submerged weight is recorded. Then the pill is retrieved from water and surface dried with a towel to reach the saturated surface dry, SSD, condition and the weight is recorded. The bulk specific gravity is computed as: 


$$
G_{m b}=\frac{A}{B-C}
$$

Where,

$G_{m b}=$ bulk specific gravity of compacted sample

$A=$ dry weight of specimen $(\mathrm{g})$

$B=\mathrm{SSD}$ weight of specimen $(\mathrm{g})$

$C=$ submerged weight of the specimen $(\mathrm{g})$

\subsubsection{Maximum Specific Gravity of the Mixture.}

The maximum specific gravity is measured in accordance with AASHTO T-209. The maximum specific gravity represents the specific gravity of the mixture at zero air voids. The sample is prepared at the estimated asphalt content; WVDOH requires the same process for mixing and conditioning the specimens as used for the compacted samples. After conditioning, the sample is spread in a thin layer, broken apart and allowed to cool until it can be easily handled. It is then place in a tarred bowl and sample weight recorded. The material then is cover with water about 1 inch above material surface. A vacuum of $30 \mathrm{~mm}$ of mercury is applied for $15 \pm 2$ minutes to remove all air from sample. Finally sample and tarred bowl are suspended in water for $10 \pm 1$ minutes and the submerged weight of the bowl and sample is recorded. The maximum specific gravity, $G_{m m}$ is calculated as:

$$
G_{m m}=\frac{A}{A-(B-C)}
$$

Where,

$A=$ dry weight of sample (g)

$B=$ submerged weight of bowl and sample (g)

$C=$ submerged weight of empty bowl (g)

Once $\mathrm{G}_{\mathrm{mm}}$ at one asphalt content is measured, the maximum specific gravity at other asphalt content can be calculated. The effective specific gravity of the aggregate is 
computed. The asphalt absorption into the aggregate is independent of the asphalt content; the effective specific gravity of an aggregate blend is a constant. Effective specific gravity of the aggregate, $G_{s e}$ is calculated as:

$$
G_{s e}=\frac{P_{m m}-P_{b}}{\frac{P_{m m}}{G_{m m}}-\frac{P_{b}}{G_{b}}}
$$

Where,

$P_{m m}=$ total loose mix, percent by total weight of $\operatorname{mix}=100$

$P_{b}=$ asphalt percent by total weight of mix

$G_{m m}=$ maximum specific gravity of mix

$G_{b}=$ specific gravity of asphalt

The maximum specific gravity at any asphalt content can be calculated as:

$$
G_{m m}=\frac{P_{m m}}{\frac{P_{s}}{G_{s e}}+\frac{P_{b}}{G_{b}}}
$$

Where,

$G_{m m}=$ maximum specific gravity of mix

$P_{m m}=$ total loose mix, percent by total weight of mix $=100 \%$

$P_{b}=$ asphalt percent by total weight of mix

$P_{s}=$ aggregate percent by total weight of mix

$G_{s e}=$ effective specific gravity of aggregate

$G_{b}=$ specific gravity of asphalt

\subsubsection{Air Voids}

Air voids are small air spaces or pockets of air that occur between the coated aggregate particles in compacted HMA. The durability of an asphalt pavement is a function of the air void content. An excess in the air void content provides passageways 
through the HMA for the entrance of damaging air and water. On the other hand too low an air void content, can produce "flushing", a condition where excess binder squeezes out of the HMA to the surface (INDOT, 2001).

Density and air void content are directly related. The higher the density, the lower the percentage of air voids in the HMA. Specifications require pavement densities that will produce the proper amount of air voids in the pavement.

The WVDOH Marshall design requires a content of $4 \%$ air voids at optimum asphalt content, except for Base I mixes which requires a $4.5 \%$ void content. For a given compaction effort, air voids can be increased or decreased by three means (INDOT, 2001):

- changing the binder content,

- changing the percent mineral filled, and

- altering the aggregate gradation

The percent of air voids, or voids in total mix, VTM, is computed as:

$$
V T M=\frac{G_{m m}-G_{m b}}{G_{m m}} \times 100
$$

Where,

$G_{m m}=$ maximum specific gravity of the paving mix

$G_{m b}=$ bulk specific gravity of the compacted mix

\subsubsection{Voids in the Mineral Aggregates}

Voids in the mineral aggregate, VMA, is the volume of intergranular void space between the aggregate particles of a compacted paving mixture. The VMA is considered the most important mix design parameter which affects the durability of the HMA (Kandhal and Koehler, 1985). It includes the space filled with the effective binder and air voids. Since asphalt concrete is designed for a specific air void content, the VMA criteria essentially controls the effective asphalt content. VMA is expressed as a percentage of the total volume of the mix. 
VMA is calculated as:

$$
V M A=100\left[1-\frac{G_{m b}\left(1-P_{b}\right)}{G_{s b}}\right]
$$

Where,

$G_{s b}=$ bulk specific gravity of aggregate

$G_{m b}=$ bulk specific gravity of compacted mix

$P_{b}=$ percent asphalt content, in decimal fraction

\subsubsection{Voids Filled with Asphalt}

Voids filled with asphalt, VFA, are the void spaces between the aggregate particles in the compacted mix that are filled with binder. In other words, it is the percentage of VMA filled with binder (INDOT, 2001). The purpose of the VFA requirement is to limit the maximum amount of voids in mineral aggregate and asphalt content.

The percent VFA is computed as:

$$
V F A=\frac{V M A-V T M}{V M A} \times 100
$$

Where,

$V M A=$ percent voids in mineral aggregate

$V T M=$ percent voids in total mix

\subsubsection{Dust to Binder Ratio.}

The amount of material passing the $75-\mu \mathrm{m}$ sieve has a significant effect on HMA properties (Anderson, 1987). Fines that are less than $2 \mu \mathrm{m}$ in diameter may become part of the asphalt, causing hardening. Increasing the dust proportion will generally decrease VMA. Because the relationship between particle diameter and surface area, increasing the amount of material passing the $75 \mu \mathrm{m}$ sieve will result in an increase in the surface area the aggregate blend. Consequently the average film thickness is thinner producing a 
lower VMA. Some additional effects of dust content on HMA properties are (Chadbourn, et al; 1999):

- Stiffening the asphalt binder,

- Extending the asphalt binder content,

- Altering the moisture resistance of the mix,

- Affecting the aging characteristics of the mix, and

- Affecting the workability and compaction characteristics of the mix.

In the Marshall method, the dust to binder ratio is determined as the percent of the aggregate passing the $75 \mu \mathrm{m}$ divided by the total asphalt content in percent by weight. The allowable range is 0.6 to 1.2 .

\subsubsection{STABILITY AND FLOW MEASURES}

Next stability and flow of the specimens are measured in accordance with AASHTO T-245 or ASTM D5581. Test specimens are placed in a $60^{\circ} \mathrm{C}\left(140^{\circ} \mathrm{F}\right)$ water bath for 30 to 40 minutes. The sample is then removed from the water bath and placed in the Marshall testing head. The test is started and the force versus deformation is plotted. The force at the peak of the curve is the stability value and its corresponding deformation is the flow.

The stability criteria are based on a specimen height of $2.5 \mathrm{inch}(63.5 \mathrm{~mm})$. For specimens ranging $2.5 \pm 0.2 \mathrm{inch}(5.1 \mathrm{~mm})$ a correlation ratio value is used to adjust the measured stability.

\subsubsection{OPTIMUM BINDER CONTENT DETERMINATION}

Once all volumetric parameters, stability and flow are evaluated for each asphalt content, the optimum asphalt content can be determined. Plots of asphalt content versus each design parameter are prepared. The optimum asphalt content is determined as the asphalt content needed to produce an air void content of 4 percent (4.5 percent for Base I mixes). Once the asphalt content is found values for density, VMA, VFA, stability and flow are also determined from charts and compared to the Marshall criteria, Tables 2.2 and 2.3 (WVDOH, MP 401.02.22). If all parameter are with in the required range, the 
mix design process was successful. If any of the parameters fail to comply with the criteria, the aggregate blend is altered and the mix design process is repeated.

\subsection{SUPERPAVE OVERVIEW}

The Superpave mix design procedure was a final product of the Strategic Highway Research Program (Harman, et al; 2002). It is a volumetric mix design procedure where the material selection process has been improved over the Marshall method.

There are four main steps in Superpave mixture design:

- Selection of Materials

- Selection of a Design Aggregate Structure

- Selection of the Design Asphalt Binder Content

- Evaluation of Moisture Sensitivity of the Design Mixture

For the volumetric analysis samples are compacted using the Superpave Gyratory Compactor, SGC, Figure 2.3. The SGC uses a mold with a $150 \mathrm{~mm}$ diameter and compacts samples to a height of $115 \pm 5 \mathrm{~mm}$. This sample size is large enough to accommodate $37.5 \mathrm{~mm}$ nominal maximum aggregate size mixes.

During compaction a vertical force of $600 \mathrm{kPa}$ is applied, and the mold is tilted to an angle of $1.25^{\circ}$, Figure 2.4. The SGC forces the tilt of the mold to rotate at a rate of 30 rpm. The height of the sample is recorded for each revolution. The compactive effort is regulated by the number of revolutions. The compactive effort is varied based on traffic level defined as the cumulative number of single axle loads expected on a highway for a 20-year period, Tables 2.4 and 2.5 (Amirkhanian, 2001, WVDOH MP 401.02.28). For each traffic level, three compaction parameters are defined, $\mathrm{N}_{\mathrm{ini}}, \mathrm{N}_{\mathrm{des}}$, and $\mathrm{N}_{\max } \cdot \mathrm{N}_{\mathrm{des}}$ specifies the number of revolutions used for the design process. Samples compacted to $\mathrm{N}_{\text {des }}$ have a density similar to that achieved at the end of the construction process. All samples are compacted using $\mathrm{N}_{\text {des }}$ number of revolutions for determining optimum asphalt content. 
Table 2.2 WVDOH Marshall method mix design criteria

\begin{tabular}{|c|c|c|c|}
\hline \multicolumn{4}{|c|}{ MARSHALL METHOD MIX DESIGN CRITERIA } \\
\hline Design Criteria ${ }^{(\text {Note } 1)}$ & $\begin{array}{l}\text { Medium } \\
\text { Traffic Design }\end{array}$ & $\begin{array}{l}\text { Heavy } \\
\text { Traffic } \\
\text { Design }\end{array}$ & $\begin{array}{l}\text { Base-1 } \\
\text { Heavy } \\
\text { Traffic } \\
\text { Design } \\
\text { (Note 3) }\end{array}$ \\
\hline $\begin{array}{l}\text { Compaction number of } \\
\text { blows each end of specimen }\end{array}$ & 50 & 75 & 112 \\
\hline $\begin{array}{l}\text { Stability (Newtons) } \\
\text { minimum }\end{array}$ & 5300 & 8000 & 13300 \\
\hline Flow $(0.25 \mathrm{~mm})^{(\text {Note } 4)}$ & $8-16$ & $8-14$ & $12-21$ \\
\hline Air Voids & $3-5$ & $3-5$ & $3-6$ \\
\hline $\begin{array}{c}\text { Voids Filled With Asphalt } \\
(\%)\end{array}$ & $65-78$ & $\begin{array}{c}\text { (Note 5) } \\
65-75\end{array}$ & $63-75$ \\
\hline
\end{tabular}

Note 1: A medium traffic design will typically be used on pavements with 20 year projected design ESAL value of less than 3 million. A heavy traffic design will be used on pavement with a 20 year projected design ESAL value of 3 million or greater.

Note 2: All mixtures will be a medium traffic design unless otherwise specified in contract documents. Wearing -III material will always be a medium traffic design.

Note 3: Base-I will always be a heavy traffic design and will be tested using six inch diameter specimens in accordance with ASTM D5581.

Note 4: When using a recording chart to determine the flow value, the flow is normally read at the point where the maximum stability begins to decrease. This approach works fine when the stability plot is a smooth rounded curve. However, when aggregate interlocking causes the plot to produce a flat line at the peak stability, the flow value shall be read at the point of initial peak stability. If this method of determining the flow value adversely affects a previously verified design then a new design verification shall be considered to reaffirm the design tolerances.

Note 5: A Wearing - I heavy traffic design verification shall have a VFA range of 65-76 percent. 
Table 2.3 WVDOH requirements for minimum percent voids in mineral aggregate

\begin{tabular}{|c|c|c|}
\hline \multicolumn{2}{|c|}{ Minimum Percent Voids in Mineral Aggregate } \\
\hline $\begin{array}{c}\text { WVDOH MIX } \\
\text { TYPE }\end{array}$ & Sieve Size & $\begin{array}{c}\text { Minimum Voids in Mineral } \\
\text { Aggregate, Percent }\end{array}$ \\
\hline Wearing - III & No. $4-(4.75 \mathrm{~mm})$ & 17 \\
\hline $9.5 \mathrm{~mm}$ or Wearing - I & $3 / 8 \mathrm{in}-(9.5 \mathrm{~mm})$ & 15 \\
\hline $12.5 \mathrm{~mm}$ & $1 / 2 \mathrm{in}-(12.5 \mathrm{~mm})$ & 14 \\
\hline $19 \mathrm{~mm}$ or Base II & $3 / 4 \mathrm{in}-(19 \mathrm{~mm})$ & 13 \\
\hline $25 \mathrm{~mm}$ & $1 \mathrm{in}-(25 \mathrm{~mm})$ & 12 \\
\hline 37.5 or Base I & $11 / 2 \mathrm{in}-(37.5 \mathrm{~mm})$ & 10.5 \\
\hline $50 \mathrm{~mm}$ & $2 \mathrm{in}-(50 \mathrm{~mm})$ & \\
\hline
\end{tabular}

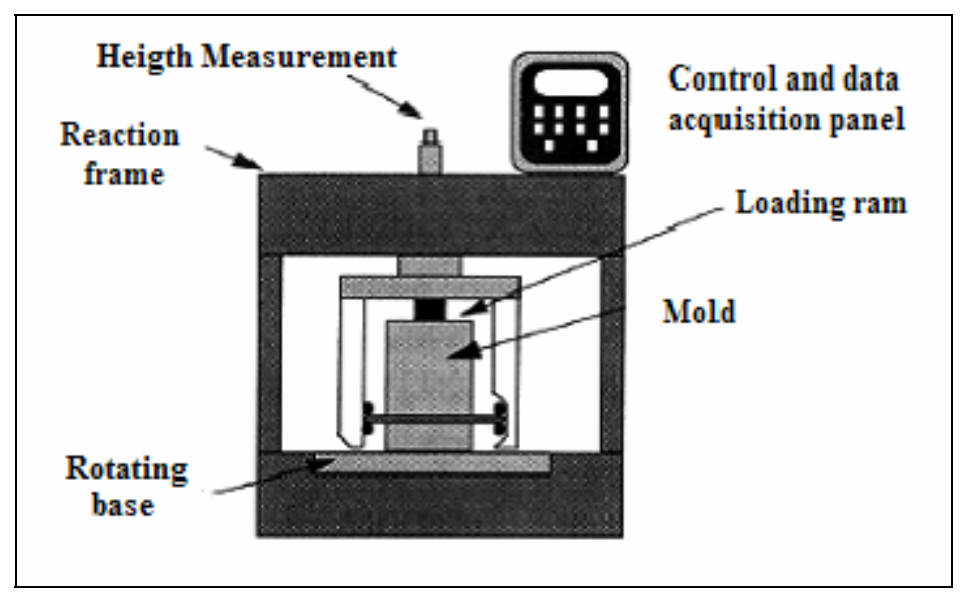

Figure 2.3 Superpave Gyratory Compactor

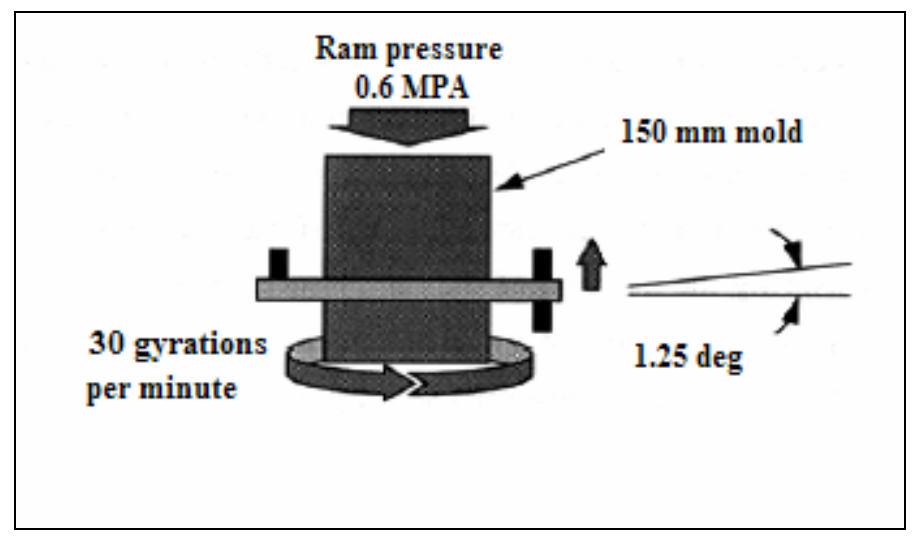

Figure 2.4 Superpave Gyratory Compactor mold configuration and compaction parameters 
Table 2.4 Typical roadway applications for Superpave mixes

\begin{tabular}{|c|l|}
\hline $\begin{array}{c}\text { ESAL } \\
\text { (million) }\end{array}$ & \multicolumn{1}{|c|}{ Typical Roadway Application } \\
\hline$<0.3$ & $\begin{array}{l}\text { Roadway with very light traffic volumes such as local roads, } \\
\text { county roads and city streets where truck traffic is prohibited } \\
\text { or at minimum level. } \\
\text { Special purpose roadways serving recreational sites may be } \\
\text { applicable }\end{array}$ \\
\hline 0.3 to $<3$ & $\begin{array}{l}\text { Collector roads or access street. Medium-trafficked city } \\
\text { streets and majority of county roadways may be applicable to } \\
\text { this level }\end{array}$ \\
\hline 3 to $<30$ & $\begin{array}{l}\text { Two-lane, multilane, divided and partially or completed } \\
\text { controlled access roadways. Among these are medium to } \\
\text { highly trafficked city streets many state routes. US } \\
\text { highways, and some rural interstates }\end{array}$ \\
\hline 30 & $\begin{array}{l}\text { Vast Majority of the US Interstate system. Special } \\
\text { applications such as truck-weighing stations or truck- } \\
\text { climbing lanes on two-lane roadways may also be applicable } \\
\text { to this level }\end{array}$ \\
\hline
\end{tabular}

Superpave requires checking the percent of maximum theoretical specific gravity, $\mathrm{G}_{\mathrm{mm}}$, of the samples at $\mathrm{N}_{\mathrm{ini}}$ and $\mathrm{N}_{\max }$. The $\mathrm{N}_{\mathrm{ini}}$ compaction criteria is used to limit tender mixes. The $\mathrm{N}_{\max }$ criteria is used to ensure the mix will maintain a minimum air void content over the life of pavement, Table 2.5 shows the Superpave compaction criteria.

Table 2.5 WVDOH gyratory compaction criteria

\begin{tabular}{|c|c|c|c|c|c|}
\hline \multicolumn{6}{|c|}{ Gyratory compactive effort } \\
\hline $\begin{array}{c}\text { ESAL } \\
\text { (million) }\end{array}$ & $\mathrm{N}_{\text {ini }}$ & $\mathrm{N}_{\text {des }}$ & $\mathrm{N}_{\max }$ & $\begin{array}{c}\text { Max } \% \mathrm{G}_{\mathrm{mm}} \\
\text { at } \mathrm{N}_{\text {ini }}\end{array}$ & $\begin{array}{c}\text { Max } \% \mathrm{G}_{\mathrm{mm}} \\
\text { at } \mathrm{N}_{\max }\end{array}$ \\
\hline$<0.3$ & 6 & 50 & 75 & 91.5 & 98.0 \\
\hline 0.3 to $<3$ & 7 & 75 & 115 & 90.5 & 98.0 \\
\hline 3 to $<30$ & 8 & 100 & 160 & 89.0 & 98.0 \\
\hline$>30$ & 9 & 125 & 205 & 89.0 & 98.0 \\
\hline
\end{tabular}




\subsubsection{SELECTION OF MATERIALS}

Criteria for materials selection are mainly functions of environment, traffic and pavement structure. All these factors influence the binder grade selection. The traffic level and pavement structure affects the aggregate requirements.

\subsubsection{Asphalt Cement Grade}

Performance grade binder specifications were introduced with concurrently with Superpave. Under these specifications, the binder is graded based on maximum and minimum pavement temperatures. Table 2.6 shows the range of performance grade binders that are potentially available (WVDOH, 2003). However, only a limited number of grades will be available in a geographic area. The high temperature designation is based on the maximum seven day moving average pavement temperature. The minimum temperature designation is based on the coldest pavement temperatures. These pavement temperatures are computed based on air temperatures and geographic locations. The standard Performance Grade binder used in West Virginia is PG 64-22.

In addition to pavement temperatures, the traffic volume and speed are considered in the selection of a binder grade. The high temperature grade of the binder can be increased one level to accommodate high traffic levels. In West Virginia, a PG $70-22$ binder is specified when the anticipated 20 year cumulative traffic is greater than 20 million ESALs (WVDOH supplemental specifications, 2003).

The high temperature grade can also be increased one temperature grade for slow moving traffic, such as intersections and climbing lanes. In the presence of both high traffic volume and slow moving traffic, the high temperature grade can be increased two levels. For example, in 2002 WVDOH rehabilitated an intersection on a coal haul route using a PG 76-22 (Nallamothu, 2003). For pavement lifts more than 4 in below the pavement surface, WVDOH uses the standard PG 64-22 regardless of traffic considerations.

\subsubsection{Aggregate Requirements}

Superpave aggregate requirements are classified as source properties and consensus properties. Source properties are characteristics, which are a function of local 
conditions, and there are no national standards. The WVDOH uses the Marshall aggregate requirements as the source aggregate requirements for Superpave, with two exceptions, the coarse aggregate fractured face and flat and elongated are treated as consensus properties in Superpave. The consensus aggregate specifications in Superpave Table 2.6 Performance grades of asphalt binders

\begin{tabular}{|c|c|}
\hline $\begin{array}{c}\text { High Temperature } \\
\text { Grades }\left({ }^{\circ} \mathrm{C}\right)\end{array}$ & $\begin{array}{c}\text { Low Temperature } \\
\text { Grades }\left({ }^{\circ} \mathrm{C}\right)\end{array}$ \\
\hline PG 46 & $-34,-40,-46$ \\
\hline PG 52 & $-10,-16,-22,-28,-34,-40,-46$ \\
\hline PG 58 & $-16,-22,-28,-34,-40$ \\
\hline PG 64 & $-10,-16,-22,-28,-34,-40$ \\
\hline PG 70 & $-10,-16,-22,-28,-34,-40$ \\
\hline PG 76 & $-10,-16,-22,-28,-34$ \\
\hline PG 82 & $-10,-16,-22,-28,-34$ \\
\hline
\end{tabular}

control aggregate properties, which are essential to the performance of the pavement. The consensus property requirements were implemented on a nationwide basis.

- Coarse Aggregate Angularity (ASTM D 5821): This property ensures a high degree of aggregate internal friction and help to prevent severe rutting. It is defined as "the percent by weight of aggregates larger than 4.75 millimeters with one or more than one fractured faces" (Harman, et al; 2002).

- Fine Aggregate Angularity FAA (AASHTO T304): This property is related to particle shape, angularity, and surface texture. It ensures a high degree of fine aggregate internal friction and also help to prevent severe rutting. The test is performed on material passing $2.36 \mathrm{~mm}$ sieve using the Uncompacted Void Content procedure.

- Flat / Elongated Particles (ASTM D 4791): Elongated particles in mix design aggregate are undesirable because they have a predisposition to break during construction and under traffic loads. This characteristic is evaluated by calculating the weight of coarse material that has a maximum to minimum 
dimension-ratio grater than five. It is performed on coarse aggregate retained on the $9.5 \mathrm{~mm}$ sieve. The Superpave consensus test defines a flat / enlongated particle as one with a maximum to minimum dimension ratio greater than five.

- Clay content, Sand Equivalent Test (AASHTO T 176): Clay content is measured as the percent of clay material contained in the aggregate fraction which passes the $4.75 \mathrm{~mm}$ sieve.

The consensus properties are evaluated for each stockpile. The individual results are combined based on the blending equation.

$$
X=\frac{x_{1} P_{1} p_{1}+x_{2} P_{2} p_{2}+\ldots}{P_{1} p_{1}+P_{2} p_{2}+\ldots}
$$

Where

$X=$ Blended value of a consensus properties

$x_{i}=$ Consensus property value for stockpile $\mathrm{i}$

$P_{i}=$ Percent of stockpile $\mathrm{i}$ which either passes or is retained on the test dividing sieve

$p_{i}=$ Percent of stockpile $\mathrm{i}$ in the aggregate blend

Table 2.7 presents the WVDOH aggregate consensus property requirements.

As with the Marshall procedure, the aggregate blend is selected to meet the gradation requirements for each type of mix. The Superpave gradation requirements are presented in Table 2.8 .

\subsubsection{SELECTION OF THE DESIGN AGGREGATE STRUCTURE}

Selection of design aggregate structure is made by evaluating the volumetric properties of mixes made with the three aggregate blends. The process for determining the aggregate blends is the same as used for the Marshall procedure, except the control points used in Table 2.8 are used for Superpave.

After the three blends are selected, the consensus aggregate properties are computed using Equation 2.10 and the results are compared to the criteria in Table 2.7. 
Table 2.7 WVDOH Superpave aggregate consensus property requirements

\begin{tabular}{|c|c|c|c|c|c|c|}
\hline \multicolumn{7}{|c|}{ Aggregate Property Requirements ${ }^{\text {(Note 1) }}$} \\
\hline \multirow{2}{*}{$\begin{array}{l}20 \text { Year } \\
\text { Projected } \\
\text { Design } \\
\text { ESALs } \\
\text { (millions) }\end{array}$} & \multicolumn{2}{|c|}{$\begin{array}{c}\text { Coarse Agg. } \\
\text { Angularity } \\
\text { (\% Minimum) } \\
\text { ASTM D5821 } \\
\text { (Note 2 and 3) }\end{array}$} & \multicolumn{2}{|c|}{$\begin{array}{c}\text { Fine Agg. } \\
\text { Angularity } \\
\text { (\% Minimum) } \\
\text { AASHTO T304 }\end{array}$} & $\begin{array}{c}\text { Fine Agg. } \\
\text { Sand } \\
\text { Equivalent } \\
\text { AASHTO } \\
\text { T176 }\end{array}$ & $\begin{array}{l}\text { Coarse Agg. } \\
\text { Flat and } \\
\text { Enlongated } \\
\text { ASTM D4791 }\end{array}$ \\
\hline & $\begin{array}{c}\leq 100 \mathrm{~mm} \\
\text { From } \\
\text { Surface }\end{array}$ & $\begin{array}{l}>100 \mathrm{~mm} \\
\text { From } \\
\text { Surface }\end{array}$ & $\begin{array}{l}\leq 100 \mathrm{~mm} \\
\text { From } \\
\text { Surface }\end{array}$ & $\begin{array}{l}>100 \mathrm{~mm} \\
\text { From } \\
\text { Surface }\end{array}$ & $\begin{array}{l}\text { Percent } \\
\text { Minimum }\end{array}$ & $\begin{array}{c}\text { Percent } \\
\text { Maximum } \\
\text { (Note 4) }\end{array}$ \\
\hline$<0.3$ & $55 /-$ & $-/-$ & - & - & 40 & - \\
\hline 0.3 to $<3$ & $75 /-$ & $50 /-$ & 40 & 40 & 40 & 10 \\
\hline 3 to $<10$ & $85 / 80$ & $60 /-$ & 45 & 40 & 45 & 10 \\
\hline 10 to $<30$ & $95 / 90$ & $80 / 75$ & 45 & 40 & 45 & 10 \\
\hline$\geq 30$ & $100 / 100$ & $100 / 100$ & 45 & 45 & 50 & 10 \\
\hline
\end{tabular}

Note 1: The aggregate property requirements shall be applied to the blend of coarse and fine aggregates within a mixture. The properties of the blended coarse aggregates may be obtained by mathematical proportioning if one or more of the aggregates in the blend fail one or both of the required properties. The properties of the blend fail one or both of the required properties.

Note 2: Depth from surface shall be interpreted to mean that if less than $25 \%$ of a layer is within 4 inches $(100 \mathrm{~mm})$ of the surface then the greater-than 4 inches $(100 \mathrm{~mm})$ criteria shall apply.

Note 3: " $85 / 80$ " denotes that a minimum of $85 \%$ of the coarse aggregate has one fractured face and a minimum of $80 \%$ has two fractured faces.

Note 4: Flat or elongated particles in coarse aggregates shall be tested in accordance with ASTM D4791 for a maximum to minimum ratio of 5:1. The amount of coarse aggregate exceeding this ratio shall be a maximum of ten percent by weight for all pavements where the estimated traffic level is $\geq 0.3$ million ESALs. 
Table 2.8 WVDOH Superpave aggregate gradation requirements

\begin{tabular}{|c|c|c|c|c|c|}
\hline $\begin{array}{c}\text { Nominal } \\
\text { Max. Size }\end{array}$ & $\begin{array}{c}37.5 \mathrm{~mm} \\
(11 / 2 \mathrm{inch})\end{array}$ & $\begin{array}{c}25 \mathrm{~mm} \\
(1 \mathrm{inch})\end{array}$ & $\begin{array}{c}19 \mathrm{~mm} \\
(3 / 4 \mathrm{inch})\end{array}$ & $\begin{array}{c}12.5 \mathrm{~mm} \\
(1 / 2 \mathrm{inch})\end{array}$ & $\begin{array}{c}9.5 \mathrm{~mm} \\
(3 / 8 \mathrm{inch})\end{array}$ \\
\hline $\begin{array}{c}\text { Standard } \\
\text { Sieve Size }\end{array}$ & Base-I & $\begin{array}{c}\text { Base-II } \\
(\mathrm{P} \& \mathrm{~L})\end{array}$ & & & \\
\hline $50 \mathrm{~mm}(2 ”)$ & 100 & & & & \\
\hline $37.5 \mathrm{~mm}(11 / 2 ")$ & $90.0-100.0$ & 100 & & & \\
\hline $25 \mathrm{~mm}(1 ”)$ & $90 \mathrm{Max}$ & $90.0-100.0$ & 100 & & \\
\hline $19 \mathrm{~mm}(3 / 4 ”)$ & - & $90 \mathrm{Max}$ & $90.0-100.0$ & 100 & \\
\hline $12.5 \mathrm{~mm}(1 / 2 ”)$ & - & & $90 \mathrm{Max}$ & $90-100$ & 100 \\
\hline $9.5 \mathrm{~mm}(3 / 8 ”)$ & - & - & - & $90 \mathrm{Max}$ & $90-100$ \\
\hline $4.75 \mathrm{~mm}($ No. 4$)$ & - & - & - & - & $90 \mathrm{Max}$ \\
\hline $2.36 \mathrm{~mm}($ No.8) & $15.0-41.0$ & $19.0-45.0$ & $23.0-49.0$ & $28.0-58.0$ & $32.0-67.0$ \\
\hline $1.18 \mathrm{~mm}$ (No.16) & - & - & - & - & - \\
\hline $600 \mu \mathrm{m}($ No.30) & - & - & - & - & - \\
\hline $300 \mu \mathrm{m}($ No. 50$)$ & - & - & - & - & - \\
\hline $75 \mu \mathrm{m}($ No.200) & $0.0-6.0$ & $1.0-7.0$ & $2.0-8.0$ & $2.0-10.0$ & $2.0-10.0$ \\
\hline
\end{tabular}

Once these aggregate blends are determined, the optimum asphalt content is estimated for each blend using the following equations:

1. Estimate aggregate effective specific gravity:

$$
G_{s e}=G_{s b}+F \times\left(G_{s a}-G_{s b}\right)
$$

Where:

$G_{s e}=$ Effective specific gravity of aggregate

$G_{s b}=$ Bulk specific gravity of aggregate

$G_{s a}=$ Apparent specific gravity of aggregate

$F=$ Absorption factor

$F$ for normal aggregates, such as limestone and gravel, is 0.8 , absorptive aggregates such as slag require values close to 0.6 . 
2. Estimate the volume of asphalt binder absorbed into the aggregate, $\mathrm{V}_{\mathrm{ba}}$ :

$$
V_{b a}=\frac{P_{s} \times\left(1-V_{a}\right)}{\frac{P_{b}}{G_{b}}+\frac{P_{s}}{G_{s e}}} \times\left(\frac{1}{G_{s b}}-\frac{1}{G_{s e}}\right)
$$

Where:

$V_{b a}=$ Volume of absorbed binder

$V_{a}=$ Volume of air voids

$G_{s e}=$ Effective specific gravity of aggregate

$G_{s b}=$ Bulk specific gravity of aggregate

$G_{s a}=$ Apparent specific gravity of aggregate

$G_{b}=$ Specific gravity of binder

$P_{b}=$ Asphalt content, percent by weight of mix

$P_{s}=$ Aggregate content, percent by weight of mix

For the initial estimate of $\mathrm{V}_{\mathrm{ba}}$, the air content, $\mathrm{V}_{\mathrm{a}}$, is usually assumed to be 4 percent. Experience is used to estimate the percent binder, e.g. 5.8 percent for a $9.5 \mathrm{~mm}$ mix.

3. Estimate the volume of effective binder, $\mathrm{V}_{\text {be }}$ of the trial blends:

$$
V_{b e}=0.176-0.0675 \times \log _{10}\left(S_{n}\right)
$$

Where,

$V_{b e}=$ volume of effective binder

$S_{n}=$ the nominal maximum sieve size of the aggregate blend in millimeters

4. Estimate weight of aggregates, $\mathrm{W}_{\mathrm{s}}$ :

$$
W_{s}=\frac{P_{s} \times\left(1-V_{a}\right)}{\frac{P_{b}}{G_{b}}+\frac{P_{s}}{G_{s e}}}
$$


5. Estimate initial trial asphalt binder, $\mathrm{P}_{\mathrm{bi}}$ content for the trial blends:

$$
P_{b i}=\frac{G_{b} \times\left(V_{b e}+V_{b a}\right)}{\left(G_{b} \times\left(V_{b e}+V_{b a}\right)\right)+W_{s}}
$$

Where

$P_{b i}=$ percent, by weight of mix, of binder

$\mathrm{P}_{\mathrm{bi}}$ from Equation 2.15 should be compared to the estimated $\mathrm{P}_{\mathrm{b}}$ used with

Equation 2.12. If the value differs by more than 0.1 percent, an iterative solution method is used to equilibrate the two estimates.

For each of the aggregate blends, two compaction specimens are prepared and the bulk specific gravity is determined. A sample is also prepared to determine the maximum theoretical specific gravity. A volumetric analysis is performed using Equations 2.16, 2.17 and 2.18 to determine VTM, VMA, and VFA. In addition, the dust to binder ratio, $\mathrm{P}_{0.075} / \mathrm{P}_{\mathrm{be}}$, must be evaluated. The Superpave definition of the dust to binder ratio uses the effective asphalt content in the denominator. The equations required to compute $\mathrm{P}_{0.075} / \mathrm{P}_{\text {be }}$ are:

$$
\begin{aligned}
& P_{b a}=100\left[\frac{G_{s e} G_{s b}}{G_{s b} G_{s e}}\right] G_{b} \\
& P_{b e}=P_{b}-\left[\frac{P_{b a}}{100}\right] P_{s} \\
& P_{0.075} / P_{b e}=\frac{P_{0.075}}{P_{b e}}
\end{aligned}
$$

Where:

$\mathrm{P}_{0.075} / \mathrm{P}_{\text {be }}=$ dust to binder ratio,

$P_{b a}=$ percent absorbed binder based on the mass of aggregates,

$P_{0.075}=$ percent dust, or percent of aggregate passing the $0.075 \mathrm{~mm}$ sieve,

$P_{b e}=$ percent effective binder content, 
$G_{s e}=$ Effective specific gravity of aggregate

$G_{s b}=$ Bulk specific gravity of aggregate

$G_{b}=$ Specific gravity of binder

The percent of $\mathrm{G}_{\mathrm{mm}} @ \mathrm{~N}_{\mathrm{ini}}$ is computed from the measured bulk specific gravity of samples compacted to $\mathrm{N}_{\mathrm{des}}$ and the height of the sample measured during compaction. The percent $\mathrm{G}_{\mathrm{mm}} @ \mathrm{~N}_{\mathrm{ini}}$ is computed as:

$$
\% G_{m m \text { Nini }}=\frac{h_{\text {des }}}{h_{\text {ini }}} \times \% G_{m m \text { Ndes }}
$$

Where

$h_{\text {des }}=$ height of compacted sample at $\mathrm{N}_{\text {des }}$

$h_{\text {ini }}=$ height of compacted sample at $\mathrm{N}_{\text {ini }}$ successively obtained from compaction report of the SGC.

$\% G_{m m N d e s}=$ percent of maximum theoretical gravity for a sample compacted with $\mathrm{N}_{\text {des }}$ gyrations

After the optimum asphalt content is determined at $\mathrm{N}_{\text {des, }}$, additional samples are compacted using $\mathrm{N}_{\max }$ revolutions and the percent of maximum theoretical specific gravity is determined and compared to the criteria in Table 2.5

$G_{s e}$ used in Equation 2.16 is computed from the measured $\mathrm{G}_{\mathrm{mm}}$ using Equation 2.5. Since trial blends are based in estimated asphalt content, VTM at this asphalt content generally is not the 4 percent required at $\mathrm{N}_{\text {des }}$. Superpave provides a procedure for adjusting volumetric parameters to reflect what will likely values at 4.0\% VTM:

$$
\begin{aligned}
& P_{b, e s t}=P_{b t}-\left(0.4 \times\left(4-V T M_{t}\right)\right. \\
& V M A_{e s t}=V M A_{t}+C\left(4-V T M_{t}\right) \\
& V F A_{e s t}=100 \times \frac{V M A_{t}-V T M_{t}}{V M A_{t}}
\end{aligned}
$$




$$
\begin{aligned}
& \% G m m_{e s t i n i}=\% G m m_{t i n i}-\left(4-V T M_{t}\right) \\
& P_{b e, e s t}=P_{b, e s t}-\frac{P_{s} G_{b}\left(G_{s e}-G_{s b}\right)}{G_{s e}} \\
& P_{0.075} / P_{b e, e s t}=\frac{P_{0.075}}{P_{b e, e s t}}
\end{aligned}
$$

Where:

$P_{b, e s t}=$ adjusted estimated asphalt content at $4.0 \% \mathrm{VTM}$

$P_{b t}=$ asphalt content of trial specimen

$V T M_{t}=\mathrm{VTM}$ of trial specimen

$V M A_{\text {est }}=$ adjusted estimated VMA at $4.0 \% \mathrm{VTM}$

$V M A_{t}=$ VMA of trial specimen

$C=0.1$ When $\mathrm{VTM}_{\mathrm{t}}$ is less than $4.0 \%$ or

$C=0.2$ When $\mathrm{VTM}_{\mathrm{t}}$ is $4.0 \%$ or greater

$V F A_{\text {est }}=$ adjusted estimated VFA at $4.0 \%$ VTM

$\% G m m_{\text {est ini }}=$ adjusted estimated $\% G m m_{\text {est }}$ at $\mathrm{N}_{\mathrm{ini}}$

$\% G m m_{\text {tini }}=$ actual $\% G m m$ of $\mathrm{N}_{\text {ini }}$ at trial specimen

$P_{b e, e s t}=$ adjusted estimated effective binder at $4.0 \%$ VTM

$P_{b, e s t}=$ adjusted estimated asphalt content at $4.0 \% \mathrm{VTM}$

$P_{0.075} / P_{b e, e s t}=$ adjusted estimated dust to binder ratio at $4.0 \% \mathrm{VTM}$

$P_{b e, e s t}=$ adjusted estimated effective binder at $4.0 \%$ VTM

The estimated volumetric criteria for each of the three aggregate blends are compared to the Superpave criteria, Table 2.9 (WVDOH MP 401.02.28), to select the design aggregate structure. If none of the blends meet all of the criteria, the process is repeated for a new blend of the stockpiles. 


\subsubsection{SELECTION OF THE DESIGN ASPHALT BINDER CONTENT}

Once the design aggregate structure is selected, two set of specimens are compacted at each of four different asphalt contents as follows:

- Estimated asphalt content, from Equation 2.20

- Estimated asphalt content $\pm 0.5 \%$

- Estimated asphalt content $+1.0 \%$

Maximum theoretical specific gravity samples are prepared for each asphalt content. The volumetric parameters for each sample are calculated and data for each asphalt content are plotted as in Marshall design. The design asphalt binder content is established as the one that produces $4.0 \%$ VTM at $\mathrm{N}_{\text {des. }}$. The volumetric parameters, VMA, VFA, $\% \mathrm{G}_{\mathrm{mm}} @ \mathrm{~N}_{\text {ini }}$ and $\mathrm{P}_{0.075} / \mathrm{P}_{\text {be }}$ are determined at this asphalt content and are compared to the criteria in Table 2.9. If all the parameters comply with the criteria, the optimum asphalt content has been determined.

Finally, the design asphalt content is checked by compacting two more samples at maximum number of gyrations, $\mathrm{N}_{\max }$ and determining the percent of the maximum theoretical specific gravity at $\mathrm{N}_{\max }$. The result is compared to the criteria in Table 2.9.

If the mix design fails to meet all requirements the aggregate gradation should be adjusted and the process repeated. 
Table 2.9 WVDOH Superpave design criteria

\begin{tabular}{|c|c|c|c|c|c|c|c|}
\hline \multicolumn{3}{|c|}{ Design Air Voids } & \multicolumn{5}{|c|}{$4.0 \%$} \\
\hline \multicolumn{3}{|c|}{ Fines to effective asphalt (FA) ratio ${ }^{(\text {Note } 1)}$} & \multicolumn{5}{|c|}{$0.6-1.2$} \\
\hline \multicolumn{3}{|c|}{ Tensile strength ratio ( AASHTO T283) (Note 2) } & \multicolumn{5}{|c|}{$80 \%$ minimum } \\
\hline & & & \multicolumn{5}{|c|}{ Nominal Maximum Size } \\
\hline & & & $\begin{array}{c}37.5 \mathrm{~mm} \\
\left(11 / 2^{\prime \prime}\right)\end{array}$ & $\begin{array}{c}25 \mathrm{~mm} \\
(1 ")\end{array}$ & $\begin{array}{c}19 \mathrm{~mm} \\
(3 / 4 ")\end{array}$ & $\begin{array}{c}12.5 \mathrm{~mm} \\
\left(1 / 2^{\prime \prime}\right)\end{array}$ & $\begin{array}{c}9.5 \mathrm{~mm} \\
\left(3 / 8^{\prime \prime}\right)\end{array}$ \\
\hline \multicolumn{3}{|c|}{$\begin{array}{l}\text { Minimum Voids in Mineral Aggregate } \\
\text { (VMA) \% }\end{array}$} & 11.0 & 12.0 & 13.0 & 14.0 & 15.0 \\
\hline \multirow{2}{*}{$\begin{array}{l}\text { Design } \\
\text { ESALs } \\
\text { (millions) }\end{array}$} & \multicolumn{5}{|c|}{$\begin{array}{c}\text { Percent of Theoretical Maximum } \\
\text { Specific Gravity }\end{array}$} & \multirow{2}{*}{\multicolumn{2}{|c|}{$\begin{array}{c}\text { Percent Voids } \\
\text { Filled With } \\
\text { Asphalt } \\
\text { (Note 3,4,5) }\end{array}$}} \\
\hline & $\mathrm{N}_{\text {initial }}$ & \multicolumn{2}{|c|}{$\mathrm{N}_{\text {design }}$} & \multicolumn{2}{|c|}{$\mathrm{N}_{\max }$} & & \\
\hline$<0.3$ & $\leq 91.5$ & \multicolumn{2}{|c|}{96} & \multicolumn{2}{|c|}{$\leq 98.0$} & \multicolumn{2}{|c|}{$70-80$} \\
\hline $0.3<3$ & $\leq 90.5$ & \multicolumn{2}{|c|}{96} & \multicolumn{2}{|c|}{$\leq 98.0$} & \multicolumn{2}{|c|}{$65-78$} \\
\hline $3<10$ & $\leq 89.0$ & \multicolumn{2}{|c|}{96} & \multicolumn{2}{|c|}{$\leq 98.0$} & \multicolumn{2}{|c|}{$65-75$} \\
\hline $10<30$ & $\leq 89.0$ & \multicolumn{2}{|c|}{96} & \multicolumn{2}{|c|}{$\leq 98.0$} & \multicolumn{2}{|c|}{$65-75$} \\
\hline$\geq 30$ & $\leq 89.0$ & \multicolumn{2}{|c|}{96} & \multicolumn{2}{|c|}{$\leq 98.0$} & \multicolumn{2}{|c|}{$65-75$} \\
\hline
\end{tabular}

Note 1: When the design aggregate gradation passes beneath the restricted zone, the dust to binder criteria shall be 0.8 to 1.6

Note 2: Test specimens shall be $150 \mathrm{~mm}$ in diameter and $95 \mathrm{~mm}$ in height. If the $80 \%$ minimum tensile strength ratio is not met, a new design will be required. A Division approved antistripping additive, such as hydrated lime conforming to the requirements of AASHTO M303 or a liquid antistripping additive, may be added to the mixture if needed. If such an additive is used, all design testing must be conducted with additive in the mixture.

Note 3: For $9.5 \mathrm{~mm}(3 / 8$ ") nominal maximum size mixtures, the specified VFA range shall be $73 \%$ to $76 \%$ for design traffic levels $\geq 0.3$ million ESALs.

Note 4: For $25 \mathrm{~mm}(1$ ") nominal maximum size mixture, the specified lower limit of the VFA shall be $64 \%$ for design traffic levels $<0.3$ million ESALs.

Note 5: For $37.5 \mathrm{~mm}\left(1 \frac{1}{2}\right.$ ") nominal maximum size mixtures, the specified lower limit of the VFA shall be $64 \%$ for all design traffic levels. 


\subsubsection{EVALUATION OF MOISTURE SUSCEPTIBILITY}

This final step requires that the design asphalt mixture be evaluated using AASHTO T283, "Resistance of Compacted Bituminous Mixture to Moisture Induced Damage." Six test specimens are fabricated using the Superpave gyratory compactor. The samples are compacted to a height of $95 \mathrm{~mm}$ and VTM of $7 \pm 0.5$ percent. Three of the six are moisture conditioned. The remaining three specimens remain unconditioned. All of the test specimens are evaluated for their indirect tensile strength. The ratio of average conditioned to average unconditioned tensile strength is the tensile strength ratio, TSR. The design asphalt mixture is judged to be non-moisture susceptible if it has a TSR greater than 80 percent. If the TSR criteria are not met and antistrip agent is incorporated into the mix, then the design binder content must be reevaluated.

\subsection{AGGREGATE SURFACE AREA}

The rationale behind the current Superpave VMA requirement was to incorporate a minimum asphalt content into the mix to ensure its durability (Kandhal, et al; 1998). Recent studies have shown that asphalt mix durability is directly related to asphalt film thickness (Kandhal, and Chakraborty; 1996). Since the minimum asphalt content will be different for mixes with different gradations, a more rational approach for VMA should be based on the minimum average film thickness rather than a minimum VMA. An average film thickness of 8 microns at 4 percent air voids was used and recommended by (Kandhal, et al; 1998). Film thickness is computed using the aggregate surface area and effective binder content.

Surface area is affected mainly by aggregate gradation. This parameter is slightly affected by percentage passing the larger sieves sizes but significantly affected by the percent passing small sizes. For this reason, surface area and asphalt film thickness could be an issue for low traffic volume HMA applications with a large percent of fines. As a consequence, it is possible increase or decrease surface area by increasing or decreasing the amount of fines in the mixture, and especially by altering the amount of dust, material finer than $75 \mu \mathrm{m}$, present in the HMA. Several methods of computing aggregate surface area based on gradation are available in the literature (Reyes, 2003). 
The method developed by Edwards and adopted by Hveem assumes aggregate particles are perfect spheres. The surface area of aggregates passing through a sieve is computed assuming the diameter of the particle is equal to the edge dimension of the sieve. The total surface area of an aggregate blend is then determined as the sum of surface area factors times the percentage passing each size:

$$
S A=\sum S F_{i} \times P_{i}
$$

Where

$\mathrm{SA}=$ Surface area $\mathrm{m}^{2} / \mathrm{kg}$

$\mathrm{SF}_{\mathrm{i}}=$ Surface factor for sieve $\mathrm{i}$

$\mathrm{P}_{\mathrm{i}}=$ Percent passing sieve $\mathrm{i}$ in decimal form

The Edwards-Hveem specific surface area factors are shown in Table 2.10 (Roberts, et al; 1996). While the surface area can be computed based on the presumed diameter of the "sphere" the specific surface area, mass/unit area, is dependent on the specific gravity of the aggregates. The value used to determine the specific surface area factors in Table 2.10 was not documented. An example calculation of surface area using the Edwards-Hveem factors is presented in Table 2.11.

Craus and Ishai (1977) developed a similar method that assumes the aggregate particles have a sphere or a cube form with $\mathrm{D}$ being the diameter or length of the edge of an aggregate of density $\rho$. Under this method, surface area factors for all sieves greater than $4.75 \mathrm{~mm}$ are not taken into consideration. Specific surface area is computed as:

$$
S F_{i}=\frac{6}{\rho \times D_{i}}
$$

Where:

$S F_{i}=$ Surface factor for sieve $\mathrm{i}$

$D_{i}=$ Sieve size of sieve $\mathrm{i}$ in decimal

$\rho=$ Density of the aggregate in $\mathrm{kg} / \mathrm{m}^{3}$ 
Table 2.10 Edwards-Hveem surface area factors

\begin{tabular}{|l|c|}
\hline \multicolumn{1}{|c|}{ Sieve Size } & $\begin{array}{c}\text { Surface Area } \\
\text { Factor } \\
\left(\mathrm{m}^{2} / \mathrm{kg}\right)\end{array}$ \\
\hline Percent passing maximum sieve size & 0.41 \\
\hline Percent passing No.4 & 0.41 \\
\hline Percent passingNo.8 & 0.82 \\
\hline Percent passing No.16 & 1.64 \\
\hline Percent passing No.30 & 2.87 \\
\hline Percent passing No.50 & 6.14 \\
\hline Percent passing No.100 & 12.29 \\
\hline Percent passing No.200 & 32.77 \\
\hline
\end{tabular}

Table 2.11 Hveem surface area calculation example.

\begin{tabular}{cccc}
\hline $\begin{array}{c}\text { Sieve } \\
\text { Size }\end{array}$ & $\begin{array}{c}\text { Percent } \\
\text { Passing }\end{array}$ & $\begin{array}{c}\text { Surface Area } \\
\text { Factor } \\
\mathrm{m}^{2} / \mathrm{kg}\end{array}$ & $\begin{array}{c}\text { Surface Area } \\
\mathrm{m}^{2} / \mathrm{kg}\end{array}$ \\
\hline & $\mathrm{P}_{\mathrm{i}}$ & $\mathrm{SF}_{\mathrm{i}}$ & $\mathrm{SA}_{\mathrm{i}}=\mathrm{P}_{\mathrm{i}} \times \mathrm{SF}_{\mathrm{i}}$ \\
\hline 25 & 100 & 0.41 & 0.41 \\
19 & 95 & - & 0.00 \\
12.5 & 78 & - & 0.00 \\
9.5 & 66 & - & 0.00 \\
4.75 & 51 & 0.41 & 0.21 \\
2.36 & 35 & 0.82 & 0.29 \\
1.18 & 25 & 1.64 & 0.41 \\
0.6 & 19 & 2.87 & 0.55 \\
0.3 & 14 & 6.14 & 0.86 \\
0.15 & 9 & 12.29 & 1.11 \\
0.075 & 5 & 32.77 & 1.64 \\
& & & $\sum=5.47$ \\
\hline
\end{tabular}


Table 2.12 is an example of the specific surface area computed with the CraussIshai method. The gradation used in this example is the same as was used for the Edwards-Hveem example. The specific gravity was assumed to be 2.650 . The surface area factors between the Edwards-Hveem and Crauss-Ishai methods are similar, but not exactly the same. There are inconsistencies between the two methods that cannot be explained through analysis.

Table 2.12 Craus and Ishai method surface area calculation example.

\begin{tabular}{cccc}
\hline $\begin{array}{c}\text { Sieve } \\
\text { Size }\end{array}$ & $\begin{array}{c}\text { Percent } \\
\text { Passing }\end{array}$ & $\begin{array}{c}\text { Surface Area } \\
\text { Factor } \\
\mathrm{m}^{2} / \mathrm{kg}\end{array}$ & $\begin{array}{c}\text { Surface Area } \\
\mathrm{m}^{2} / \mathrm{kg}\end{array}$ \\
\hline $\mathrm{D}_{\mathrm{i}}$ & $\mathrm{P}_{\mathrm{i}}$ & $\mathrm{SF}_{\mathrm{i}}=6 /\left(\rho^{*} \mathrm{D}_{\mathrm{i}}\right)$ & $\mathrm{SA}_{\mathrm{i}}=\mathrm{P}_{\mathrm{i}} \times \mathrm{SF}_{\mathrm{i}}$ \\
\hline 25 & 100 & - & - \\
19 & 95 & - & - \\
12.5 & 78 & - & - \\
9.5 & 66 & - & - \\
4.75 & 51 & 0.48 & 0.24 \\
2.36 & 35 & 0.96 & 0.34 \\
1.18 & 25 & 1.92 & 0.48 \\
0.6 & 19 & 3.77 & 0.72 \\
0.3 & 14 & 7.55 & 1.06 \\
0.15 & 9 & 15.09 & 1.36 \\
0.075 & 5 & 30.19 & 1.51 \\
& & & $\sum=5.70$ \\
\hline
\end{tabular}

Duriez and Arrambide (1962) proposed another method based on the following formula:

$$
S A=(135 \cdot A)+(12 \cdot B)+(2.3 \cdot C)
$$

Where

$S A=$ Specific surface area $\left(\mathrm{m}^{2} / \mathrm{kg}\right)$

$A=$ Percent by weight of the fraction finer than $80 \mu \mathrm{m}$

$B=$ Percent by weight of the fraction between $80 \mu \mathrm{m}$ and $0.315 \mathrm{~mm}$ 
$C=$ Percent by weight of the fraction between $0.315 \mathrm{~mm}$ and $5.0 \mathrm{~mm}$

Research conducted at West Virginia University found surface area values not only vary with the aggregate blend but also with aggregate source (Reyes, 2003). Based on measurements of surface area using the Blaine apparatus, it was determined that the surface area of material passing the $0.15 \mathrm{~mm}$ sieve is much greater than the values computed by assuming a nominal dimension for the material. Significant differences were found between surface area values of crushed limestone fine material versus fine material from natural sands for material passing $0.15 \mathrm{~mm}$ sieve. Table 2.13 presents the surface area factors measured with the Blaine apparatus.

Table 2.13 Measured surface area for materials finer than $150 \mu \mathrm{m}$

\begin{tabular}{|l|c|c|c|}
\hline \multicolumn{1}{|c|}{ Source } & S.G. & $\begin{array}{c}\text { Average SA } \\
\operatorname{Pan}^{1}\left(\mathrm{~m}^{2} / \mathrm{kg}\right)\end{array}$ & $\begin{array}{c}\text { Average S.A. } \\
75 \mathrm{~mm}^{2}\left(\mathrm{~m}^{2} / \mathrm{kg}\right)\end{array}$ \\
\hline Summersville & 2.575 & 457.64 & 24.84 \\
\hline Beaver Boxley (A) & 2.667 & 434.77 & 21.48 \\
\hline Beaver Boxley (B) & 2.620 & 288.87 & 13.90 \\
\hline APAC Sand & 2.684 & 478.01 & 30.69 \\
\hline APAC \# 10 & 2.603 & 437.09 & 18.45 \\
\hline New Enterprise & 2.523 & 614.77 & 11.18 \\
\hline Natural Sand & 2.522 & 118.49 & 7.26 \\
\hline Edwards-Hveem & & 32.77 & 12.29 \\
\hline Craus-Ishai & 30.19 & 15.09 \\
\hline
\end{tabular}

${ }^{1}$ Passing $75 \mu \mathrm{m}$, retained in pan

${ }^{2}$ Passing $150 \mu \mathrm{m}$, retained on $75 \mu \mathrm{m}$

\subsection{ASPHALT FILM THICKNESS}

Asphalt film thickness is directly related with durability and moisture susceptibility of HMA (Chadbourn, et al; 1999). It is generally agreed that high permeability, high air voids and thin asphalt coatings on the aggregate particles are the primary causes of excessive aging (Kandhal, et al; 1998). 
The asphalt film thickness is an indicator of the amount of binder coating the aggregate particles, Figure 2.5. It is measured in microns and calculated by dividing the effective volume of asphalt binder by the total estimated surface area of the aggregate. Thicker asphalt binder films produces mixes which are flexible and durable, while thin films produces mixes which tend to crack and ravel excessively. An insufficient coating on aggregate particles is one of the causes leading to premature aging of the asphalt binder. Lacking of film thickness also leads also to inadequate cohesion between particles known as "dry" mixes. Also, aggregates being coated by a thin asphalt film are easily penetrated by water causing striping and brittle (Chadbourn, et al; 1999).

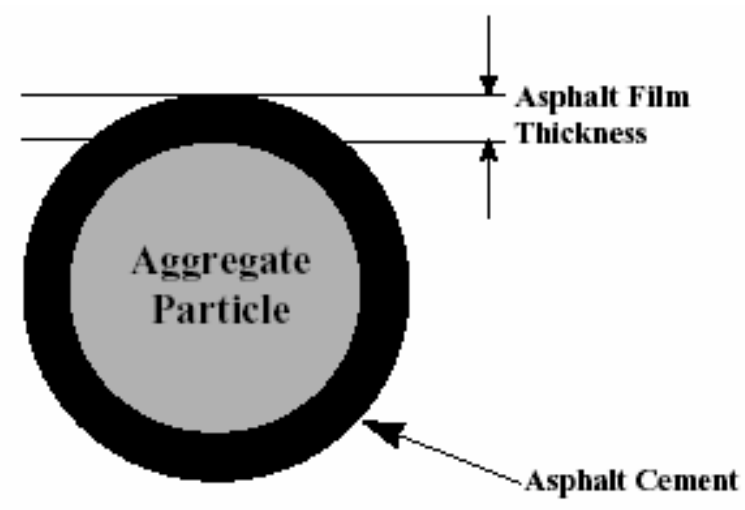

Figure 2.5 Illustration of asphalt film thickness

Asphalt film thickness can be calculated as:

$$
T_{f}=\frac{V_{a s p}}{S A \times W}(1000)
$$

Where:

$T_{f}=$ average thin film in microns

$V_{a s p}=$ effective volume of asphalt cement (1)

$S A=$ surface area of the aggregate $\left(\mathrm{m}^{2} / \mathrm{kg}\right)$

$W=$ weight of aggregate $(\mathrm{kg})$

The average asphalt film thickness generally recommended ranges from six to eight microns (Campen, et al; 1959). Kandhal also suggested an optimum film thickness 
value of 8 microns (Kandhal, et al; 1998). These recommendations are based on using the Edwards-Hveen surface are factors.

\subsection{ASPHALT PAVEMENT ANALYZER}

Permanent deformation, or rutting, occurs in the pavements wheel path as a result of repetitive traffic producing a depression in the pavement structure. Excessive asphalt binder content, excessive amount of fine aggregate and high percentage of natural rounded aggregate particles are mix design factors that contribute to rut susceptible mixes (Jackson and Baldwin, 2000). Currently, Superpave method has no standard to evaluate the potential for permanent deformation, or rutting, of the asphalt mix. As a consequences many states have addressed this issue by using loaded-wheel testers. The Asphalt Technology Laboratory at West Virginia University has been using the Asphalt Pavement Analyzer as mean to test the Superpave asphalt mixtures constructed in the state.

The Asphalt Pavement Analyzer, APA, Figure 2.6, manufactured by Pavement Technology Inc., can be used to evaluate rutting, fatigue, and moisture resistance of HMA mixtures. APA evaluates rutting in HMA pavement by placing rectangular or cylindrical samples under repetitive loads and measuring the amount of permanent deformation, rut depth, resulting under the loaded path. Load is applied through a pneumatic tube inflated to $100 \mathrm{psi}$. The loading wheel applies a load of $100 \mathrm{lbs}$ and travels back and forth across the pneumatic tube, usually applying 8000 cycles.

Under APA specifications, $75 \mathrm{~mm}$ tall by $150 \mathrm{~mm}$ diameter cylindrical samples are compacted using the SGC to achieve 7+/- 0.5 percent air voids. The air void content was selected to be representative of the air content at the completion of construction. Typical highway department specifications require the contractor to achieve between four to eight percent air voids during compaction of the pavement. The APA chamber is set at proper temperature to simulate field conditions. Samples are temperature conditioned for four hours prior to testing. Samples are subjected to cyclical loads and depth measurements are obtained. Figure 2.7 shows the testing configuration. 


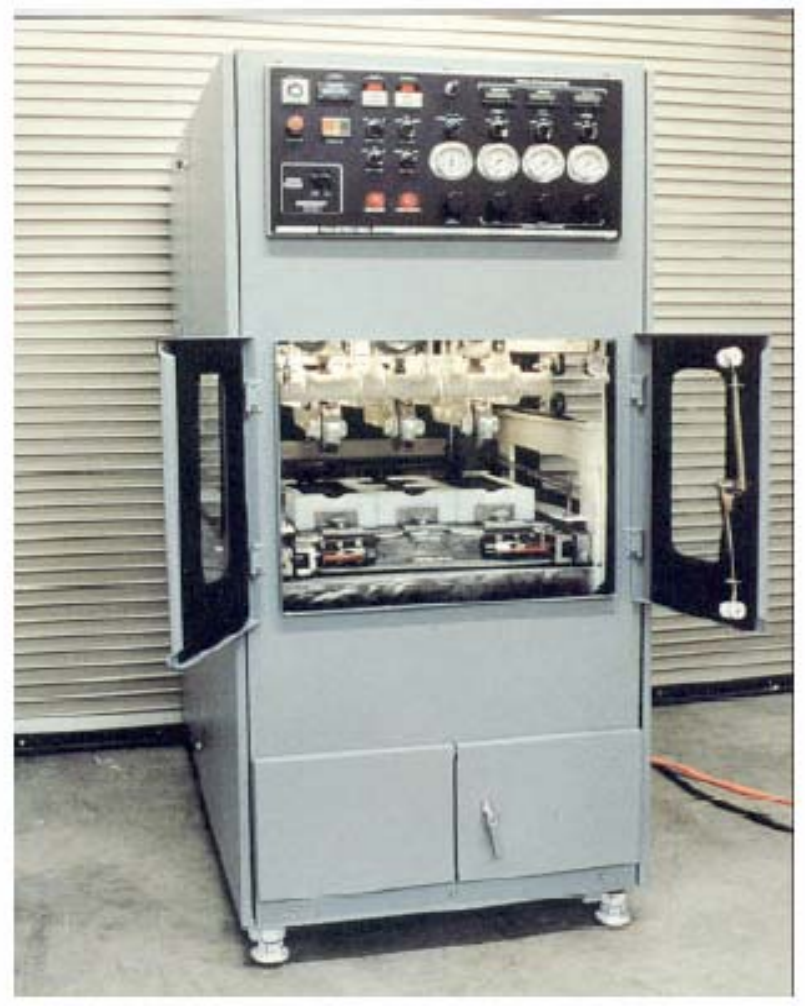

Figure 2.6 Asphalt pavement analyzer

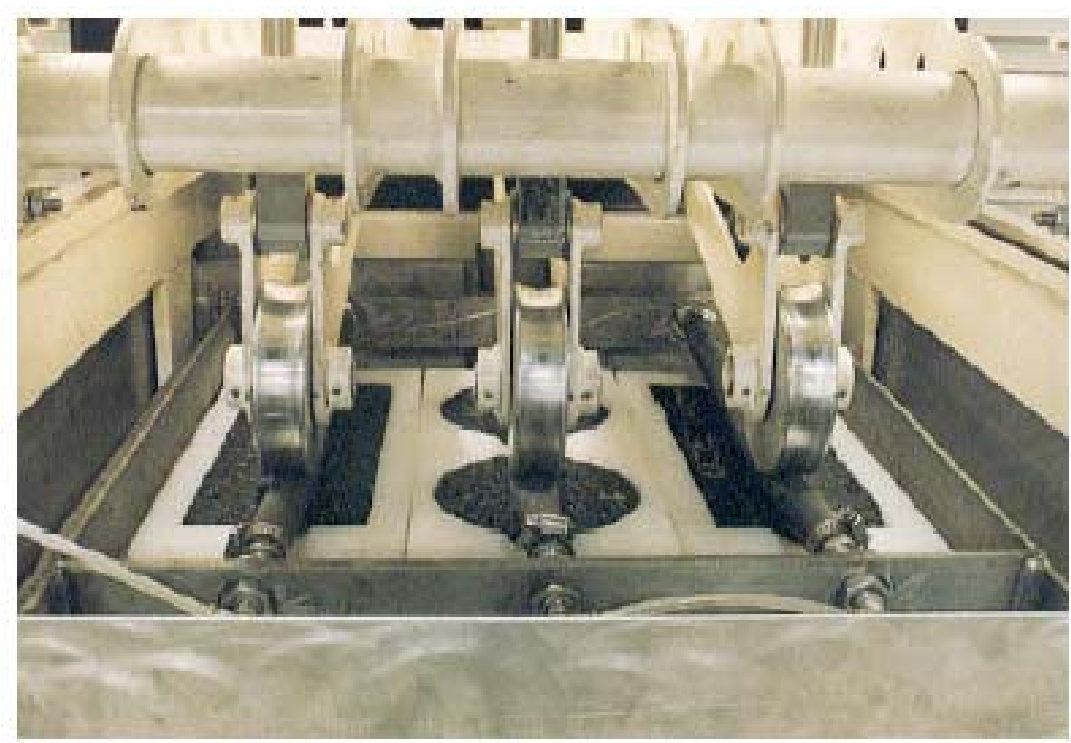

Figure 2.7 Specimens being tested in APA 
Research has established APA as a viable means of evaluating the rutting potential of asphalt concrete mixes. Many states are using APA to rank the rutting potential of asphalt mixtures (Kandhal and Cooley, 1999). Williams and Prowell (1999) successively established correlation between APA results and field rut depths in an evaluation of ten West Track test pavements. The correlation coefficient for a regression analysis between lab and field performance was 0.82 .

The National Center for Asphalt Technology, NCAT, evaluated the APA (Kandhal and Mallick, 1999). Some of the conclusions of this study were:

- The APA is sensitive to aggregate gradation based on statistical significance of differences in rut depths.

- The APA was sensitive to the asphalt binder PG grade based on statistical significance of differences in rut depths. The rut depths of mixes with PG 58- 22 asphalt binder, tested at $58^{\circ} \mathrm{C}$, were higher than those of mixes with PG 64-22 asphalt binder tested at $64^{\circ} \mathrm{C}$.

- The APA had a fair correlation with the repeated shear constant height test conducted with the Superpave shear tester.

- It appears from this study that the APA has a potential to predict the relative rutting potential of hot mix asphalt.

In 1997, the Georgia Department of Transportation established a rut depth criteria of $5 \mathrm{~mm}$ after 8,000 cycles at $50^{\circ} \mathrm{C}$. Since then, APA testing temperature has varied in the literature. It has ranged from 40.6 to $64^{\circ} \mathrm{C}$. Recent research has recommended a test temperature at or slightly above expected high pavement temperatures (Williams and Prowell, 1999, and Kandhal and Cooley, 1999). These changes in test temperature have confounded the problem of establishing universal criteria for the interpretation of APA results. The manufacturer recommends the testing parameters given in Table 2.14.

Shami, et al; (1997) presented a temperature-effect model to predict APA rut depths based on testing conducted at a given number of gyrations. This model was used to convert Georgia's critical rut depth of $5 \mathrm{~mm}$ at $50^{\circ} \mathrm{C}$ after 8000 cycles to a critical rut 
depth of $9.5 \mathrm{~mm}$ at a test temperature of $64^{\circ} \mathrm{C}$ after 8000 . Equation 2.27 presents the temperature-effect model:

$$
\left[\frac{R}{R_{0}}\right]=\left[\frac{T}{T_{0}}\right]^{2.625}\left[\frac{N}{N_{0}}\right]^{0.276}
$$

Where:

$R=$ predict rut depth,

$R_{0}=$ reference rut depth obtained at the reference test condition $T_{0}$ and $N_{0}$,

$T, N=$ temperature and number of load cycles the rut depth is sought,

$T_{0}, N_{0}=$ reference temperature and load cycles at $R_{0}$

Table 2.14 APA test specifications

\begin{tabular}{|l|l|}
\hline Factors & Range specified \\
\hline Air void content & $7 \pm 0.5$ percent \\
\hline Test temperature & $\begin{array}{l}\text { Based on average high temperature } \\
\text { pavement temperature }\end{array}$ \\
\hline Wheel load & $100 \pm 5 \mathrm{lb}$ \\
\hline Hose pressure & $100 \pm 5 \mathrm{lb}$ \\
\hline Specimen type & Beams, cylinders \\
\hline Compaction & Rolling, vibratory and gyratory \\
\hline
\end{tabular}

A potential rut depth criteria for the APA has been proposed by Zhang, et al;

(2002). In this study, APA considered as a simulative test, was compared with two fundamental tests, Repeated Shear at Constant Height, RSCH, and Repeated Load Confined Creep, RLCC, tests. The research showed based upon the relationship between $\mathrm{RSCH}$ and APA, a critical range for APA rut depth of 8.2 to $11.0 \mathrm{~mm}$ approximately. The relationship between RLCC and APA showed a critical rut depth of 8.0 to 9.5. Interestingly, the overlaps in both ranges occur at 8.2 to $9.5 \mathrm{~mm}$ which is consistent with the $9.5 \mathrm{~mm}$ result from Shami's temperature-effect model conversion. These results are summarized in Table 2.15. 
Table 2.15 Guideline for evaluating rut resistance using the APA.

\begin{tabular}{|c|c|c|c|}
\hline \multirow{2}{*}{$\begin{array}{l}\mathrm{RSCH} \text { - APA } \\
\text { Relationship }\end{array}$} & $\begin{array}{c}\text { RSCH } \\
\text { Plastic Shear } \\
\text { Stain (\%) }\end{array}$ & $\begin{array}{l}\text { Corresponding } \\
\text { APA rut depth }\end{array}$ & $\begin{array}{l}\text { APA Rut } \\
\text { Depth } \\
\text { Guidelines }\end{array}$ \\
\hline & $\begin{array}{c}<2.0=\text { Good } \\
>3.0=\text { Poor }\end{array}$ & $\begin{array}{l}<8.2=\text { Good } \\
>11.0=\text { Poor }\end{array}$ & \multirow{3}{*}{$\begin{array}{l}<8.2=\text { Good } \\
>9.5=\text { Poor }\end{array}$} \\
\hline \multirow{2}{*}{$\begin{array}{c}\text { RLCC - APA } \\
\text { Relationship }\end{array}$} & $\begin{array}{c}\text { RLCC } \\
\text { Permanent } \\
\text { Stain (\%) }\end{array}$ & $\begin{array}{l}\text { Corresponding } \\
\text { APA rut depth }\end{array}$ & \\
\hline & $\begin{array}{l}<10.0=\text { Good } \\
>13.0=\text { Poor }\end{array}$ & $\begin{array}{l}<8.0=\text { Good } \\
>9.5=\text { Poor }\end{array}$ & \\
\hline $\begin{array}{l}\text { Georgia Criterion evaluated } \\
\text { on Temperature-effect model }\end{array}$ & $\begin{array}{c}\mathrm{APA} @ 64 \mathrm{C} \\
5.0 \mathrm{~mm}\end{array}$ & $\begin{array}{l}\text { APA @ 50C } \\
9.5 \mathrm{~mm}\end{array}$ & $>9.5=$ Poor \\
\hline
\end{tabular}

Note: All rut depth values in millimeters

\subsection{SUPERPAVE 4.75 MM NMAS MIXES}

There is at least a perception that Superpave was developed primarily for high and medium traffic volume roadways (Public Works Magazine, 2003). Research and implementation procedures for low traffic applications are ongoing. Superpave currently does not have any criteria and procedures for the design of $4.75 \mathrm{~mm}$ mixes which are commonly used for maintenance and overlaying of low volume roads.

Many agencies have expressed interest in using a $4.75 \mathrm{~mm}$ Superpave mixes to provide an economical surface mix for low traffic volume facilities. These types of mixes are used for thin lift applications, to improve ride quality, to correct surface defects, to increase skid resistance, to enhance appearance and to reduce road tire noise (Cooley, et al; 2002b).

Maryland, Georgia and North Carolina with significant mileage of minor roads carrying very low traffic, have develop criteria for designing $4.75 \mathrm{~mm}$ mixes with the Superpave method. The Maryland DOT has used $4.75 \mathrm{~mm}$ nominal size mixtures placed as $19.00 \mathrm{~mm}$ overlays. The Georgia DOT has a similar mix. Both states based these mixtures on the AASHTO MP2 Superpave method, but with modifications for air voids 
and number of compaction gyrations. The North Carolina Department of Transportation is experimenting with a $4.75 \mathrm{~mm}$ mix, similar to their fine I-2 coarse sand asphalt mix used on extremely low volume traffic roads. These mixes are not as open to water and air at the same air void level as larger NMAS mixes, so a higher design air void content is used to allow a lower asphalt content for economic considerations without reducing the mix durability (Cooley, et al; 2002a).

Maryland is getting excellent rutting and cracking resistance using $4.75 \mathrm{~mm}$ NMAS for preventive maintenance. These mixes generally contain about $65 \%$ percent manufactured screenings and $35 \%$ natural sand (Cooley, et al; 2002a).

Georgia also has used $4.75 \mathrm{~mm}$ NMAS mixes for low volume roads and for leveling purpose, showing excellent performance. Georgia mixes are designed using the Superpave Gyratory Compactor with an $\mathrm{N}_{\text {des }}$ of 50 gyrations. Design air voids range from 4 to 7 percent. These mixes generally have 60 to 65 aggregate percent passing the $2.36 \mathrm{~mm}$ sieve, with an average dust content of 8 percent. The gradation and design parameters for these mixes are presented in Tables 2.16 and 2.17, respectively. Figure 2.8 shows typical gradation curves for the three states. In each case, these mixes are classified as "fine" gradations since they fall above the maximum density line.

Table 2.17 shows that Maryland and Georgia require relatively high percentage of binder for $4.75 \mathrm{~mm}$ NMAS mixes. Since $4.75 \mathrm{~mm}$ NMAS mixes are intended for leveling and low traffic volume, with little or no truck traffic, aging of binder and not rutting is the primary design concern. High binder contents reduce binder aging.

On the other hand, it has been observed that $4.75 \mathrm{~mm}$ mixes are not as permeable to water and air at the same air void level as other larger NMAS mixes (Cooley, et al; 2002a). Superpave typically recommends a design air void content of 4 percent. For $4.75 \mathrm{~mm}$ NMAS mixes, since they are intended for very low volume traffic and leveling applications, a higher design air void content is sometimes allowed to produce lower asphalt content without decreasing durability, this primary for economic considerations. For these mixes, thin-lift HMA layers usually are placed at thickness ranging from $6 \mathrm{~mm}$ to $50 \mathrm{~mm}$. Georgia and Maryland indirectly address durability by specifying a minimum asphalt content value and maximum percent passing the $0.075 \mathrm{~mm}$ sieve. From these 
values, a theoretical maximum dust-to effective-binder ratio that should be not exceed is calculated as 2.0 and 2.4 for Georgia and Maryland, respectively. This calculation assumes no binder absorption.

Table 2.16 Gradation requirements for $4.75 \mathrm{~mm}$ NMAS mixes

\begin{tabular}{|l|c|c|c|}
\hline \multicolumn{4}{|c|}{ Gradation Requirements } \\
\hline \% Passing & Maryland & Georgia & $\begin{array}{c}\text { North } \\
\text { Carolina }\end{array}$ \\
\hline $9.5 \mathrm{~mm}$ Sieve & 100 & 100 & 100 \\
\hline $4.75 \mathrm{~mm}$ Sieve & $80-100$ & $75-95$ & $90-100$ \\
\hline $2.36 \mathrm{~mm}$ Sieve & $36-76$ & $60-65$ & $65-90$ \\
\hline $0.030 \mathrm{~mm}$ Sieve & & $20-50$ & \\
\hline $0.075 \mathrm{~mm}$ Sieve & $2-12$ & $4-12$ & $4-8$ \\
\hline
\end{tabular}

Table 2.17 Design specifications for $4.75 \mathrm{~mm}$ NMAS mixes

\begin{tabular}{|l|c|c|c|}
\hline Aggregate & Maryland & Georgia & North Carolina $^{1}$ \\
\hline Uncompacted Voids Fine (min. \%) & & & \\
\hline Sand Equivalent (min. \%) & $40 \%$ & $40 \%$ & $40 \%$ \\
\hline Binder & PG 64-22 & PG 67-22 & PG 64-22 \\
\hline \multicolumn{4}{|c|}{ Compaction Revolutions } \\
\hline Nini & 6 & 6 & 6 \\
\hline Ndes & 50 & 50 & 50 \\
\hline Nmax & 75 & 75 & 75 \\
\hline \multicolumn{4}{|c|}{ Mix Criteria } \\
\hline Range for Asphalt Content & $5.0-8.0$ & $6.0-7.5$ & --- \\
\hline Design Optimum Air Voids & 4 & $4.0-7.0$ & $7.0-15$ \\
\hline VFA & $67-80$ & $67-80$ & $<0.3$ \\
\hline Design ESAL & $0.3-3$ & $<0.3$ & \\
\hline$\%$ Gmm \% @ Nini & & 91.5 & \\
\hline$\%$ Gmm \% @ Nmax & & & 80 min \\
\hline Dust to binder ratio & & $0.8-1.6$ & $0.6-1.4$ \\
\hline Tensile strength ratio & 80 min & 80 min & \\
\hline
\end{tabular}

A minimum of 50 percent of the aggregate is required to be crushed stone. 


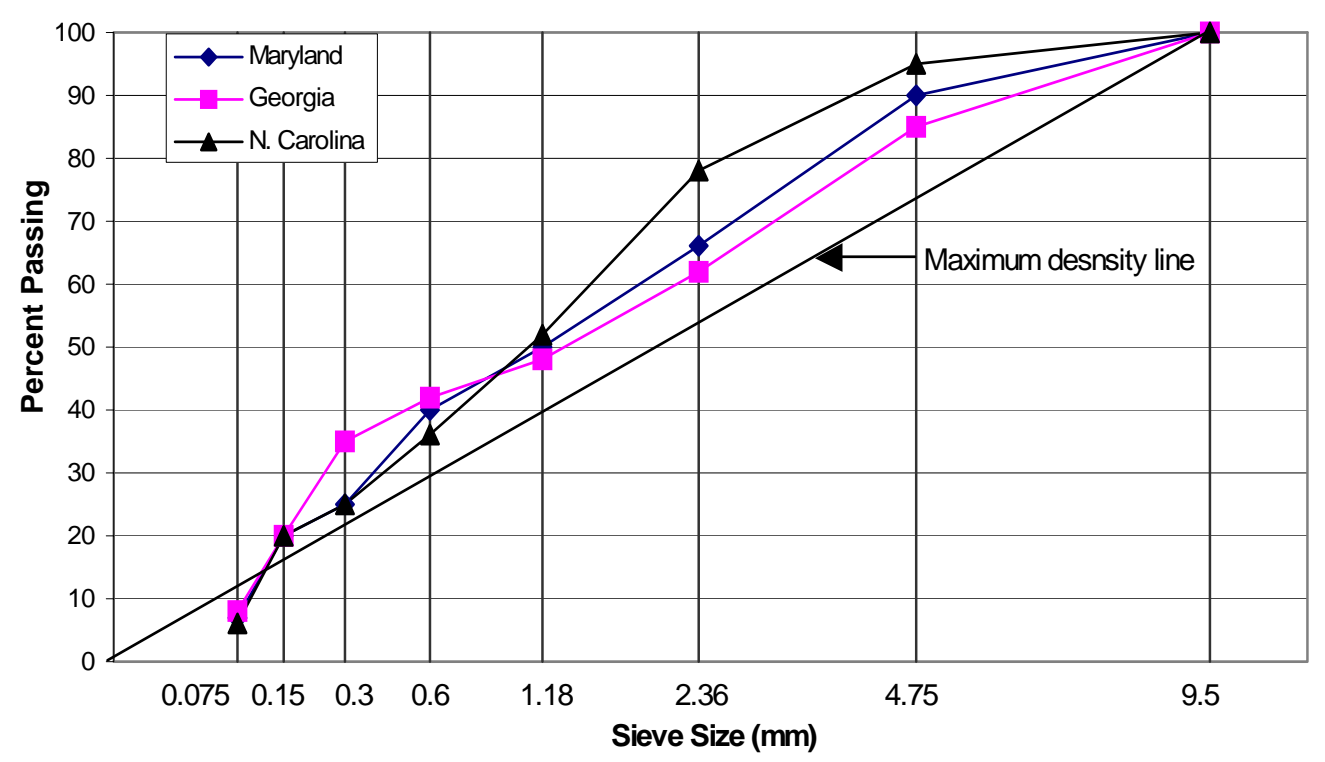

Figure 2.8 Typical gradation curves for $4.75 \mathrm{~mm}$ mixes.

The NCAT conducted two studies on Superpave criteria for $4.75 \mathrm{~mm}$ mixes.

NCAT report No 2002-04, was conducted in order to develop a Superpave mix design criteria for $4.75 \mathrm{~mm}$ (Cooley, et al; 2002a). The second study, NCAT report No 2002-10 was conducted to evaluate the effectiveness of using 100 percent aggregate screenings for HMA mixes (Cooley, et al; 2002b). The methodology from NCAT report No 2002-04 was closely followed in this research in order to develop criteria applicable for West Virginia mixes.

\section{NCAT Report No 2002-04, Development of Mix Design Criteria for $4.75 \mathrm{~mm}$ Superpave Mixes}

The objective of the NCAT Report No 2002-04 work was to develop Superpave criteria for $4.75 \mathrm{~mm}$ NMAS mixes. The parameters included in the study were gradation and volumetric property requirements, VTM, VMA, VFA, and dust to binder ratio. Two aggregate types, granite and limestone were used in this research. For each aggregate type, three gradation blends, coarse, medium, and fine, were evaluated. Additionally, three dust contents 6,9 , and 12 percent were studied in order to evaluate the effect of dust on volumetric parameters and rutting resistance. Finally, two design air contents 4 and 6 
were studied for each resulting mix design. Table 2.18 summarizes the factors and levels studied in the NCAT research.

Table 2.18 Main experimental factors used in NCAT REPORT No 2002 - 04

\begin{tabular}{|l|l|}
\hline \multicolumn{1}{|c|}{ Factors } & \multicolumn{1}{c|}{ Levels } \\
\hline Aggregate type & Limestone, Granite \\
\hline Gradation blend & Coarse, Medium, Fine \\
\hline Dust content & 6,8 and 12 \\
\hline VTM level & 4, and 6 percent \\
\hline
\end{tabular}

Samples with $4.75 \mathrm{~mm}$ NMAS were compacted in the SGC using a compactive effort, $\mathrm{N}_{\text {des }}$, of 75 gyrations. This compactive effort corresponds to an equivalent single axle load range of 0.3 to 3 million. A PG 64-22 was used for all the mixes.

APA testing was conducted for each mix on $115 \mathrm{~mm}$ height cylindrical samples prepared at appropriated binder content. The VTM of the samples was 4 or 6 percent, equal to the design air voids. The report did not identify the reason for the variance from the standard test APA test parameter of 7 percent air voids. Test conditions in this research included a test temperature of $64^{\circ} \mathrm{C}$, wheel load of $534 \mathrm{~N}$ and hose pressure of $827 \mathrm{kPa}$. These values correspond to $120 \mathrm{lb}$ vertical force and $120 \mathrm{psi}$ tube pressure. These values are higher than the recommended test parameters for APA testing, Table 2.14. Results from this research are summarized in Table 2.19.

From this research, a tentative design criteria for $4.75 \mathrm{~mm}$ NMAS Superpave mixes was established:

- $\quad$ Gradations for $4.75 \mathrm{~mm}$ NMAS mixes should be controlled on the 1.18 $\mathrm{mm}$ and $0.075 \mathrm{~mm}$ sieves,

- On the $1.18 \mathrm{~mm}$ sieve, the gradation control points are recommended as 30 to 54 percent. On the $0.075 \mathrm{~mm}$ sieve, the control points are recommended as 6 to 12 percent,

- Design air void content of 4 percent should be used during mix design, 
Table 2.19 Coolley optimum binder contents and volumetric properties

\begin{tabular}{|c|c|c|c|c|c|c|c|c|c|c|c|}
\hline Mix & Blend & $\begin{array}{c}\text { Dust } \\
\text { Content } \\
\text { percent }\end{array}$ & $\begin{array}{c}\text { Design } \\
\text { Air } \\
\text { Cont. } \\
\text { percent }\end{array}$ & $\begin{array}{c}\mathrm{P}_{\mathrm{b}} \\
\text { percent }\end{array}$ & $\begin{array}{c}\text { VMA } \\
\text { percent }\end{array}$ & $\begin{array}{c}\text { VFA } \\
\text { percent }\end{array}$ & $\begin{array}{l}\% \mathrm{G}_{\mathrm{mm}} \\
@ \mathrm{~N}_{\mathrm{ini}}\end{array}$ & $\begin{array}{c}\mathrm{P}_{\mathrm{be}} \\
\text { percent }\end{array}$ & $\mathrm{P}_{0.075} / \mathrm{P}_{\text {be }}$ & $\begin{array}{c}\text { Film } \\
\text { Thickness } \\
\mu \mathrm{m}\end{array}$ & $\begin{array}{l}\text { Rut Depth } \\
\text { mm }\end{array}$ \\
\hline \multirow{2}{*}{1} & \multirow{6}{*}{ Coarse } & \multirow{2}{*}{6} & 4 & 6.1 & 17.7 & 77.4 & 86.0 & 5.8 & 1.03 & 8.25 & 10.04 \\
\hline & & & 6 & 5.5 & 18.1 & 66.9 & 84.0 & 5.2 & 1.15 & 7.35 & 14.77 \\
\hline \multirow{2}{*}{2} & & \multirow{2}{*}{9} & 4 & 5.8 & 16.5 & 75.8 & 86.2 & 5.3 & 1.7 & 6.62 & 13.47 \\
\hline & & & 6 & 5.2 & 16.9 & 64.5 & 84.6 & 4.7 & 1.91 & 5.83 & 11.33 \\
\hline \multirow{2}{*}{3} & & \multirow{2}{*}{12} & 4 & 5.6 & 14.9 & 73.2 & 85.7 & 5.1 & 2.61 & 5.68 & 13.56 \\
\hline & & & 6 & 4.8 & 14.4 & 58.3 & 84.0 & 4.3 & 3.43 & 4.75 & 11.97 \\
\hline \multirow{2}{*}{4} & \multirow{6}{*}{ Medium } & \multirow{2}{*}{6} & 4 & 5.7 & 16.5 & 75.8 & 86.9 & 5.3 & 1.13 & 6.57 & 6.32 \\
\hline & & & 6 & 5.0 & 16.7 & 64.1 & 85.8 & 4.6 & 1.3 & 5.66 & 6.75 \\
\hline \multirow{2}{*}{5} & & \multirow{2}{*}{9} & 4 & 5.3 & 15.4 & 74.0 & 86.5 & 4.8 & 1.88 & 5.3 & 6.26 \\
\hline & & & 6 & 4.6 & 15.5 & 61.3 & 85.3 & 4.1 & 2.2 & 4.49 & 4.31 \\
\hline \multirow{2}{*}{6} & & \multirow{2}{*}{12} & 4 & 4.8 & 14.2 & 71.8 & 86.3 & 4.3 & 2.79 & 4.27 & 5.25 \\
\hline & & & 6 & 4.2 & 14.7 & 59.2 & 85.5 & 3.7 & 3.24 & 3.65 & 5.36 \\
\hline \multirow{2}{*}{7} & \multirow{6}{*}{ Fine } & \multirow{2}{*}{6} & 4 & 6.8 & 18.5 & 78.4 & 88.1 & 6.3 & 0.95 & 6.72 & 8.79 \\
\hline & & & 6 & 6.0 & 18.5 & 67.6 & 86.5 & 5.5 & 1.09 & 5.81 & 8.6 \\
\hline \multirow{2}{*}{8} & & \multirow{2}{*}{9} & 4 & 6.0 & 16.6 & 75.9 & 87.8 & 5.4 & 1.67 & 5.19 & 6.67 \\
\hline & & & 6 & 5.2 & 16.6 & 63.9 & 86.4 & 4.6 & 1.96 & 4.38 & 6.68 \\
\hline \multirow{2}{*}{9} & & \multirow{2}{*}{12} & 4 & 5.2 & 15.4 & 74.0 & 87.6 & 4.8 & 2.5 & 4.19 & 5.39 \\
\hline & & & 6 & 4.6 & 15.7 & 61.8 & 86.1 & 4.2 & 2.85 & 3.64 & 4.33 \\
\hline
\end{tabular}


- A VMA minimum limit of 16 percent is recommended for all traffic levels,

- $\quad$ For mixes designed with 75 gyrations and above, a maximum VMA criteria of 18 percent should be used to prevent excessive optimum binder,

- $\quad$ For mixes designed at 75 gyrations and above, VFA criteria should be 75 to 78 percent,

- $\quad \% \mathrm{Gmm} @ \mathrm{~N}_{\text {ini }}$ values currently specified in AASHTO MP2-01 for the different traffic levels are recommended, and

- $\quad$ Criteria for dust-to-effective binder ratio are recommended as 0.9 to 2.2.

Although the mix designs evaluated during this research were compacted to $\mathrm{N}_{\text {des }}$ of 75 revolutions, the researchers provided the following recommendations for mixes designed using $\mathrm{N}_{\text {des }}$ of 50 revolutions:

- $\quad$ For mixes designed at 50 gyrations, no maximum VMA criteria should be utilized, and

- $\quad$ For mixes designed at 50 gyrations and above, VFA criteria should be 75 to 80 percent.

Additionally the following conclusions were obtained from this report:

- Mixes having $4.75 \mathrm{~mm}$ NMAS can be successfully designed in the laboratory,

- $\quad$ Optimum binder contents of designed mixes were affected by aggregate type, gradation, shape, dust content, and design air void content,

- Voids in mineral aggregate values were affected by aggregate type, gradation shape, and dust content, and

- The primary cause of excessive laboratory rutting was high optimum binder contents.

Cooley, et al; (2002a) did not give specific recommendations for gradation control points. However, they noted the mixes used in the research had a range of 30 to 54 
percent passing the 1.18 sieve. The performance of the mixes when evaluated with the APA showed variable results, with an interaction with the aggregate type. However, overall the mixture performance was acceptable with this range of material passing the $1.18 \mathrm{~mm}$ sieve.

\section{NCAT Report No 2002-10, Use of Screenings to Produce HMA Mixtures}

NCAT Report No 2002-10 was conducted to develop a rut resistant asphalt concrete mix using processed aggregates screenings that have accumulated due to the increased used of coarse-graded mixes. The screenings used in this research were a 4.75 mm NMAS aggregate. Four factors were studied in this research; aggregate type, asphalt grade, VTM level and effect of cellulose additive on rutting resistance of HMA mixtures. Table 2.20 show the factors and levels studied in this research.

Table 2.20 Main factors used in NCAT REPORT No 2002 - 10

\begin{tabular}{|l|l|}
\hline \multicolumn{1}{|c|}{ Factors } & \multicolumn{1}{c|}{ Levels } \\
\hline Aggregate type & Limestone, and Granite \\
\hline Asphalt grade & PG 64-22 and PG 76-22 \\
\hline VTM level & 4,5 and 6 percent \\
\hline Cellulose fiber additive & $0.3 \%$ added and none added \\
\hline
\end{tabular}

Superpave $4.75 \mathrm{~mm}$ NMAS mixes were designed using the, SGC, at $\mathrm{N}_{\mathrm{des}}=100$ gyrations for 4, 5 and 6 percent air voids. The gradations of the mixes are presented in Table 2.21. The granite aggregate was considerably finer than the limestone.

Samples were compacted to 100 gyrations and then cut them to a height of $75 \mathrm{~mm}$ for the APA. This resulted in samples at the target air voids, \pm 0.5 percent, rather than the standard $7 \pm 0.5$ percent air voids. Tests were conducted using 8000 cycles and rut depth measurements were taken after completion to evaluate rutting susceptibility. The pneumatic pressure and applied wheel load were $100 \mathrm{psi}$ and $100 \mathrm{lbs}$, respectively. Volumetric properties and rut testing results are show in Table 2.22. 
Table 2.21 Study gradation NCAT REPORT No 2002 - 10

\begin{tabular}{|c|c|c|}
\cline { 2 - 3 } \multicolumn{1}{c|}{} & \multicolumn{2}{c|}{ Percent Passing } \\
\hline Sieve size mm & Granite & Limestone \\
\hline 9.5 & 100.0 & $100 \%$ \\
\hline 4.75 & 98.7 & 91.6 \\
\hline 2.36 & 81.8 & 68.5 \\
\hline 1.18 & 65.7 & 45.3 \\
\hline 0.6 & 52.3 & 30.3 \\
\hline 0.3 & 38.1 & 21.4 \\
\hline 0.15 & 24.1 & 15.5 \\
\hline 0.075 & 14.4 & 12 \\
\hline
\end{tabular}

Table 2.22 Test Results NCAT REPORT No $2002-10$

\begin{tabular}{|c|c|c|c|c|c|c|}
\hline Aggregate type & $\begin{array}{c}\text { VTM } \\
\%\end{array}$ & $\begin{array}{c}\text { Effective } \\
\text { Asphalt \% }\end{array}$ & VMA \% & $\begin{array}{c}\text { VFA } \\
\%\end{array}$ & $\begin{array}{c}\text { Dust / } \\
\text { Asphalt }\end{array}$ & $\begin{array}{c}\text { Rut Depth } \\
\mathrm{mm}\end{array}$ \\
\hline \multirow{2}{*}{ Granite } & \multirow{2}{*}{4} & 7.63 & 21.0 & 81.9 & 1.89 & 8.77 \\
\cline { 3 - 7 } & & 3.55 & 12.2 & 68.5 & 3.38 & 4.00 \\
\hline Limestone & \multirow{2}{*}{5} & 7.18 & 21.0 & 77.1 & 2.00 & 5.45 \\
\cline { 1 - 5 } Granite & 3.15 & 12.1 & 61.2 & 3.81 & 3.22 \\
\hline Limestone & \multirow{2}{*}{6} & 6.63 & 21.8 & 71.4 & 2.17 & 5.53 \\
\cline { 1 - 5 } Granite & 2.79 & 12.9 & 50.4 & 4.30 & 3.65 \\
\hline Limestone & & & &
\end{tabular}

Note 1: Since the effect of adding cellulose and PG 76-22 binder on Superpave mixes is not of interest for this research the results are not displayed.

The granite mixes have significant higher optimum asphalt contents than the limestone mixes, primarily due to increased finesses and rougher surface texture of the granite. When rut depths were observed, it seemed in general that the screenings mixes have the potential to provide good rut resistance. Some conclusions from this report are:

- Mixes having screenings as the sole aggregate portion can be successfully designed in the laboratory for some screenings but may be difficult for others.

- Screening type, and design air void content significantly affected optimum binder content. 
- Screenings material and design air void content significantly affected $\% \mathrm{G}_{\mathrm{mm}}$ @ $\mathrm{N}_{\text {ini }}$ results. The screening material type had the largest impact.

- Screenings material, design air void content, and binder type significantly affected laboratory rut depths. Of these three, binder type had the largest impact followed by screening material and design air void content, respectively. Mixes designed at 4 percent air voids had significantly higher rut depths than mixes designed at 5 or 6 percent air voids.

\subsection{NATURAL SAND AS HMA AGGREGATE}

Aggregate shape and texture are two main factors affecting final asphalt performance. It has been widely accepted that it is advantageous to use angular and rough texture aggregates for minimizing undesired conditions such as rutting, shoving and bleeding (Freeman and Kuo, 1999). Aggregate angularity also substantially affects VMA, with crushed aggregates providing more VMA and round aggregate less (Coree and Hislop, 1998).

Natural sands are defined as fine aggregates that are obtained from natural deposits, rather than those produced by crushing operations. Although natural sands can range widely in shape from round to angular depending of its mineralogy history, typically natural sands have a rounded shape and a smooth texture due to weathering. In general, it is accepted that mixtures containing natural sands are more likely to rut than mixtures containing manufactured or crushed fine aggregates. The Federal Highway Administration, FHWA, recommends limiting the amount of natural sands from 15 to 20 percent for high volume pavements and from 20 to 25 percent for low medium and low volume pavements (Freeman and Kuo, 1999).

Natural sands are generally less expensive than crushed materials and can improve the workability of an asphalt concrete mix. For these reasons designers feel that natural sands can be a desirable aggregate for asphalt concrete. The quality of natural sands can vary considerably from source to source. Arbitrary limits on the quality of sand in a mix can either limit the use of a valuable material or permit the use of an undesirable material. During the development of Superpave, a test method and criteria 
were sought that would control the use of undesirable fine materials in a prudent manner. The Uncompacted Void Content test, AASHTO T304 method A, was adopted to measure fine aggregate angularity, FAA, and consensus criteria were established. Kandhal, et al. (1998) suggested a FAA value of 44.5 percent distinguishes angular from subangular sands. Superpave sets fine aggregate angularity requirements of 40 and 45 percent for medium traffic and high traffic applications, respectively. The FAA requirement is not applied for mix designs for roads with less than 0.3 million ESALs.

The FAA requirement ensures a high degree of fine aggregate internal friction to promote rutting resistance of the mix. The uncompacted void content is defined as the percent air voids present in a loosely compacted aggregate smaller than $2.36 \mathrm{~mm}$. A $190 \mathrm{~g}$ sample of sand is prepared from four size fractions as given in Table 2.23. The sample is allowed to flow through a funnel with a $12.7 \mathrm{~mm}$ diameter orifice into a calibrated cylinder $100 \mathrm{~cm}^{3}$, that is $114 \mathrm{~mm}$ below from the bottom of the funnel, Figure 2.9. After the sample runs through the funnel, excess of material is struck off the cylinder, and its weight is recorded.

By determining the weight of fine aggregate in the filled cylinder of known volume, void content can be calculated as the difference between the cylinder volume and fine aggregate volume collected in the cylinder. The volume of the aggregate is calculated by dividing its mass by the bulk dry specific gravity, $\mathrm{G}_{\mathrm{sb}}$.

Table 2.23 Gradation of FAA samples

\begin{tabular}{|c|c|}
\hline Individual size fraction & $\begin{array}{c}\text { Mass } \\
(\mathrm{g})\end{array}$ \\
\hline $2.36 \mathrm{~mm}$ (No.8) to $1.18 \mathrm{~mm}$ (No. 16) & 44 \\
\hline $1.18 \mathrm{~mm}$ (No.16) to $600 \mu \mathrm{m}$ (No. 30) & 57 \\
\hline $0.6 \mathrm{~mm}$ (No. 30) to $0.3 \mathrm{~mm}$ (No. 50) & 72 \\
\hline $0.3 \mathrm{~mm}$ (No. 50) to $0.15 \mathrm{~mm}$ (No. 100) & 17 \\
\hline Total & 190 \\
\hline
\end{tabular}




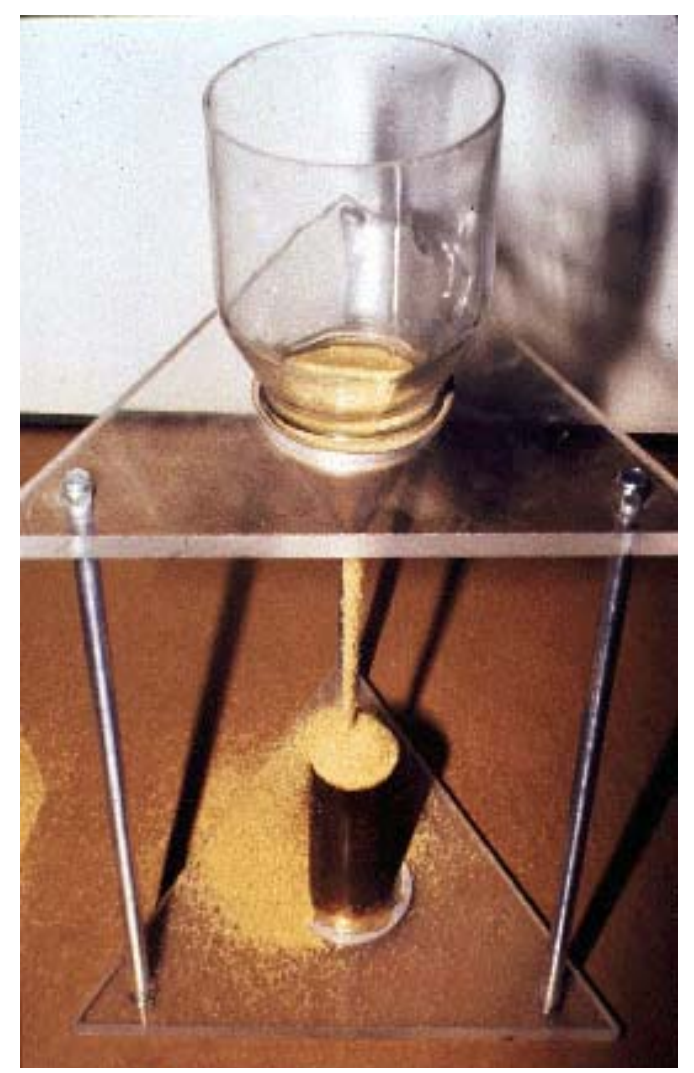

Figure 2.9 Fine aggregate angularity apparatus

High amount of voids indicates material with high angularity and rough texture. Similarly, low amount of voids indicates the aggregate is rounded and smooth.

The Kansas Department of Transportation studied two $12.5 \mathrm{~mm}$ Superpave gradations, one coarse and one fine, using blends crushed and natural aggregate (Purcell and Cross, 2001). A mix design for 100 percent limestone was established. Samples were then produced with increasing natural sand percentages by direct replacement of the limestone on each sieve allowing the gradation to remain constant and the effect of fine aggregate angularity to be observed. Rutting potential was evaluated with the APA tested at $58^{\circ} \mathrm{C}$. A rut criterion of less than $6.0 \mathrm{~mm}$ was used to identify mixes with acceptable performance. Some of the results of this study were:

- The calculated FAA values for the aggregate blends, obtained from the FAA of the individual aggregates, as recommended by Superpave, were found to be equal 
to those found by testing individual blends. For the two gradations tested, it is reasonable to use the weighted average, Equation 2.10, as suggested by SHRP.

- For rounded natural sand, both gradations showed that until a minimum FAA was reached, the effect of FAA on VMA was negligible. This minimum FAA value was different for the two gradations and was greater than the 40 percent FAA criteria used in Superpave mixes for traffic levels of 0.3 to 3 million ESALs.

- For samples made with crushed limestone and natural sand, rutting susceptibility decreased as FAA increased.

- Increasing FAA increases VMA for mixes that contain natural sand and crushed limestone. However, a minimum FAA value must be exceeded before this increase in FAA has an effect on VMA.

- Increasing natural sand content increases rutting. For the gradations tested, greater than $10 \%$ natural sand resulted in increased rutting. Samples with greater than $20 \%$ natural sand show a more pronounced increase in rutting potential.

- Meeting the minimum FAA requirements is not adequate assurance that a mix will perform well.

\subsection{COMPARISON OF MARSHALL AND SUPERPAVE DESIGNS}

The literature review identified four studies comparing the Marshall and Superpave methods. It is important to note that Superpave compaction requirements have been recently modified and reduced to the current four levels (Brown and Buchanan, 2001). As a result, some of the research used Superpave compaction levels that are different than the current criteria set forth in Table 2.5.

D'Angelo, et al. (1995) studied five asphalt mixes designed with the Superpave and the Marshall compaction procedures. Two of the mixes were designed first using the SGC at $\mathrm{N}_{\text {des }}$ levels of 86 and 100 gyrations and later evaluated with the Marshall hammer using 112 blows and 50 blows. The 112 blow Marshall compaction was used with 6 in. Marshall molds. Three other mixes were designed first using the Marshall hammer with 
112,75 and 50 blows and then evaluated with the SGC at $\mathrm{N}_{\text {des }}$ levels of 100, 126, and 109 gyrations, respectively. Conclusions from this study demonstrated:

- Samples compacted with the SGC had slightly less variability in air voids than did the Marshall samples.

- Based on air voids alone, the SGC and the Marshal hammer could both be expected to perform well in quality control applications.

- VMA distinguishes the two compaction devices. The results show that for every mixture tested, the SGC samples had lower VMA than Marshall samples. The general trend of lower VMA with SGC indicates that the compaction effort obtained with the SGC is greater than with the Marshall hammer.

- The overall conclusion of the study was that the SGC was better able to track plant production variability than the Marshall hammer.

Another research project was conducted in 1998 by the Kansas Department of Transportation, KDOT, to compare the Superpave and Marshall mix designs for low volume roads and paved shoulders (Habib, et al; 1998). In this research, five blends were compacted by using the Superpave gyratory and the Marshall hammer. Mixes studied were $19 \mathrm{~mm}$ nominal maximum size with an AC-10 binder. This binder also meets the PG 58-22 requirements. Bulk densities and maximum theoretical specific gravity were measured for each blend and design volumetric parameters were calculated and analyzed to a 4 percent design air content.

Superpave samples were designed for less than 0.3 million ESALs with $\mathrm{N}_{\text {ini }}=7$, $\mathrm{N}_{\text {des }}=68$ and $\mathrm{N}_{\max }=104$ gyrations. Note that the number of gyrations used in this research is not the same as number of gyrations in current Superpave specification. Marshall samples were compacted to 50 blows per face. Results from this research were:

- Superpave mix design for low volume roads and shoulders results in lower optimum asphalt content compared with the Marshall method. Apart from the aggregate property requirements, Superpave mixtures would be economical in these applications because of lower asphalt content.

- The VMA and VFA values also were lower than those for the Marshall mixes 
- River sands appear to have the potential to be used as fine aggregates in the Superpave mixes for low volume pavements and shoulders. However, the use of coarse river sand should be minimized because it increases the optimum asphalt content and could result in a weaker aggregate structure.

- Superpave requirements for VFA for low volume traffic, less than 0.3 millions ESALs appear to be too high.

- Lowering $\mathrm{N}_{\text {des }}$ would result in increased asphalt requirement for a Superpave mixture with a given gradation.

The Virginia Transportation Research Council compared several asphalt design methods and also found differences in the optimum asphalt content obtained by Marshall and Superpave methods (Maupin, 1998). In this research, six 19 mm NMAS mixes were tested using the 50-blow Marshall design, the 75-blow Marshall design, two brands of SHRP gyratory compactors, Pine and Troxler, and the U.S. Army Corps of Engineers' gyratory testing machine, GTM. For purposes of this research, only results from Superpave and Marshall designs are described.

The Superpave criteria for this study were based on a traffic level of 3 to 10 million ESALs and a average high temperature less than $39^{\circ} \mathrm{C}$. The corresponding compaction levels were $\mathrm{N}_{\text {initial }}=8, \mathrm{~N}_{\text {des }}=96$ and $\mathrm{N}_{\max }=152$. This compaction level is slightly less than the current $\mathrm{N}_{\text {des }}$ requirement of 100 revolutions for 3 to 30 million ESALs. Design air void contents for Marshall were 4.0 and 4.5 percent and for Superpave only 4 percent. Results of this research for the mixes designed to four percent air voids are shown in Table 2.24, and summarized in Figure 2.10. The optimum asphalt content of 96 gyration Superpave mixes was consistent less than for 75 blow Marshall mixes. This implies that at 96 gyrations the SGC is compacting the mixes more than 75 blow Marshall.

Research conducted at West Virginia University compared mix designs prepared using the Marshall and Superpave methods for $19 \mathrm{~mm}$ base mixtures using a PG 70-22 binder (Kanneganti, 2002). Mix designs were prepared with limestone aggregates for three traffic levels. Mix performance was evaluated with the APA. Statistical evaluation of the data indicated that there was not a statistically significant difference between the 
optimum asphalt and performance of the mixes at a 95 percent confidence level. Mix designs prepared under the Superpave criteria were evaluated under the Marshall method and found to pass all criteria. Similarly, mixes prepared under the Marshall criteria passed all Superpave criteria when compacted with the SGC.

\subsection{SUMMARY OF LITERATURE REVIEW}

Based on the literature, the following volumetric parameters need to be defined for the development a $4.75 \mathrm{~mm}$ mix for Superpave. The criteria fall into three categories, aggregate requirements, volumetric parameters, and compaction requirements.

Superpave does not have a test for the performance of the mix. Several researchers have used the Asphalt Pavement Analyzer to evaluate the rutting potential of mixes.

\subsubsection{Aggregate Requirements}

The aggregate requirements that need to be defined in the mix design process are:

- Source criteria,

- Consensus criteria, and

- Gradation control points

Table 2.24 Marshall-Superpave optimum asphalt content, Virginia study

\begin{tabular}{|c|c|c|c|c|c|c|}
\cline { 2 - 7 } \multicolumn{1}{c|}{} & \multicolumn{2}{c|}{50 -Blow Marshall } & \multicolumn{2}{c|}{75 -Blow Marshall } & $\begin{array}{c}\text { Pine } \\
\text { SGC }\end{array}$ & $\begin{array}{c}\text { Troxler } \\
\text { SGC }\end{array}$ \\
\hline Mix & $4.0 \%$ & $4.5 \%$ & $4.0 \%$ & $4.5 \%$ & $4.0 \%$ & $4.0 \%$ \\
No. & VTM & VTM & VTM & VTM & VTM & VTM \\
\hline 1 & 5.9 & 5.6 & 5.5 & 5.4 & 5.4 & 5.5 \\
\hline 2 & 5.9 & 5.7 & 5.6 & 5.4 & 5.4 & 5.5 \\
\hline 3 & 5.6 & 5.4 & 5.3 & 5.0 & 5.1 & 5.1 \\
\hline 4 & 4.8 & 4.6 & 4.6 & 4.3 & 4.5 & 4.4 \\
\hline 5 & 5.1 & 4.9 & 4.6 & 4.6 & 4.5 & 4.8 \\
\hline 6 & 5.3 & 5.1 & 4.9 & 5.0 & 4.7 & 5.0 \\
\hline
\end{tabular}




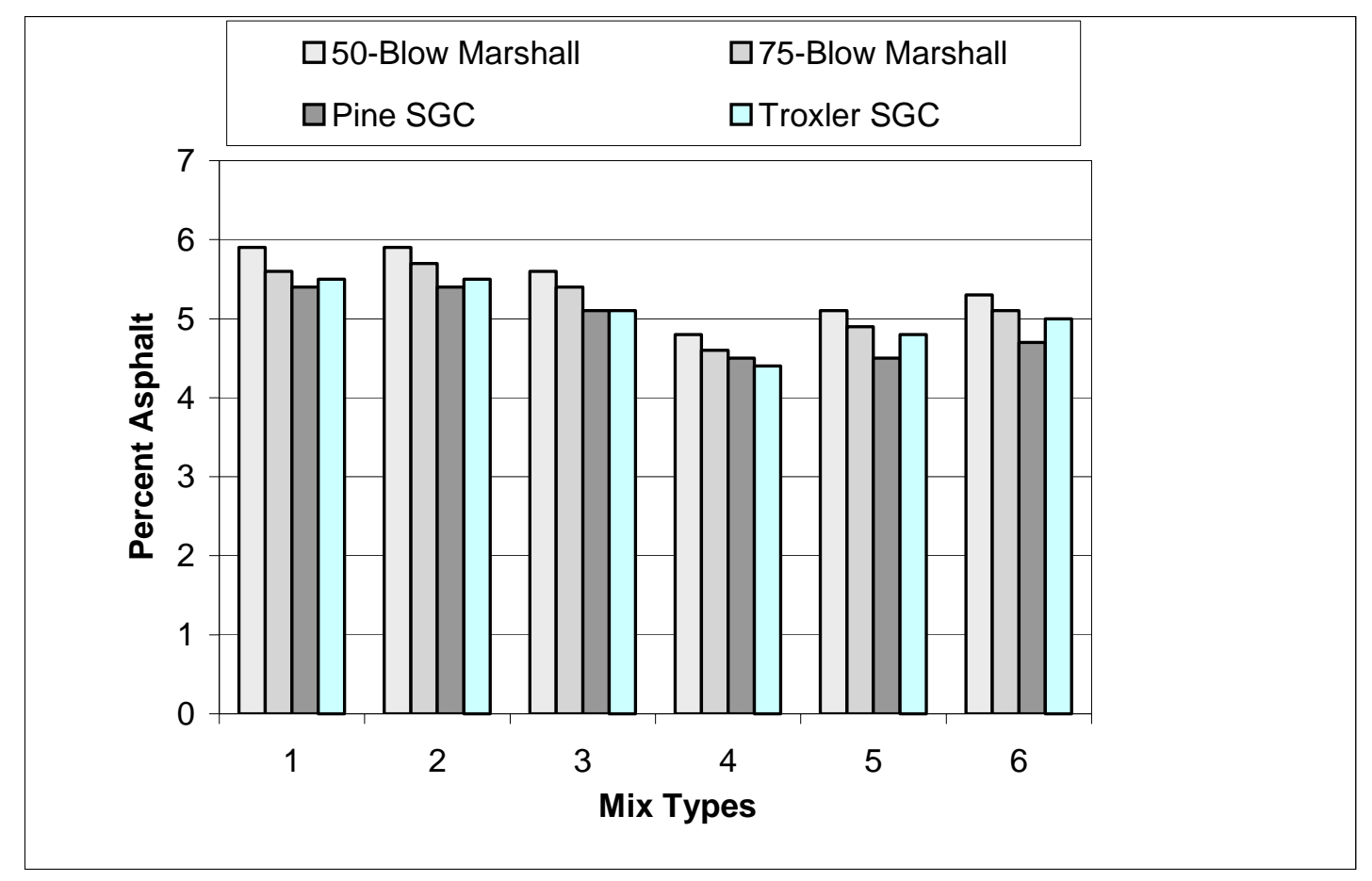

Figure 2.10 Comparison of Marshall and Superpave optimum asphalt contents, 4 percent air voids, Virginia study.

Source property requirements were not addressed in the reviewed literature. These properties are developed by each specifying agency and are tailored to meet local conditions. Since this issue was not addressed in the literature, there are no recommendations for altering the criteria that are currently used in Superpave mix design.

Consensus criteria are set at a national level. These criteria are sensitive to the level of traffic. Since $4.75 \mathrm{~mm}$ mixes are composed of fine aggregate, the flat and elongated and coarse aggregate angularity criteria do not apply to these mixes. The fine aggregate angularity criteria is not applied for mix designs for less than 0.3 million ESALs. The validity of the FAA test was questioned in one project (Purcell and Cross, 2001). The sand equivalency criterion is 40 , regardless of traffic level. None of the literature reviewed indicated a need or desire to alter these criteria for $4.75 \mathrm{~mm}$ mixes. 
Superpave uses four gradation control points, the maximum aggregate size, the nominal maximum aggregate size, and the 2.36 and $0.075 \mathrm{~mm}$ sieves. Cooley, et al. (2002a) recommend using the $1.18 \mathrm{~mm}$ sieve as the intermediate control point for $4.75 \mathrm{~mm}$ mixes. They did not recommend specific limits for these control points.

\subsubsection{Volumetric Parameters}

Criteria are needed for the following volumetric parameters:

- Voids in the total mix,

- Voids in the mineral aggregate,

- Voids filled with asphalt, and

- Dust to effective binder ratio

It is widely accepted that asphalt concrete mixes should be designed for a four percent air void content. Cooley, et al. (2002a) evaluated mixes at four and six percent air voids, concluding that four percent air voids provide mixes with the desired characteristics.

The voids in the mineral aggregate criteria is used to ensure that mixes have a sufficient volume of effective binder content to ensure adequate film thickness to coat and bind the aggregate. Based on using criteria for the dust to effective binder ratio and the asphalt film thickness, Cooley, et al. (2002a) recommended a minimum VMA of 16 percent for $4.75 \mathrm{~mm}$ mixes. This is consistent with the Superpave trend on increasing the VMA by 1 percent for each drop in the nominal maximum aggregate size as shown in Table 2.9. However, this is one percent less than the WVDOH Marshall mix design criteria for Wearing III, $4.75 \mathrm{~mm}$, mixes, as shown in Table 2.3 .

As shown by Equation 2.9 voids filled with asphalt, VFA, is computed from VTM and VMA. If the VTM is fixed at four percent, then VFA is only a function of VMA. Hence, the minimum VFA can be directly derived from, and is redundant with, the minimum VMA criteria. For a VMA of 16 percent and four percent air voids, the minimum VFA is 75 percent. Repeating this calculation for all the Superpave mixes demonstrates that the lower limit of the VFA in Table 2.9 is essentially meaningless as 
the minimum VMA criteria, with four percent air voids, always produces a VFA restriction that is greater than the lower limits in the table. Therefore, the VFA criteria are essentially limits on the maximum asphalt effective content that should be used in the mix. Cooley, et al. (2002a) recommended a maximum VFA of 80 percent for mixes designed with $\mathrm{N}_{\text {des }}$ of 50 gyrations.

Both the VMA and VFA criteria are used to control the effective asphalt content of the mix. An alternative to these criteria is to use a computed asphalt film thickness as a controlling parameter. The advantages of this approach is that the computed asphalt film thickness is directly a function of the specific gradation used in the mix and therefore film thickness is a more consistent criteria than VMA and VFA. Kandhal, et al. (1996) has recommended a film thickness of $8 \mu \mathrm{m}$ for mix design. Kandhal used the Edwards-Hveem method for computing surface area. Recent research indicates these surface area factors may be incorrect, especially for material finer than $0.15 \mathrm{~mm}$ (Reyes, 2003).

The fines to effective asphalt content, $\mathrm{P}_{0.075} / \mathrm{P}_{\text {be }}$ is used to ensure that there is sufficient asphalt to coat the mineral filler in a mix. The WVDOH currently has a criteria for 0.6 to 1.2 for the dust to binder ratio for Marshall mixes, based on the total, rather than the effective, asphalt content. The WVDOH Superpave criteria are 0.6 to 1.2 for fine gradations and 0.8 to 1.6 for coarse gradations; based on effective binder content.

\subsubsection{SGC Compaction Parameters}

In addition, compaction parameters need to be defined, including:

- Number of gyrations for initial, design and maximum,

- Percent of the maximum theoretical specific gravity at the initial number of gyrations, and

- Percent of the maximum theoretical specific gravity at the maximum number of gyrations.

The research on $4.75 \mathrm{~mm}$ mixes has used various levels of compaction for evaluating $4.75 \mathrm{~mm}$ mixes. Generally, these were selected in accordance with the Superpave requirements for the traffic level selected for the research. Since the 
Superpave compaction effort has changed over time, the compaction levels used in some of the research does not match the current design recommendations.

The criteria for the percent of maximum theoretical specific gravity at the initial compaction level, $\mathrm{N}_{\text {ini, }}$, is set as a function of the traffic level used for the mix design. None of the research reviewed addressed this compaction parameter.

The criteria for the percent of maximum theoretical specific gravity at the maximum number of gyrations, $\mathrm{N}_{\max }$, is 98 percent, regardless of other design parameters. None of the research reviewed addressed this compaction parameter.

\subsubsection{Asphalt Pavement Analyzer Parameters and Criteria}

The APA has been used in several research projects for evaluating the rutting potential of asphalt concrete mixes. The APA provides flexibility in the number of load repetitions, the load force, the tube pressure and the test temperature. In addition, the air voids of the sample can have a major effect on the rut measurements. Research is ongoing into the development of the testing protocol and criteria for the APA. Until an ASTM or AASHTO approved protocol is available, the following the manufacturers recommendations seems prudent. Since the rutting performance is a function of the test protocol, and since the protocol has varied between researchers, there is no standard criteria available for judging the performance of a mix. Originally, a criteria of less than $5 \mathrm{~mm}$ was used to identify a suitable mix. However, through further analysis and the work of other researchers, it appears that for the current testing protocol, a criteria of $9.5 \mathrm{~mm}$ appears to be reasonable. 


\section{CHAPTER 3 RESEARCH METHODOLOGY}

The experimental research work was performed in two phases; Phase I: evaluation of Superpave criteria for $4.75 \mathrm{~mm}$ NMAS mixes and Phase II: natural sand evaluation for $4.75 \mathrm{~mm}$ mixes. During Phase I, a variety of $4.75 \mathrm{~mm}$ NMAS limestone mixes were developed following Superpave methodology for low traffic volume. Based on the literature, Superpave mix design parameters were selected to allow the development of these mix designs. Gradation requirements and design specifications obtained from $4.75 \mathrm{~mm}$ Superpave mixes in service developed by Georgia, Maryland and North Carolina DOT along with data obtained from related studies and environmental characteristic of the state of West Virginia were used to set the study parameters to be analyzed. Volumetric and rutting data from the study mixes were gathered and used as an analysis platform. Some design parameters as minimum asphalt content and typical dust contents from the DOT's mixes along with rutting and film thickness criteria obtained from literature review were used then to set a provisional Superpave criteria for VTM, VMA, VFA, $\% \mathrm{G}_{\mathrm{mm}} @ \mathrm{~N}_{\mathrm{ini}},{ }_{0 \mathrm{G}} \mathrm{G}_{\mathrm{mm}} @ \mathrm{~N}_{\max }$ and $\mathrm{P}_{0.075} / \mathrm{P}_{\mathrm{be}}$ for $4.75 \mathrm{~mm}$ NMAS mixes in West Virginia.

During Phase II, three approved Marshall designs were obtained from the WVDOT. Two of the mixes contained natural sand and the other was a 100 percent limestone mix. The Marshall mix design were verified in the West Virginia University Asphalt Technology Laboratory and then redesigned using Superpave methodology for low volume traffic. Comparisons in volumetric parameters and compaction effort from Marshall mechanical hammer and SGC were analyzed in order to identify differences between the two methods. Additionally, surface area and film thickness calculations were performed along with APA rutting susceptibility for Superpave mixes. Finally, Superpave criteria from Phase I were used to evaluate the Superpave mixes and develop conclusions.

\subsection{PHASE I EVALUATION OF CRITERIA FOR 4.75 MM MIXES}

In order to develop mix design criteria, nine mixes were developed following Superpave methodology for low traffic volume designs. A design compaction effort of 
50 gyrations, which corresponds to an equivalent single axle load, ESAL, of less than 0.3 million was used. Crushed limestone sand was chosen as main material since it has proved to be a very successful material in high and medium traffic level mix design applications.

Three $4.75 \mathrm{~mm}$ NMAS gradation blends, coarse, medium and fine were evaluated to represent the practical ranges that could be produced in the field. In order to evaluate the effect of dust on volumetric parameters and rutting resistance and be able to establish a possible control point to sieve $0.075 \mathrm{~mm}$, three dust contents, 4,8 and 12 percent were evaluated. Additionally, two design air void contents were evaluated, 4 and 5 percent. The rutting potential for each mix was analyzed with the APA. Figure 3.1 shows the test plan for this part of the research.

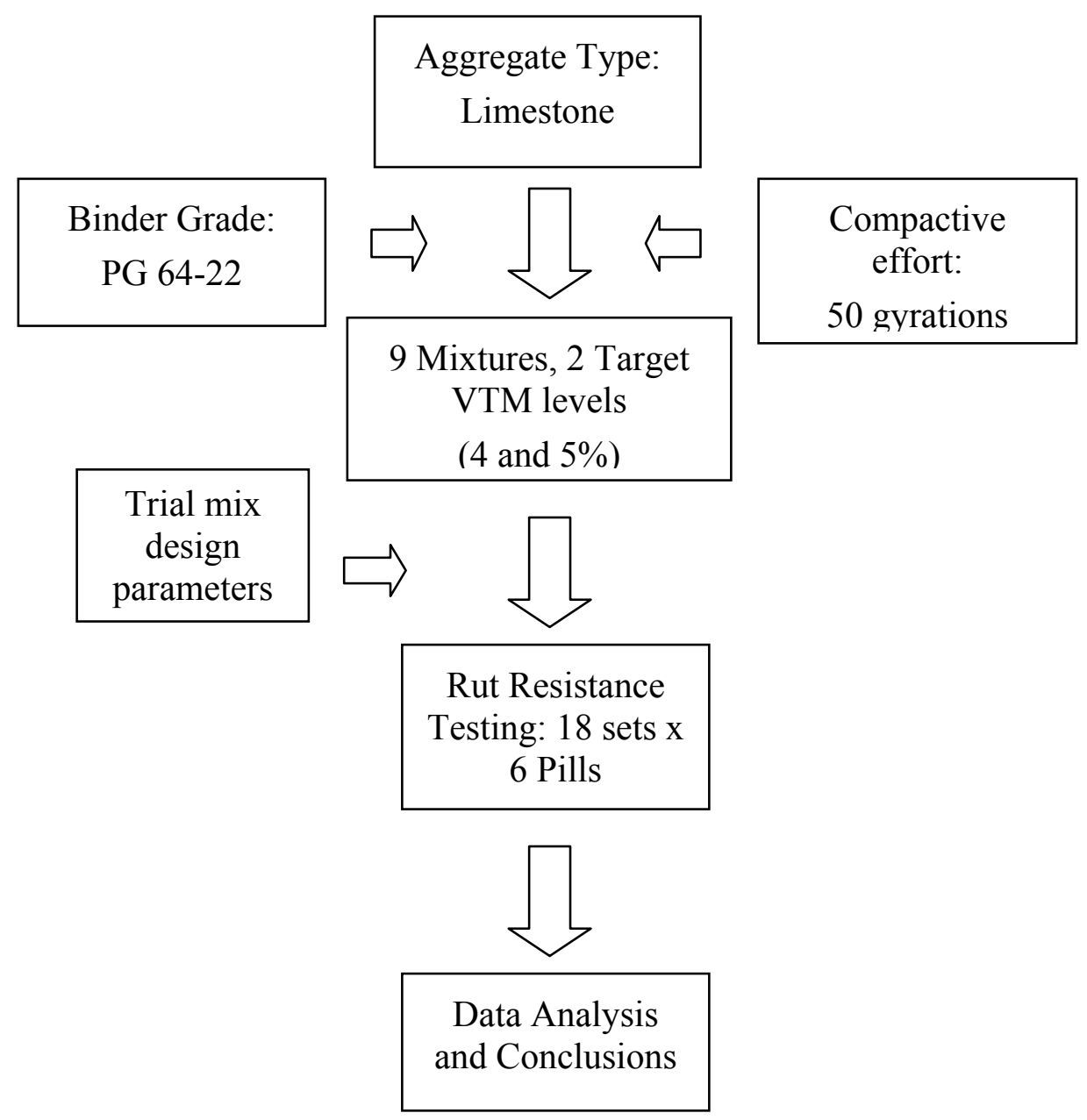

Figure 3.1 Research test plan for Phase I 


\subsubsection{Trial Superpave Criteria}

Based on the literature, the criteria and parameters presented in Table 3.1 were selected for evaluation during this research.

Table 3.1 Trial Superpave design criteria and parameters

\begin{tabular}{|c|c|}
\hline $\begin{array}{l}\text { Number of gyrations for initial, design } \\
\text { and maximum }\end{array}$ & $\begin{array}{c}\text { Nini }=6 \\
\text { Ndes }=50 \\
\text { Nmax }=75\end{array}$ \\
\hline \multicolumn{2}{|c|}{ Aggregate properties } \\
\hline Source criteria & Same as WVDOH Superpave \\
\hline Consensus criteria & Same as WVDOH Superpave \\
\hline Gradation control points & $\begin{array}{c}\text { Same as WVDOH Marshall } \\
\text { Wearing III }\end{array}$ \\
\hline \multicolumn{2}{|c|}{ Volumetric parameters } \\
\hline Voids in the total mix & 4 percent \\
\hline Voids in the mineral aggregate & 16 percent \\
\hline Voids filled with asphalt & $75-80$ percent \\
\hline Dust to effective binder ratio & Evaluated in research plan \\
\hline $\begin{array}{l}\text { Percent of the maximum theoretical } \\
\text { specific gravity at the initial number of } \\
\text { gyrations }\end{array}$ & $\begin{array}{l}\text { Same as Superpave for } \\
<0.3 \text { million ESAL design }\end{array}$ \\
\hline $\begin{array}{l}\text { Percent of the maximum theoretical } \\
\text { specific gravity at the maximum } \\
\text { number of gyrations. }\end{array}$ & Same as Superpave \\
\hline
\end{tabular}

\subsubsection{Materials}

J.F Allen Company, Buckhannon, WV, provided the crushed limestone sand. A PG 64-22 asphalt binder grade, obtained from Marathon Ashland Company, was selected since it is the standard binder for West Virginia

\subsubsection{Aggregate Preparation}

Material sent from JF Allen Company was first air-dried when moisture in the material required it. It was then sieved using a mechanical sieve shaker allowing material split in $4.75 \mathrm{~mm}, 2.36 \mathrm{~mm}, 1.18 \mathrm{~mm}, 0.6 \mathrm{~mm}, 0.3 \mathrm{~mm}$ and $0.075 \mu \mathrm{m}$ sieve sizes. Coarse 
size fractions were washed and oven dried to allow accurate proportioning of the material. Finally, each size fraction was properly stored to be use in controlled amounts in the mixes. The specific gravity was measured following AASHTO T84 procedure. The bulk and apparent specific gravities were 2.655 and 2.729 , respectively, and the absorption was 1.6 percent. The fine aggregate angularity AASHTO T304, and sand equivalency tests, AASHTO T176, were measured as 44.8 and 78 percent, respectively. These values are within the Superpave criteria for aggregates used for low traffic volume mix designs. Since there are no coarse materials in $4.75 \mathrm{~mm}$ NMAS aggregate blends, the coarse aggregate angularity and flat elongated tests were not performed.

\subsubsection{Binder}

Marathon Ashland PG 64-22 was used for all tests. The supplier provided the specific gravity, 1.034 , and mixing and compaction temperature ranges, 151 to $157^{\circ} \mathrm{C}$ and 141 to $145^{\circ} \mathrm{C}$, respectively.

\subsubsection{Superpave Trial Designs}

\subsubsection{Gradations}

Three gradations with 4.75 NMAS were selected:

- Coarse, passing below maximum density line,

- Medium, passing near the maximum density line, and

- Fine, passing above the maximum density line.

The gradations are presented in Table 3.2 and are graphically displayed in Figure 3.2. The gradations were established for the 8 percent material passing the $75 \mu \mathrm{m}$ sieve, and sample weight out values were computed for each sieve. For the blends with 4 percent and 12 percent passing the $75 \mu \mathrm{m}$, the weight of mineral filler was decreased and increased by 50 percent. The weight of material on the other sieve was kept constant. This resulted in a shift in the traditional gradation curves, which are based on the percent of material passing a sieve. However, it provides more consistent experimental results as the properties of materials on the other sieves remain constant. Three gradations were selected to check for possible control point issues. 
GRADATION CURVES 100\% Limestone

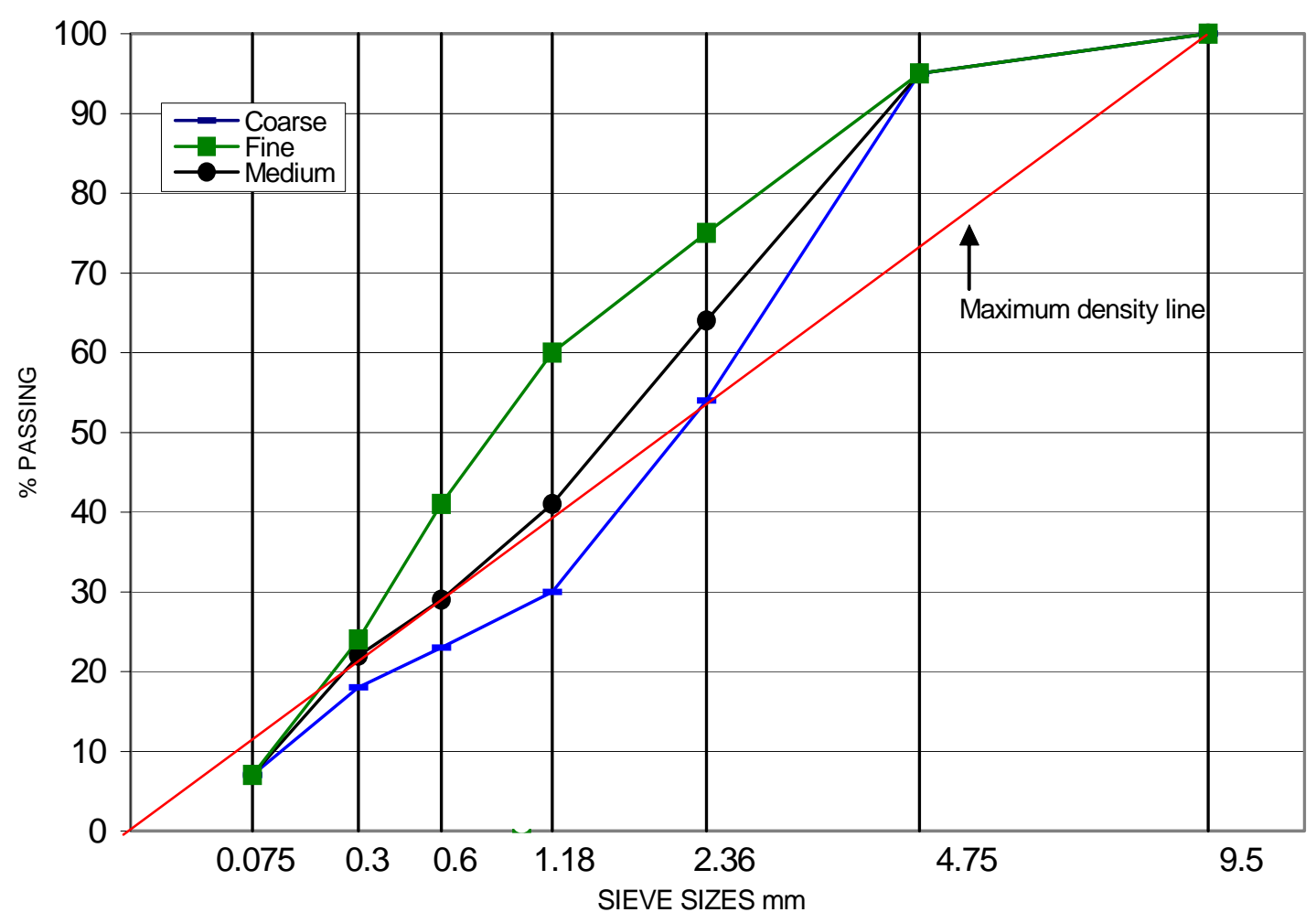

Figure 3.2 Gradations used for development of Superpave criteria

Table 3.2 Gradations used for development of Superpave criteria

\begin{tabular}{|c|c|c|c|c|}
\hline $\begin{array}{c}\text { Sieve } \\
\text { Size }\end{array}$ & \multicolumn{3}{|c|}{ Percent Passing } & $\begin{array}{c}\text { WV DOH } \\
\text { Marshall } \\
\text { Criteria }\end{array}$ \\
\hline & Coarse & Medium & Fine & \\
\hline 9.5 & 100 & 100 & 100 & 100 \\
\hline 4.75 & 92 & 92 & 92 & $90-100$ \\
\hline 2.36 & 54 & 64 & 75 & 90 Max \\
\hline 1.18 & 30 & 41 & 60 & $40-65$ \\
\hline 0.6 & 23 & 29 & 41 & \\
\hline 0.3 & 18 & 22 & 24 & \\
\hline 0.075 & $4,8,12$ & $4,8,12$ & $4,8,12$ & $3-11$ \\
\hline
\end{tabular}


The medium and fine gradations fall within the WVDOH requirements for Marshall Wearing III mixes. To balance the experimental design, the coarse gradation was allowed to fall outside the WVDOH Marshall criteria for the $1.18 \mathrm{~mm}$ sieve. This provided a gradation close to one studied by Cooley et al (2002a).

Each gradation was studied at three different dust contents. This approach also is supported in the literature review, were importance of fines on volumetric properties was highlighted (Cooley et al; 2002a). To balance the experiment, the dust contents were evenly spaced at four percent increments. This resulted in one set of mixes having 12 percent mineral filler, which is higher than the 11 percent allowed in the WVDOH Marshall Wearing III specification.

\subsubsection{Estimate Binder Content}

Using Equations 2.12 to 2.16, the estimated initial asphalt content was calculated. From this calculation, trial percent of binder, $\mathrm{P}_{\mathrm{bi}}$, of $6.3 \%$ was obtained for all mixes. The common asphalt content is an artifact of the fact that Equation 2.13 for estimating the required effective volume of asphalt is only dependent on the nominal maximum aggregate size. The estimation of asphalt content is not sensitive to variation in aggregate gradation and dust content. Two samples at this asphalt content were compacted to 50 gyrations. Samples were prepared to measure the maximum specific gravity. The volumetric properties were calculated. Then using Equations 2.20 to 2.25, the initial volumetric properties were adjusted to a design air content of four percent. The estimated binder content, $\mathrm{P}_{\mathrm{b} \text {,est }}$, and effective binder content, $\mathrm{P}_{\mathrm{be}, \text { est }}$, are shown in Table 3.3 along with the fines to binder ratio. 
Table 3.3 Adjusted values for estimated and effective binder contents

\begin{tabular}{|c|c|c|c|c|c|c|}
\hline$\underset{\#}{\operatorname{Mix}}$ & $\begin{array}{c}\text { Gradation } \\
\text { Blend }\end{array}$ & $\begin{array}{l}\text { Dust } \\
\text { Content } \\
\text { percent }\end{array}$ & $\begin{array}{c}\mathrm{P}_{\mathrm{bi}} \\
\text { percent }\end{array}$ & $\begin{array}{c}\mathrm{P}_{\mathrm{b}, \mathrm{est}} \\
\text { percent }\end{array}$ & $\begin{array}{c}\mathrm{P}_{\text {be,est }} \\
\text { percent }\end{array}$ & $\mathrm{P}_{0.075} / \mathrm{P}_{\mathrm{be}, \text { est }}$ \\
\hline 1 & \multirow{3}{*}{ Coarse } & 4 & 6.3 & 6.6 & 5.8 & 0.69 \\
\hline 2 & & 8 & 6.3 & 6.1 & 5.3 & 1.51 \\
\hline 3 & & 12 & 6.3 & 5.4 & 4.6 & 2.61 \\
\hline 4 & \multirow{3}{*}{ Medium } & 4 & 6.3 & 6.4 & 5.6 & 0.71 \\
\hline 5 & & 8 & 6.3 & 5.9 & 5.1 & 1.57 \\
\hline 6 & & 12 & 6.3 & 5.1 & 4.3 & 2.79 \\
\hline 7 & \multirow{3}{*}{ Fine } & 4 & 6.3 & 6.8 & 6.0 & 0.67 \\
\hline 8 & & 8 & 6.3 & 6.1 & 5.3 & 1.51 \\
\hline 9 & & 12 & 6.3 & 5.3 & 4.5 & 2.67 \\
\hline
\end{tabular}

\subsubsection{Design Binder Content}

Once estimated binder contents were computed, two set of Superpave samples were prepared at four binder contents: estimated binder content, \pm 0.5 percent, and +1.0 percent. Volumetric analysis was performed, and plotted. The results are presented in Appendix A. The optimum asphalt content was selected as the one to produce the design air content in the total mix. At this point, results were analyzed for 4 and 5 percent VTM. The resulting volumetric parameters are given in Table 3.4. Additional samples were compacted in the, $\mathrm{SGC}$, to $\mathrm{N}_{\max } 75$ gyrations, and $\% \mathrm{G}_{\mathrm{mm}} @ \mathrm{~N}_{\max }$ was calculated for each mix. The results are presented in Table 3.4.

\subsubsection{Surface Area and Thin Film Thickness Calculations}

From individual mix gradations and using surface area factors shown in Table 2.10, surface area values were computed. Surface area was then used to compute film thickness values. Surface area and film thickness data are shown in Table 3.4. 
Table 3.4 Optimum binder contents and volumetric properties

\begin{tabular}{|c|c|c|c|c|c|c|c|c|c|c|c|c|c|}
\hline Mix & Blend & $\begin{array}{c}\text { Dust } \\
\text { Content } \\
\text { percent }\end{array}$ & $\begin{array}{l}\text { Design } \\
\text { Air } \\
\text { Cont. } \\
\text { percent }\end{array}$ & $\begin{array}{c}\mathrm{P}_{\mathrm{b}} \\
\text { percent }\end{array}$ & $\begin{array}{c}\text { VMA } \\
\text { percent }\end{array}$ & $\begin{array}{c}\text { VFA } \\
\text { percent }\end{array}$ & $\begin{array}{l}\% \mathrm{G}_{\mathrm{mm}} \\
@ \mathrm{~N}_{\mathrm{ini}}\end{array}$ & $\begin{array}{c}\mathrm{P}_{\text {be }} \\
\text { percent }\end{array}$ & $\mathrm{P}_{0.075} / \mathrm{P}_{\mathrm{be}}$ & $\begin{array}{l}\% \mathrm{G}_{\operatorname{mm}} \\
@ \mathrm{~N}_{\max }\end{array}$ & $\begin{array}{c}\text { Surface } \\
\text { Area } \\
\mathrm{kg} / \mathrm{m}^{2}\end{array}$ & $\begin{array}{c}\text { Film } \\
\text { Thickness } \\
\qquad \mu \mathrm{m}\end{array}$ & $\begin{array}{c}\text { Rut Depth } \\
\text { mm }\end{array}$ \\
\hline \multirow{2}{*}{1} & \multirow{6}{*}{ Coarse } & \multirow{2}{*}{4} & 4 & 6.8 & 17.6 & 77.8 & 87.0 & 6.0 & 0.66 & 97.8 & 4.8 & 13.04 & 10.4 \\
\hline & & & 5 & 6.3 & 17.5 & 71.5 & 86.0 & 5.5 & 0.72 & 96.7 & 4.8 & 11.88 & 9.3 \\
\hline \multirow{2}{*}{2} & & \multirow{2}{*}{8} & 4 & 6.0 & 15.9 & 75.0 & 86.5 & 5.2 & 1.53 & 97.4 & 6.11 & 8.80 & 9.4 \\
\hline & & & 5 & 5.6 & 16.1 & 68.5 & 86.0 & 4.8 & 1.66 & 96.6 & 6.11 & 8.09 & 9.0 \\
\hline \multirow{2}{*}{3} & & \multirow{2}{*}{12} & 4 & 5.4 & 14.7 & 73.0 & 86.5 & 4.7 & 2.58 & 97.1 & 7.42 & 6.40 & 7.7 \\
\hline & & & 5 & 5.1 & 15.0 & 67.0 & 85.8 & 4.3 & 2.76 & 96.0 & 7.42 & 5.97 & 7.0 \\
\hline \multirow{2}{*}{4} & \multirow{6}{*}{ Medium } & \multirow{2}{*}{4} & 4 & 6.5 & 17.0 & 76.5 & 86.5 & 5.7 & 0.70 & 96.9 & 5.47 & 10.81 & 9.5 \\
\hline & & & 5 & 6.1 & 17.1 & 70.5 & 85.0 & 5.3 & 0.75 & 96.0 & 5.47 & 10.00 & 8.6 \\
\hline \multirow{2}{*}{5} & & \multirow{2}{*}{8} & 4 & 5.8 & 15.6 & 74.0 & 86.5 & 4.7 & 1.70 & 97.4 & 6.78 & 7.57 & 8.3 \\
\hline & & & 5 & 5.5 & 15.7 & 68.5 & 86.0 & 5.0 & 1.60 & 97.1 & 6.78 & 7.09 & 7.8 \\
\hline \multirow{2}{*}{6} & & \multirow{2}{*}{12} & 4 & 5.3 & 14.4 & 72.5 & 86.9 & 4.1 & 2.93 & 97.7 & 8.09 & 5.67 & 8.1 \\
\hline & & & 5 & 4.9 & 14.6 & 65.3 & 85.5 & 4.5 & 2.67 & 97.2 & 8.09 & 5.14 & 7.4 \\
\hline \multirow{2}{*}{7} & \multirow{6}{*}{ Fine } & \multirow{2}{*}{4} & 4 & 6.7 & 17.7 & 77.0 & 88.0 & 5.7 & 0.70 & 97.5 & 6.35 & 9.77 & 11.7 \\
\hline & & & 5 & 6.4 & 17.8 & 72.0 & 87.0 & 6.0 & 0.67 & 97.9 & 6.35 & 9.24 & 10.4 \\
\hline \multirow{2}{*}{8} & & \multirow{2}{*}{8} & 4 & 6.2 & 16.6 & 76.0 & 87.5 & 5.1 & 1.56 & 97.3 & 7.66 & 7.43 & 9.8 \\
\hline & & & 5 & 5.8 & 16.6 & 70.0 & 86.5 & 5.5 & 1.45 & 96.2 & 7.66 & 6.86 & 10.1 \\
\hline \multirow{2}{*}{9} & & \multirow{2}{*}{12} & 4 & 5.3 & 14.7 & 73.0 & 86.2 & 4.6 & 2.60 & 96.7 & 8.97 & 5.25 & 9.0 \\
\hline & & & 5 & 4.9 & 14.8 & 66.0 & 85.2 & 4.2 & 2.85 & 96.6 & 8.97 & 4.77 & 9.3 \\
\hline
\end{tabular}




\subsubsection{APA Samples and Rut Depths}

Once optimum asphalt contents for each mix were determined, the Superpave Gyratory Compactor was used to compact $75 \mathrm{~mm}$ high samples for APA test at $7.0 \pm 0.5$ air content. All samples were tested at $64^{\circ} \mathrm{C}$, with a hose pressure of $100 \mathrm{psi}$ and a wheel load of $100 \mathrm{lb}$. Rut depth was measure device after 8000 cycles. Average results for each mix type are shown in Table 3.4, complete results are shown in Appendix A, Tables A10 to A12.

\subsubsection{Analysis Procedures}

The first step in the analysis was to prepare and review bar charts of the data to review how the mix design factors, gradation, dust content, and voids in the total mix affected the volumetric properties of the mix. Next bar charts of the mix design parameters were evaluated with respect to rutting performance. An analysis of variance was performed to identify mix design factors, and their interactions, which have significant correlation with rutting potential. Finally, the data from the mixes were evaluated to determine if the trial $4.75 \mathrm{~mm}$ criteria presented in Table 3.1 produce viable mix designs. The film thickness and dust to binder ratio data were used as parameters to check if the voids in the mineral aggregate and voids filled with asphalt criteria are "reasonable". The recommendations of Kandhal, et al. (1998) were used to evaluate the film thickness data. The recommendations of Cooley, et al. (2002a) were used to evaluate the dust to binder ratio data.

\subsection{PHASE II COMPARISON OF MARSHALL AND SUPERPAVE}

The purpose of this phase of the research was to compare the $4.75 \mathrm{~mm}$ NMAS mix design prepared under the proposed Superpave criteria and the Marshall mix design method. Three Marshall mix designs approved by the WVDOH were obtained. The mixes were redesigned in the WVU Asphalt Technology laboratory to verify the volumetric properties and optimum asphalt content. The gradations from Marshall mix designs were then used to prepare Superpave mix designs. All mixes were then evaluated for film thickness and rutting potential. Figure 3.3 displays the research test plan for Phase II. 


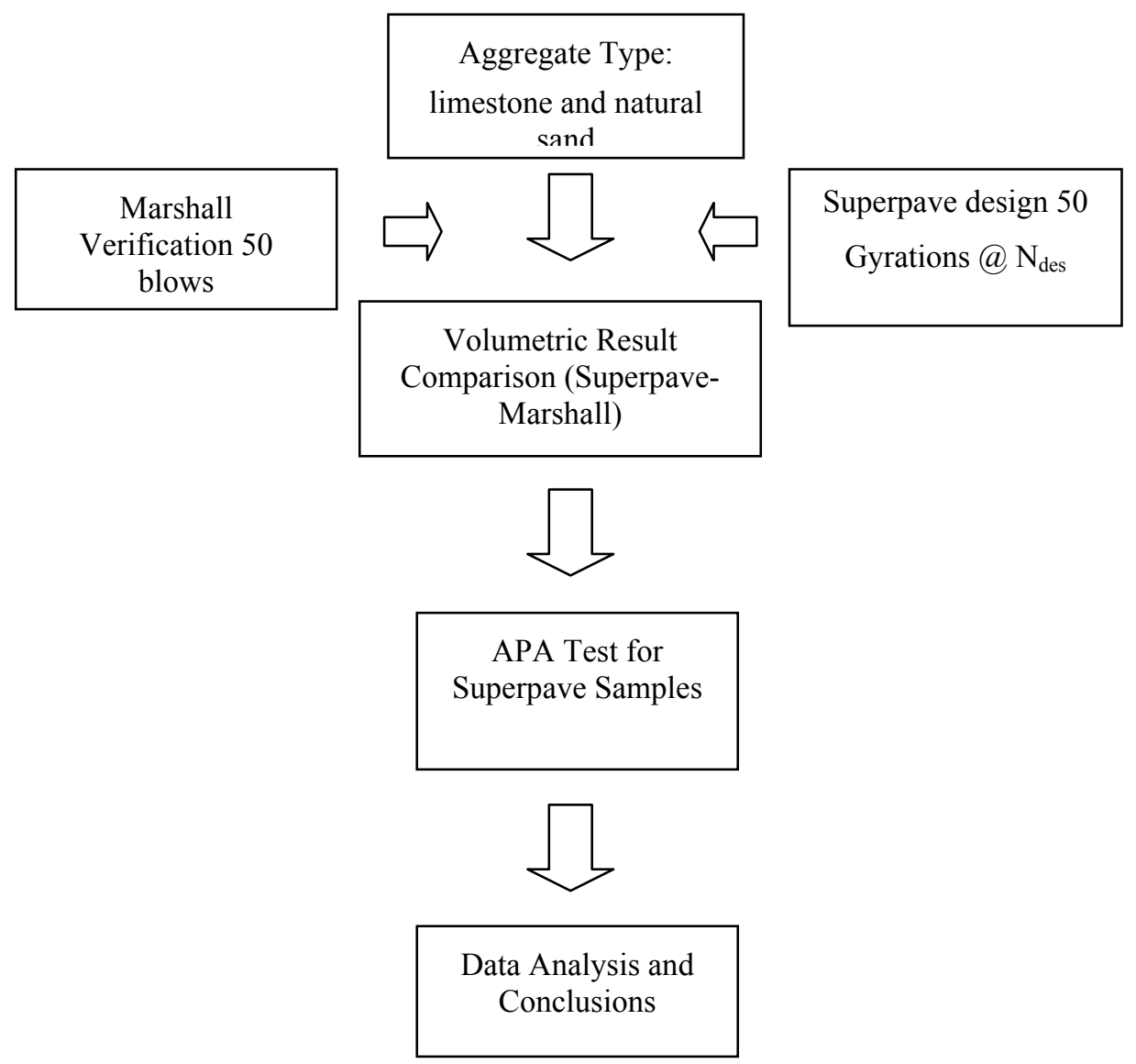

Figure 3.3 Research test plan for Phase II

\subsubsection{Materials}

Two aggregate types were used during Phase II. Limestone from JF Allen Company, Buckhannon, WV, and natural sand from Martin Marietta Company Elkins WV. Two limestone stockpiles were used, a \#9 gradation and a crushed fine aggregate. The crushed fine aggregate limestone material was the same as used during Phase I. Aggregate was prepared as described in Section 3.1.2.1. The three blends of aggregates evaluated during Phase II consisted of:

- Blend 1: 85 percent limestone fines, 15 percent $\# 9$

- Blend 2: 55 percent limestone fines 45 percent natural sand

- Blend 3: 60 percent limestone fines 40 percent natural sand

The binder grade selected was PG 64-22, provided by Marathon Ashland Petroleum Company, binder specifications are described in Section 3.1.2.2. 


\subsubsection{Consensus Properties}

The fine aggregate angularity and sand equivalent of the aggregates are shown in Table 3.5. Coarse aggregate properties of the material was not tested due to the nominal maximum aggregate size of the materials. The sand equivalency of the limestone fine aggregate and the natural sand were both higher than the minimum requirement. It was not necessary to check the blended value. The blended fine aggregate angularity could not be computed in the conventional manner since contrived gradations were used, i.e. the blends were composed of the specific weights of each material needed for each sieve rather than percents of stockpiles. Therefore, samples were blended in the proportions used for each blend and meeting the sample weight requirements of the FAA test and the FAA was measured for these blends of materials.

Table 3.5 Consensus properties of aggregates used in Phase II.

\begin{tabular}{|c|c|c|c|c|c|c|}
\hline $\begin{array}{c}\text { Consensus } \\
\text { Property }\end{array}$ & $\begin{array}{c}\text { Limestone } \\
\text { Fine } \\
\text { Aggregate }\end{array}$ & $\begin{array}{c}\text { Limestone } \\
\# 9\end{array}$ & $\begin{array}{c}\text { Natural } \\
\text { Sand }\end{array}$ & Blend 1 & Blend 2 & Blend 3 \\
\hline $\begin{array}{c}\text { Fine aggregate, } \\
\text { angularity }\end{array}$ & 45.5 & 46.0 & 38.8 & 45.8 & 41.5 & 42.1 \\
\hline Sand equivalent & 78 & - & 95.6 & & & \\
\hline
\end{tabular}

\subsubsection{Aggregate Specific Gravity}

The specific gravity of the aggregates used in Phase II are shown in Table 3.6. The coarse material from the \# 9 stockpile was evaluated with AASHTO T85. The specific gravity of the fine material was evaluated with AASHTO T84.

Table 3.6 Specific gravity of Phase II aggregates

\begin{tabular}{|c|c|c|c|}
\hline $\begin{array}{c}\text { AGGREGATE } \\
\text { TYPE }\end{array}$ & $\begin{array}{c}\text { BULK } \\
\text { SPECIFIC } \\
\text { GRAVITY }\end{array}$ & $\begin{array}{c}\text { APPARENT } \\
\text { SPECIFIC } \\
\text { GRAVITY }\end{array}$ & $\begin{array}{c}\text { WATER } \\
\text { ABSORBTION } \\
\%\end{array}$ \\
\hline Limestone \#9 & 2.647 & 2.741 & 1.3 \\
\hline Limestone Sand & 2.655 & 2.729 & 1.6 \\
\hline Natural Sand & 2.545 & 2.688 & 2.1 \\
\hline
\end{tabular}




\subsubsection{Aggregate Gradation}

These mixes were selected to represent range from fine to coarse blends. One blend combined \#9 limestone with $85 \%$ limestone fine aggregate. The other two blends were combination of limestone fine aggregate and natural sand in two proportions. Table 3.7 and Figure 3.4 show combine gradation used from WVDOH mix designs.

Table 3.7 WVDOH aggregate gradations, percent passing

\begin{tabular}{|c|c|c|c|}
\hline \multirow{2}{*}{ Sieve Size } & Mix 10 & Mix 11 & Mix 12 \\
\cline { 2 - 4 } & $\begin{array}{c}85 \% \text { LM - } \\
15 \% \text { \#9 }\end{array}$ & $\begin{array}{c}55 \% \text { LM - } \\
45 \% \text { NS }\end{array}$ & $\begin{array}{c}60 \% \text { LM - } \\
40 \% \text { NS }\end{array}$ \\
\hline 9.5 & 100 & 100 & 100 \\
\hline 4.75 & 95 & 94 & 98 \\
\hline 2.36 & 69 & 74 & 73 \\
\hline 1.18 & 43 & 57 & 46 \\
\hline 0.6 & 27 & 38 & 31 \\
\hline 0.3 & 16 & 19 & 16 \\
\hline 0.075 & 6.4 & 7.1 & 7.0 \\
\hline
\end{tabular}

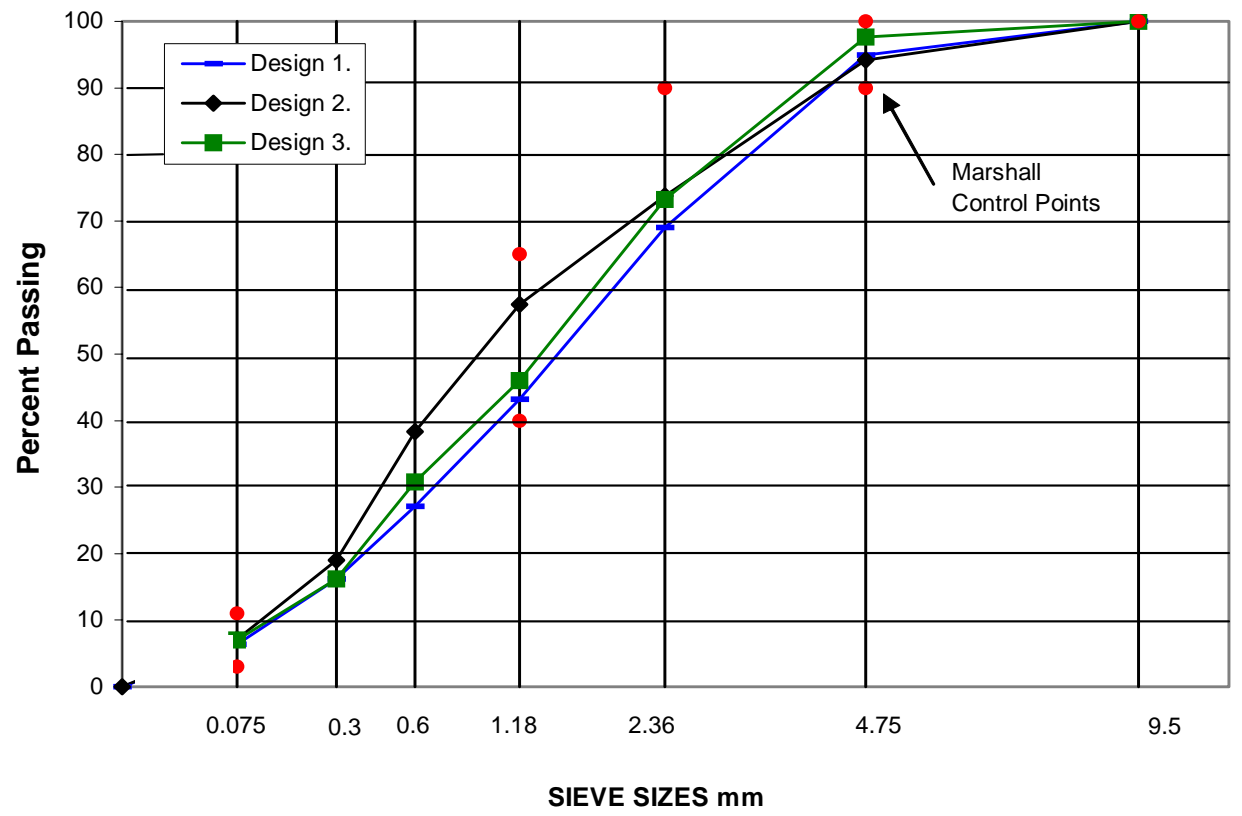

Figure 3.4 Gradation curves for WVDOH Marshall mixes 


\subsubsection{Marshall Mix Designs}

The design traffic selected for this study was less than 3 million ESALs for medium traffic volume. The WVDOH does not have low traffic Marshall mix design parameters. The required compaction effort is 50 blows per side. West Virginia Department of Transportation MP 401.02.22 was used to design the mixes.

Trial blends were made to determine optimum binder content. Estimated optimum asphalt contents were 7.0, 7.5 and 7.5 percent for Designs 1, 2 and 3, respectively. Then samples were prepared at estimated asphalt content and $+/-0.5 \%$ and $+/-1.0 \%$ from the estimated asphalt content. Volumetric parameters, stability and flow were evaluated and plotted and the optimum asphalt content was determined. The volumetric results are summarized in Table 3.8, with the details presented in Appendix B. The dust to binder ratios in Appendix B are based on the effective asphalt content to allow comparison to the Superpave mixes. The results meet all WVDOH mix design criteria as set forth in Tables 2.2 and 2.3. The design parameters for these mixes were compiled from the approved mix design packages are presented in to Table 3.9.

The optimum asphalt contents of the mixes designed at the WVU Asphalt Technology Laboratory were consistently 0.2 to 0.4 percent less than the approved WVDOH mixtures. However, given that different aggregate stockpiles and binders were used in different laboratories the differences are insignificant. The other mix design parameters also show reasonable agreement.

Table 3.8 West Virginia Asphalt Technology Lab Marshall results

\begin{tabular}{|c|c|c|c|c|c|c|c|}
\hline Mix \# & $\begin{array}{c}\text { Blend } \\
\text { Proportions }\end{array}$ & $\begin{array}{c}\text { Asphalt } \\
\text { Content } \\
\text { percent }\end{array}$ & $\begin{array}{c}\text { Air Voids } \\
\text { percent }\end{array}$ & $\begin{array}{c}\text { VMA } \\
\text { percent }\end{array}$ & $\begin{array}{c}\text { VFA } \\
\text { percent }\end{array}$ & $\begin{array}{c}\text { Flow } \\
(0.25 \mathrm{~mm})\end{array}$ & $\begin{array}{c}\text { Stability } \\
(\mathrm{N})\end{array}$ \\
\hline 10 & $\begin{array}{c}85 \% \text { LM S } \\
15 \% \text { LM \#9 }\end{array}$ & 6.9 & 4.0 & 17.9 & 78 & 11.0 & 13256 \\
\hline 11 & $\begin{array}{c}55 \% \text { LM S }- \\
45 \% \mathrm{NS}\end{array}$ & 7.6 & 4.0 & 18.2 & 78 & 14.5 & 7384 \\
\hline 12 & $\begin{array}{c}60 \% \text { LM S - } \\
40 \% \mathrm{NS}\end{array}$ & 7.3 & 4.0 & 17.9 & 78 & 13.5 & 10631 \\
\hline
\end{tabular}


Table 3.9 WVDOH Marshall mix designs

\begin{tabular}{|c|c|c|c|c|c|c|c|}
\hline Mix \# & $\begin{array}{c}\text { Blend } \\
\text { Proportions }\end{array}$ & $\begin{array}{c}\text { Asphalt } \\
\text { Content } \\
\text { percent }\end{array}$ & $\begin{array}{c}\text { Air } \\
\text { Voids } \\
\text { percent }\end{array}$ & $\begin{array}{c}\text { VMA } \\
\text { percent }\end{array}$ & $\begin{array}{c}\text { VFA } \\
\text { percent }\end{array}$ & $\begin{array}{c}\text { Flow } \\
(0.25 \mathrm{~mm})\end{array}$ & $\begin{array}{c}\text { Stability } \\
(\mathrm{N})\end{array}$ \\
\hline 10 & $\begin{array}{c}85 \% \text { LM S. }- \\
15 \% \text { LM \# }\end{array}$ & 7.2 & 4.0 & 17.6 & 77 & 9.6 & 10860 \\
\hline 11 & $\begin{array}{c}55 \% \text { LM S. } \\
\text { 45\%N.S. }\end{array}$ & 8.0 & 4.0 & 20.7 & 78 & 10.0 & 7200 \\
\hline 12 & $\begin{array}{c}60 \% \text { LM S. } \\
\text { 40\%N.S. }\end{array}$ & 7.5 & 4.0 & 19.3 & 78 & 11.2 & 8500 \\
\hline
\end{tabular}

The film thickness for each mix was computed using the Edwards-Hveem method:

$\begin{array}{ccc}\text { Mix \# } & \text { WVDOH } & \text { WVU } \\ 10 & 11.2 & 10.7 \\ 11 & 12.9 & 9.71 \\ 12 & 12.5 & 10.7\end{array}$

These values are reasonable compared to the Kandhal and Chakrabourty (1996) criteria of $8 \mu \mathrm{m}$.

\subsubsection{Superpave Mix Designs}

Once Marshall designs were verified, designs were developed under Superpave procedures for the same aggregate and binder. A compactive effort of 50 gyrations for $\mathrm{N}_{\text {des }}$ was selected according to Superpave specifications for less 0.3 millions ESALs. An estimated asphalt content was determined using Equations 2.12 to 2.16 and adjusted after making trial mixes. The optimum binder content was determined by preparing compaction and theoretical maximum specific gravity test at the estimated asphalt content and \pm 0.5 and +1.0 percent from the estimated asphalt content. The volumetric parameters for each mix are detailed in Appendix B. The optimum asphalt content was determined as the percent asphalt required to produce four percent air voids in the compacted samples. The volumetric parameters at the optimum asphalt content are summarized in Table 3.10. The film thickness, computed with the Edwards-Hveem 
method, is also given in Table 3.10. All mix designs are in reasonable agreement with the recommended minimum film thickness of $8 \mu \mathrm{m}$ (Kandhal and Chakrabourty; 1996).

Table 3.10 Phase II Superpave volumetric results

\begin{tabular}{|c|c|c|c|c|c|c|c|c|}
\hline $\begin{array}{c}\text { Mix } \\
\#\end{array}$ & Blend Proportions & $\begin{array}{c}\text { Air } \\
\text { Voids }\end{array}$ & $\begin{array}{c}\text { Asphalt } \\
\text { Content }\end{array}$ & $\begin{array}{c}\text { VMA } \\
\text { percent }\end{array}$ & $\begin{array}{c}\text { VFA } \\
\text { percent }\end{array}$ & $\begin{array}{c}\text { Dust / } \\
\text { Eff. } \\
\text { Binder }\end{array}$ & $\begin{array}{c}\text { Rut } \\
\text { Depth } \\
(\mathrm{mm})\end{array}$ & $\begin{array}{c}\text { Film } \\
\text { Thickness } \\
(\mu \mathrm{m})\end{array}$ \\
\hline 13 & $\begin{array}{c}85 \% \text { LM S. }- \\
15 \% \text { LM } \# 9\end{array}$ & 4 & 6.4 & 17 & 76 & 1.14 & 9.6 & 9.7 \\
\hline 14 & $\begin{array}{c}55 \% \text { LM S. }- \\
45 \% \text { N.S. }\end{array}$ & 4 & 6.4 & 15.8 & 72 & 1.35 & 22.3 & 7.9 \\
\hline 15 & $\begin{array}{c}60 \% \text { LM S. }- \\
40 \% \text { N.S. }\end{array}$ & 4 & 6.6 & 16.6 & 74 & 1.28 & 19.9 & 8.9 \\
\hline
\end{tabular}

\subsubsection{APA Samples and Rut Depths}

Samples with the optimum asphalt content determined by the Superpave method were compacted at $7 \pm 0.5$ percent air voids. The standard procedure used throughout the research was followed to test the samples. The rut depth data are given in Appendix B Table B7 and average values are reported in Table 3.10. After reviewing the optimum asphalt contents of the Marshall and Superpave mixes, it was decided that rutting evaluation of the mixes at the Marshall optimum asphalt content would not be meaningful. The Superpave mixes in Phase II showed a high rutting potential. The Marshall mixes with a higher asphalt content would have an even higher rutting potential so little would be learned by APA testing of these mixes.

\subsubsection{Analysis Procedures}

The purpose of the Phase II study was to compare the Marshall and Superpave mix designs. The analysis consisted of comparing volumetric properties, optimum asphalt content, and film thickness. The data set is not sufficient to support a statistical analysis. Therefore, only graphical comparisons and observations were made about the data set.

One of the issues of concern in the literature is that the Superpave Gyratory Compactor applies a greater compactive effort than the Marshall hammer (D'Angelo et al; 
1995, Cross and Johnson, 2000). This results in lower asphalt contents than is obtained with the Marshall method. This is a particular concern with the design of mixes for low volume roads where the durability of the mix to withstand environmentally related distresses is frequently more critical distress due to traffic. The minimum compactive effort described in the literature was of 50 gyrations. One of the features of the $\mathrm{SGC}$ is that the height of the sample is measured throughout the compaction procedure. Using Equation 2.19 the percent of the maximum theoretical gravity, which corresponds to percent air voids, can be estimated throughout the compaction process. Using this analysis procedure allowed an estimate of the number of gyrations that would yield the same optimum asphalt content as was determined for the Marshall samples. 


\section{CHAPTER 4 RESULT AND ANALYSIS}

\subsection{EVALUATION OF CRITERIA FOR 4.75 MM MIXES \\ 4.1.1 DATA OBSERVATIONS}

The data collected during this research has many similar characteristics to the data collected by Cooley, et al. (2002a) so comparisons were drawn between the two data sets. However, Cooley compacted samples to 75 gyrations while 50 gyrations were used during this research. The higher compactive effort used by Cooley resulted in lower overall binder contents that were developed for this research. None the less, many of the trends observed from the WVU data set are confirmed by the Cooley data set. In developing the comparisons for the Phase I data, only the data from the Cooley's limestone mixes to match the aggregate type used in Phase I.

\subsubsection{Binder Content}

A review of the volumetric data in Table 3.4 indicates VTM, dust content, and gradation affect optimum binder content. Optimum binder contents ranged from 5.0 to 6.8 percent for mixes designed to 4 percent VTM and from 4.8 to 6.3 percent for 5 percent VTM, Figure 4.1. Increasing VTM results in a decrease of optimum asphalt content of about 0.38 percent on average. This trend was also displayed in the data collected by Cooley, et al. (2002a). Figure 4.2 shows the WVU and Cooley, et al (2002a) data both display the same rate of decrease in percent binder as VTM increases. Increases in dust content by 4 percent resulted in an average decrease in optimum binder contents of about 0.7 percent. Again, the same trend is demonstrated in the Cooley data. As shown on Figure 4.3, the change in optimum binder content decreases at the same rate for both data sets, when analyzed for 4 percent VTM; the slope of both trend lines are equal. The scatter shown in the data on this graph is an artifact of the different gradations in the data sets, not an indication of highly variable results. The fine gradation required the highest asphalt content, 5.9 percent, followed by the coarse, 5.8 percent, and medium gradations, 5.6 percent. Cooley's data also showed that the medium gradation had the lowest optimum binder content as shown in Figure 4.4. 


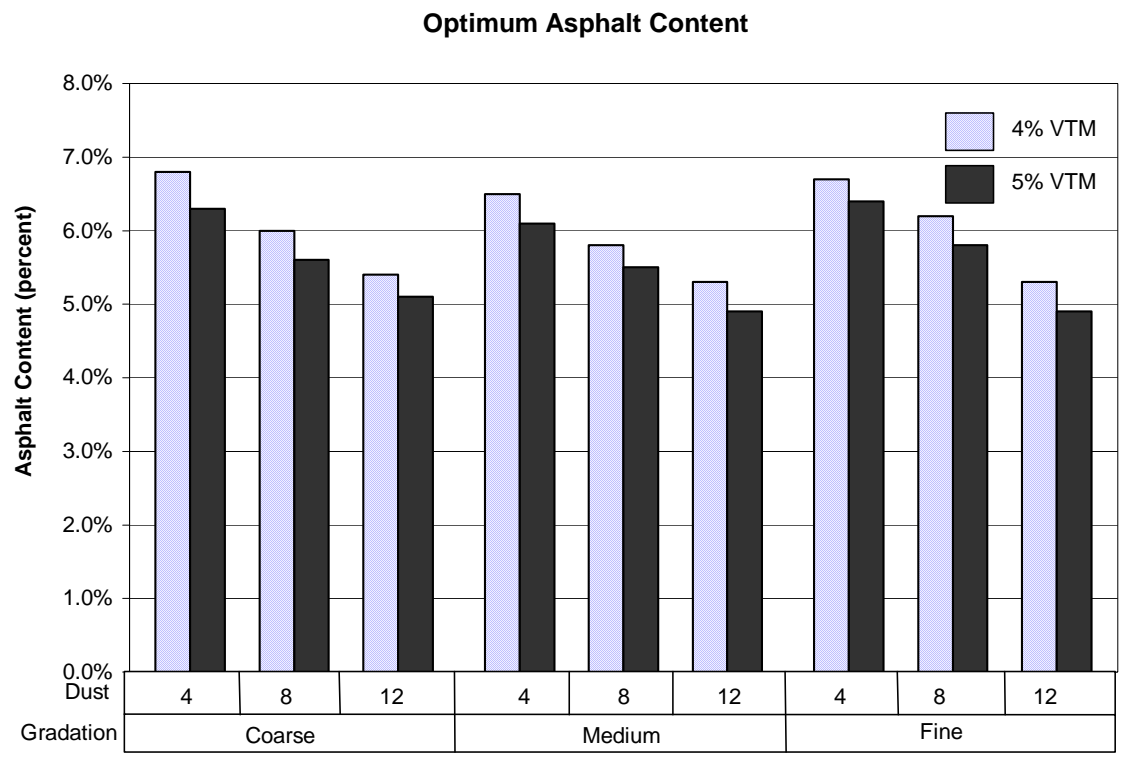

Figure 4.1 Range of optimum asphalt content

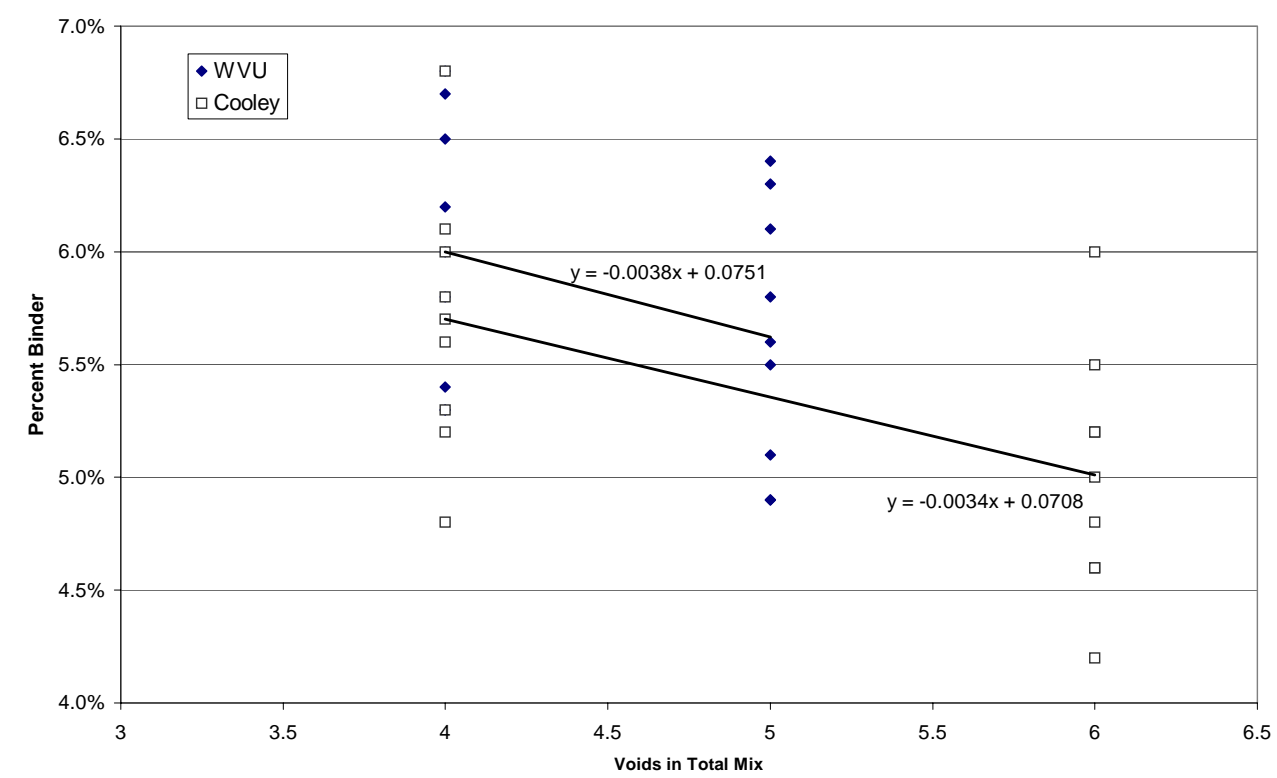

Figure 4.2 Optimum asphalt content versus voids in the mix 


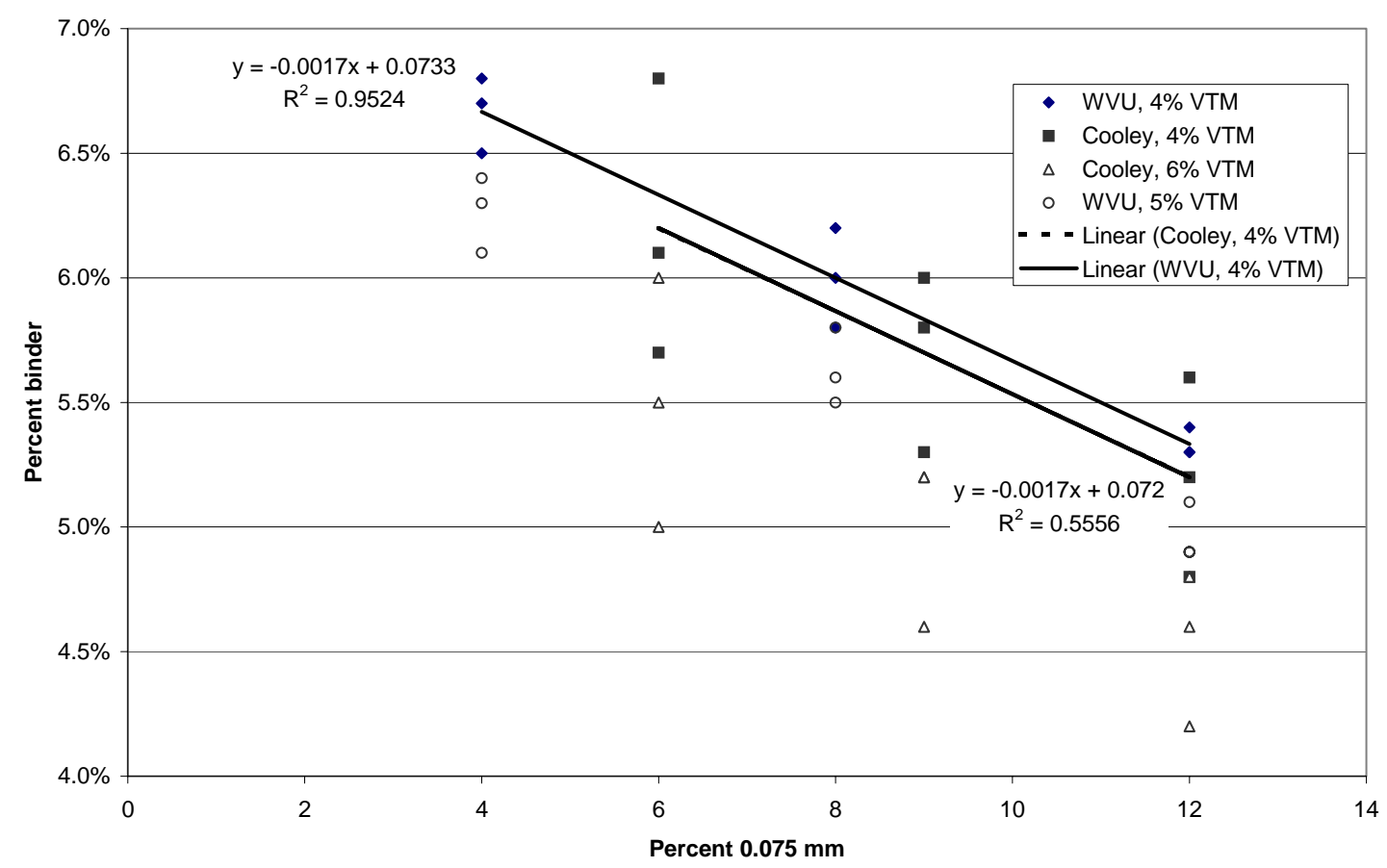

Figure 4.3 Optimum binder content versus dust content

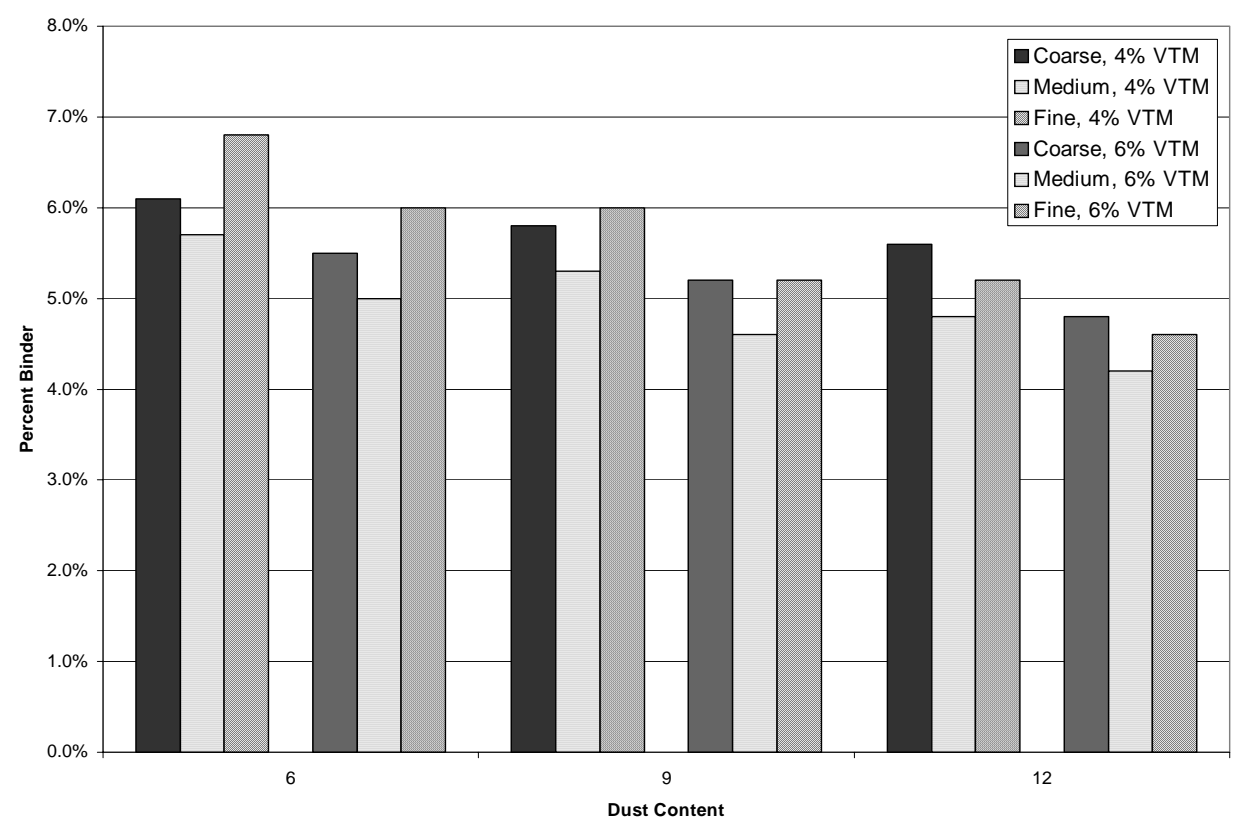

Figure 4.4 Range in binder contents, Cooley data 


\subsubsection{Voids in Mineral Aggregate}

When VMA was observed, values ranged from 14.4 percent to 17.2 percent,

Figure 4.5. Cooley, et al.'s (2002 a) data show similar trends, Figure 4.6. Dust content affects VMA. When dust content was increased VTM values decreased. An increment in dust content by four percent resulted in a decrease of about 1.36 percent in VMA. As shown on Figure 4.7, the trend in the WVU and Cooley data sets are very similar, with the slope of the trend line for the Cooley data being only slightly greater than for the WVU data. Gradation also affected VMA results, medium gradations have on average the lowest VMA values 15.7 percent, followed by coarse 16.2 percent and fine gradation 16.4 percent. Changing VTM had little effect on VMA. The maximum difference in VMA due to changes in VTM was 0.3 percent. As shown on Figure 4.6, Cooley's data also show little effect of VTM on VMA.

Voids in the Mineral Aggregate

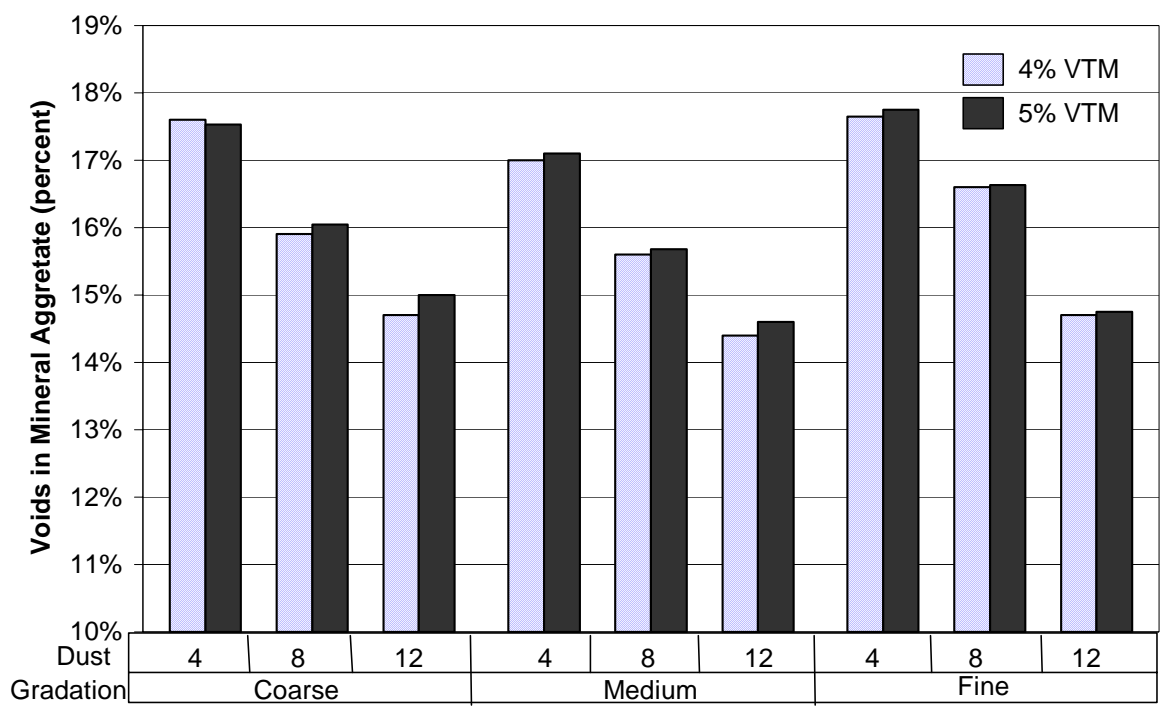

Figure 4.5 Range of voids in mineral aggregate 


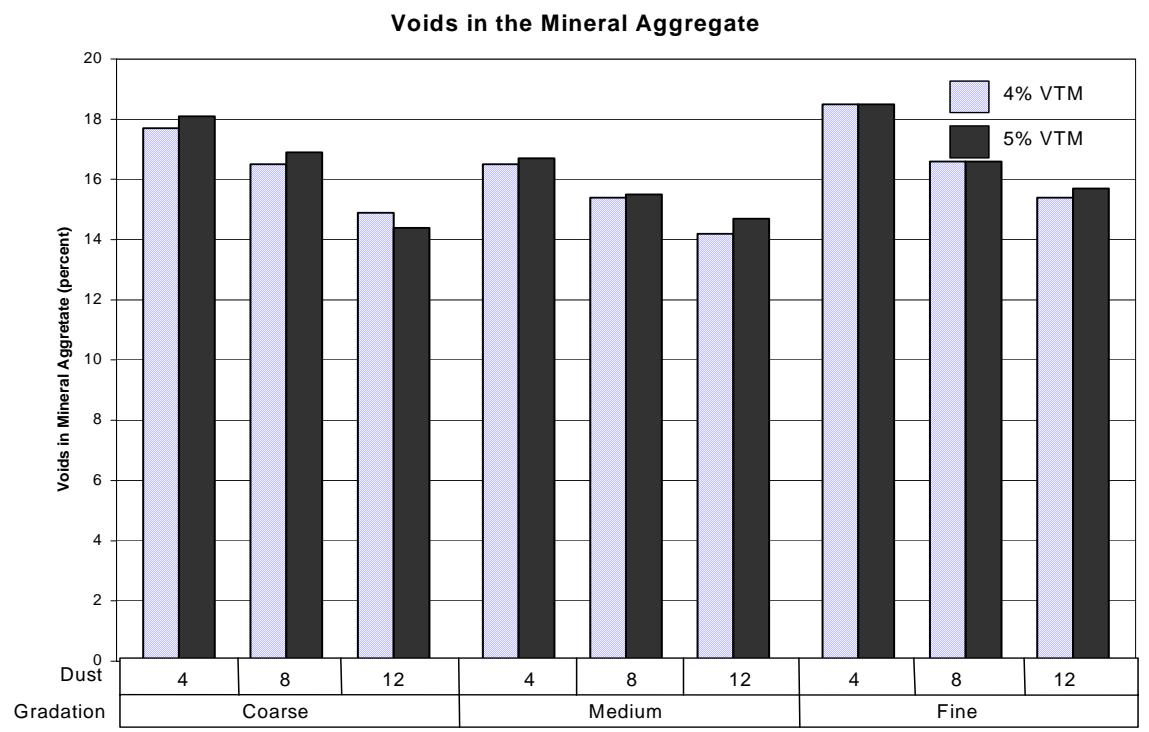

Figure 4.6 Trends in voids in the mineral aggregate with experiment variables, Cooley data

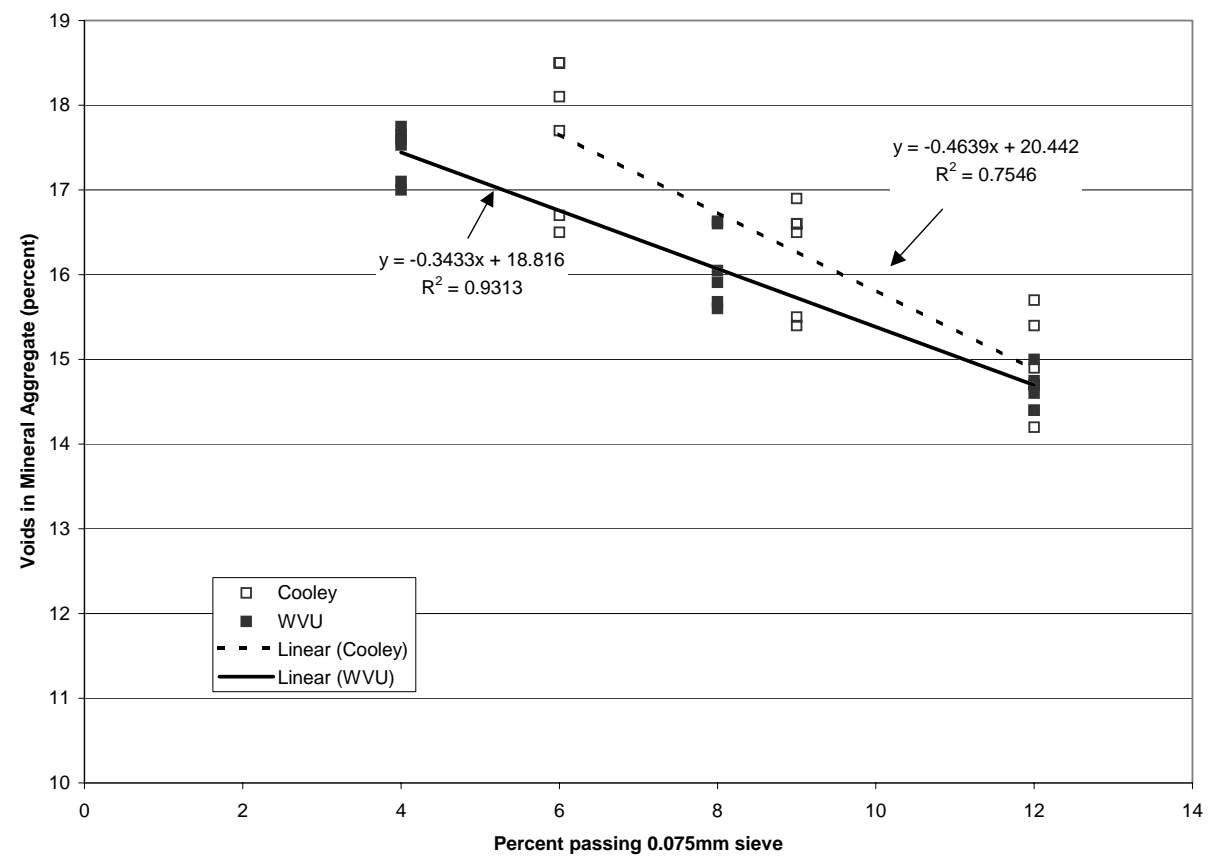

Figure 4.7 Trend lines for voids filled with asphalt versus dust content 


\subsubsection{Voids Filled with Asphalt}

VFA is affected by the 3 main factors. Values for VFA ranged from 65 percent to 78 percent, Figure 4.3. As with VMA, medium gradations present the lowest average VMA, 70.2 percent, followed by the coarse 71.8 percent, and fine gradations, 72.0 percent. Changing VTM by one percent caused an average reduction of 6.2 percent in the VFA, Figure 4.8. Dust content affected VFA by reducing it by 2.4 percent on average when dust content is increased by 4 percent. When the VFA data are compared with Cooley's data, similar trends are apparent, Figure 4.9. Both data sets show a decrease in VFA as dust increases, and the slope of the trend line increases with an increase in VTM. The slope of the trend lines for the WVU data are slightly less than the trends in Cooley's data. Figure 4.10 shows the trend of VFA with VTM is almost identical between the two data sets.

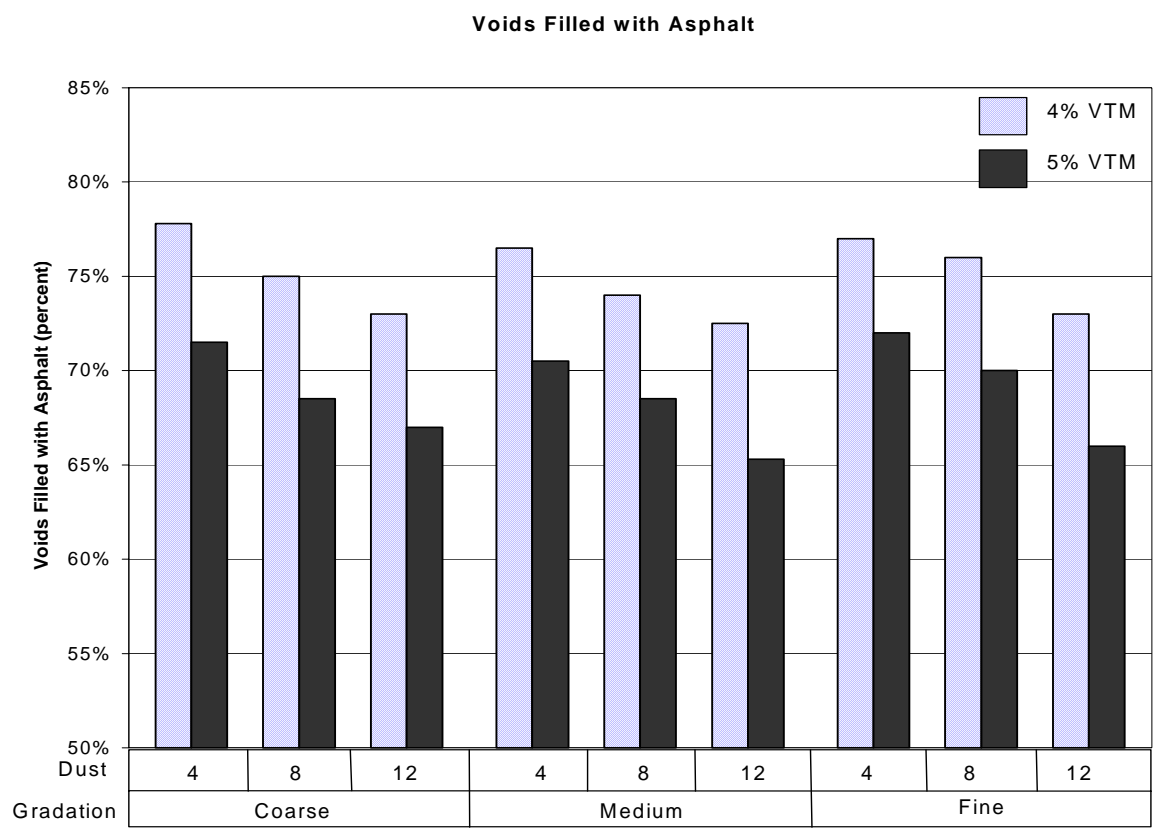

Figure 4.8 Range in voids filled with asphalt 


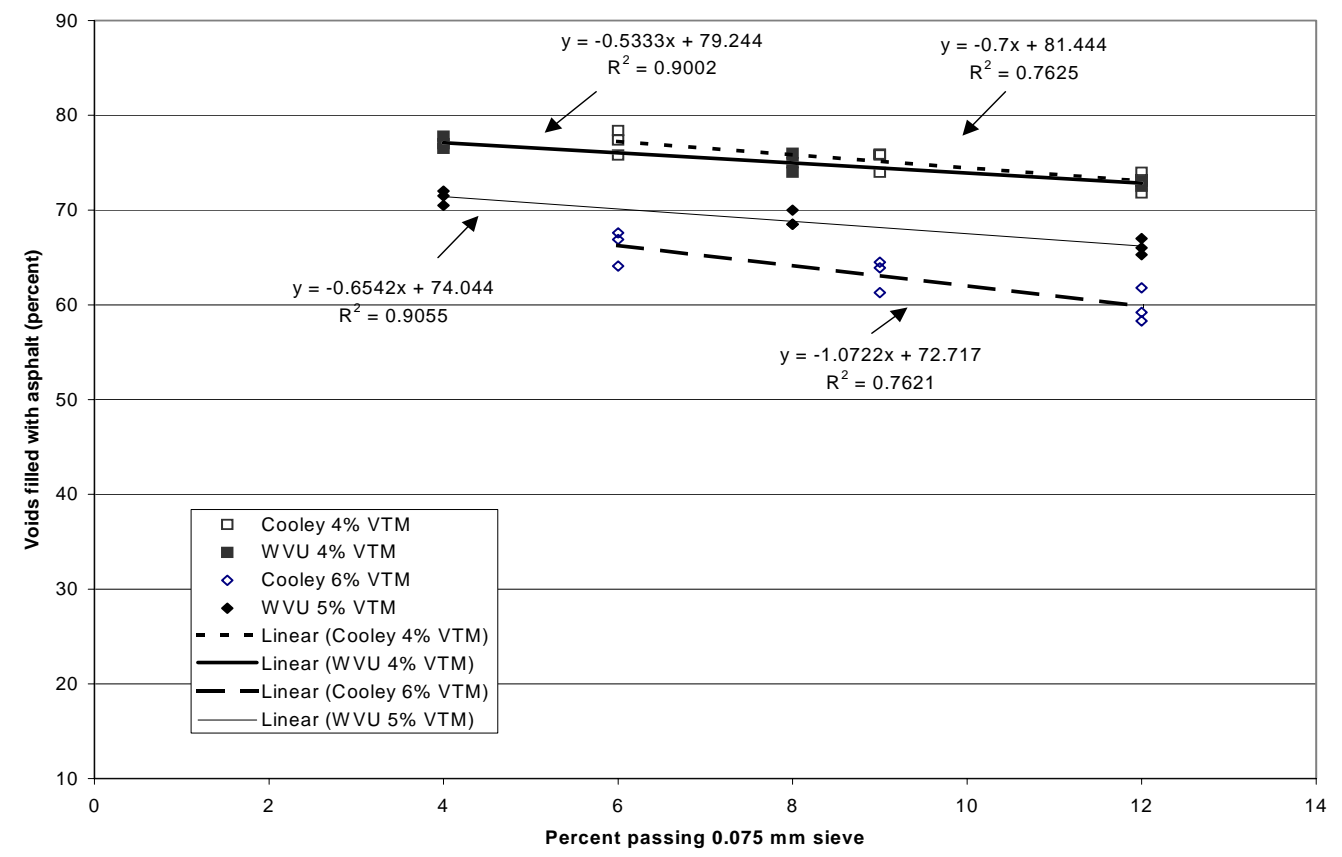

Figure 4.9 Trend of voids filled with asphalt and dust content

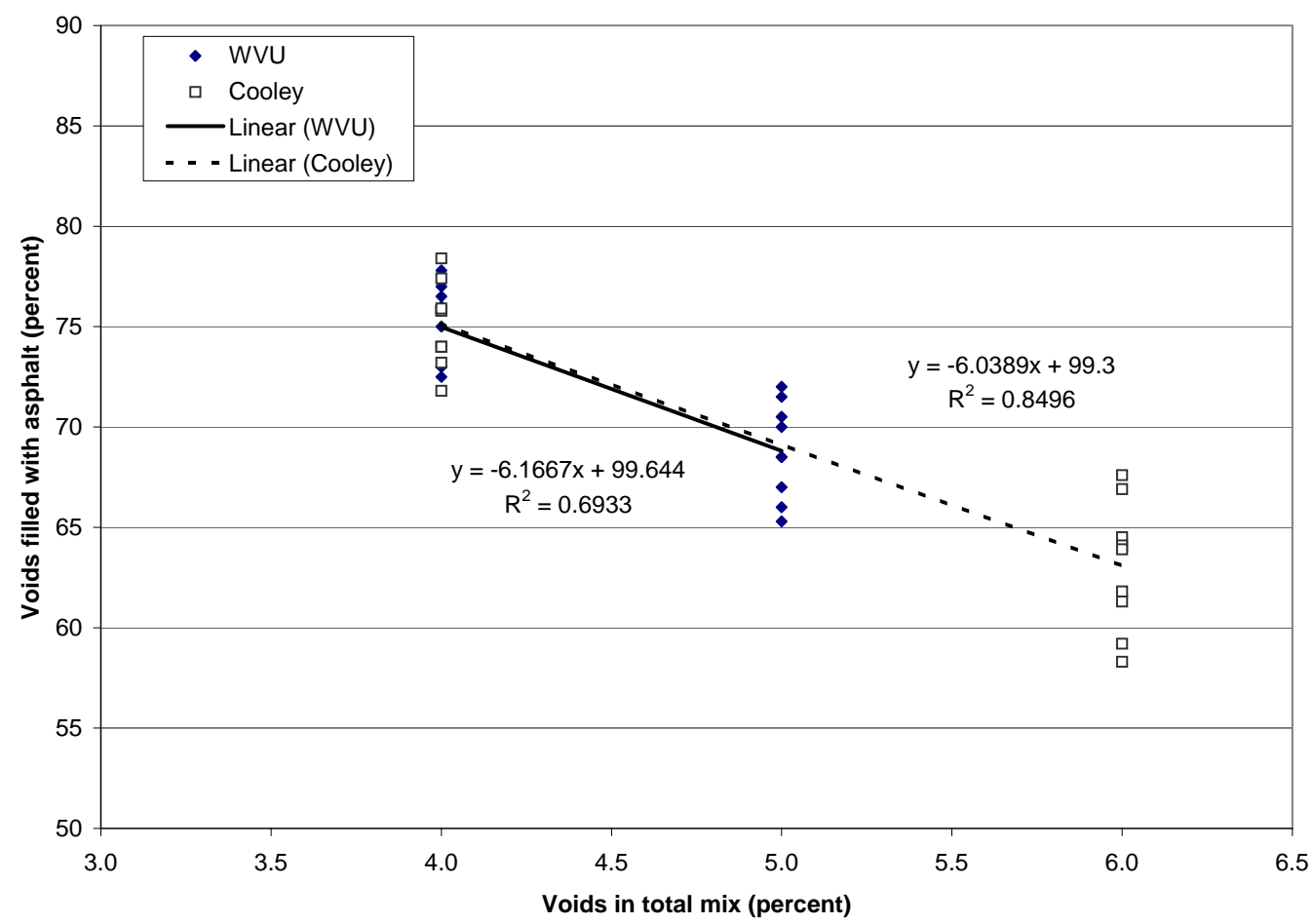

Figure 4.10 Trend of voids filled with asphalt with voids in total mix 


\subsubsection{4\%G $\mathrm{mm}_{\mathrm{m}} @ \mathrm{~N}_{\text {ini }}$}

Percent of theoretical maximum specific gravity at the initial number of gyrations, ranged from 85.0 to 87.5 percent, Figure 4.11. $\% \mathrm{G}_{\mathrm{mm}} @ \mathrm{~N}_{\text {ini }}$ seemed be primary affected by VTM and gradation. When VTM was increased by 1 percent, $\% \mathrm{G}_{\mathrm{mm}} @ \mathrm{~N}_{\text {ini }}$ decreased by 1.1 percent on average. The medium gradation had the lowest values, 86.0 percent, of $\% \mathrm{G}_{\mathrm{mm}} @ \mathrm{~N}_{\text {ini }}$ followed by the coarse, 86.2 percent, and by fine gradations, 86.7 percent.

Dust content did not appear to affect $\% \mathrm{G}_{\mathrm{mm}} @ \mathrm{~N}_{\mathrm{ini}}$. It was observed that none of the mixes failed the maximum Superpave criteria for $\% \mathrm{G}_{\mathrm{mm}} @ \mathrm{~N}_{\mathrm{ini}}$. Cooley also found all the mixes met the \% $\mathrm{G}_{\mathrm{mm}} @ \mathrm{~N}_{\mathrm{ini}}$ criteria was met for all mixes and that the range in the data was small.

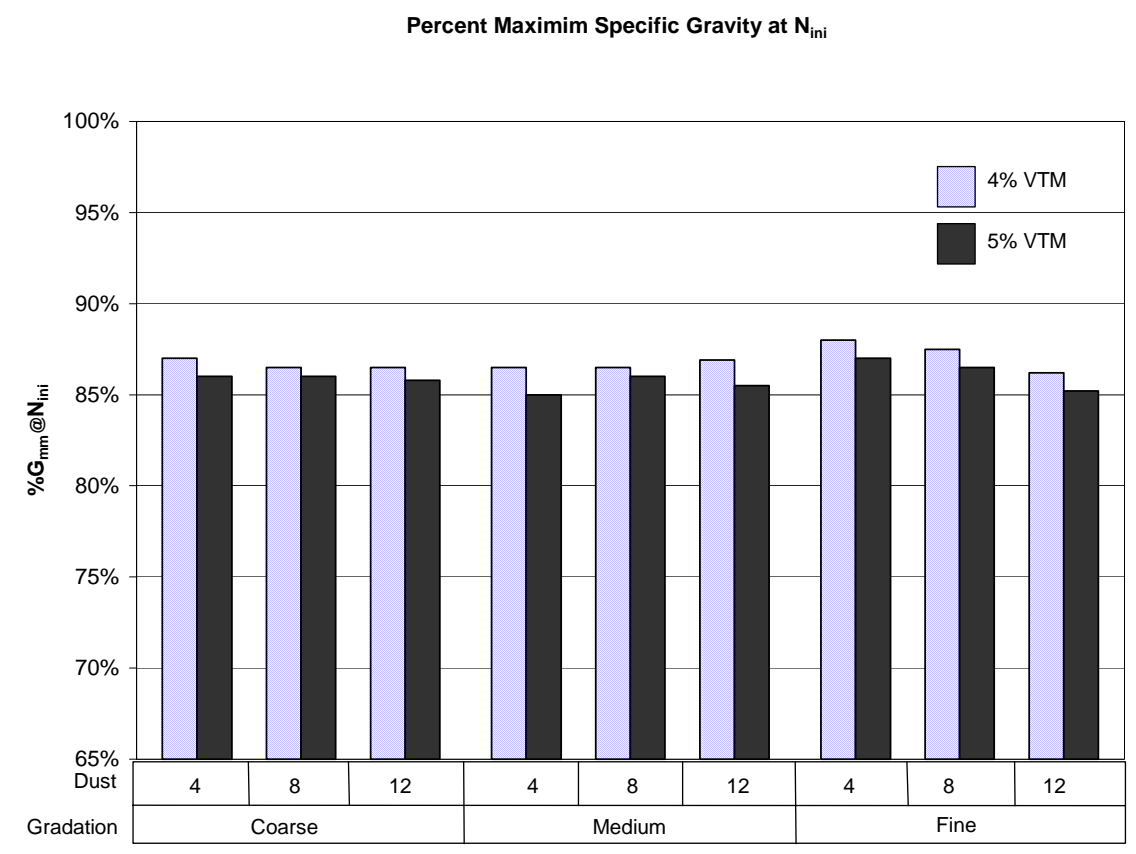

Figure 4.11 Range in $\% \mathrm{G}_{\mathrm{mm}} @ \mathrm{~N}_{\text {ini }}$

\subsubsection{Dust to Effective Binder Ratio}

VTM, gradation and dust content affected the dust to effective binder ratio, $\mathrm{P}_{0.075} / \mathrm{P}_{\text {be }}$, which ranged from 0.66 to 2.93 , Figure 4.12. As expected, the increases in dust content resulted in an increase in $\mathrm{P}_{0.075} / \mathrm{P}_{\text {be }}$. Increases in dust content by 1 percent resulted in an increase of $\mathrm{P}_{0.075} / \mathrm{P}_{\text {be }}$ by 0.25 on average .Cooley's data displays similar 
trends, for four percent VTM. Figure 4.13. Cooley's rate of change in $\mathrm{P}_{0.075} / \mathrm{P}_{\text {be }}$ was 0.26 . The medium gradation had the highest $\mathrm{P}_{0.075} / \mathrm{P}_{\text {be }}$ values, 1.75 , followed by the coarse, 1.66, and fine gradations, 1.44. Increasing VTM one percent resulted in a slight increase of $\mathrm{P}_{0.075} / \mathrm{P}_{\text {be }}, 0.09$ on average. This is attributed to the effect on VTM on the optimum binder content. VMA has a negative correlation with the dust to binder ratio, with similar trends apparent in the WVU and Cooley data as shown on Figure 4.14.

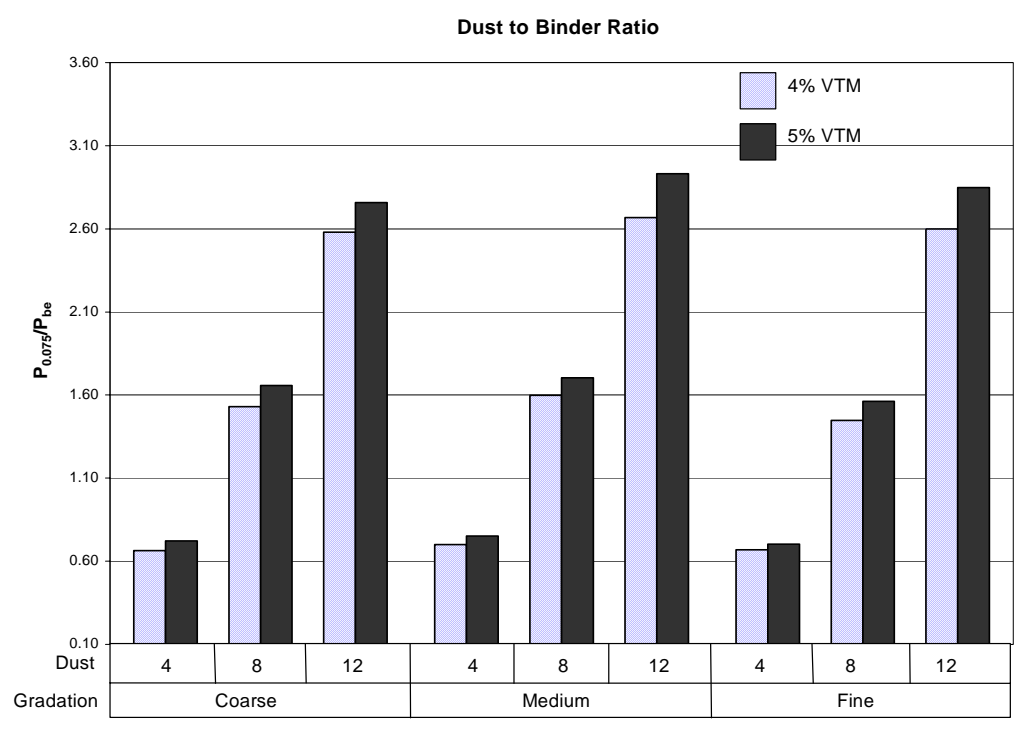

Figure 4.12 Range of dust to effective binder ratio

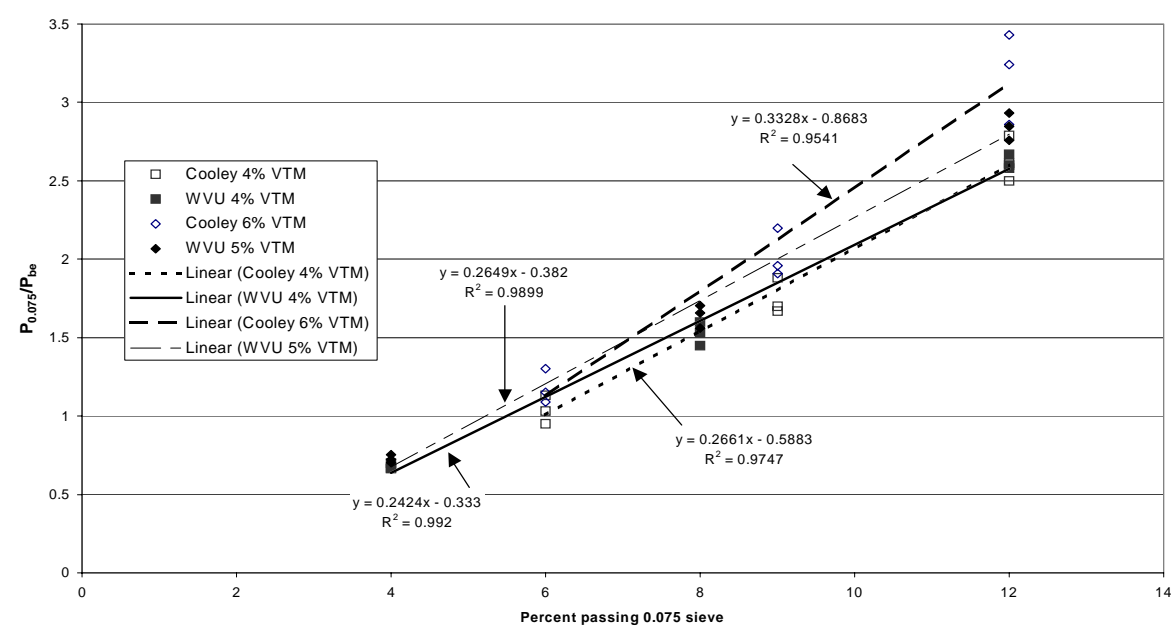

Figure 4.13 Trends in dust to effective binder ratio 


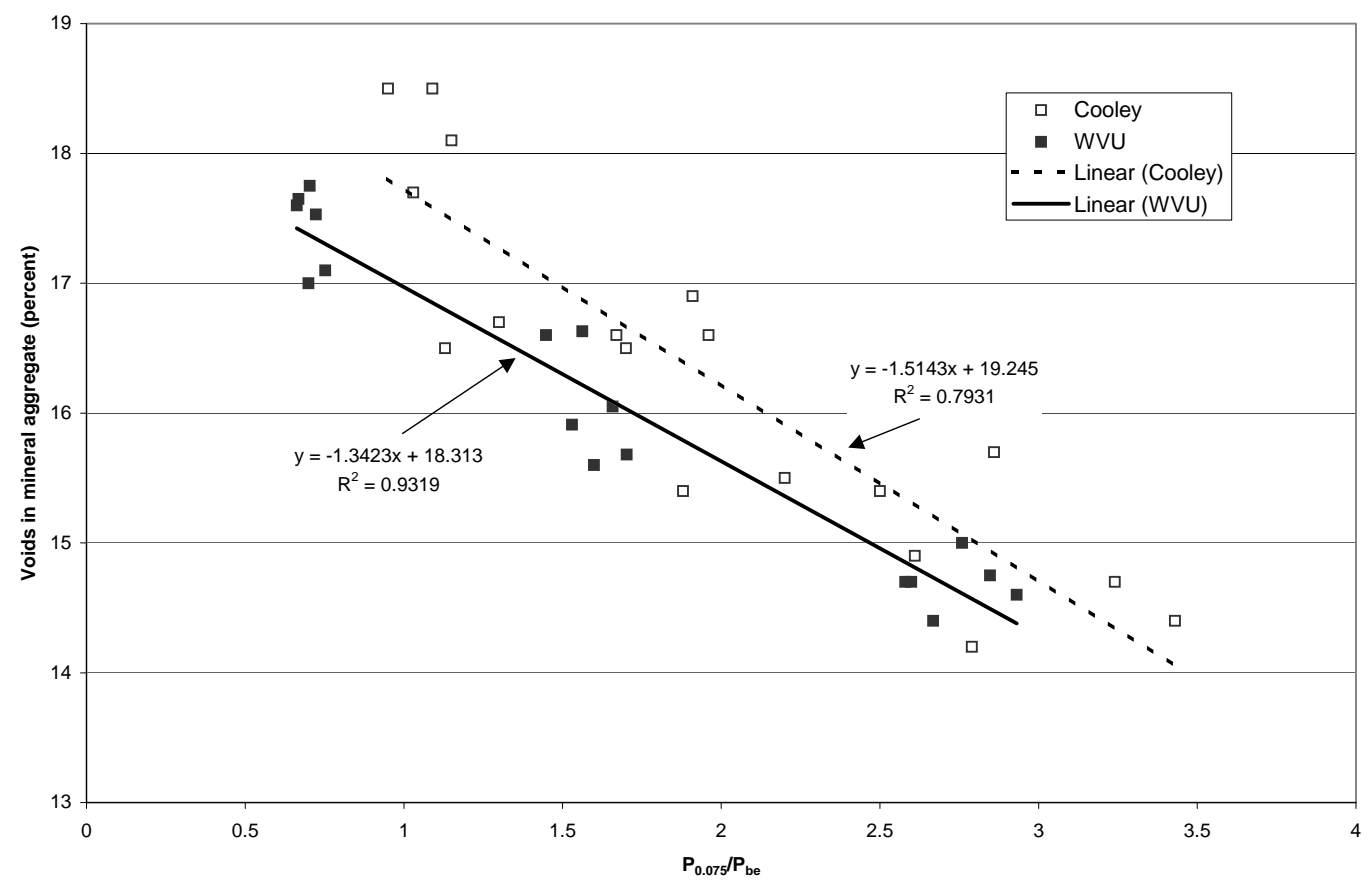

Figure 4.14 Trend in voids in mineral aggregate and dust to effective binder content

\subsubsection{Asphalt Film Thickness}

Film thickness values range from 4.77 to 13.04 microns. Gradation, VTM and dust content affected film thickness, with dust content having the greatest impact, Figure 4.15. Increasing dust content by 4 percent decreased film thickness by 2.63 microns on average. This effect was expected since increasing dust content increases the computed surface area. For the mixes studied, increasing dust content decreased the optimum asphalt content, which also contributes to the decrease in film thickness. The fine gradation had the lowest film thickness, followed by the coarse, and medium gradations. Changing VTM by 1 percent decreased film thickness by 0.4 microns on average. Although the Cooley data were for mixes compacted to 75 gyrations, and therefore had lower asphalt contents, the trends in the data are similar to those observed for the WVU data, as shown on Figure 4.16. All of the Cooley mixes have a film thickness less than 8 microns, which is the recommended minimum (Kandhal, et al; 1998). 


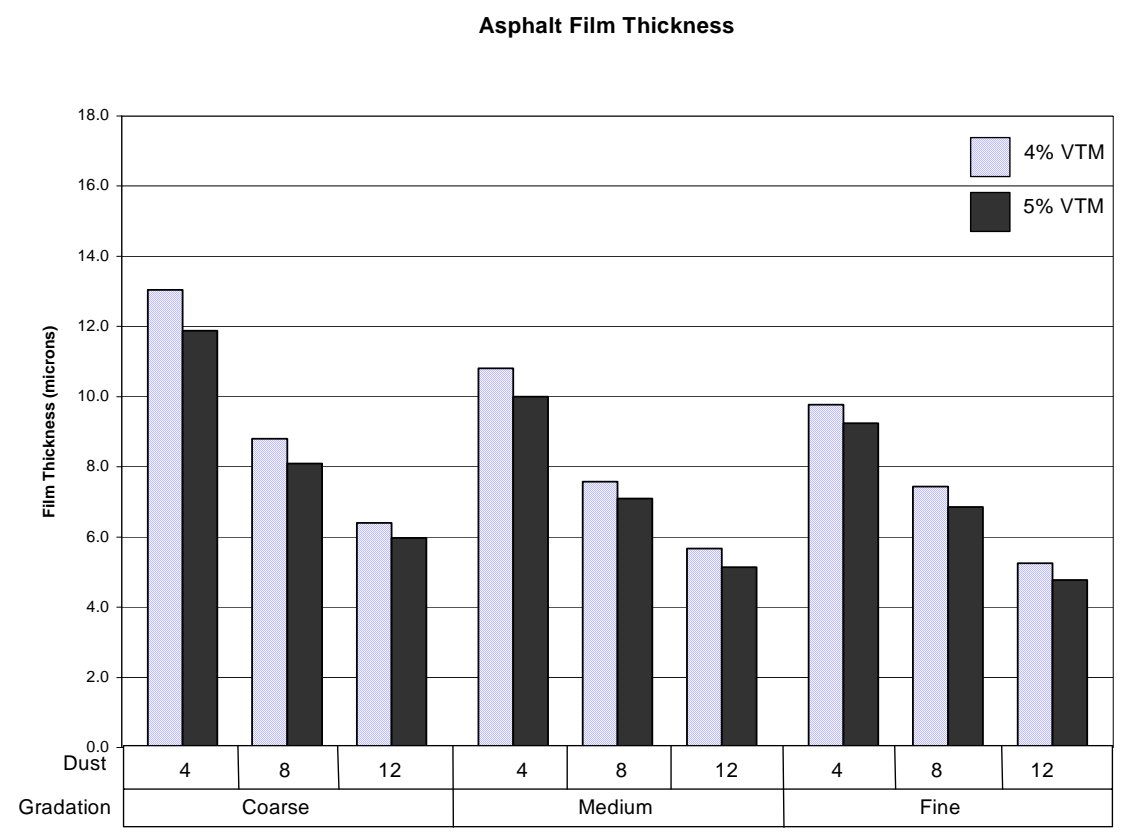

Figure 4.15 Range in asphalt binder film thickness

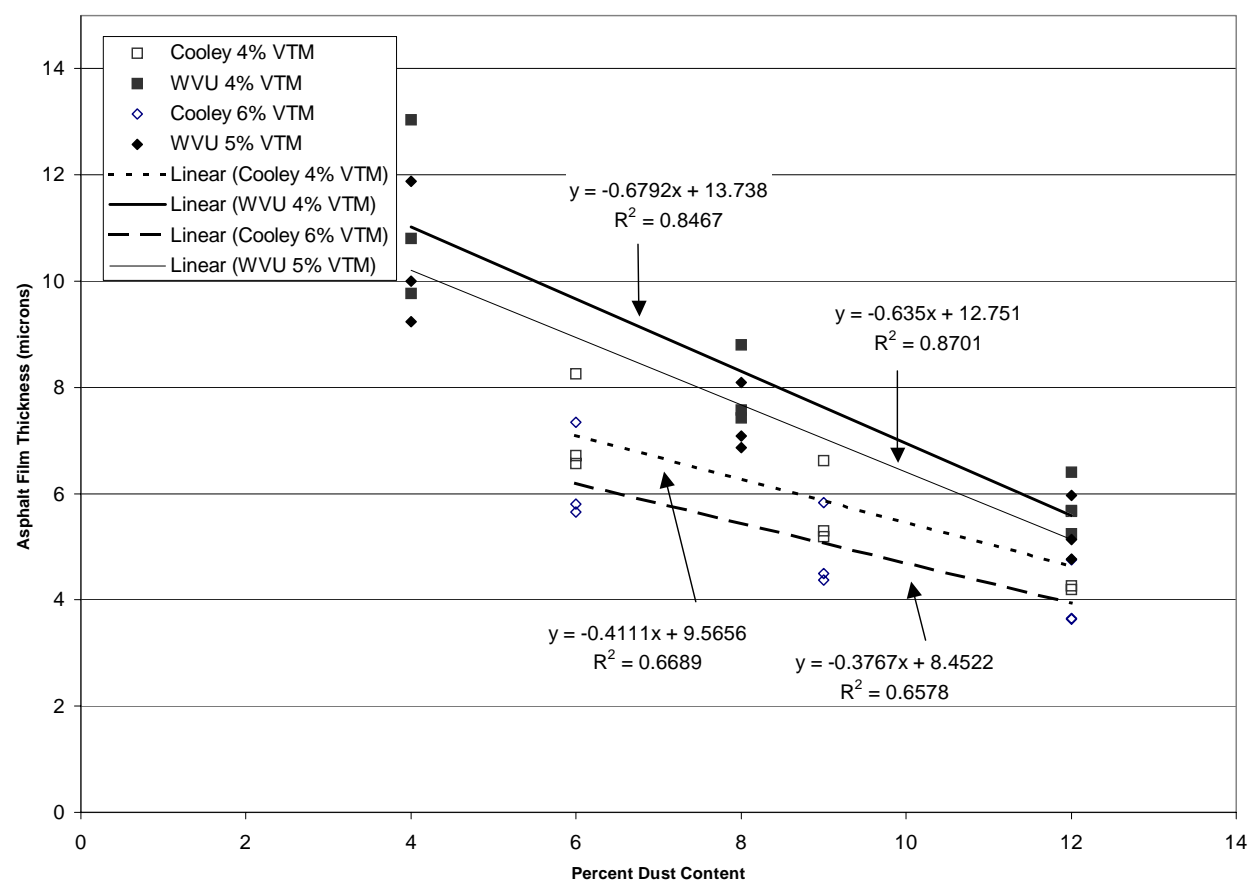

Figure 4.16 Trends in film thickness results 


\subsubsection{APA Rut Depth}

Rut depths obtained from the APA were affected by the three main factors, gradation shape, dust content, and design air content. Rut depth values ranged from 7.0 to $11.1 \mathrm{~mm}$, Figure 4.17. Gradation appeared to directly affect rut depth, with the medium gradation having the lowest values, $8.28 \mathrm{~mm}$, followed by the coarse, $8.81 \mathrm{~mm}$, and fine gradations, $10.04 \mathrm{~mm}$. When dust content was increased by 4 percent, rut depths increased an average $0.9 \mathrm{~mm}$. The trends in the data are shown in Figure 4.18. The Cooley data set is presented in Figure 4.19. Due to the different testing parameters used by Cooley, the rutting data are not directly comparable to the WVU data set. The range of rutting results measured by Cooley is much greater than in the WVU data set, and the same trends are not apparent in Cooley's data. The only consistent factor between the two data sets is the medium gradation in both studies had the least rutting.

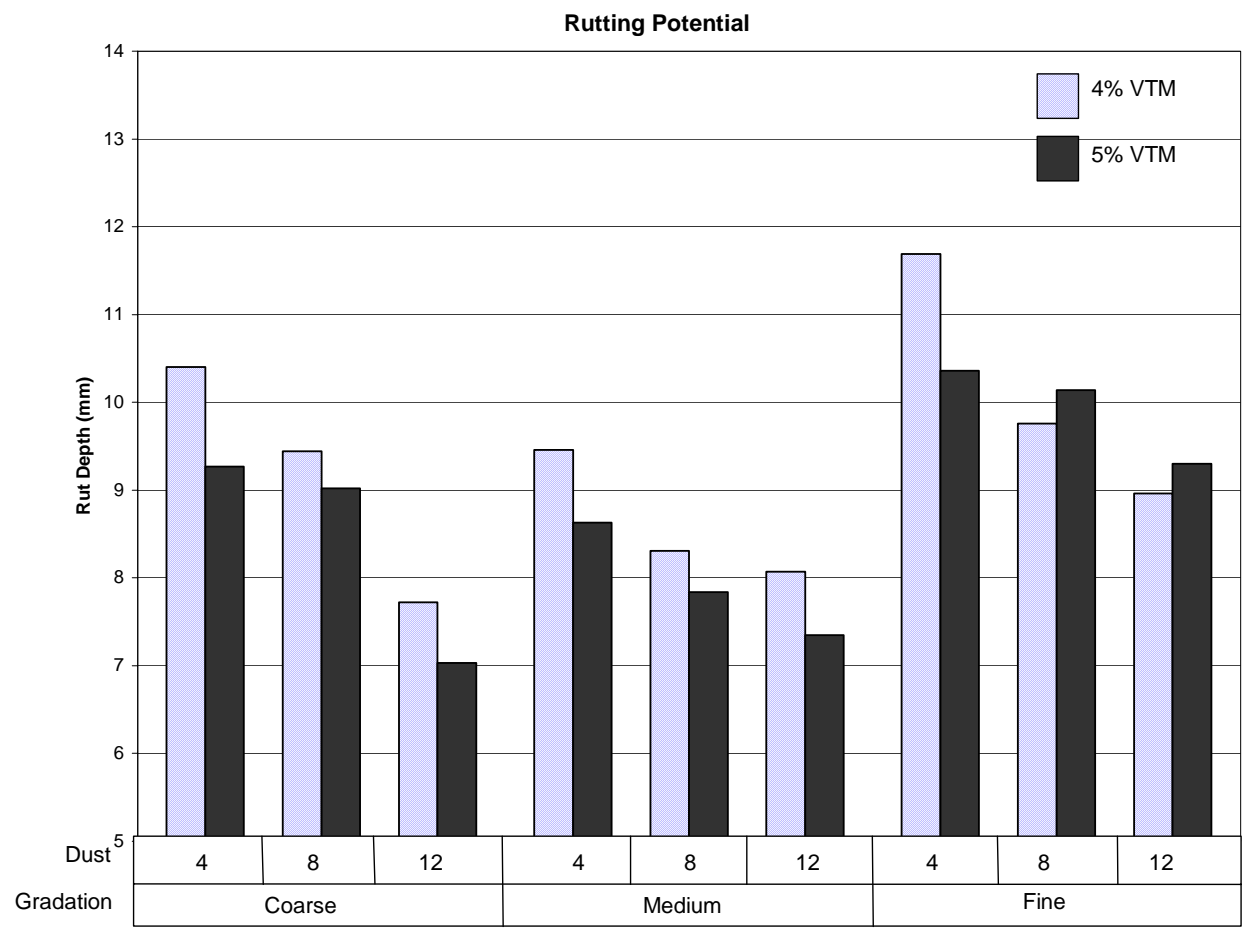

Figure 4.17 Result of Asphalt Pavement Analyzer testing 


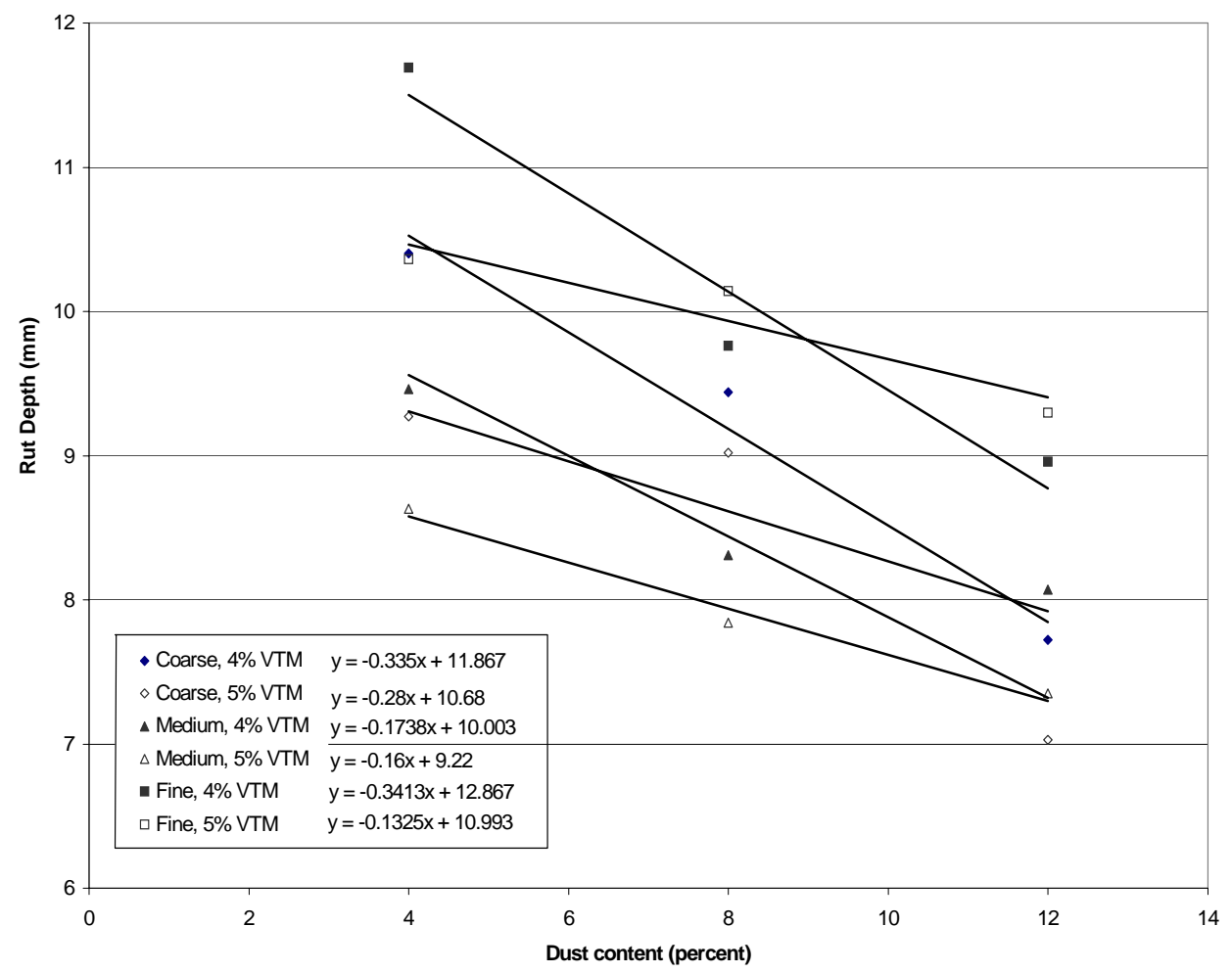

Figure 4.18 Trends in rut depth versus dust content

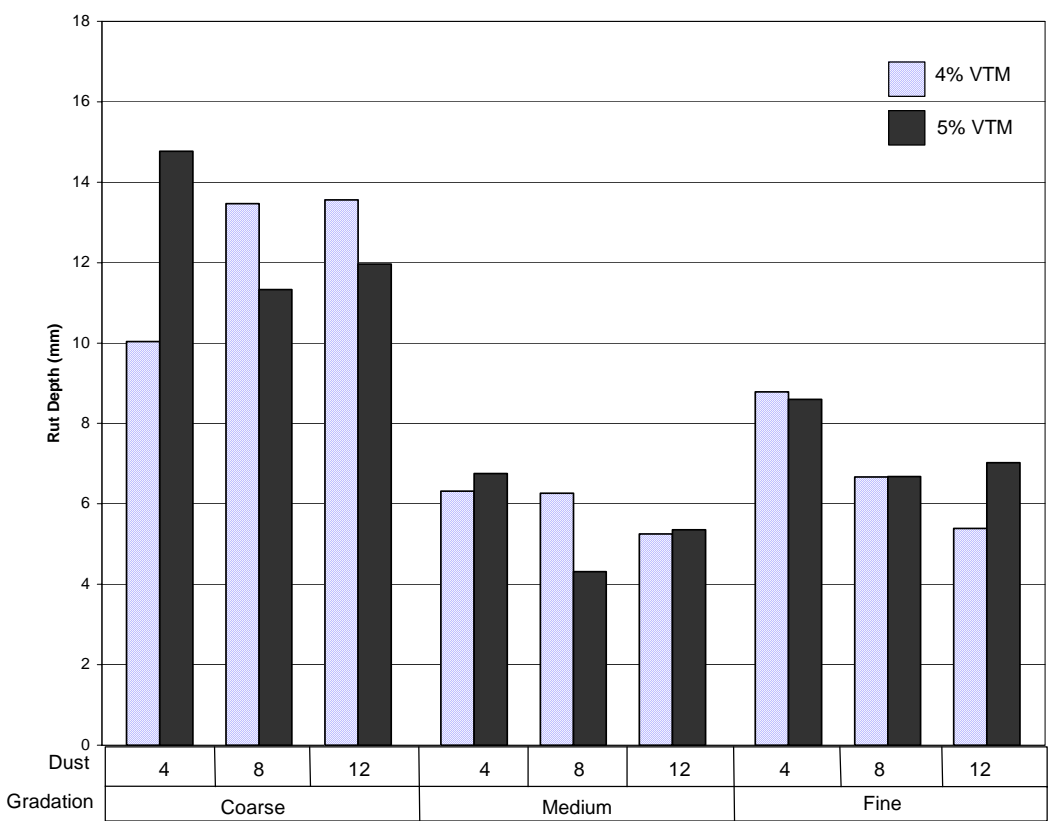

Figure 4.19 Range of rutting data, Cooley 


\subsubsection{STATISTICAL ANALYSIS}

An analysis of variance, ANOVA, was performed to evaluate the effects of main factors, gradation blend, dust content and design air voids and any interaction between them on the measured rutting potential. Figure 4.20 shows the output of SAS (Spector, 1993) analysis. The following factors and interactions were significant to 0.95 percent level:

- Gradation,

- Dust content,

- Air void content,

- Gradation * dust content, and

- Gradation * air void content.

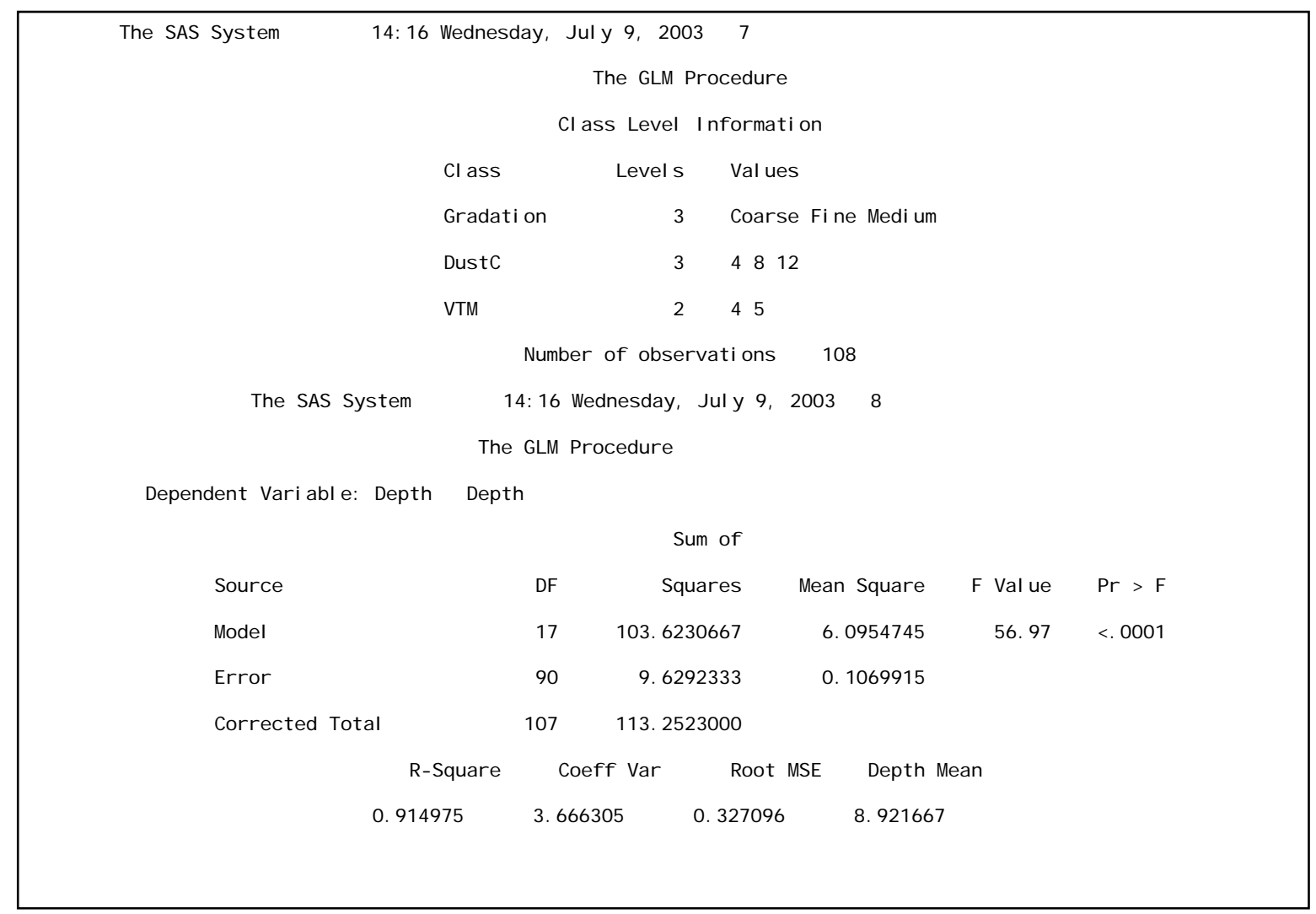

Figure 4.20 ANOVA of Phase I experiment 


\subsubsection{CRITERIA}

Based on the data available in this study, criteria could be evaluated for VTM, VMA, VFA, and $\mathrm{P}_{0.075} / \mathrm{P}_{\text {be }}$. The mixes used in this study had a wider gradation band than is allowed under the WVDOH Marshall specification, so recommendations could be developed for the gradation control points. The control points for dust, $\mathrm{P}_{0.075}$, could also be examined in the data set. \% $\mathrm{G}_{\mathrm{mm}} @ \mathrm{~N}_{\mathrm{ini}}$ and \% $\mathrm{G}_{\mathrm{mm}} @ \mathrm{~N}_{\max }$ were measured during the study, but none of the mixes studied had issues with passing the current Superpave parameters. Therefore, there was no basis for evaluating these parameters.

\subsubsection{Voids in the Total Mix}

Historically VTM has been fixed at four percent for mix design. This study evaluated mixes designed for both four and five percent VTM. Due to the mix design methodology, as VTM increases the optimum binder content decreases. This is undesirable for mixes designed for low volume roads where durability is of greater importance than rutting and fatigue characteristics. Based on the data collected during this research, there is no indication that increasing the VTM used for selecting the optimum asphalt content would improve the performance of the mix. This conclusion is supported by Cooley, et al. (2002a) wherein mixes with four and six percent VTM were evaluated.

\subsubsection{Voids in Mineral Aggregate}

VMA is a critical parameter in the Superpave mix design process as it controls the minimum asphalt content and asphalt film thickness (Kandhal, et al; 1998). Following approach used by Cooley, et al; (2002a) to evaluate a minimum criteria for VMA, the relationships between VMA and $\mathrm{P}_{0.075} / \mathrm{P}_{\text {be }}$, and VMA versus were analyzed.

Following Cooley's lead, a maximum dust to binder ratio was used as one of the criteria in determining the minimum VMA for a mix. Using the Georgia and Maryland specifications for maximum allowable percent material passing the $0.75 \mathrm{~mm}$ sieve and the minimum binder content allowed in a mix, the maximum dust to binder ratio was determined. Values of 2.0 and 2.4 were determined for the Georgia and Maryland mixes, respectively. Cooley used the average of these values, 2.2, to establish VMA criteria. 
The current supplement of the WVOH Standard Specifications Roads and Bridges manual does not specify an allowable range of asphalt contents. However, the 2000 version of the manual specified an asphalt range of 5 to 11 percent and the percent of aggregate passing the $75 \mu \mathrm{m}$ sieve was 3 to 11 percent. Using the minimum asphalt content and the maximum percent 0.075 material, yields a dust to binder ratio of 2.2. This ratio is based on the total binder content, rather than the effective asphalt content as prescribed with in Superpave. Although this calculation is convenient, and was used by Cooley, it cannot be implied that $4.75 \mathrm{~mm}$ NMAS mixes should be designed with this ratio of dust to asphalt content. The WVDOH Materials Procedure for the development of Marshall mixes, MP 401.02.22, limits the dust to binder (termed the fines-to-asphalt ratio in the MP) to 0.6 to 1.2 based on optimum asphalt content. The Materials Procedure for Superpave mixes has a dust to effective binder limit of 0.6 to 1.2 for mixes, unless the gradation falls below the restricted zone, coarse mixes, in which case the limits are 0.8 to 1.6 .

Due to the different definitions of the dust to binder ratio, it is necessary to have a basis for comparing the two ratios. Figure 4.21 shows the relationship between two methods for computing dust to binder ratio for the mixes used in this study. As expected, using the optimum binder content in the denominator yields lower dust to binder ratios than when effective binder content is used. Using the relationship on Figure 4.22, a dust to binder ratio of 2.2 based on optimum asphalt content would be the equivalent of a dust to binder ratio of 2.56 based on effective asphalt content. The upper limit of the Marshall dust to binder ratio of 1.6 based on optimum asphalt content would equal 1.86 under the Superpave definition that is based on effective asphalt content.

In selecting a VMA based on the dust to binder ratio, several candidate values are available:

Maximum Superpave value for fine mixes

Maximum Marshall value, adjusted for effective binder content 


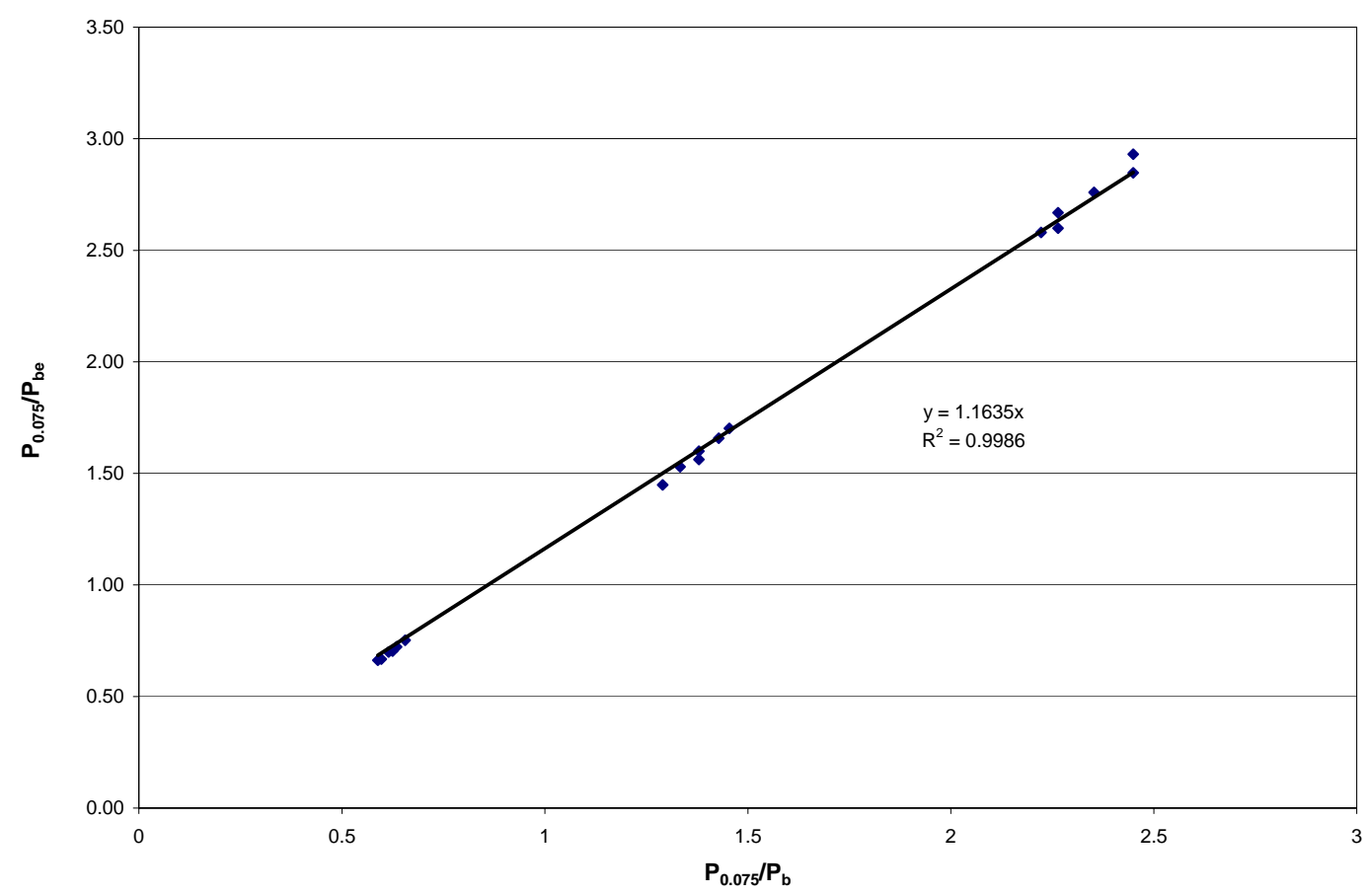

Figure 4.21 Relationship between dust to optimum content ratio and dust to effective asphalt content ratio

Figure 4.22 shows the relationships between dust to effective binder content and VMA and film thickness. The equations for the trend lines on Figure 4.22 were used to compute VMA and film thickness for each of the candidate dust to binder ratios, Table 4.1. The limit of 2.2 suggested by Cooley would yield a minimum VMA criterion of 15.3 percent and asphalt film thickness of 5.8 microns. Both these values are lower than current design practices and recommendations. A dust to effective binder ratio of 1.6 indicates a minimum VMA of 16.1 and a film thickness of 7.9 microns. This film thickness is in close agreement with Kandhal's recommendation for a minimum of 8 microns. The current Superpave dust to effective binder limit of 1.2 for fine mixes yields a VMA of 16.7 and a film thickness of 9 microns. Since $4.75 \mathrm{~mm}$ NMAS mixes are primarily intended for low volume roads, the higher film thickness, associated with a lower dust to effective binder ratio may be appropriate. 


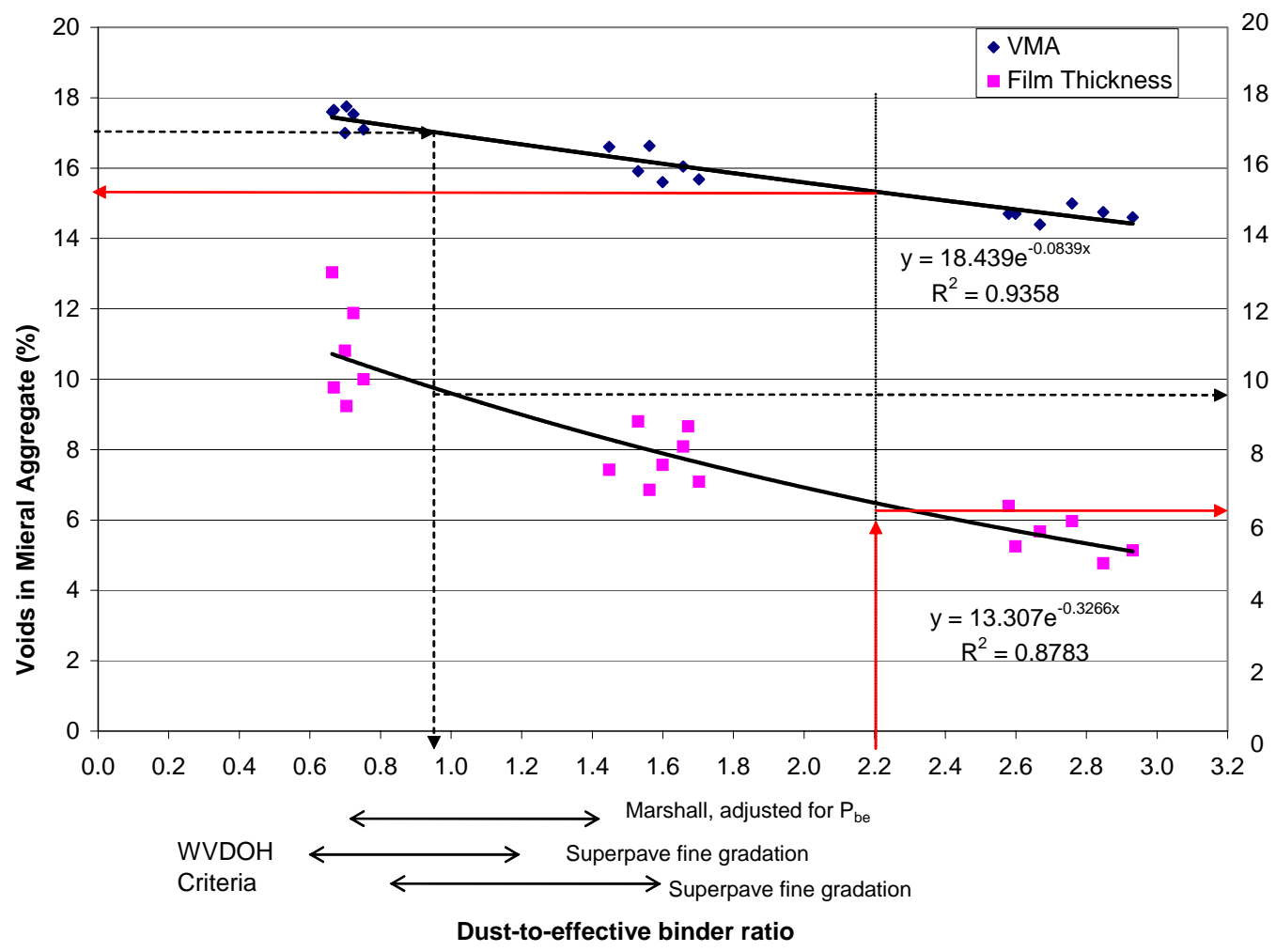

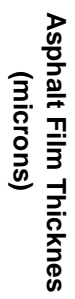

Figure 4.22 Relationship between voids in mineral aggregate, film thickness, dust to effective binder ratio

Table 4.1 Data for VMA criteria

\begin{tabular}{|c|c|c|}
\hline $\mathrm{P}_{0.075} / \mathrm{P}_{\mathrm{be}}$ & $\begin{array}{c}\text { VMA } \\
\text { (percent) }\end{array}$ & $\begin{array}{c}\text { Film Thickness } \\
\text { (microns) }\end{array}$ \\
\hline 1.2 & 16.7 & 9.0 \\
\hline 1.4 & 16.4 & 8.4 \\
\hline 1.6 & 16.1 & 7.9 \\
\hline 2.2 & 15.3 & 6.5 \\
\hline 2.56 & 14.9 & 5.8 \\
\hline
\end{tabular}

The current WVDOH VMA criteria for Wearing III mixes, which have a $4.75 \mathrm{~mm}$ NMAS, is a minimum 17 percent. Figure 4.22 shows for the mixes evaluated during Phase I, this would correspond to a maximum dust to effective binder ratio of 0.95 and a film thickness of 10 microns. 
For low to medium traffic designs, the Marshall compaction effort is 50 blows per side. Samples in this research were prepared with 50 gyrations. If the compactive energy of the Superpave gyratory compactor is greater than the Marshall hammer, then the optimum asphalt contents obtained during Phase I are lower than they would be for the Marshall method. This would contribute to a lower VMA. Hence, the Marshall minimum criteria is probably too high for a Superpave mix designed at 50 gyrations.

Based on the above factors, it appears that a minimum VMA of 16 is appropriate for 4.75 mm NMAS mixes designed with 50 gyrations. This is also Cooley's recommendation; however, that was for mixes designed with 75 gyrations.

The minimum VMA criteria effectively establishes the minimum effective binder content of a mix. Mixes with too much asphalt can also exhibit poor performance. Generally, the maximum asphalt content is controlled by the maximum allowable VFA. Since VMA and VFA are related, Equation 2.9, and VTM is fixed at four percent in the design criteria, the maximum binder content could be established using either VMA or VFA.

\subsubsection{Voids Filled with Asphalt}

Too much binder in an asphalt mix leads to potential rutting problems. So the rut depth data were analyzed to determine if a maximum VFA criteria could be established from the Phase I mixes. Following Cooley's approach, and using a $9.5 \mathrm{~mm}$ critical rut depth value for the APA, as suggested in Table 2.15, the corresponding VFA was determined as shown in Figure 4.23. For the mixes designed to four percent air voids, the VFA that corresponds to the critical rut depth criterion is 76 percent. This corresponds to a VMA of 16.6. A minimum VMA restriction of 16 percent would be a very restrictive criterion and is not practical for mix design.

Rutting is generally not critical for low volume roads, so the critical rut criteria could be relaxed. There is currently no basis for establishing criteria. Therefore, there is no basis for changing the maximum VFA criteria, which are 80 and 78 for the Superpave and Marshall, respectively. Since West Virginia uses a medium Marshall design for low volume roads, a maximum VFA of 78 may be too restrictive for the design of mixes for 


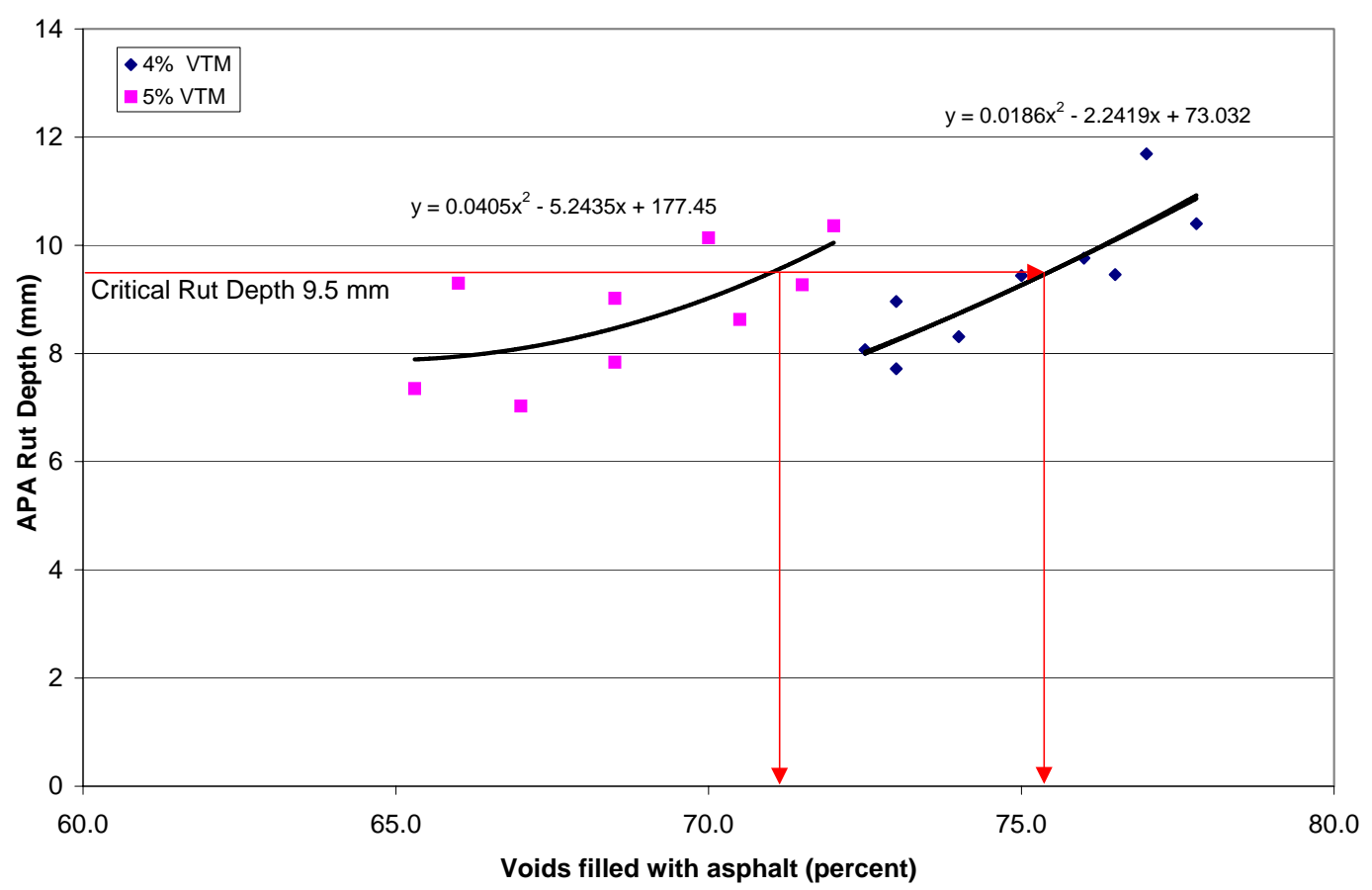

Figure 4.23 Rut depth versus voids filled with asphalt

low volume roads. Therefore, the current Superpave practice of a maximum of 80 percent for VFA is recommended.

\subsubsection{4 $\mathrm{P}_{0.075} / \mathrm{P}_{\mathrm{be}}$}

The minimum VMA criterion was established for a $\mathrm{P}_{0.075} / \mathrm{P}_{\text {be }}$ ratio of 1.6 , so for consistency in the recommendations, this value must be specified as the maximum $\mathrm{P}_{0.075} / \mathrm{P}_{\text {be }}$. Low $\mathrm{P}_{0.075} / \mathrm{P}_{\text {be }}$ values are associated with "rich" mixes, which in turn would be associated with rutting. Figure 4.24 shows the relationship between rut depth and $\mathrm{P}_{0.075} / \mathrm{P}_{\text {be }}$. At the recommended critical rut depth, the dust to binder ratio is 1.2. However, there is too much scatter in the data to allow development of a firm recommendation. If the critical rut depth was increased to $10 \mathrm{~mm}$, a minimum dust to binder ratio of 0.6 to 0.7 would be recommended. This suggests that the current Superpave criterion for fine mixes of 0.6 is reasonable. 


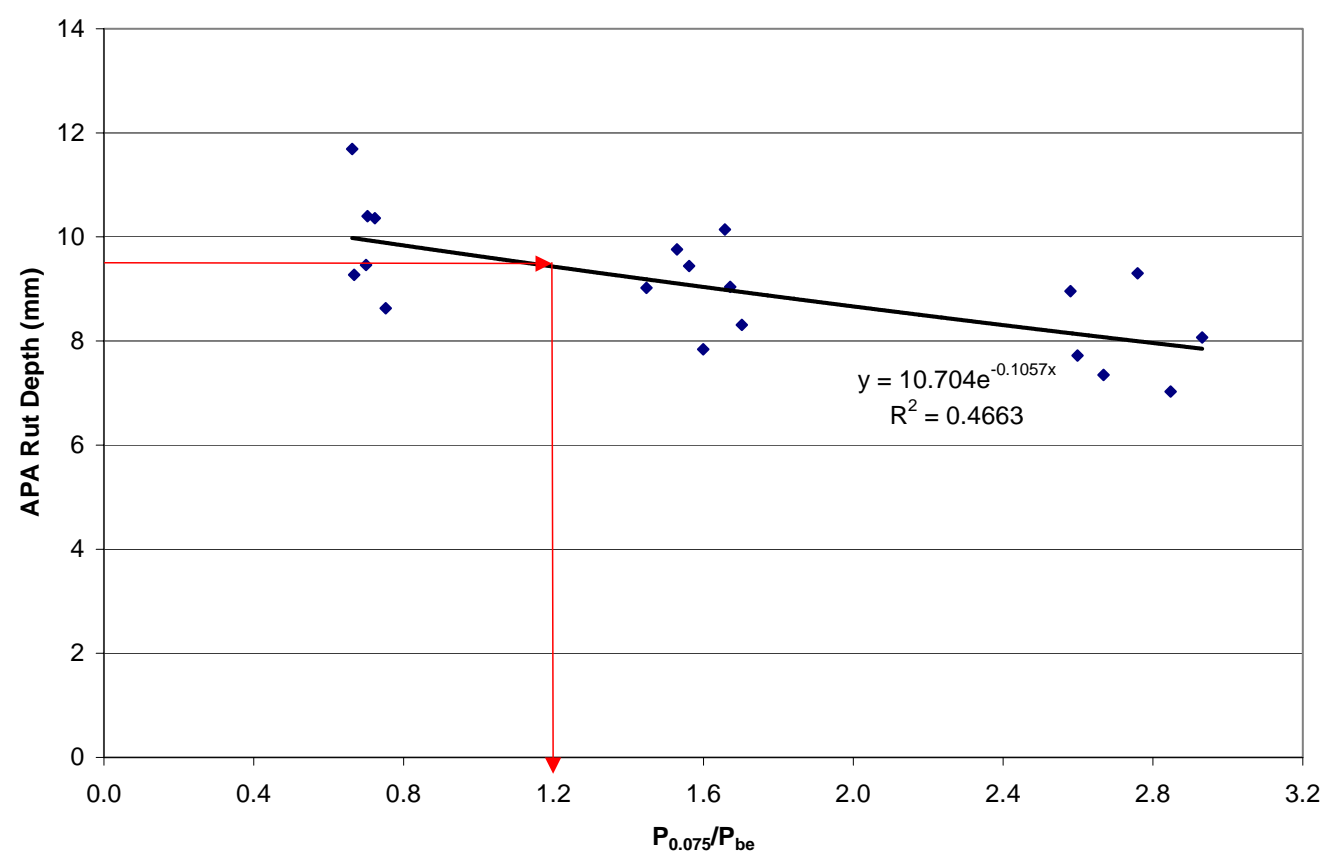

Figure 4.24 Development of minimum P0.075/Pbe criteria.

\subsubsection{Gradation Control Points}

When reviewing the control points used in this study, no evidence of gradation issues were founded. This result suggests that the lower limit for the $1.18 \mathrm{~mm}$ sieve could be decreased from 40 to 30 percent. Mixes were successfully designed with 30 percent material passing the $1.18 \mathrm{~mm}$ sieve. Cooley also recommended this gradation limit.

Figure 4.6 shows mixes with 12 percent dust had unacceptable values of VMA. Cooley's data shows a similar result for limestone mixes. However, some of the granite mixes studied by Cooley were acceptable with 12 percent dust. The Marshall specification allows 3 to 11 percent dust. There were no data from the Phase I study to suggest a need to alter these control points.

\subsubsection{Summary of Mix Design Recommendations}

The recommended mix design parameters for a $4.75 \mathrm{~mm}$ NMAS mix are given in Table 4.2. 
Table 4.2 Mix design requirements

\begin{tabular}{|c|c|c|c|c|}
\hline \multicolumn{5}{|c|}{ Volumetric Mix Design Criteria } \\
\hline \multicolumn{3}{|l|}{ Design Air Voids } & \multicolumn{2}{|c|}{4.0} \\
\hline \multicolumn{3}{|c|}{ Fines to effective asphalt ratio } & \multicolumn{2}{|c|}{$0.6-1.6$} \\
\hline \multicolumn{3}{|c|}{ Tensile strength ratio ( AASHTO T283) } & \multicolumn{2}{|c|}{$80 \%$ minimum } \\
\hline \multicolumn{3}{|c|}{ Minimum Voids in Mineral Aggregate (VMA) \% } & \multicolumn{2}{|c|}{16.0} \\
\hline \multirow{2}{*}{$\begin{array}{l}\text { Design ESALs } \\
\text { (millions) }\end{array}$} & \multicolumn{3}{|c|}{ Percent of Theoretical Maximum Specific Gravity } & \multirow{2}{*}{$\begin{array}{l}\text { Percent Voids } \\
\text { Filled With } \\
\text { Asphalt }\end{array}$} \\
\hline & $\mathrm{N}_{\text {initial }}$ & $\mathrm{N}_{\text {design }}$ & $\mathrm{N}_{\max }$ & \\
\hline$<0.3$ & $\leq 91.5$ & 96 & $\leq 98.0$ & $75-80$ \\
\hline \multicolumn{5}{|c|}{ Gradation } \\
\hline Sieve size & 9.5 & 4.75 & 1.18 & 0.075 \\
\hline Percent Passing & 100 & $90-100$ & $30-60$ & $3-11$ \\
\hline
\end{tabular}

\subsection{COMPARISON OF MARSHALL AND SUPERPAVE 4.75 mm MIXES}

Three WVDOH-approved $4.75 \mathrm{~mm}$ NMAS mix designs were verified in the Asphalt Technology Laboratory. The blend proportion and resulting optimum asphalt content and volumetric parameters for each mix are summarized in Table 3.8. The aggregate structure from each of these mixes was then used to develop Superpave mix designs. The optimum asphalt content and volumetric parameters of these mixes are presented in Table 3.10. All of the volumetric parameters for each of the mixes meet the recommendations presented in Table 4.2, with the exception of the voids in the mineral aggregate for the mix with 45 percent natural sand, Design 2. The VMA of this mix was 15.8, which is slightly less than the minimum of 16 percent. It was decided to keep this mix in the research to see if the low VMA could be associated with poor performance of the mix.

Figure 4.25 shows the Superpave mixes have a lower optimum asphalt content than the Marshall mixes, the average reduction is about 0.8 percent. The difference in the optimum asphalt content between the Marshall and Superpave methods was greater for the natural sand mixes than for the limestone fine aggregate mixes. The lower optimum 


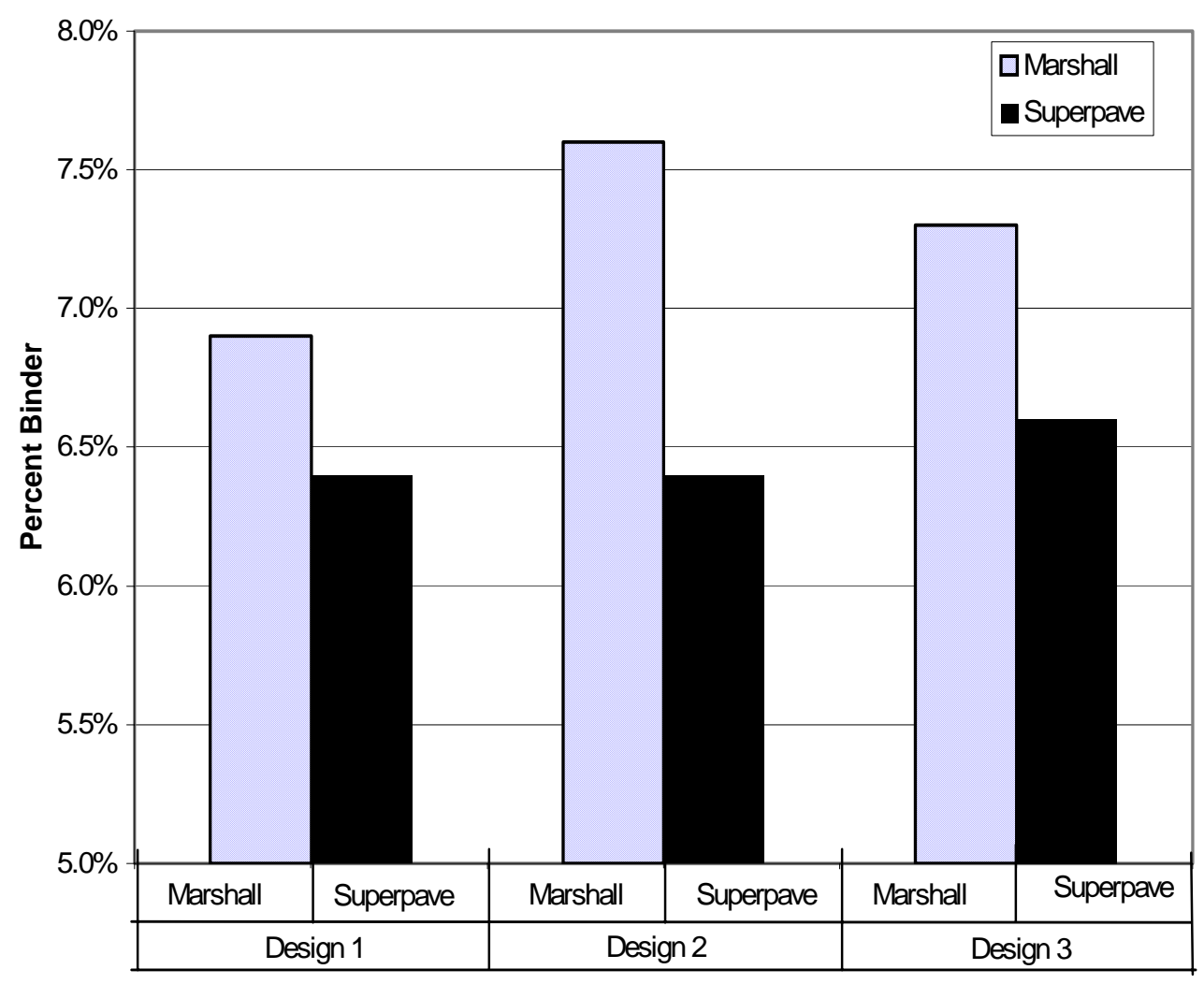

Figure 4.25 Comparison of Superpave and Marshall optimum asphalt contents asphalt content of the Superpave mixes indicates SGC at 50 gyrations for $\mathrm{N}_{\mathrm{des}}$ is applying more compaction energy than the Marshall hammer at 50 blows.

Figure 4.26 shows the Superpave mixes also had lower VMA, ranging from 15.8 to 17.3 percent, than the equivalent Marshall mixes, which ranging from 17.9 to 18.2 percent. The VMA of the Marshall mixes was fairly consistent across the three aggregate blends, and the Marshall mix with the greatest amount of natural sand had the highest VMA. This is counter intuitive as one would associate a high sand content with a mix that has lower interparticle friction, and therefore a greater collapse of the void structure during compaction. On the other hand, the Superpave mixes behaved as one would expect, the limestone fine aggregate mix had the highest VMA and the mix with the greatest amount of natural sand had the lowest VMA. Although the data set is not large enough to draw firm conclusions, the available data supports a hypothesis that the shearing action during SGC compaction is efficiently orienting the aggregate into a dense configuration. 
Figure 4.27 shows the trends in the VFA results. As expected, the VFA shows the same trends as the VMA. This is expected since the VTM for the mix design was a constant four percent and therefore VMA and VFA are mathematically linked as shown in Equation 2.9.

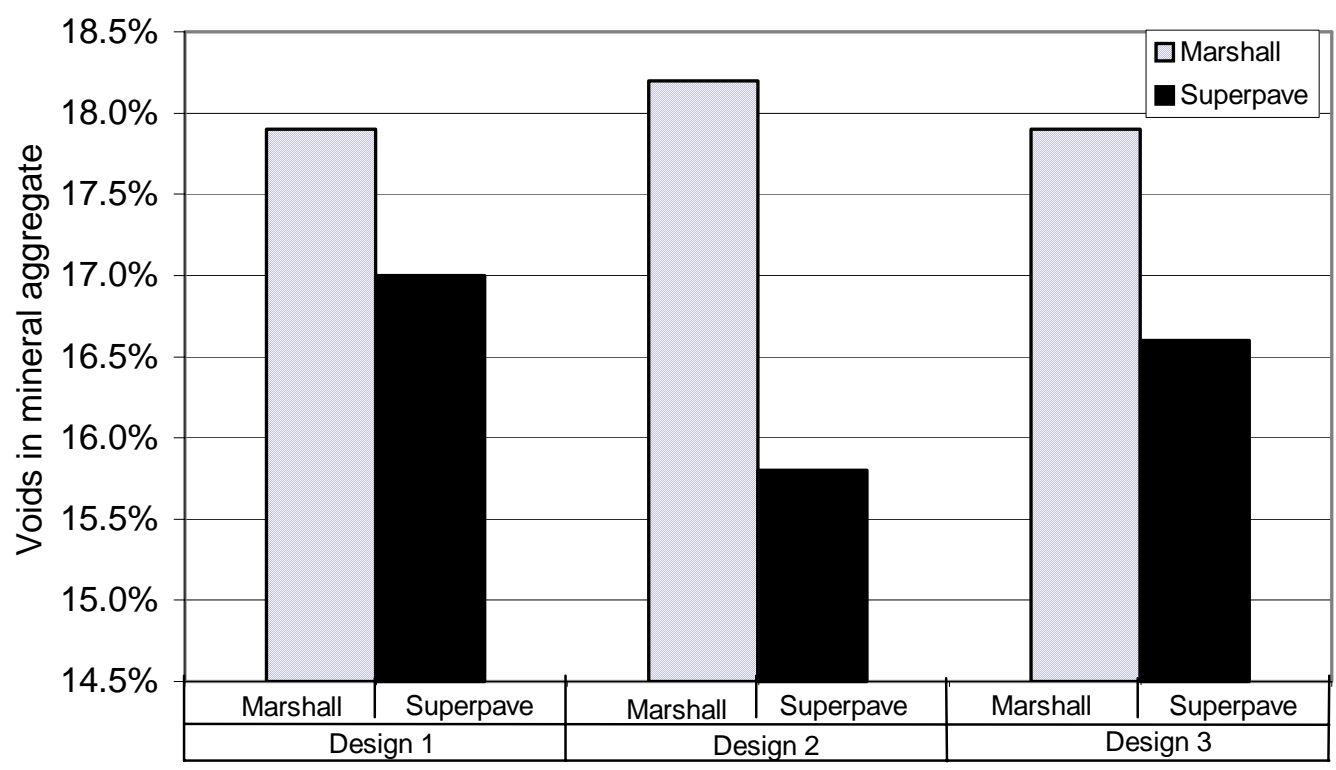

Figure 4.26 Comparison of voids in mineral aggregate for Marshall and Superpave mixes

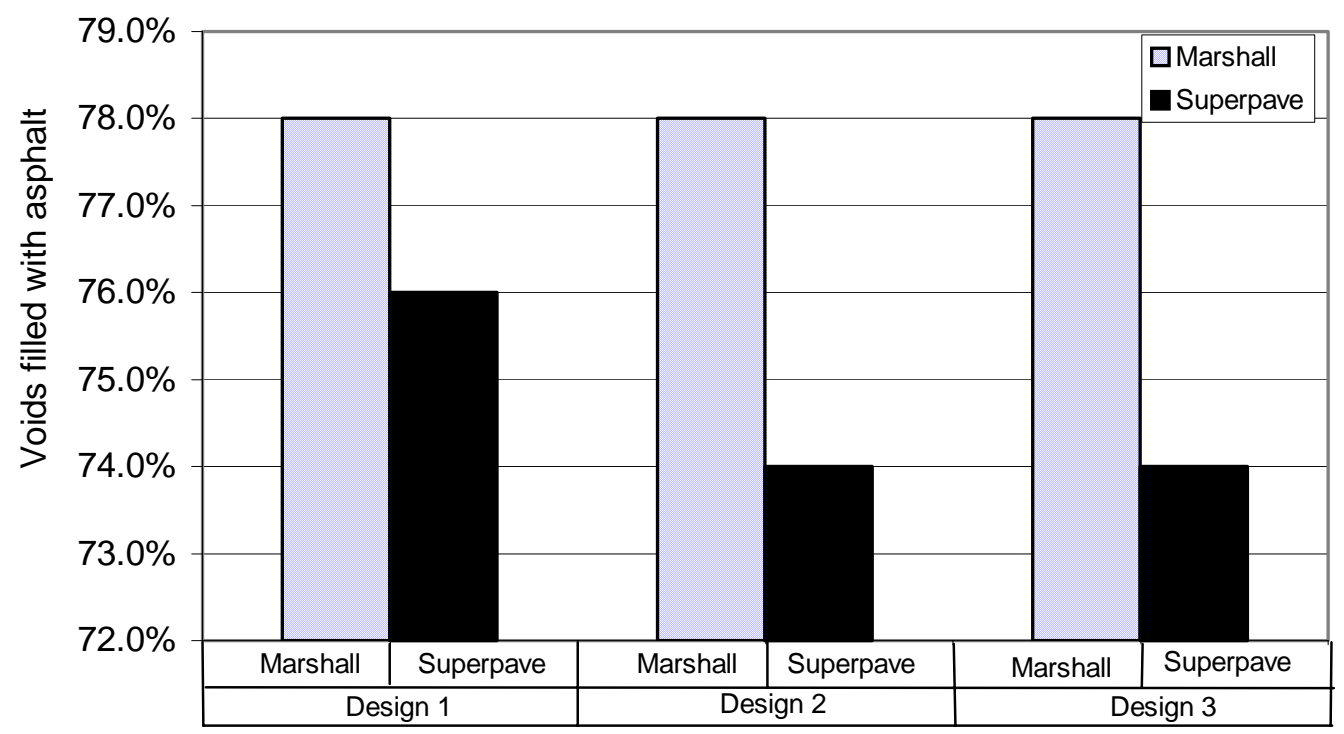

Figure 4.27 Comparison of voids filled with asphalt for Marshall and Superpave mixes 
Figure 4.28 shows values for asphalt film thickness for both Superpave and Marshall mixtures. In general Marshall mixtures show values higher than Superpave mixture. This is expected since Marshall mixtures have higher optimum asphalt contents. All mixtures appear have acceptable values for asphalt film thickness ranging from 7.7 to 11.5 microns.

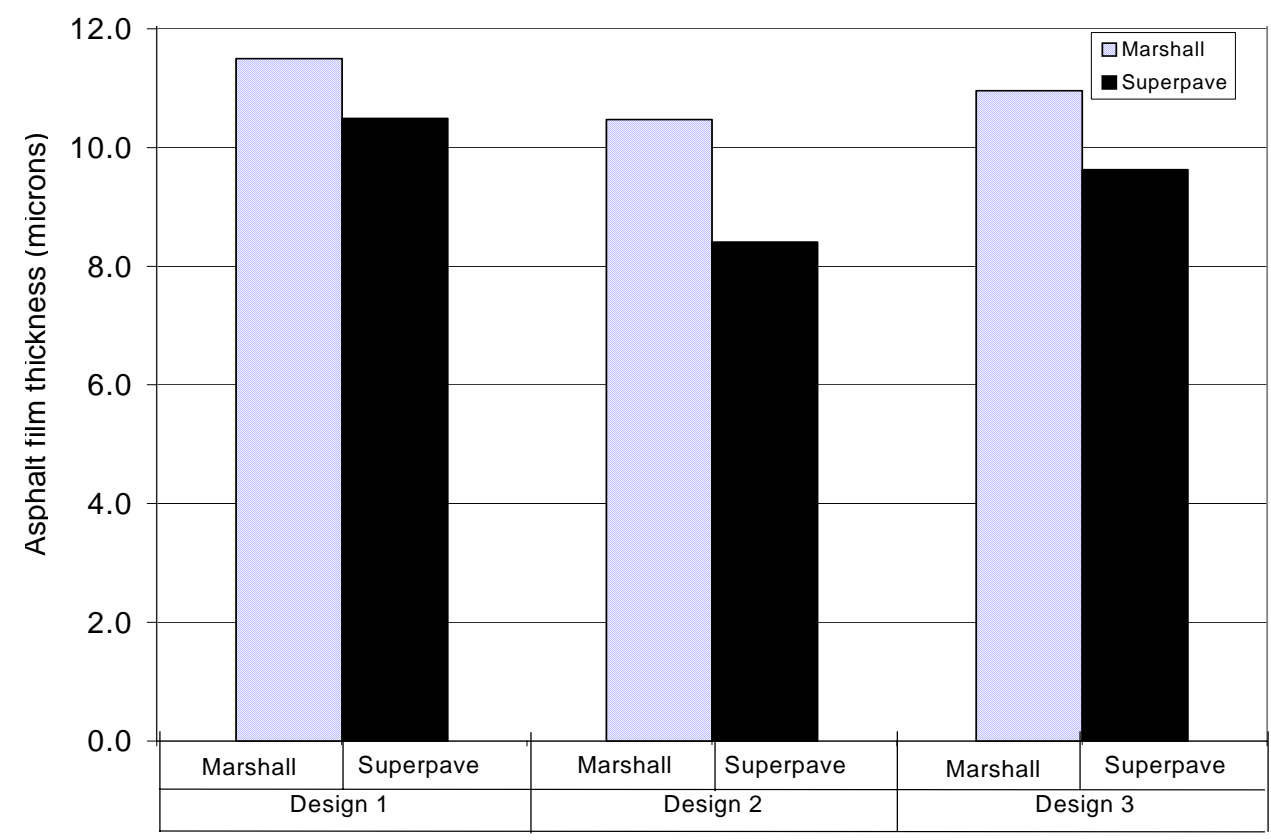

Figure 4.28 Comparison of film thickness for Marshall and Superpave mixes

The differences in the optimum asphalt content and associated volumetric parameters of this study are consistent with the literature. These differences are often associated with the differences in the compaction characteristics between the SGC and the Marshall hammer. Evaluation of differences in the compaction characteristics of the two methods was not an objective of this research. However, it was possible to analyze the SGC compaction data to estimate a number of gyrations that would produce the same optimum asphalt content as the Marshall method. This involved using the heights measured during compaction of the Superpave samples and Equation 2.19, plots of $\% \mathrm{G}_{\mathrm{mm}}$ versus gyration number prepared for each mix and each asphalt content. Using 96 percent $\mathrm{G}_{\mathrm{mm}}$ and the optimum asphalt content from the Marshall designs, the number of gyrations that provide the same compactive effort as the Marshall method could be estimated. Figure 4.29 shows this process for each of the mixes. The number of 
gyrations needed to select the same optimum asphalt content as the Marshall mixes would be 36,21 , and 34 , for the three mixes.

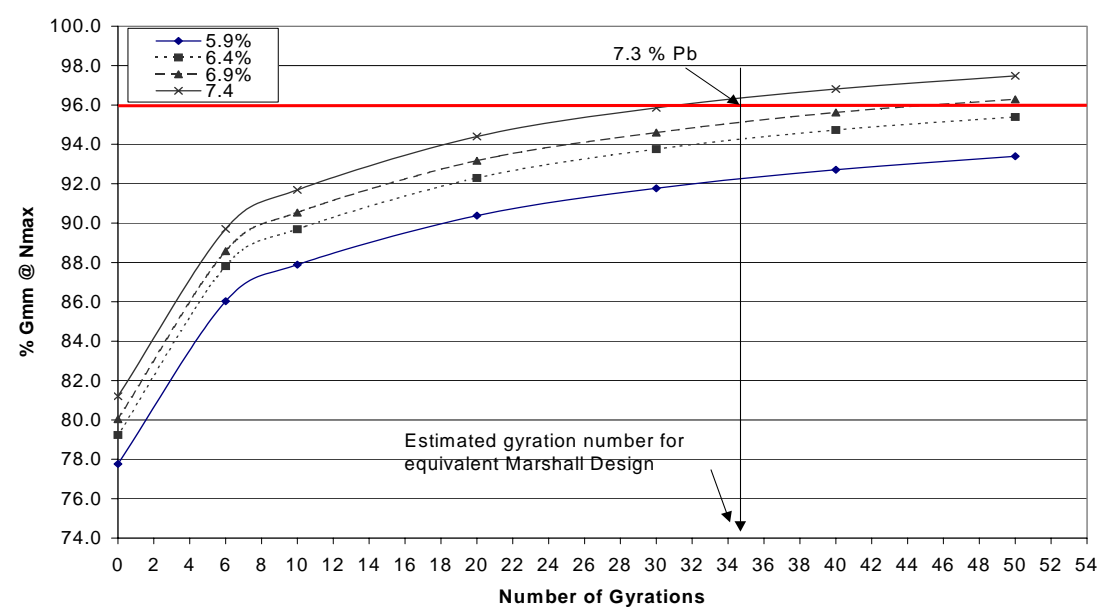

(a)

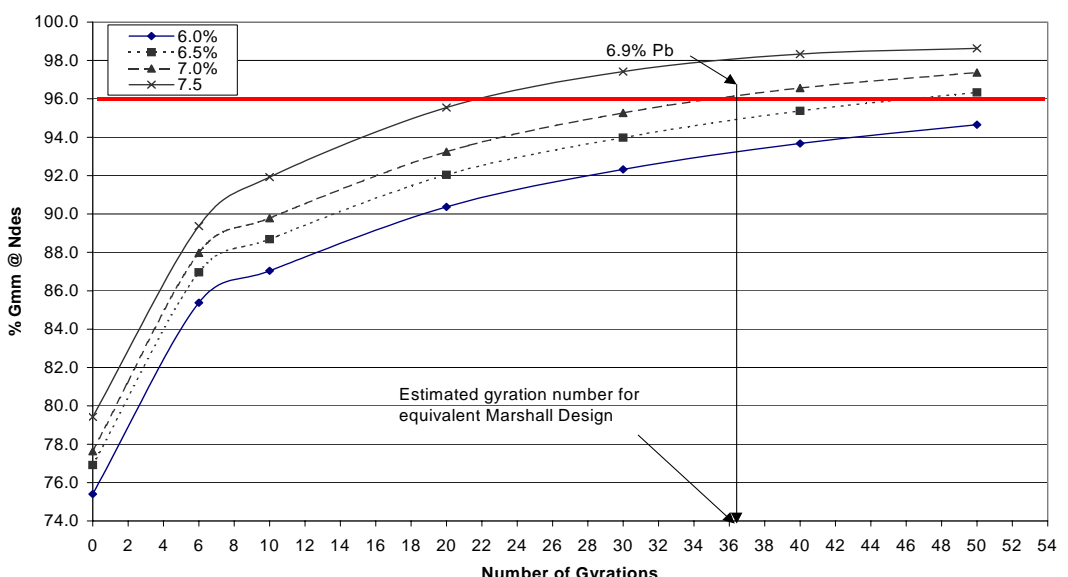

(b)

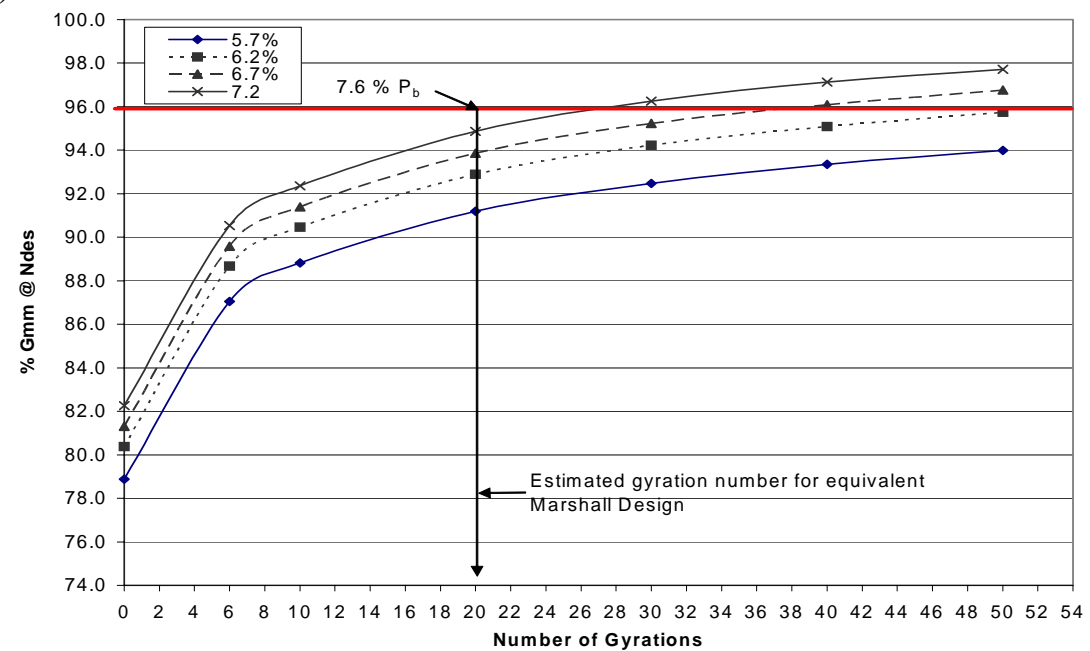

(c)

Figure 4.29 Compaction characteristics of Phase II Superpave mixes 
The rutting potential of the three Superpave mixes was evaluated with the APA. The results are presented in Table 3.10. Design 1, with 100 percent limestone had a rutting of $9.56 \mathrm{~mm}$. This is comparable to the rutting potential of the mixes evaluated in Phase I. Design 2 and 3, with natural sand had a rutting potential of more than 22.3 and $19.9 \mathrm{~mm}$, respectively. This is an undesirable level and indicates a strong potential that these mixes would rut if placed in a pavement that carried even a moderate level of truck traffic. The rutting potential of the Phase II Marshall mixes was not evaluated. Their optimum asphalt contents were considerably greater than the Superpave mixes, and therefore it can be anticipated that their rutting potential would be even greater. Figures 4.30 and 4.31 show typical rut depths for 100 percent limestone fine samples and 60 percent limestone fines, 40 percent natural sand, respectively.

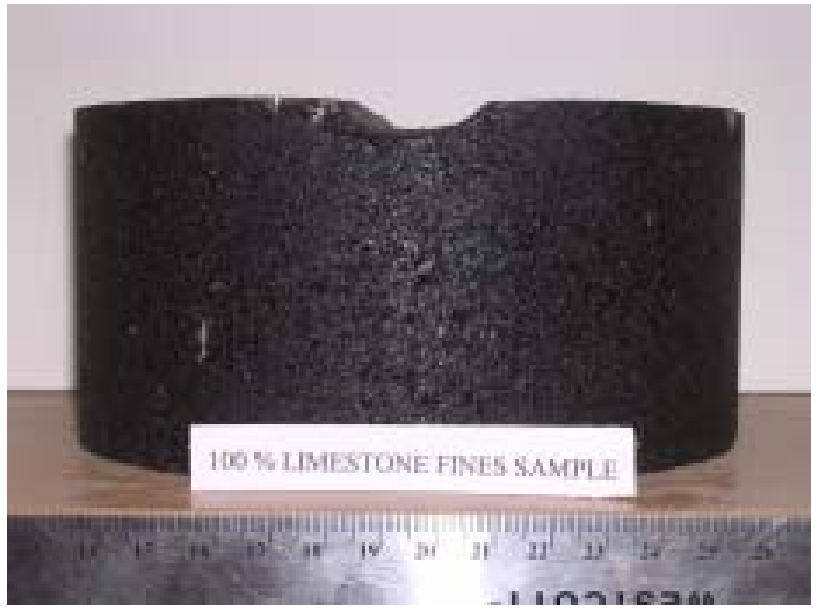

Figure 4.30 Typical rut depth for 100 percent limestone sample

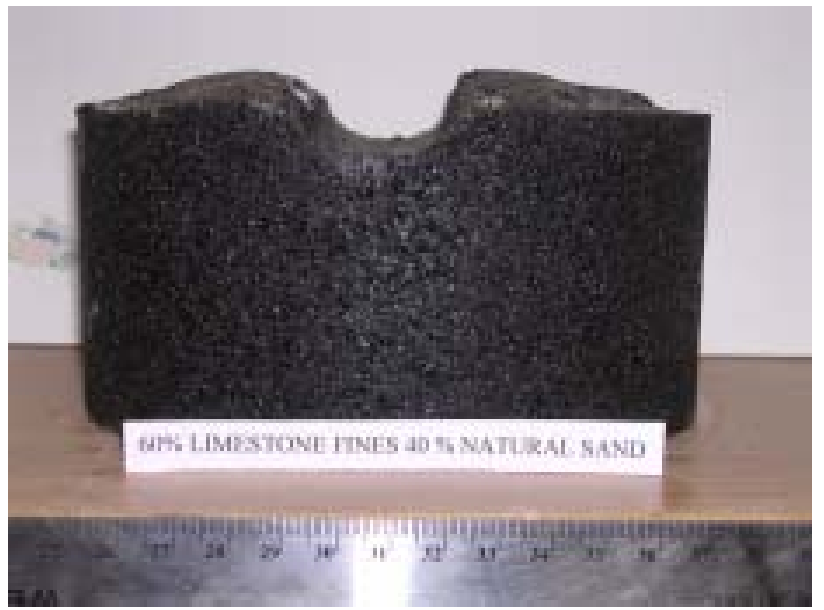

Figure 4.31 Typical rut depth for 60 percent limestone 40 percent natural sand sample 


\section{CHAPTER 5 CONCLUSIONS AND RECOMMENDATIONS}

\subsection{CONCLUSIONS}

Although, currently, there is not a Superpave standard specification for designing $4.75 \mathrm{~mm}$ NMAS mixes, research work and field experience from some DOTs have allowed proposing possible design parameters for these mixes. Based on Superpave methodology, volumetric parameters where selected as a study parameters. The evaluation of these parameters in this research suggests that national implementation of a Superpave criteria for $4.75 \mathrm{~mm}$ NMAS could be established. Locally, the implementation of a criteria for $4.75 \mathrm{~mm}$ NMAS mixes allows for full implementation of the Superpave mix design method for all West Virginia projects.

Mix design results from the Phase I of this research suggest that $4.75 \mathrm{~mm}$ NMAS limestone Superpave mixes were successfully designed in the laboratory for a variety of gradations and dust content mixes. Recommended mix design parameters were developed from these mixes. All of the evaluated design parameters displayed logical trends or were consistent with existing criteria for other mix types.

It is important to note that durability, and not rutting or fatigue, is the main distress addressed for mixes for low volume roads. As a result, greater binder contents are expected relative to mixes designed for high or medium traffic levels. For a given aggregate type and gradation, the optimum asphalt content is primarily a function of the number of gyrations used to compact the samples for determining the bulk specific gravity. In this research, a compaction effort of 50 gyrations was used for Superpave mixes and 50 blows for Marshall mixes. The Superpave mixes had lower optimum asphalt contents than the Marshall mixes. The available data indicates comparable asphalt contents would be achieved using approximately 30 to 35 gyrations for the Superpave mix design process.

Results from the laboratory evaluation using the Asphalt Pavement Analyzer showed gradation, dust content, and voids in total mix affect rutting potential. These results suggest APA can be used as a economical means for comparing the relative performance of Superpave mixes 
Both the Marshall and Superpave mix design methods use VMA to ensure a minimum asphalt content. However, VMA is an indirect measure of effective asphalt content. To remain consistent with current mix design practices a VMA criteria were developed using asphalt film thickness. However, this raises the question of why should an indirect parameter be used when a direct indicator of desired asphalt content is available. Kandhal, et al. (1998) have suggested the use of film thickness as a mix design parameter. The manner of using asphalt film thickness to establish VMA criteria is consistent with Kandhal's suggestion.

Phase II of this research demonstrated that natural sand aggregate could be used as HMA aggregate for low traffic volume mixes when blended with crushed aggregate. A mix blend of 40 percent natural sand and 60 percent crushed limestone was successfully designed under the proposed Superpave criteria. It should be noted that the rutting potential of the mixes with natural sand was much greater than the rutting potential of the mixes with 100 percent crushed material. Rutting potential is generally not an issue for mixes designed for low traffic volume roads, as studied during this research. However, if the results from this research are extrapolated to the design of mixes for higher traffic highways, rutting potential could be a significant issue.

\subsection{RECOMMENDATIONS.}

The evaluation of the criteria in this research was limited to single sources of crushed limestone and natural sand and a single type and source of binder. Similar studies should be conducted on a larger variety of aggregate and binder types to establish more robust confidence in Superpave mix design criteria proposed from this research.

Further evaluation of the Superpave gyratory compactor, SGC, for mixes designed for less than 0.3 million ESALs should be performed to evaluate the suitability of the current Superpave compactive effort requirements for this design traffic mixes.

The gradation limits used in this research produced acceptable mixes. However, more extensive research is needed to verify the gradation control point limits recommended from this research. 
Field verification for different applications should be conducted to monitor the performance of these mixes prior to adopting a final standard for $4.75 \mathrm{~mm}$ NMAS Superpave mixtures. A greater variety of mixes containing natural sand should be used to compare Marshall and Superpave $4.75 \mathrm{~mm}$ NMAS mixes in order to clearly establish the role of natural sand on mixture performance. Since aggregate properties vary from source to source a variety of natural sand sources, with a range of FAA values, should be studied. 


\section{REFERENCES}

1. Anderson, D. Guidelines for the Use of Dust in Hot-Mix-Asphalt Concrete Mixtures, Proceedings of the Association of Asphalt Paving Technologists, Vol 56, pp. 492-516, 1987.

2. Amirkhanian S.N., Development of a Gyratory Design for Conventional SCDOT Hot Mixed Asphalt Mixtures, Report No. FHWA-SC-01-05. South Carolina Department of Transportation. Columbia S.C., June, 2001.

3. Asphalt Institute, Mix Design Methods for Asphalt Concrete and Other Hot Mix Types, MS-2, Sixth Edition, Lexington KY, 1993.

4. Brown E. R., and M.S. Buchanan, Consolidation of the $N_{\text {design }}$ Compaction Matrix and Evaluation of Gyratory Compaction Requirements, NCHRP Web Document 34 Project D9-9[1]: Contractor's Final Report, National Cooperative Highway Research Program, January, 2001.

5. Campen W.H., J.R. Smith, L.G. Erickson, and L.R. Mertz, "The Relationships Between Voids, Surface Area, Film Thickness and Stability in Bituminous Paving Mixtures. Proceedings, Association of Asphalt Paving Technologists, Vol 28, 1959.

6. Chadbourn B.A., E.L. Skok. Jr., D.E. Newcomb, B. L. Crow, and S. Spindler. The Effect of Voids in Mineral Aggregate (VMA) on Hot-Mix Asphalt Pavements, Minnesota Department of Transportation, St. Paul, Minnesota, 1999

7. Cooley L.A, Jr., M.H. Huner and E.R. Brown, Use of Screenings to Produce HMA Mixture, NCAT Report No. 02-10, National Center for Asphalt Technology, Auburn, AL., October, 2002a.

8. Cooley, L.A. Jr., R.S. James and M.S. Buchanan, Development of Mix Design Criteria for $4.75 \mathrm{~mm}$ Superpave Mixes, NCAT Report No. 02-04. National Center for Asphalt Technology, Auburn, AL., February, 2002b.

9. Coree B.J., W.P. Hislop, The Difficult Nature of Minimum VMA: A Historical Perspective, Iowa State University, Ames, Iowa. 1998.

10. Craus, J., and I. Ishai, A Method for Determination of the Surface Area of Fine Aggregates in Bituminous Mixtures, ASTM Journal of Testing and Evaluation, Vol. 5, 1977.

11. Cross, S.A., and C. Johnson, Evaluation of the Superpave Gyratory Compactor for Low Volume Roads, Report No. KS-00-2. Kansas University Center for Research Inc. Lawrence, KS. June 2000.

12. D’Angelo, J.A., C. Paught, T.P. Harman, and J. Bukowski, Comparison of the Superpave Gyratory Compactor to the Marshall for Field Quality Control, Journal, Association of Asphalt Paving Technologist, Vol. 64, pp. 611-635, 1995

13. Duriez, M., and J. Arrambide, Nouveau Traite de Materiaux de Construction, Paris, 1962. 
14. Freeman, R.B., and C.Y. Kuo, Quality Control for Natural Sand Content of Asphalt Concrete, Journal of Transportation Engineering, November/December, pp. 539-546, 1999

15. Habbib, A., M. Hossain, R. Kaldate and G.A. Fager, Comparison of Superpave and Marshall Mixtures for Low-Volume Roads and Shoulders. Transportation Research Record 1609, pp. 44-50, 1998.

16. Harman, T., J.A. D’Angelo, and J. Bukowski, Superpave Asphalt Mixture Design. Workbook Version 8.0, Federal Highway Administration, Washington D.C, January 2002.

17. Indiana Department of Transportation, Certified Hot Mix Asphalt Technician Program, Procedures and Policies Manual., Indianapolis, IN, August, 2001.

18. Jackson N. M., and C. D. Baldwin, Assessing the Relative Rutting Susceptibility of HMA in the Laboratory with the Asphalt Pavement Analyzer, International Journal of Pavement Engineering, Volume 1(3), University of Mississippi, University, MS, pp. 203-217, 2000.

19. Kandhal, P.S. and L.A. Cooley, "Accelerated Laboratory Rutting: Asphalt Pavement Analyzer", Phase I, Interim Report, National Cooperative Highway Research Program, Project 9-17, Transportation Research Board, August, 1999.

20. Kandhal, P.S, K.Y. Foo, and R.B. Mallick, A Critical Review of VMA Requirements in Superpave. NCAT Report No. 98-1, National Center for Asphalt Technology, Auburn, Al., January 1998.

21. Kandhal P.S. and S. Chakraborty, Effect of Asphalt Film Thickness on Short and Long Aging of Asphalt Paving Mixtures, NCAT Report No. 96-1, National Center for Asphalt Technology, Auburn, Al., January 1996.

22. Kandhal, P. S., and W.S. Koehler, Marshall Mix Design Method: Current Practices, Proceedings of the Association of Asphalt Paving Technologists, Vol. 54, pp. 284-303, 1985.

23. Kandhal P.S. and R.B. Mallick, Evaluation of Asphalt Pavement Analyzer for HMA Mix Design, NCAT Report No. 99-4, National Center for Asphalt Technology, Auburn, Al., June 1999.

24. Kanneganti V., Comparison of $19 \mathrm{~mm}$ Superpave and Marshall Base II Mixes in West Virginia, Masters Thesis, West Virginia University, Morgantown, WV, 2002

25. Mack P. J., 2000 - 2001 Superpave Implementation and Needs Assessment, Communication, Training and Outreach Expert Task Group to the Transportation Research Board Superpave Committee, TRB, Washington, May, 2001.

26. Maupin, G.W., Comparison of Several Asphalt Design Methods, Virginia Transportation Research Council, Charlottesville, VA, January 1998

27. McLeod, N. W., Relationship between Density, Bitumen Content, and Voids Properties of Compacted Paving Mixtures, Proceedings, Highway Research Board, Vol. 35, 1956. 
28. Nallamothu H.S., Evaluation of Binder Grades on Rutting Performance, Masters Thesis, West Virginia University, Morgantown, WV, 2003.

29. Public Works Magazine, Superpave Makes Progress on Local Roads, February, Vol. 134 \#2, pp. 22-25, 2003.

30. Purcell, E.M. and S.A. Cross, Effects of Aggregate Angularity on VMA and Rutting of KDOT Superpave Level I Mixes, Kansas Department of Transportation, Topeka, KN, May 2001.

31. Reyes C.H., Evaluation of the Effect of Fines on Asphalt Concrete, Masters Thesis, West Virginia University, Morgantown, WV, 2003.

32. Roberts F. L., P. S. Kandhal, E. R. Brown, D. Lee, and T.W. Kennedy, Hot Mix Asphalt Material, Mixture Design and Construction, NAPA Education Foundation, Lanham, MD, 1996.

33. Shami H.I., J. S. Lai, J.A. D'Angelo, and R.T.Harman, Development of Temperature-Effect Model for Predicting Rutting of Asphalt Mixtures Using Georgia Loaded Wheel Tester. Transportation Research Record, TRB, No 1950, Washington D.C., pp. 17-22, September 1997.

34. Spector P. E., SAS Programming for Researchers and Social Scientist, Sage Publications, Newbury Park, CA, 1993

35. West Virginia Division of Highways, Hot Mix Asphalt Technician Instruction Manual, Charleston, WV, 2003.

36. Williams C.R. and B.D. Prowell. "Comparison of Laboratory Wheel-Tracking Test Results to West Track Performance." Transportation Research Record No. 1681,Transportation Research Board. National Research Council, 1999.

37. Zhang, J., L.A. Cooley, and P.S. Kandhal, Comparison of Fundamental and Simulative Test Methods for Evaluating Permanent Deformation of Hot Mix Asphalt, NCAT Report No. 02-07. National Center for Asphalt Technology, Auburn, Al., October 2002.

\section{SPECIFICATIONS AND TEST METHODS}

ASTM

1. Test Method for Resistance to Plastic Flow of Bituminous Mixtures Using Marshall Apparatus, ASTM D5581-96, 1996.

2. Test Method for Determining the Percentage of Fractured Particles in Coarse Aggregate, ASTM D5821-95, 1955.

3. Test Method for Flat Particles, Elongated Particles, or Flat and Elongated Particles in Coarse Aggregates, ASTM D4791-99, 1999. 


\section{AASHTO}

4. Resistance to Plastic Flow of Bituminous Mixtures Using the Marshall Apparatus, AASHTO T245-97, 1997.

5. Bulk Specific Gravity of Compacted Bituminous Mixtures Using Saturated Surface-Dry Specimens, AASHTO T166-00, 200.

6. Theoretical Maximum Specific Gravity and Density of Bituminous Paving Mixtures, AASHTO T209-99, 1999.

7. Specific Gravity and Absorption of Fine Aggregate, AASHTO T84-00 2000.

8. Specific Gravity and Absorption of Coarse Aggregate, AASHTO T85-91, 1996.

9. Uncompacted Void Content of Fine Aggregate, AASHTO T 304-96, 1996.

10. Plastic Fines in Graded Aggregates and Soils by Use of the Sand Equivalent Test, AASHTO T 176-00, 2000.

11. Resistance of Compacted Bituminous Mixture to Moisture Induced Damage, AASHTO T283-89, 1993.

12. Specification for Superpave Volumetric Mix Design, AASHTO MP 2-01, 2001.

13. Lime for Asphalt Mixtures, AASHTO M303-89, 1998.

\section{WVDOH}

14. West Virginia Division of Highways, Standard Specifications Roads and Bridges, Charleston, WV, 2000.

15. West Virginia Division of Highways, Supplemental Specifications, Charleston, WV, 2003

16. Guide to Designing Hot Mix Asphalt Using the Marshall Design Method. WVDOT MP 401.02.22, 2000.

17. Guide to Designing Hot Mix Asphalt Using the Superpave Volumetric Design System. WVDOT MP 402.02.28, 2000. 
APPENDIX A. PHASE I MIX DESIGN DATA 
Table A1. Volumetric properties mix design 1: Superpave, coarse gradation, 4 percent dust content

\begin{tabular}{|c|c|c|c|c|c|c|c|c|c|c|c|c|c|}
\hline \multirow{3}{*}{$\begin{array}{l}\text { Specimen } \\
\text { Number }\end{array}$} & \multirow{3}{*}{$\begin{array}{l}\text { Percent } \\
\text { Asphalt } \\
\text { Content }\end{array}$} & \multirow{3}{*}{$\begin{array}{l}\text { Gyration } \\
\text { Number }\end{array}$} & \multirow{3}{*}{$\begin{array}{c}\text { Specimen } \\
\text { Height } \\
(\mathrm{mm})\end{array}$} & \multicolumn{3}{|c|}{ Weight $(\mathrm{g})$} & \multicolumn{2}{|c|}{ Specific gravity } & \multirow{2}{*}{$\begin{array}{l}\text { Voids in } \\
\text { total mix }\end{array}$} & \multirow{2}{*}{$\begin{array}{c}\text { Voids in } \\
\text { mineral } \\
\text { aggregate }\end{array}$} & \multirow{2}{*}{$\begin{array}{l}\text { Voids } \\
\text { Filled }\end{array}$} & \multirow{3}{*}{$\begin{array}{c}\% \mathrm{G}_{\mathrm{mm}} @ \\
\mathrm{~N}_{\mathrm{ini}}\end{array}$} & \multirow{3}{*}{$\begin{array}{c}\mathrm{P}_{0.075} \text { to } \\
\mathrm{P}_{\text {be }}\end{array}$} \\
\hline & & & & In Air & In Water & (SSD) & Bulk & Maximum & & & & & \\
\hline & & & & A & $\mathrm{C}$ & B & & & VTM & VMA & VFA & & \\
\hline \multirow[t]{2}{*}{1} & \multirow{5}{*}{$6.1 \%$} & 6 & 128.3 & & & & 2.108 & & & & & $85.4 \%$ & \\
\hline & & 50 & 115.8 & 4756.4 & 2727.9 & 4765.1 & 2.335 & & & & & & \\
\hline \multirow[t]{2}{*}{2} & & 6 & 128.1 & & & & 2.105 & & & & & $85.3 \%$ & \\
\hline & & 50 & 115.6 & 4749.1 & 2716.3 & 4752.1 & 2.333 & & & & & & \\
\hline Avg. & & & & & & & 2.334 & 2.468 & $5.4 \%$ & $17.5 \%$ & $69.1 \%$ & $85.4 \%$ & 0.75 \\
\hline \multirow[t]{2}{*}{1} & \multirow{5}{*}{$6.6 \%$} & 6 & 128.3 & & & & 2.109 & & & & & $86.1 \%$ & \\
\hline & & 50 & 115.6 & 4782.7 & 2743.9 & 4787.0 & 2.341 & & & & & & \\
\hline \multirow[t]{2}{*}{2} & & 6 & 127.4 & & & & 2.134 & & & & & $87.1 \%$ & \\
\hline & & 50 & 116.0 & 4778.3 & 2739.7 & 4778.1 & 2.344 & & & & & & \\
\hline Avg. & & & & & & & 2.343 & 2.450 & $4.4 \%$ & $17.6 \%$ & $75.0 \%$ & $86.6 \%$ & 0.69 \\
\hline \multirow[t]{2}{*}{1} & \multirow{5}{*}{$7.1 \%$} & 6 & 128.8 & & & & 2.118 & & & & & $87.1 \%$ & \\
\hline & & 50 & 116.0 & 4801.4 & 2765.2 & 4807.0 & 2.352 & & & & & & \\
\hline \multirow[t]{2}{*}{2} & & 6 & 127.1 & & & & 2.156 & & & & & $88.7 \%$ & \\
\hline & & 50 & 116.3 & 4810.2 & 2774.5 & 4816.6 & 2.356 & & & & & & \\
\hline Avg. & & & & & & & 2.354 & 2.432 & $3.2 \%$ & $17.6 \%$ & $81.8 \%$ & $87.9 \%$ & 0.63 \\
\hline \multirow[t]{2}{*}{1} & \multirow{5}{*}{$7.6 \%$} & 6 & 129.0 & & & & 2.128 & & & & & $88.1 \%$ & \\
\hline & & 50 & 116.0 & 4821.3 & 2788.4 & 4826.2 & 2.366 & & & & & & \\
\hline \multirow[t]{2}{*}{2} & & 6 & 127.2 & & & & 2.161 & & & & & $89.5 \%$ & \\
\hline & & 50 & 116.3 & 4809.6 & 2783.2 & 4818.4 & 2.363 & & & & & & \\
\hline Avg. & & & & & & & 2.365 & 2.415 & $2.1 \%$ & $17.7 \%$ & $88.1 \%$ & $88.8 \%$ & 0.59 \\
\hline
\end{tabular}



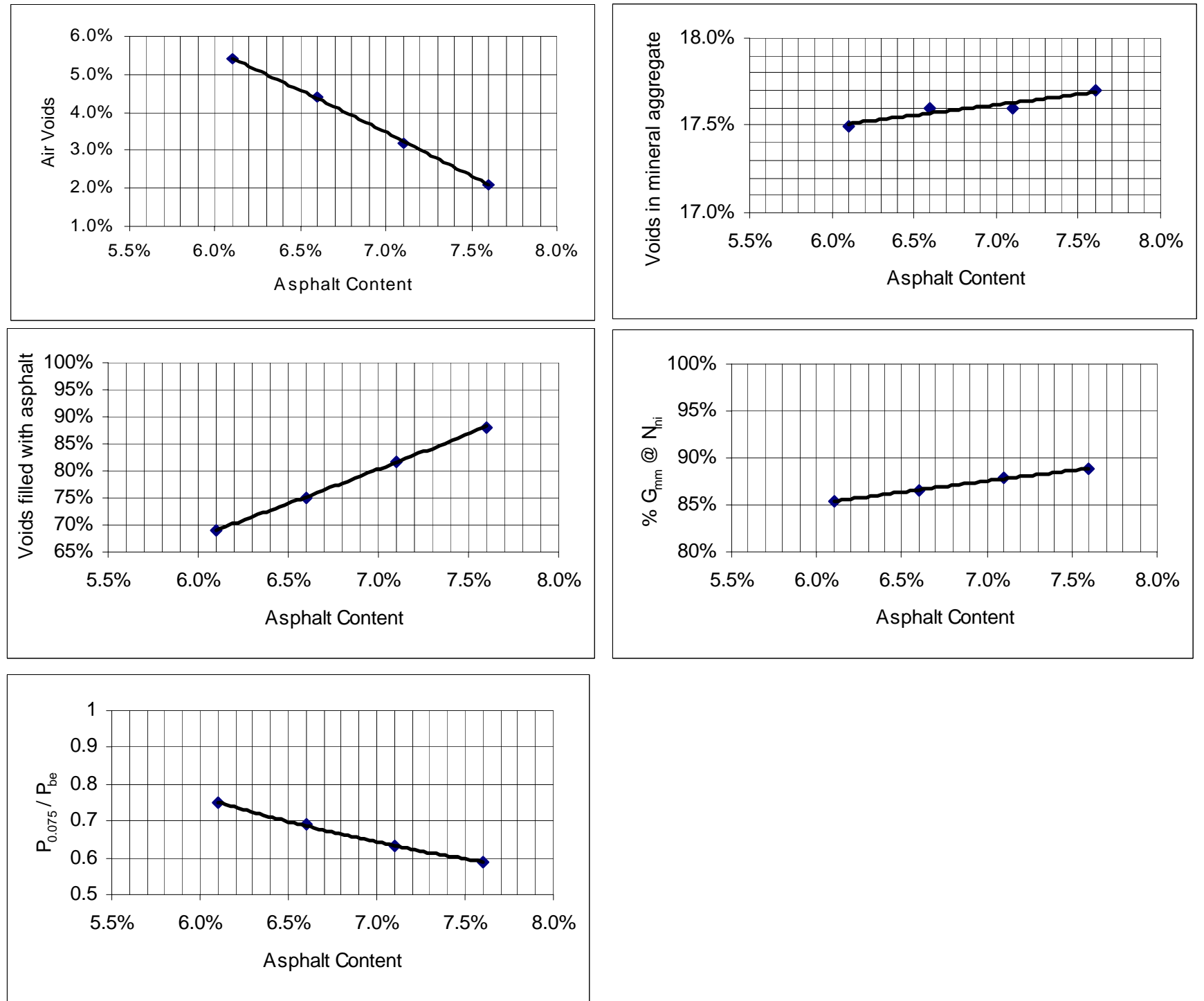

Figure A.1 Volumetric properties plots mix design 1: Superpave, coarse gradation, 4 percent dust content 
Table A2. Volumetric properties mix design 2: Superpave, coarse gradation, 8 percent dust content

\begin{tabular}{|c|c|c|c|c|c|c|c|c|c|c|c|c|c|}
\hline \multirow{3}{*}{$\begin{array}{l}\text { Specimen } \\
\text { Number }\end{array}$} & \multirow{3}{*}{$\begin{array}{l}\text { Percent } \\
\text { Asphalt } \\
\text { Content }\end{array}$} & \multirow{3}{*}{$\begin{array}{l}\text { Gyration } \\
\text { Number }\end{array}$} & \multirow{3}{*}{$\begin{array}{c}\text { Specimen } \\
\text { Height } \\
(\mathrm{mm})\end{array}$} & \multicolumn{3}{|c|}{ Weight (g) } & \multicolumn{2}{|c|}{ Specific gravity } & \multirow{3}{*}{$\begin{array}{c}\begin{array}{c}\text { Voids in } \\
\text { total mix }\end{array} \\
\text { VTM }\end{array}$} & \multirow{3}{*}{$\begin{array}{c}\begin{array}{c}\text { Voids in } \\
\text { mineral } \\
\text { aggregate }\end{array} \\
\text { VMA }\end{array}$} & \multirow{3}{*}{$\begin{array}{c}\begin{array}{c}\text { Voids } \\
\text { Filled }\end{array} \\
\text { VFA }\end{array}$} & \multirow{3}{*}{$\underset{\mathrm{N}_{\mathrm{ini}}}{\% \mathrm{G}_{\mathrm{mm}}} @$} & \multirow{3}{*}{$\begin{array}{c}\mathrm{P}_{0.075} \text { to } \\
\mathrm{P}_{\mathrm{be}}\end{array}$} \\
\hline & & & & In Air & In Water & (SSD) & Bulk & Maximum & & & & & \\
\hline & & & & A & $\mathrm{C}$ & $\mathrm{B}$ & & & & & & & \\
\hline \multirow[t]{2}{*}{1} & \multirow{5}{*}{$5.6 \%$} & 6 & 127.9 & & & & 2.133 & & & & & $85.8 \%$ & \\
\hline & & 50 & 115.6 & 4759.0 & 2750.8 & 4767.1 & 2.360 & & & & & & \\
\hline \multirow[t]{2}{*}{2} & & 6 & 127.5 & & & & 2.122 & & & & & $85.4 \%$ & \\
\hline & & 50 & 114.8 & 4761.1 & 2744.7 & 4764.6 & 2.357 & & & & & & \\
\hline Avg. & & & & & & & 2.359 & 2.486 & $5.1 \%$ & $16.1 \%$ & $68.3 \%$ & $85.6 \%$ & 1.67 \\
\hline \multirow{4}{*}{2} & \multirow{5}{*}{$6.1 \%$} & 6 & 127.5 & & & & 2.135 & & & & & $86.5 \%$ & \\
\hline & & 50 & 114.6 & 4775.7 & 2770.1 & 4780.9 & 2.375 & & & & & & \\
\hline & & 6 & 127.6 & & & & 2.152 & & & & & $87.2 \%$ & \\
\hline & & 50 & 115.4 & 4786.1 & 2778.9 & 4789.9 & 2.380 & & & & & & \\
\hline Avg. & & & & & & & 2.378 & 2.468 & $3.7 \%$ & $15.9 \%$ & $76.7 \%$ & $86.9 \%$ & 1.51 \\
\hline \multirow[t]{4}{*}{1} & \multirow{5}{*}{$6.6 \%$} & 6 & 127.9 & & & & 2.141 & & & & & $87.4 \%$ & \\
\hline & & 50 & 114.7 & 4811.5 & 2798.9 & 4814.8 & 2.387 & & & & & & \\
\hline & & 6 & 128.2 & & & & 2.152 & & & & & $87.8 \%$ & \\
\hline & & 50 & 115.0 & 4808.2 & 2811.2 & 4815.1 & 2.399 & & & & & & \\
\hline Avg. & & & & & & & 2.393 & 2.450 & $2.3 \%$ & $15.8 \%$ & $85.4 \%$ & $87.6 \%$ & 1.38 \\
\hline 1 & \multirow{5}{*}{$7.1 \%$} & 6 & 127.9 & & & & 2.144 & & & & & $88.2 \%$ & \\
\hline & & 50 & 114.1 & 4821.2 & 2817.1 & 4823.2 & 2.403 & & & & & & \\
\hline \multirow[t]{2}{*}{2} & & 6 & 127.6 & & & & 2.148 & & & & & $88.3 \%$ & \\
\hline & & 50 & 114.3 & 4816.9 & 2809.1 & 4818.1 & 2.398 & & & & & & \\
\hline Avg. & & & & & & & 2.401 & 2.432 & $1.3 \%$ & $16.0 \%$ & $91.9 \%$ & $88.2 \%$ & 1.27 \\
\hline
\end{tabular}



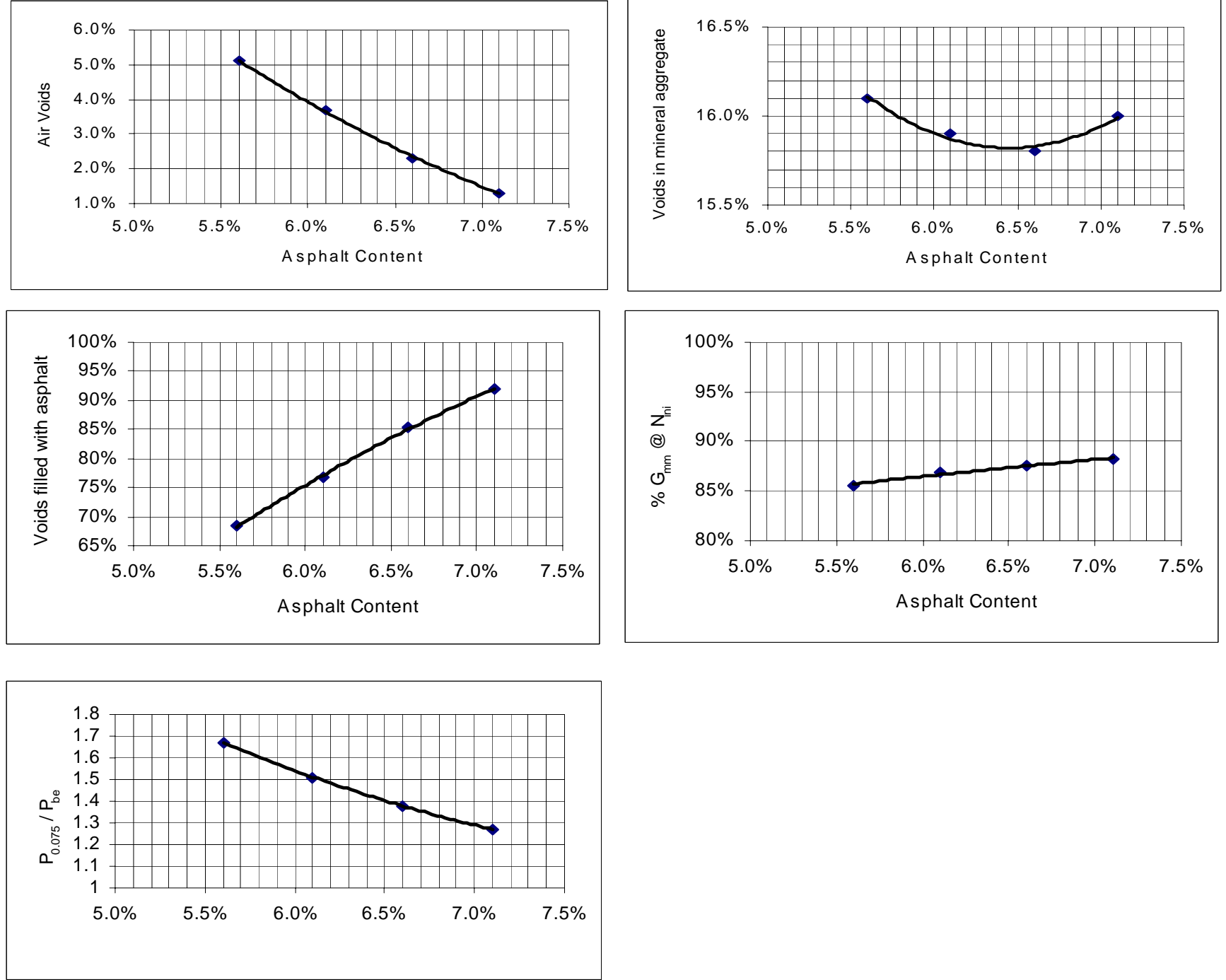

Figure A2. Volumetric properties plots mix design 2: Superpave, coarse gradation, 8 percent dust content 
Table A3. Volumetric properties mix design 3: Superpave, coarse gradation, 12 percent dust content

\begin{tabular}{|c|c|c|c|c|c|c|c|c|c|c|c|c|c|}
\hline \multirow{3}{*}{$\begin{array}{l}\text { Specimen } \\
\text { Number }\end{array}$} & \multirow{3}{*}{$\begin{array}{l}\text { Percent } \\
\text { Asphalt } \\
\text { Content }\end{array}$} & \multirow{3}{*}{$\begin{array}{l}\text { Gyration } \\
\text { Number }\end{array}$} & \multirow{3}{*}{$\begin{array}{c}\text { Specimen } \\
\text { Height } \\
(\mathrm{mm})\end{array}$} & \multicolumn{3}{|c|}{ Weight (g) } & \multicolumn{2}{|c|}{ Specific gravity } & \multirow{3}{*}{\begin{tabular}{|c}
$\begin{array}{c}\text { Voids in } \\
\text { total mix }\end{array}$ \\
VTM \\
\end{tabular}} & \multirow{3}{*}{$\begin{array}{c}\begin{array}{c}\text { Voids in } \\
\text { mineral } \\
\text { aggregate }\end{array} \\
\text { VMA }\end{array}$} & \multirow{3}{*}{$\begin{array}{c}\text { Voids } \\
\text { Filled } \\
\text { VFA }\end{array}$} & \multirow{3}{*}{$\begin{array}{c}\% \mathrm{G}_{\mathrm{mm}} \\
\mathrm{N}_{\mathrm{ini}}\end{array}$} & \multirow{3}{*}{$\begin{array}{c}\mathrm{P}_{0.075} \text { to } \\
\mathrm{P}_{\mathrm{be}}\end{array}$} \\
\hline & & & & In Air & In Water & (SSD) & Bulk & Maximum & & & & & \\
\hline & & & & $\mathrm{A}$ & $\mathrm{C}$ & $\mathrm{B}$ & & & & & & & \\
\hline \multirow[t]{2}{*}{1} & \multirow{5}{*}{$4.9 \%$} & 6 & 128.7 & & & & 2.117 & & & & & $84.3 \%$ & \\
\hline & & 50 & 115.1 & 4723 & 2747.8 & 4742.8 & 2.367 & & & & & & \\
\hline \multirow[t]{2}{*}{2} & & 6 & 127.3 & & & & 2.151 & & & & & $85.7 \%$ & \\
\hline & & 50 & 115.9 & 4737.3 & 2747.1 & 4752.1 & 2.363 & & & & & & \\
\hline Avg. & & & & & & & 2.365 & 2.511 & $5.8 \%$ & $15.3 \%$ & $62.1 \%$ & $85.0 \%$ & 2.93 \\
\hline \multirow{4}{*}{2} & \multirow{5}{*}{$5.4 \%$} & 6 & 127.5 & & & & 2.150 & & & & & $86.3 \%$ & \\
\hline & & 50 & 114.2 & 4761.2 & 2786.4 & 4770.2 & 2.400 & & & & & & \\
\hline & & 6 & 127.4 & & & & 2.166 & & & & & $86.9 \%$ & \\
\hline & & 50 & 115.2 & 4768.7 & 2789.7 & 4780.9 & 2.395 & & & & & & \\
\hline Avg. & & & & & & & 2.398 & 2.492 & $3.8 \%$ & $14.6 \%$ & $74.0 \%$ & $86.6 \%$ & 2.61 \\
\hline \multirow[t]{4}{*}{1} & \multirow{5}{*}{$5.9 \%$} & 6 & 126.2 & & & & 2.169 & & & & & $87.7 \%$ & \\
\hline & & 50 & 113.5 & 4751.1 & 2786.8 & 4756.7 & 2.412 & & & & & & \\
\hline & & 6 & 126.1 & & & & 2.178 & & & & & $88.0 \%$ & \\
\hline & & 50 & 114.4 & 4790.2 & 2801.5 & 4796.3 & 2.401 & & & & & & \\
\hline Avg. & & & & & & & 2.407 & 2.474 & $2.8 \%$ & $14.7 \%$ & $81.0 \%$ & $87.8 \%$ & 2.35 \\
\hline 1 & \multirow{5}{*}{$6.4 \%$} & 6 & 125.2 & & & & 2.190 & & & & & $89.2 \%$ & \\
\hline & & 50 & 113.5 & 4788.9 & 2810.4 & 4792.9 & 2.416 & & & & & & \\
\hline \multirow[t]{2}{*}{2} & & 6 & 127.2 & & & & 2.166 & & & & & $88.2 \%$ & \\
\hline & & 50 & 114.3 & 4809.6 & 2823.2 & 4818.4 & 2.411 & & & & & & \\
\hline Avg. & & & & & & & 2.414 & 2.455 & $1.7 \%$ & $14.9 \%$ & $88.6 \%$ & $88.7 \%$ & 2.14 \\
\hline
\end{tabular}



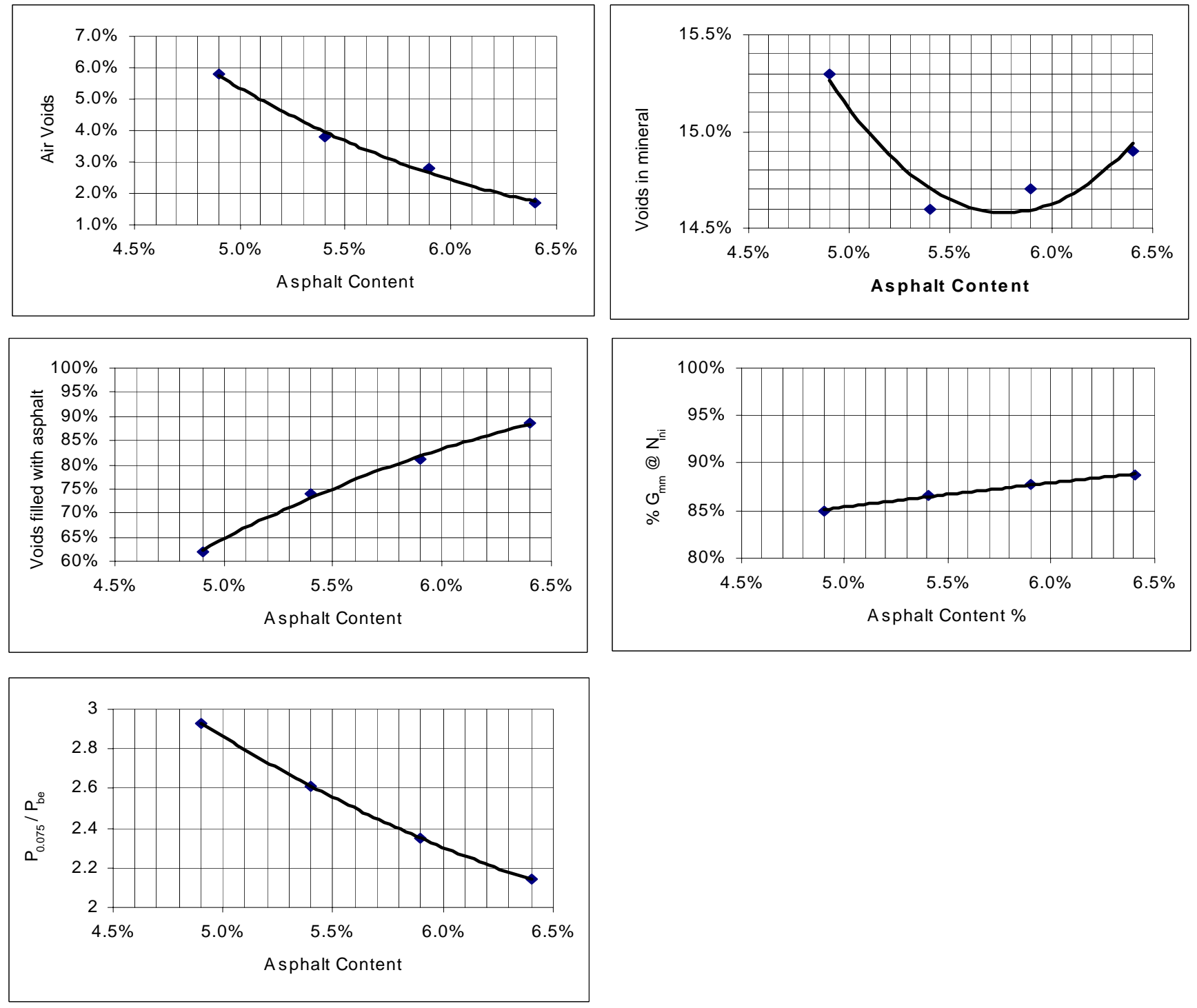

Figure A3.Volumetric properties plots mix design 3: Superpave, coarse gradation, 12 percent dust content 
Table A4.Volumetric properties mix design 4: Superpave, medium gradation, 4 percent dust content

\begin{tabular}{|c|c|c|c|c|c|c|c|c|c|c|c|c|c|}
\hline \multirow{3}{*}{$\begin{array}{l}\text { Specimen } \\
\text { Number }\end{array}$} & \multirow{3}{*}{$\begin{array}{l}\text { Percent } \\
\text { Asphalt } \\
\text { Content }\end{array}$} & \multirow{3}{*}{$\begin{array}{l}\text { Gyration } \\
\text { Number }\end{array}$} & \multirow{3}{*}{$\begin{array}{c}\text { Specimen } \\
\text { Height } \\
(\mathrm{mm})\end{array}$} & \multicolumn{3}{|c|}{ Weight (g) } & \multicolumn{2}{|c|}{ Specific gravity } & \multirow{2}{*}{$\begin{array}{l}\text { Voids in } \\
\text { total mix }\end{array}$} & \multirow{2}{*}{$\begin{array}{c}\text { Voids in } \\
\text { mineral } \\
\text { aggregate }\end{array}$} & \multirow{2}{*}{$\begin{array}{l}\text { Voids } \\
\text { Filled }\end{array}$} & \multirow{3}{*}{$\underset{\mathrm{N}_{\mathrm{ini}}}{\% \mathrm{G}_{\mathrm{mm}}} @$} & \multirow{3}{*}{$\begin{array}{c}\mathrm{P}_{0.075} \text { tc } \\
\mathrm{P}_{\mathrm{be}}\end{array}$} \\
\hline & & & & In Air & In Water & $(\mathrm{SSD})$ & Bulk & Maximum & & & & & \\
\hline & & & & A & $\mathrm{C}$ & $\mathrm{B}$ & & & VTM & VMA & VFA & & \\
\hline \multirow[t]{2}{*}{1} & \multirow{5}{*}{$5.9 \%$} & 6 & 129.1 & & & & 2.086 & & & & & $84.3 \%$ & \\
\hline & & 50 & 115.2 & 4744.1 & 2726.4 & 4755.1 & 2.338 & & & & & & \\
\hline \multirow[t]{2}{*}{2} & & 6 & 128.5 & & & & 2.096 & & & & & $84.7 \%$ & \\
\hline & & 50 & 115.3 & 4757.3 & 2725.3 & 4761.8 & 2.336 & & & & & & \\
\hline Avg. & & & & & & & 2.337 & 2.476 & $5.6 \%$ & $17.2 \%$ & $67.4 \%$ & $84.5 \%$ & 0.78 \\
\hline \multirow{4}{*}{2} & \multirow{5}{*}{$6.4 \%$} & 6 & 128.2 & & & & 2.117 & & & & & $86.1 \%$ & \\
\hline & & 50 & 115.4 & 4774.6 & 2749.7 & 4779.4 & 2.352 & & & & & & \\
\hline & & 6 & 128.4 & & & & 2.111 & & & & & $85.9 \%$ & \\
\hline & & 50 & 115.1 & 4782.1 & 2755.9 & 4786.1 & 2.355 & & & & & & \\
\hline Avg. & & & & & & & 2.354 & 2.458 & $4.3 \%$ & $17.0 \%$ & $74.7 \%$ & $86.0 \%$ & 0.71 \\
\hline \multirow{4}{*}{2} & \multirow{5}{*}{$6.9 \%$} & 6 & 127.6 & & & & 2.139 & & & & & $87.7 \%$ & \\
\hline & & 50 & 115.4 & 4796.2 & 2770.4 & 4798.8 & 2.365 & & & & & & \\
\hline & & 6 & 128.5 & & & & 2.139 & & & & & $87.7 \%$ & \\
\hline & & 50 & 116.1 & 4804.2 & 2777.9 & 4806.6 & 2.368 & & & & & & \\
\hline Avg. & & & & & & & 2.367 & 2.440 & $3.0 \%$ & $17.0 \%$ & $82.4 \%$ & $87.7 \%$ & 0.65 \\
\hline 1 & \multirow{5}{*}{$7.4 \%$} & 6 & 129.2 & & & & 2.136 & & & & & $88.2 \%$ & \\
\hline & & 50 & 116 & 4821.9 & 2796.2 & 4822.9 & 2.379 & & & & & & \\
\hline \multirow[t]{2}{*}{2} & & 6 & 128.8 & & & & 2.122 & & & & & $87.6 \%$ & \\
\hline & & 50 & 115.4 & 4816.4 & 2784.1 & 4818.1 & 2.368 & & & & & & \\
\hline Avg. & & & & & & & 2.374 & 2.422 & $2.0 \%$ & $17.2 \%$ & $88.4 \%$ & $87.9 \%$ & 0.60 \\
\hline
\end{tabular}



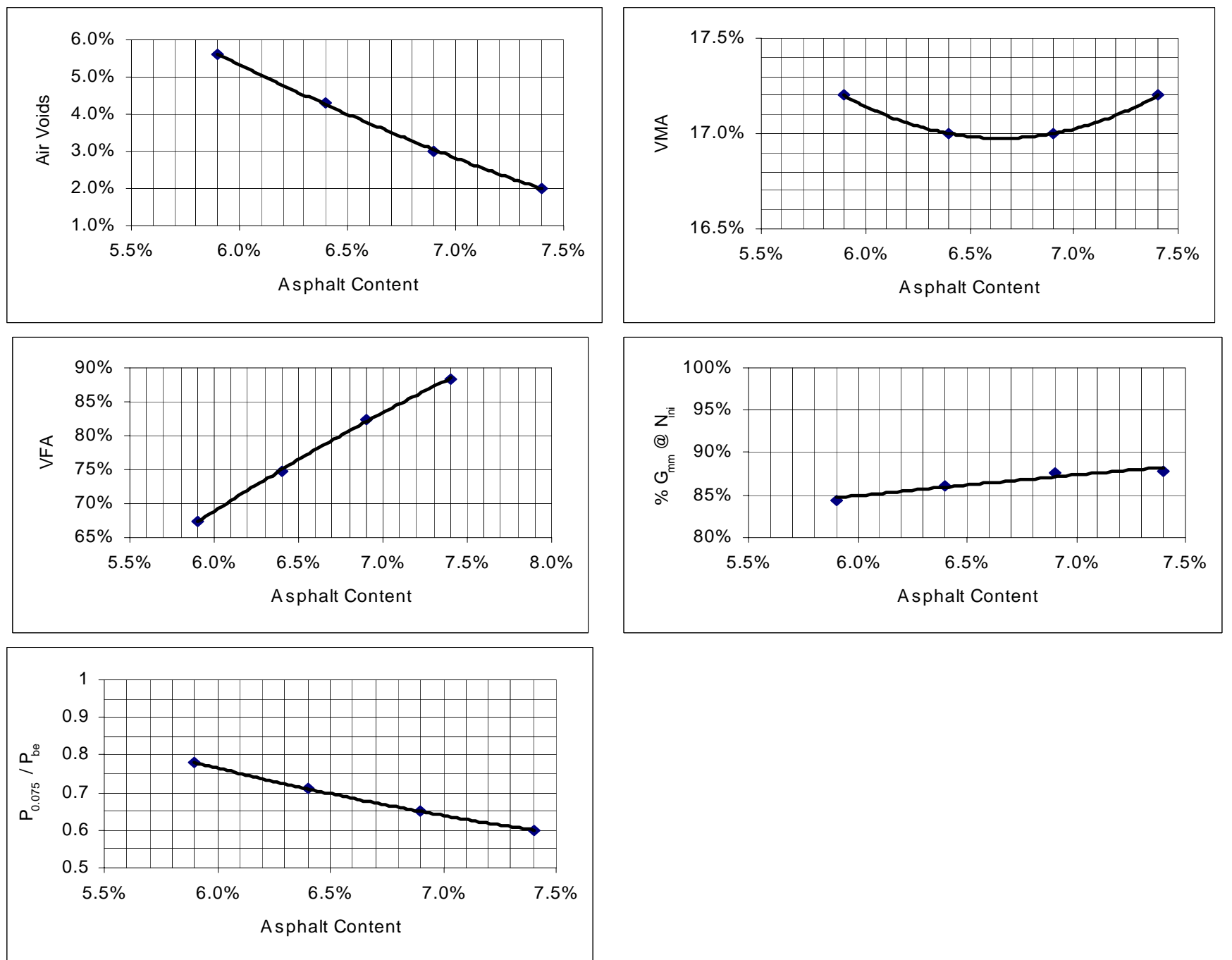

Figure A4.Volumetric properties plots mix design 4: Superpave, medium gradation, 4 percent dust content 
Table A5.Volumetric properties mix design 5: Superpave, medium gradation, 8 percent dust content

\begin{tabular}{|c|c|c|c|c|c|c|c|c|c|c|c|c|c|}
\hline \multirow{3}{*}{$\begin{array}{c}\text { Specimen } \\
\text { Number }\end{array}$} & \multirow{3}{*}{$\begin{array}{l}\text { Percent } \\
\text { Asphalt } \\
\text { Content }\end{array}$} & \multirow{3}{*}{$\begin{array}{l}\text { Gyration } \\
\text { Number }\end{array}$} & \multirow{3}{*}{$\begin{array}{c}\text { Specimen } \\
\text { Height } \\
(\mathrm{mm})\end{array}$} & \multicolumn{3}{|c|}{ Weight (g) } & \multicolumn{2}{|c|}{ Specific gravity } & \multirow{2}{*}{$\begin{array}{l}\text { Voids in } \\
\text { total mix }\end{array}$} & \multirow{2}{*}{$\begin{array}{c}\text { Voids in } \\
\text { mineral } \\
\text { aggregate }\end{array}$} & \multirow{2}{*}{$\begin{array}{l}\text { Voids } \\
\text { Filled }\end{array}$} & \multirow{3}{*}{$\begin{array}{c}\% \mathrm{G}_{\mathrm{mm}} @ \\
\mathrm{~N}_{\mathrm{ini}}\end{array}$} & \multirow{3}{*}{$\begin{array}{c}\mathrm{P}_{0.075} \text { to } \\
\mathrm{P}_{\text {be }}\end{array}$} \\
\hline & & & & In Air & In Water & (SSD) & Bulk & Maximum & & & & & \\
\hline & & & & $\mathrm{A}$ & $\mathrm{C}$ & B & & & VTM & VMA & VFA & & \\
\hline \multirow[t]{2}{*}{1} & \multirow{5}{*}{$5.4 \%$} & 6 & 128.2 & & & & 2.137 & & & & & $85.7 \%$ & \\
\hline & & 50 & 116.0 & 4748.2 & 2744.2 & 4754.2 & 2.362 & & & & & & \\
\hline \multirow[t]{2}{*}{2} & & 6 & 127.1 & & & & 2.147 & & & & & $86.1 \%$ & \\
\hline & & 50 & 115.2 & 4757.7 & 2754.2 & 4762.9 & 2.369 & & & & & & \\
\hline Avg. & & & & & & & 2.366 & 2.495 & $5.2 \%$ & $15.7 \%$ & $66.9 \%$ & $85.9 \%$ & 1.74 \\
\hline \multirow{4}{*}{2} & \multirow{5}{*}{$5.9 \%$} & 6 & 127.5 & & & & 2.150 & & & & & $86.8 \%$ & \\
\hline & & 50 & 115.2 & 4780.1 & 2776.2 & 4784.8 & 2.380 & & & & & & \\
\hline & & 6 & 127.4 & & & & 2.151 & & & & & $86.8 \%$ & \\
\hline & & 50 & 115.0 & 4788.2 & 2781.7 & 4790.6 & 2.383 & & & & & & \\
\hline Avg. & & & & & & & 2.382 & 2.477 & $3.9 \%$ & $15.6 \%$ & $75.0 \%$ & $86.8 \%$ & 1.57 \\
\hline \multirow{4}{*}{2} & \multirow{5}{*}{$6.4 \%$} & 6 & 127.5 & & & & 2.142 & & & & & $87.1 \%$ & \\
\hline & & 50 & 114.2 & 4808.3 & 2799.6 & 4810.1 & 2.392 & & & & & & \\
\hline & & 6 & 127.5 & & & & 2.159 & & & & & $87.8 \%$ & \\
\hline & & 50 & 114.8 & 4811.9 & 2806.9 & 4813.4 & 2.398 & & & & & & \\
\hline Avg. & & & & & & & 2.395 & 2.458 & $2.5 \%$ & $15.6 \%$ & $84.0 \%$ & $87.5 \%$ & 1.43 \\
\hline 1 & \multirow{5}{*}{$6.9 \%$} & 6 & 127.9 & & & & 2.148 & & & & & $88.0 \%$ & \\
\hline & & 50 & 114.3 & 4824.6 & 2818.1 & 4825.2 & 2.404 & & & & & & \\
\hline \multirow[t]{2}{*}{2} & & 6 & 127.6 & & & & 2.149 & & & & & $88.1 \%$ & \\
\hline & & 50 & 114.0 & 4819 & 2816.1 & 4820.2 & 2.405 & & & & & & \\
\hline Avg. & & & & & & & 2.405 & 2.440 & $1.4 \%$ & $15.7 \%$ & $91.1 \%$ & $88.1 \%$ & 1.31 \\
\hline
\end{tabular}



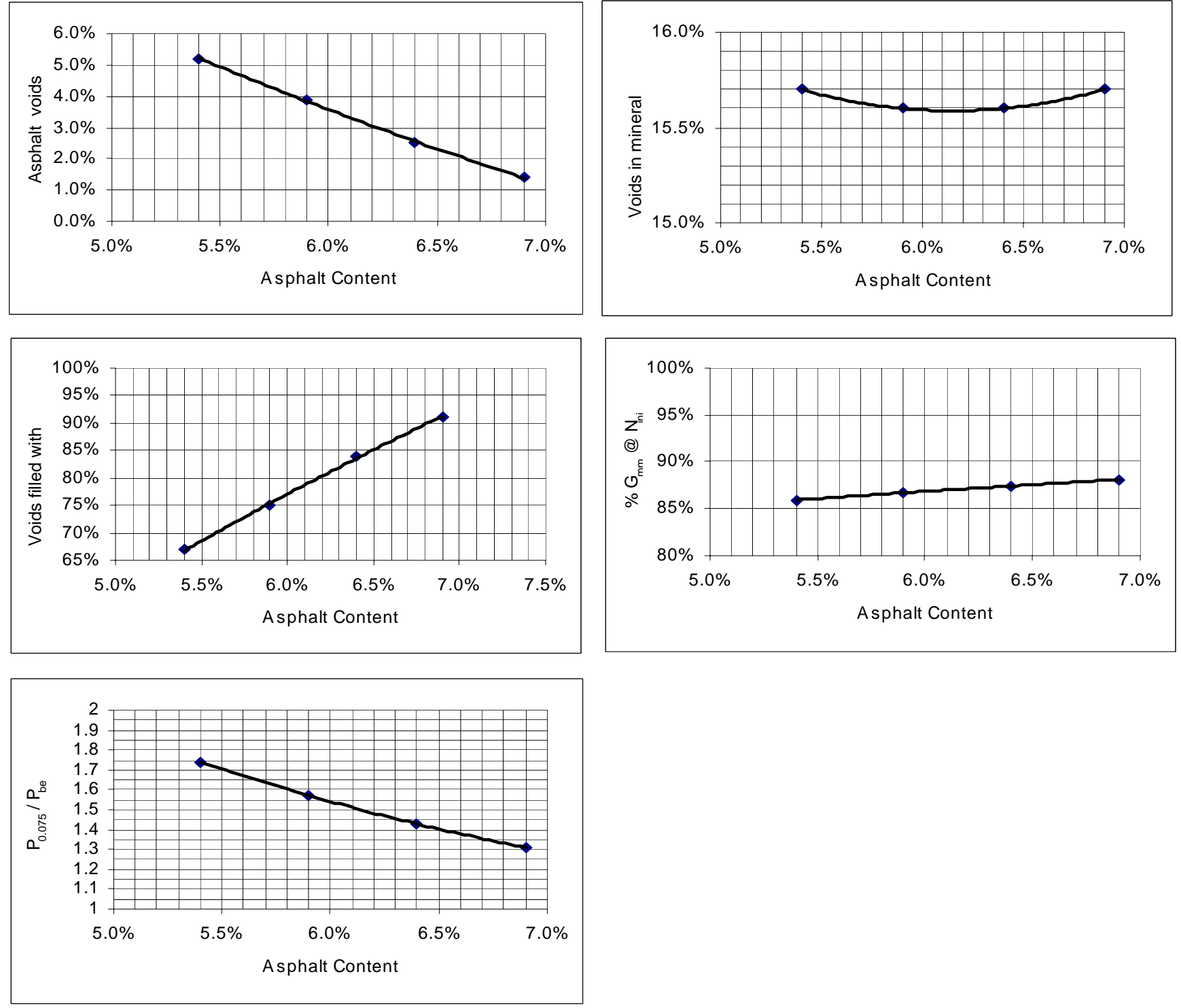

Figure A5.Volumetric properties plots mix design 5: Superpave, medium gradation, 8 percent dust content 
Table A6.Volumetric properties mix design 6: Superpave, medium gradation, 12 percent dust content

\begin{tabular}{|c|c|c|c|c|c|c|c|c|c|c|c|c|c|}
\hline \multirow{3}{*}{$\begin{array}{l}\text { Specimen } \\
\text { Number }\end{array}$} & \multirow{3}{*}{$\begin{array}{l}\text { Percent } \\
\text { Asphalt } \\
\text { Content }\end{array}$} & \multirow{3}{*}{$\begin{array}{l}\text { Gyration } \\
\text { Number }\end{array}$} & \multirow{3}{*}{$\begin{array}{c}\text { Specimen } \\
\text { Height } \\
(\mathrm{mm})\end{array}$} & \multicolumn{3}{|c|}{ Weight (g) } & \multicolumn{2}{|c|}{ Specific gravity } & \multirow{2}{*}{$\begin{array}{l}\text { Voids in } \\
\text { total mix }\end{array}$} & \multirow{2}{*}{$\begin{array}{c}\text { Voids in } \\
\text { mineral } \\
\text { aggregate }\end{array}$} & \multirow{2}{*}{$\begin{array}{l}\text { Voids } \\
\text { Filled }\end{array}$} & \multirow{3}{*}{$\begin{array}{c}\% \mathrm{G}_{\mathrm{mm}} \\
\mathrm{N}_{\mathrm{ini}}\end{array}$} & \multirow{3}{*}{$\begin{array}{c}\mathrm{P}_{0.075} \text { to } \\
\mathrm{P}_{\mathrm{be}}\end{array}$} \\
\hline & & & & In Air & In Water & (SSD) & Bulk & Maximum & & & & & \\
\hline & & & & A & $\mathrm{C}$ & $\mathrm{B}$ & & & VTM & VMA & VFA & & \\
\hline \multirow[t]{2}{*}{1} & \multirow{5}{*}{$4.6 \%$} & 6 & 128.7 & & & & 2.125 & & & & & $84.2 \%$ & \\
\hline & & 50 & 115.1 & 4731.5 & 2749.2 & 4740.6 & 2.376 & & & & & & \\
\hline \multirow[t]{2}{*}{2} & & 6 & 129.2 & & & & 2.118 & & & & & $83.9 \%$ & \\
\hline & & 50 & 115.5 & 4739.2 & 2749.2 & 4749.3 & 2.369 & & & & & & \\
\hline Avg. & & & & & & & 2.373 & 2.525 & $6.1 \%$ & $14.8 \%$ & $58.8 \%$ & $84.0 \%$ & 3.17 \\
\hline \multirow{4}{*}{2} & \multirow{5}{*}{$5.1 \%$} & 6 & 124.4 & & & & 2.171 & & & & & $86.6 \%$ & \\
\hline & & 50 & 113.2 & 4751.2 & 2778.2 & 4769.2 & 2.386 & & & & & & \\
\hline & & 6 & 125.4 & & & & 2.174 & & & & & $86.8 \%$ & \\
\hline & & 50 & 113.6 & 4760.1 & 2792.1 & 4775.1 & 2.400 & & & & & & \\
\hline Avg. & & & & & & & 2.393 & 2.506 & $4.5 \%$ & $14.5 \%$ & $69.0 \%$ & $86.7 \%$ & 2.8 \\
\hline \multirow[t]{2}{*}{1} & \multirow{5}{*}{$5.6 \%$} & 6 & 124.2 & & & & 2.200 & & & & & $88.4 \%$ & \\
\hline & & 50 & 113.5 & 4781.5 & 2799.1 & 4785.2 & 2.407 & & & & & & \\
\hline \multirow[t]{2}{*}{2} & & 6 & 124.5 & & & & 2.186 & & & & & $87.9 \%$ & \\
\hline & & 50 & 113.0 & 4796.2 & 2808.2 & 4799.1 & 2.409 & & & & & & \\
\hline Avg. & & & & & & & 2.408 & 2.488 & $3.2 \%$ & $14.4 \%$ & $77.8 \%$ & $88.2 \%$ & 2.5 \\
\hline \multirow[t]{2}{*}{1} & \multirow{5}{*}{$6.1 \%$} & 6 & 125.2 & & & & 2.178 & & & & & $88.2 \%$ & \\
\hline & & 50 & 112.9 & 4814.5 & 2822.7 & 4816.3 & 2.415 & & & & & & \\
\hline \multirow[t]{2}{*}{2} & & 6 & 124.2 & & & & 2.184 & & & & & $88.5 \%$ & \\
\hline & & 50 & 112.3 & 4816.2 & 2824.8 & 4819.1 & 2.415 & & & & & & \\
\hline Avg. & & & & & & & 2.415 & 2.469 & $2.2 \%$ & $14.6 \%$ & $84.9 \%$ & $88.4 \%$ & 2.26 \\
\hline
\end{tabular}



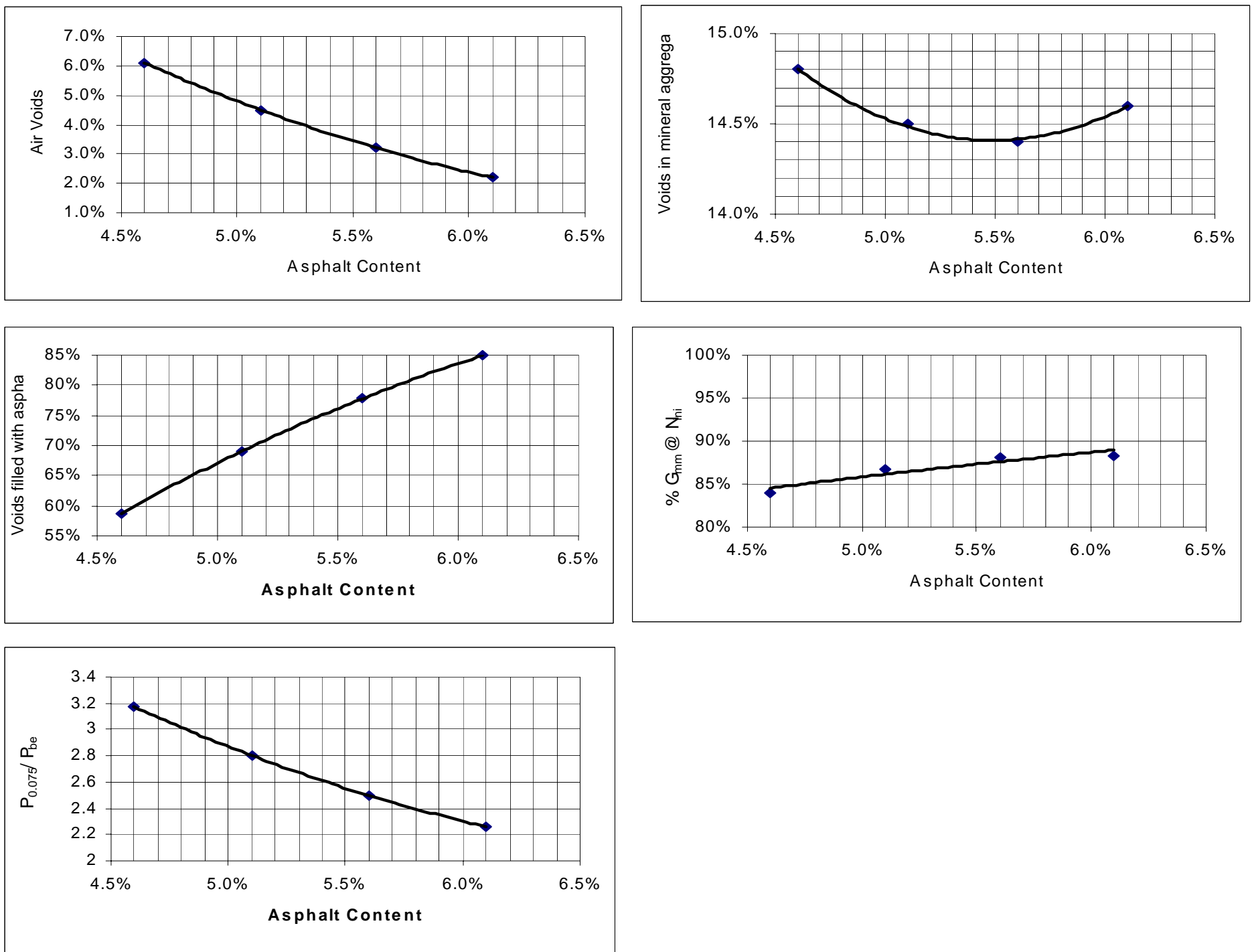

Figure A6.Volumetric properties plots mix design 6: Superpave, medium gradation, 12 percent dust content 
Table A7. Volumetric properties mix design 7: Superpave, fine gradation, 4 percent dust content

\begin{tabular}{|c|c|c|c|c|c|c|c|c|c|c|c|c|c|}
\hline \multirow{3}{*}{$\begin{array}{c}\text { Specimen } \\
\text { Number }\end{array}$} & \multirow{3}{*}{$\begin{array}{l}\text { Percent } \\
\text { Asphalt } \\
\text { Content }\end{array}$} & \multirow{3}{*}{$\begin{array}{l}\text { Gyration } \\
\text { Number }\end{array}$} & \multirow{3}{*}{$\begin{array}{c}\text { Specimen } \\
\text { Height } \\
(\mathrm{mm})\end{array}$} & \multicolumn{3}{|c|}{ Weight (g) } & \multicolumn{2}{|c|}{ Specific gravity } & \multirow{2}{*}{$\begin{array}{l}\text { Voids in } \\
\text { total mix }\end{array}$} & \multirow{2}{*}{$\begin{array}{c}\text { Voids in } \\
\text { mineral } \\
\text { aggregate }\end{array}$} & \multirow{2}{*}{$\begin{array}{l}\text { Voids } \\
\text { Filled }\end{array}$} & \multirow{3}{*}{ 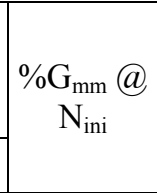 } & \multirow{3}{*}{$\begin{array}{c}\mathrm{P}_{0.075} \text { to } \\
\mathrm{P}_{\mathrm{be}}\end{array}$} \\
\hline & & & & In Air & In Water & (SSD) & Bulk & Maximum & & & & & \\
\hline & & & & $\mathrm{A}$ & $\mathrm{C}$ & $\mathrm{B}$ & & & VTM & VMA & VFA & & \\
\hline \multirow[t]{2}{*}{1} & \multirow{5}{*}{$6.3 \%$} & 6 & 126.2 & & & & 2.132 & & & & & $86.7 \%$ & \\
\hline & & 50 & 115.5 & 4772.2 & 2725.9 & 4774.4 & 2.330 & & & & & & \\
\hline \multirow[t]{2}{*}{2} & & 6 & 127.1 & & & & 2.130 & & & & & $86.7 \%$ & \\
\hline & & 50 & 116.3 & 4779.2 & 2728.3 & 4781.6 & 2.328 & & & & & & \\
\hline Avg. & & & & & & & 2.329 & 2.458 & $5.3 \%$ & $17.8 \%$ & $70.2 \%$ & $86.7 \%$ & 0.73 \\
\hline \multirow[t]{4}{*}{1} & \multirow{5}{*}{$6.8 \%$} & 6 & 127.1 & & & & 2.147 & & & & & $88.0 \%$ & \\
\hline & & 50 & 116.3 & 4821.3 & 2767.7 & 4823 & 2.346 & & & & & & \\
\hline & & 6 & 127.3 & & & & 2.148 & & & & & $88.0 \%$ & \\
\hline & & 50 & 116.4 & 4829.2 & 2776 & 4831.6 & 2.349 & & & & & & \\
\hline Avg. & & & & & & & 2.348 & 2.440 & $3.8 \%$ & $17.6 \%$ & $78.4 \%$ & $88.0 \%$ & 0.67 \\
\hline \multirow[t]{4}{*}{1} & \multirow{5}{*}{$7.3 \%$} & 6 & 126.9 & & & & 2.167 & & & & & $89.5 \%$ & \\
\hline & & 50 & 116.7 & 4858.6 & 2797.9 & 4859.8 & 2.356 & & & & & & \\
\hline & & 6 & 127.1 & & & & 2.155 & & & & & $89.0 \%$ & \\
\hline & & 50 & 116.4 & 4856.2 & 2794.2 & 4857.9 & 2.353 & & & & & & \\
\hline Avg. & & & & & & & 2.355 & 2.422 & $2.8 \%$ & $17.8 \%$ & $84.3 \%$ & $89.2 \%$ & 0.61 \\
\hline 1 & \multirow{5}{*}{$7.8 \%$} & 6 & 127.1 & & & & 2.162 & & & & & $89.9 \%$ & \\
\hline & & 50 & 116.4 & 4884.4 & 2816.9 & 4885.6 & 2.361 & & & & & & \\
\hline \multirow[t]{2}{*}{2} & & 6 & 127.3 & & & & 2.156 & & & & & $89.6 \%$ & \\
\hline & & 50 & 116.4 & 4889.2 & 2817.4 & 4890.6 & 2.358 & & & & & & \\
\hline Avg. & & & & & & & 2.36 & 2.405 & $1.9 \%$ & $18.1 \%$ & $89.5 \%$ & $89.8 \%$ & 0.57 \\
\hline
\end{tabular}



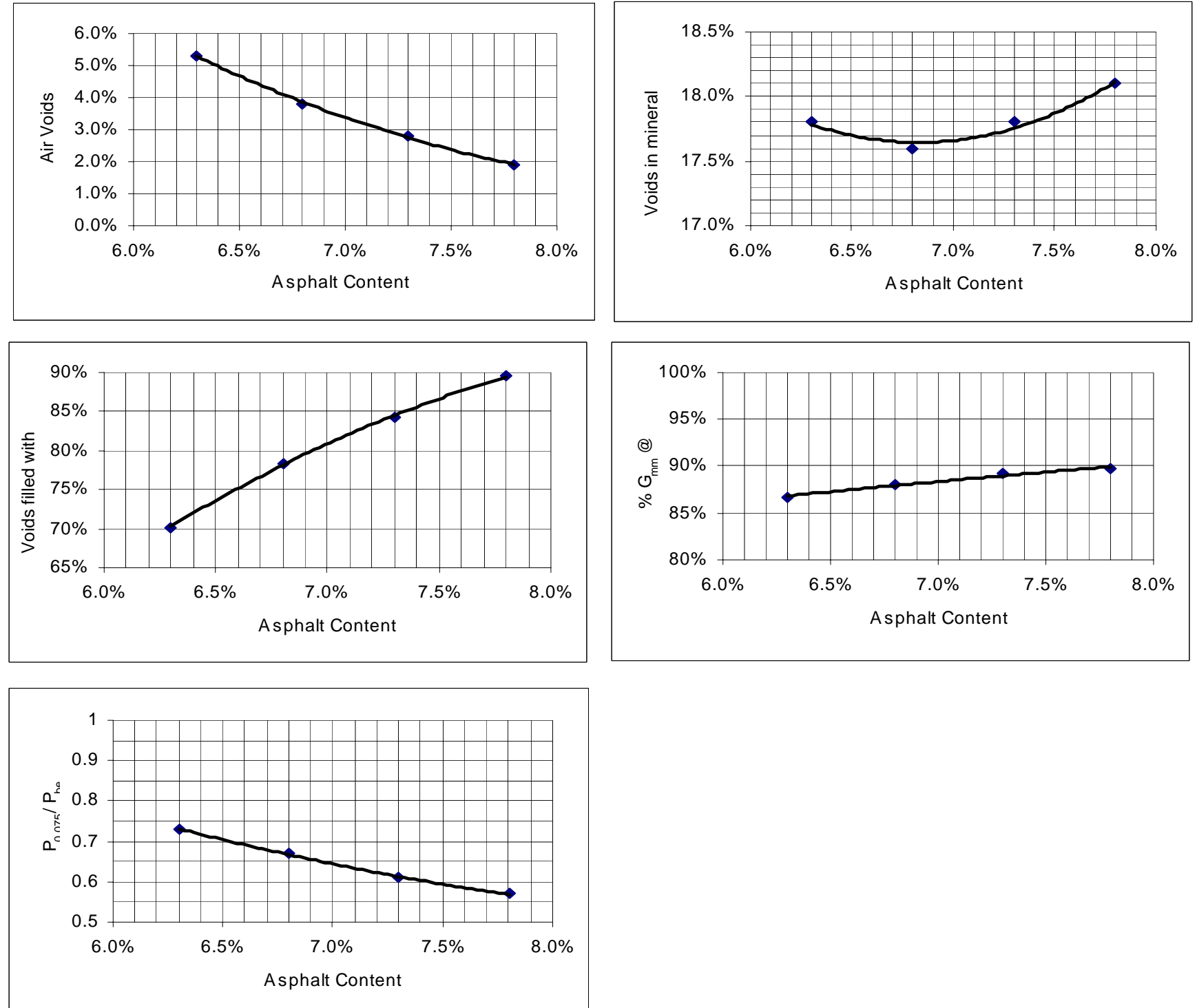

Figure A7. Volumetric properties plots mix design 7: Superpave, fine gradation, 4 percent dust content 
Table A8.Volumetric properties mix design 8: Superpave, fine gradation, 8 percent dust content

\begin{tabular}{|c|c|c|c|c|c|c|c|c|c|c|c|c|c|}
\hline \multirow{3}{*}{$\begin{array}{c}\text { Specimen } \\
\text { Number }\end{array}$} & \multirow{3}{*}{$\begin{array}{l}\text { Percent } \\
\text { Asphalt } \\
\text { Content }\end{array}$} & \multirow{3}{*}{$\begin{array}{l}\text { Gyration } \\
\text { Number }\end{array}$} & \multirow{3}{*}{$\begin{array}{c}\text { Specimen } \\
\text { Height } \\
(\mathrm{mm})\end{array}$} & \multicolumn{3}{|c|}{ Weight (g) } & \multicolumn{2}{|c|}{ Specific gravity } & \multirow{3}{*}{$\begin{array}{l}\text { Voids in } \\
\text { total mix }\end{array}$} & \multirow{3}{*}{\begin{tabular}{|c|}
$\begin{array}{c}\text { Voids in } \\
\text { mineral } \\
\text { aggregate }\end{array}$ \\
VMA \\
\end{tabular}} & \multirow{2}{*}{$\begin{array}{l}\text { Voids } \\
\text { Filled }\end{array}$} & \multirow{3}{*}{$\underset{\mathrm{N}_{\mathrm{ini}}}{\% \mathrm{G}_{\mathrm{mm}}} @$} & \multirow{3}{*}{$\begin{array}{c}\mathrm{P}_{0.075} \text { to } \\
\mathrm{P}_{\text {be }}\end{array}$} \\
\hline & & & & In Air & In Water & (SSD) & \multirow{2}{*}{ Bulk } & \multirow{2}{*}{ Maximum } & & & & & \\
\hline & & & & A & $\mathrm{C}$ & $\mathrm{B}$ & & & & & VFA & & \\
\hline \multirow[t]{2}{*}{1} & \multirow{5}{*}{$5.6 \%$} & 6 & 125.9 & & & & 2.121 & & & & & $85.5 \%$ & \\
\hline & & 50 & 114.1 & 4727 & 2711.3 & 4731.5 & 2.340 & & & & & & \\
\hline \multirow[t]{2}{*}{2} & & 6 & 127.1 & & & & 2.145 & & & & & $86.5 \%$ & \\
\hline & & 50 & 116.3 & 4739.2 & 2711.3 & 4733.1 & 2.344 & & & & & & \\
\hline Avg. & & & & & & & 2.342 & 2.480 & $5.6 \%$ & $16.7 \%$ & $66.5 \%$ & $86.0 \%$ & 1.67 \\
\hline \multirow{4}{*}{2} & \multirow{5}{*}{$6.1 \%$} & 6 & 125.2 & & & & 2.137 & & & & & $86.8 \%$ & \\
\hline & & 50 & 113.4 & 4750.1 & 2745.4 & 4759.1 & 2.359 & & & & & & \\
\hline & & 6 & 124.3 & & & & 2.151 & & & & & $87.4 \%$ & \\
\hline & & 50 & 113.4 & 4759.2 & 2730 & 4748.4 & 2.358 & & & & & & \\
\hline Avg & & & & & & & 2.359 & 2.462 & $4.2 \%$ & $16.6 \%$ & $74.7 \%$ & $87.1 \%$ & 1.51 \\
\hline \multirow[t]{2}{*}{1} & \multirow{5}{*}{$6.6 \%$} & 6 & 125.5 & & & & 2.161 & & & & & $88.4 \%$ & \\
\hline & & 50 & 114.6 & 4806.6 & 2778.5 & 4809.2 & 2.367 & & & & & & \\
\hline \multirow[t]{2}{*}{2} & & 6 & 126.1 & & & & 2.167 & & & & & $88.7 \%$ & \\
\hline & & 50 & 115.4 & 4816.2 & 2784.2 & 4817.7 & 2.368 & & & & & & \\
\hline Avg & & & & & & & 2.368 & 2.444 & $3.1 \%$ & $16.7 \%$ & $81.4 \%$ & $88.6 \%$ & 1.38 \\
\hline \multirow[t]{2}{*}{1} & \multirow{5}{*}{$7.1 \%$} & 6 & 126.1 & & & & 2.162 & & & & & $89.1 \%$ & \\
\hline & & 50 & 115.2 & 4790.9 & 2768.8 & 4792.5 & 2.367 & & & & & & \\
\hline \multirow[t]{2}{*}{2} & & 6 & 127.3 & & & & 2.170 & & & & & $89.4 \%$ & \\
\hline & & 50 & 116.4 & 4799.2 & 2777.4 & 4800.2 & 2.373 & & & & & & \\
\hline Avg & & & & & & & 2.37 & 2.427 & $2.3 \%$ & $17.1 \%$ & $86.5 \%$ & $89.2 \%$ & 1.27 \\
\hline
\end{tabular}



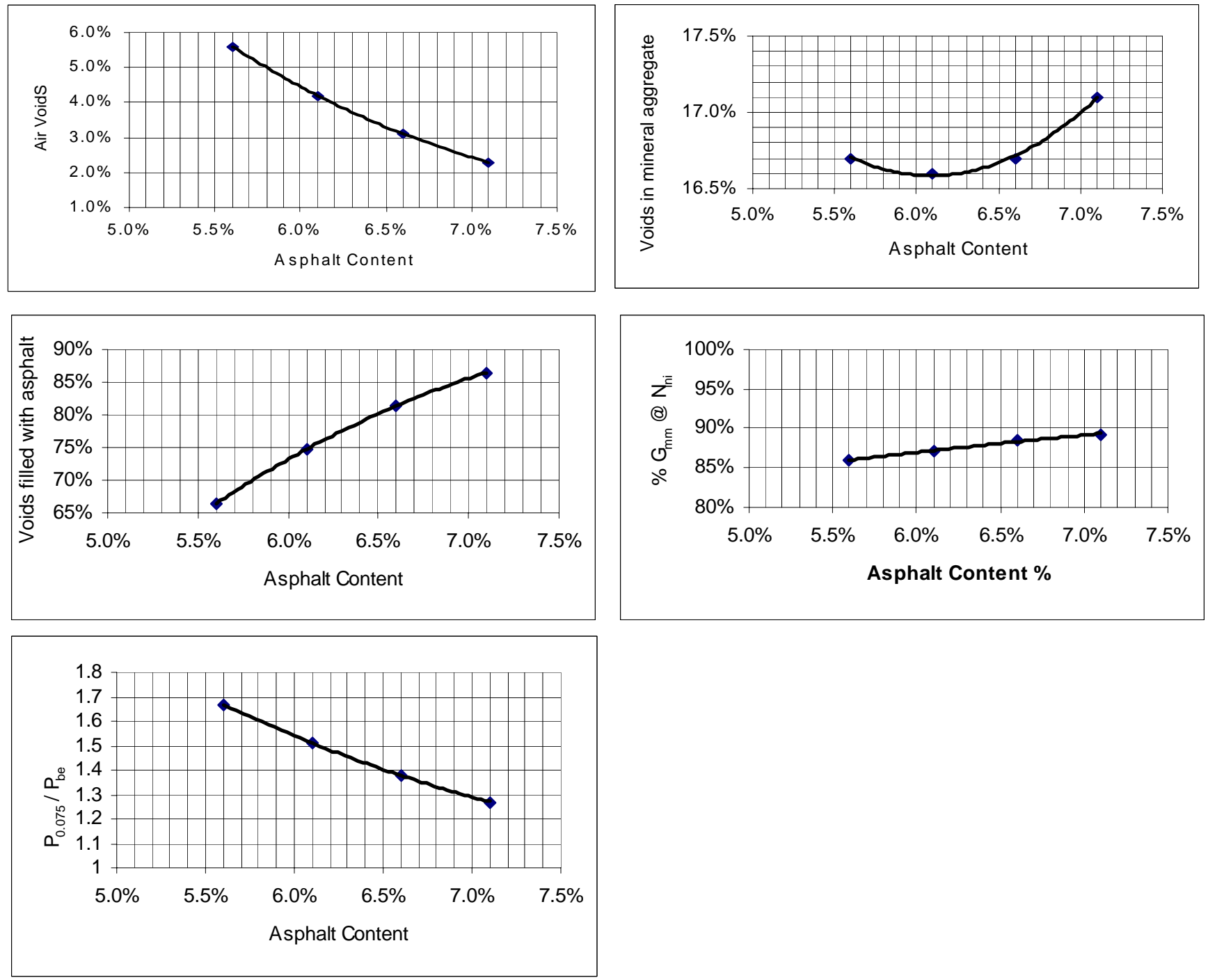

Figure A8.Volumetric properties plots mix design 8: Superpave, fine gradation, 8 percent dust content 
Table A9. Volumetric properties mix design 9: Superpave, fine gradation, 12 percent dust content

\begin{tabular}{|c|c|c|c|c|c|c|c|c|c|c|c|c|c|}
\hline \multirow{3}{*}{$\begin{array}{c}\text { Specimen } \\
\text { Number }\end{array}$} & \multirow{3}{*}{$\begin{array}{l}\text { Percent } \\
\text { Asphalt } \\
\text { Content }\end{array}$} & \multirow{3}{*}{$\begin{array}{l}\text { Gyration } \\
\text { Number }\end{array}$} & \multirow{3}{*}{$\begin{array}{c}\text { Specimen } \\
\text { Height } \\
(\mathrm{mm})\end{array}$} & \multicolumn{3}{|c|}{ Weight (g) } & \multicolumn{2}{|c|}{ Specific gravity } & \multirow{2}{*}{$\begin{array}{l}\text { Voids in } \\
\text { total mix }\end{array}$} & \multirow{2}{*}{$\begin{array}{c}\text { Voids in } \\
\text { mineral } \\
\text { aggregate }\end{array}$} & \multirow{2}{*}{$\begin{array}{l}\text { Voids } \\
\text { Filled }\end{array}$} & \multirow{3}{*}{$\begin{array}{c}\% \mathrm{G}_{\mathrm{mm}} @ \\
\mathrm{~N}_{\mathrm{ini}}\end{array}$} & \multirow{3}{*}{$\begin{array}{c}\mathrm{P}_{0.075} \text { to } \\
\mathrm{P}_{\mathrm{be}}\end{array}$} \\
\hline & & & & In Air & In Water & (SSD) & \multirow{2}{*}{ Bulk } & \multirow{2}{*}{ Maximum } & & & & & \\
\hline & & & & $\mathrm{A}$ & $\mathrm{C}$ & $\mathrm{B}$ & & & VTM & VMA & VFA & & \\
\hline \multirow[t]{2}{*}{1} & \multirow{5}{*}{$4.8 \%$} & 6 & 126.0 & & & & 2.138 & & & & $85.2 \%$ & & \\
\hline & & 50 & 113.4 & 4728.3 & 2742 & 4732.6 & 2.375 & & & & & & \\
\hline \multirow[t]{2}{*}{2} & & 6 & 127.1 & & & & 2.125 & & & & $84.7 \%$ & & \\
\hline & & 50 & 114.0 & 4736.2 & 2741.3 & 4740.4 & 2.369 & & & & & & \\
\hline Avg. & & & & & & & 2.372 & 2.510 & $5.5 \%$ & $14.9 \%$ & $84.9 \%$ & $84.9 \%$ & 3.01 \\
\hline \multirow[t]{4}{*}{1} & \multirow{5}{*}{$5.2 \%$} & 6 & 125.6 & & & & 2.155 & & & & $86.5 \%$ & & \\
\hline & & 50 & 113.0 & 4754.6 & 2777.2 & 4762.8 & 2.395 & & & & & & \\
\hline & & 6 & 126.1 & & & & 2.162 & & & & $86.8 \%$ & & \\
\hline & & 50 & 114.0 & 4768.42 & 2784.2 & 4778.4 & 2.391 & & & & & & \\
\hline Avg. & & & & & & & 2.393 & 2.491 & $3.9 \%$ & $14.6 \%$ & $86.7 \%$ & $86.7 \%$ & 2.67 \\
\hline \multirow[t]{2}{*}{1} & \multirow{5}{*}{$5.8 \%$} & 6 & 126.4 & & & & 2.146 & & & & $86.8 \%$ & & \\
\hline & & 50 & 113.0 & 4813.6 & 2814.2 & 4819.6 & 2.400 & & & & & & \\
\hline \multirow[t]{2}{*}{2} & & 6 & 126.1 & & & & 2.164 & & & & $87.5 \%$ & & \\
\hline & & 50 & 113.4 & 4820.1 & 2819.9 & 4822.9 & 2.406 & & & & & & \\
\hline Avg. & & & & & & & 2.403 & 2.473 & $2.8 \%$ & $14.7 \%$ & $87.1 \%$ & $87.1 \%$ & 2.4 \\
\hline \multirow[t]{2}{*}{1} & \multirow{5}{*}{$6.2 \%$} & 6 & 124.1 & & & & 2.205 & & & & $89.7 \%$ & & \\
\hline & & 50 & 113.2 & 4821.9 & 2828.6 & 4823.6 & 2.417 & & & & & & \\
\hline \multirow[t]{2}{*}{2} & & 6 & 125.9 & & & & 2.181 & & & & $88.7 \%$ & & \\
\hline & & 50 & 113.6 & 4838.2 & 2835.2 & 4840.7 & 2.417 & & & & & & \\
\hline Avg. & & & & & & & 2.417 & 2.459 & $1.7 \%$ & $14.6 \%$ & $89.2 \%$ & $89.2 \%$ & 2.22 \\
\hline
\end{tabular}



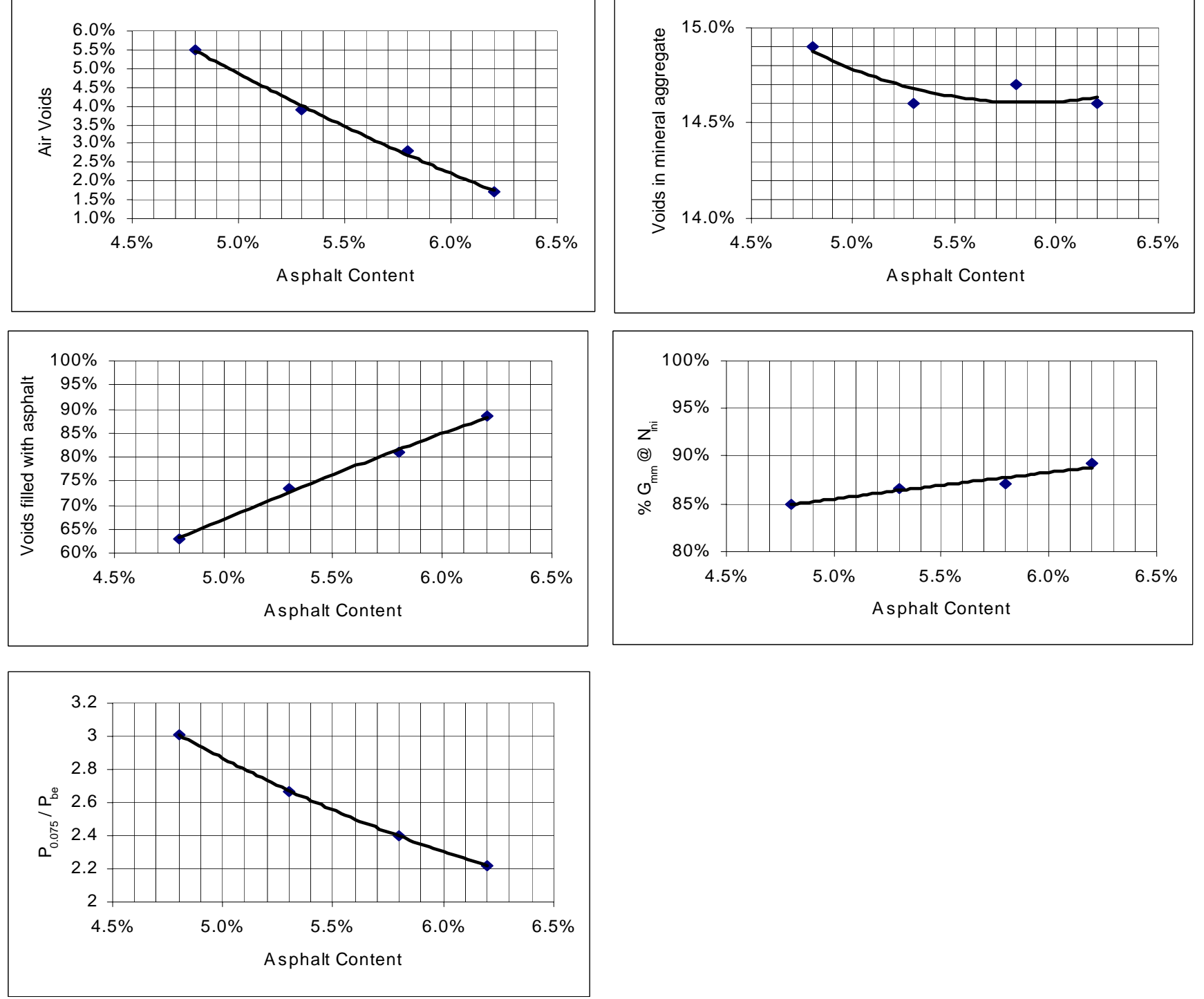

Figure A9. Volumetric properties plots mix design 9: Superpave, fine gradation, 12 percent dust content 
Table A10. APA rut depths for coarse blend gradations

\begin{tabular}{|c|c|c|c|c|c|c|c|c|c|c|}
\hline \multirow{3}{*}{ Mix \# } & \multirow{3}{*}{$\begin{array}{c}\text { Gradation } \\
\text { Blend }\end{array}$} & \multirow{3}{*}{$\begin{array}{c}\text { Dust } \\
\text { Content } \\
\text { percent }\end{array}$} & \multicolumn{4}{|c|}{ 4.0 percent Voids in total Mix } & \multicolumn{4}{|c|}{5.0 percent Voids in total Mix } \\
\hline & & & \multirow{2}{*}{$\begin{array}{l}\text { Reading } \\
\text { Position }\end{array}$} & \multicolumn{3}{|c|}{ Pill Position } & \multirow{2}{*}{$\begin{array}{l}\text { Reading } \\
\text { Position }\end{array}$} & \multicolumn{3}{|c|}{ Pill position } \\
\hline & & & & Left & Center & Front & & Left & Center & Front \\
\hline \multirow{6}{*}{1} & \multirow{6}{*}{ Coarse } & \multirow{6}{*}{4} & \multirow{2}{*}{ Back } & 11.21 & 11.02 & 9.90 & \multirow{2}{*}{ Back } & 9.98 & 9.31 & 9.03 \\
\hline & & & & 10.31 & 10.11 & 10.98 & & 8.97 & 9.98 & 9.21 \\
\hline & & & Avg. & 10.76 & 10.57 & 10.44 & Avg. & 9.48 & 9.65 & 9.12 \\
\hline & & & \multirow{2}{*}{ Front } & 10.21 & 10.04 & 10.43 & \multirow{2}{*}{ Front } & 8.98 & 9.76 & 9.88 \\
\hline & & & & 10.31 & 10.21 & 10.00 & & 8.85 & 8.34 & 8.93 \\
\hline & & & Avg. & 10.26 & 10.13 & 10.22 & Avg. & 8.92 & 9.05 & 9.41 \\
\hline \multirow{6}{*}{2} & \multirow{6}{*}{ Coarse } & \multirow{6}{*}{8} & \multirow{2}{*}{ Back } & 9.41 & 9.89 & 9.35 & \multirow{2}{*}{ Back } & 9.41 & 9.89 & 9.35 \\
\hline & & & & 9.97 & 8.44 & 9.91 & & 9.97 & 8.44 & 9.91 \\
\hline & & & Avg. & 9.69 & 9.17 & 9.63 & Avg. & 9.69 & 9.17 & 9.63 \\
\hline & & & \multirow{2}{*}{ Front } & 9.43 & 9.59 & 8.69 & \multirow{2}{*}{ Front } & 9.43 & 9.59 & 8.69 \\
\hline & & & & 9.21 & 10.11 & 9.27 & & 9.21 & 10.11 & 9.27 \\
\hline & & & Avg. & 9.32 & 9.85 & 8.98 & Avg. & 9.32 & 9.85 & 8.98 \\
\hline \multirow{6}{*}{3} & \multirow{6}{*}{ Coarse } & \multirow{6}{*}{12} & \multirow{2}{*}{ Back } & 7.89 & 7.11 & 7.32 & \multirow{2}{*}{ Back } & 9.41 & 9.89 & 9.35 \\
\hline & & & & 8.38 & 7.98 & 7.91 & & 9.97 & 8.44 & 9.91 \\
\hline & & & Avg. & 8.14 & 7.55 & 7.62 & Avg. & 9.69 & 9.17 & 9.63 \\
\hline & & & \multirow{2}{*}{ Front } & 7.67 & 7.23 & 7.09 & \multirow{2}{*}{ Front } & 9.43 & 9.59 & 8.69 \\
\hline & & & & 8.34 & 7.61 & 8.04 & & 9.21 & 10.11 & 9.27 \\
\hline & & & Avg. & 8.01 & 7.42 & 7.57 & Avg. & 9.32 & 9.85 & 8.98 \\
\hline
\end{tabular}


Table A11. APA rut depths for medium blend gradations

\begin{tabular}{|c|c|c|c|c|c|c|c|c|c|c|}
\hline \multirow{3}{*}{ Mix \# } & \multirow{3}{*}{$\begin{array}{c}\text { Gradation } \\
\text { Blend }\end{array}$} & \multirow{3}{*}{$\begin{array}{c}\text { Dust } \\
\text { Content } \\
\text { percent }\end{array}$} & \multicolumn{4}{|c|}{ 4.0 percent Voids in total Mix } & \multicolumn{4}{|c|}{5.0 percent Voids in total Mix } \\
\hline & & & \multirow{2}{*}{$\begin{array}{l}\text { Reading } \\
\text { Position }\end{array}$} & \multicolumn{3}{|c|}{ Pill Position } & \multirow{2}{*}{$\begin{array}{l}\text { Reading } \\
\text { Position }\end{array}$} & \multicolumn{3}{|c|}{ Pill position } \\
\hline & & & & Left & Center & Front & & Left & Center & Front \\
\hline \multirow{6}{*}{4} & \multirow{6}{*}{ Medium } & \multirow{6}{*}{4} & \multirow{2}{*}{ Back } & 9.45 & 9.01 & 8.89 & \multirow{2}{*}{ Back } & 8.98 & 8.34 & 8.98 \\
\hline & & & & 9.79 & 9.11 & 9.21 & & 9.21 & 9.11 & 8.41 \\
\hline & & & Avg. & 9.62 & 9.06 & 9.05 & Avg. & 9.10 & 8.73 & 8.70 \\
\hline & & & \multirow{2}{*}{ Front } & 10.13 & 9.67 & 9.63 & \multirow{2}{*}{ Front } & 8.36 & 8.22 & 8.77 \\
\hline & & & & 8.89 & 10.34 & 9.32 & & 9.02 & 8.11 & 7.99 \\
\hline & & & Avg. & 9.51 & 10.01 & 9.48 & Avg. & 8.69 & 8.17 & 8.38 \\
\hline \multirow{6}{*}{5} & \multirow{6}{*}{ Medium } & \multirow{6}{*}{8} & \multirow{2}{*}{ Back } & 7.45 & 8.22 & 8.12 & \multirow{2}{*}{ Back } & 8.98 & 7.02 & 8.11 \\
\hline & & & & 8.65 & 7.98 & 8.89 & & 7.21 & 8.32 & 7.32 \\
\hline & & & Avg. & 8.05 & 8.10 & 8.51 & Avg. & 8.10 & 7.67 & 7.72 \\
\hline & & & \multirow{2}{*}{ Front } & 8.32 & 8.30 & 9.05 & \multirow{2}{*}{ Front } & 7.89 & 7.98 & 7.21 \\
\hline & & & & 8.02 & 8.21 & 8.43 & & 8.45 & 7.22 & 8.28 \\
\hline & & & Avg. & 8.17 & 8.26 & 8.74 & Avg. & 8.17 & 7.6 & 7.75 \\
\hline \multirow{6}{*}{6} & \multirow{6}{*}{ Medium } & \multirow{6}{*}{12} & \multirow{2}{*}{ Back } & 9.21 & 7.21 & 8.01 & \multirow{2}{*}{ Back } & 7.21 & 7.34 & 7.19 \\
\hline & & & & 8.32 & 7.98 & 7.61 & & 7.34 & 8.01 & 7.04 \\
\hline & & & Avg. & 8.77 & 7.60 & 7.81 & Avg. & 7.28 & 7.68 & 7.12 \\
\hline & & & \multirow{2}{*}{ Front } & 7.11 & 8.02 & 7.99 & \multirow{2}{*}{ Front } & 8.01 & 7.02 & 7.6 \\
\hline & & & & 8.21 & 8.18 & 8.98 & & 7.16 & 7.12 & 7.08 \\
\hline & & & Avg. & 7.66 & 8.10 & 8.49 & Avg. & 7.59 & 7.07 & 7.34 \\
\hline
\end{tabular}


Table A12. APA rut depths for fine blend gradations

\begin{tabular}{|c|c|c|c|c|c|c|c|c|c|c|}
\hline \multirow{3}{*}{ Mix \# } & \multirow{3}{*}{$\begin{array}{c}\text { Gradation } \\
\text { Blend }\end{array}$} & \multirow{3}{*}{$\begin{array}{c}\text { Dust } \\
\text { Content } \\
\text { percent }\end{array}$} & \multicolumn{4}{|c|}{4.0 percent Voids in total Mix } & \multicolumn{4}{|c|}{5.0 percent Voids in total Mix } \\
\hline & & & \multirow{2}{*}{$\begin{array}{l}\text { Reading } \\
\text { Position }\end{array}$} & \multicolumn{3}{|c|}{ Pill Position } & \multirow{2}{*}{$\begin{array}{l}\text { Reading } \\
\text { Position }\end{array}$} & \multicolumn{3}{|c|}{ Pill position } \\
\hline & & & & Left & Center & Front & & Left & Center & Front \\
\hline \multirow{6}{*}{7} & \multirow{6}{*}{ Fine } & \multirow{6}{*}{4} & \multirow{2}{*}{ Back } & 11.56 & 12.23 & 11.87 & \multirow{2}{*}{ Back } & 11.23 & 10.56 & 10.41 \\
\hline & & & & 11.34 & 11.45 & 12.02 & & 10.94 & 10.27 & 10.27 \\
\hline & & & Avg. & 11.45 & 11.84 & 11.95 & Avg. & 9.88 & 10.45 & 10.56 \\
\hline & & & \multirow{2}{*}{ Front } & 10.34 & 12.32 & 12.23 & \multirow{2}{*}{ Front } & 10.31 & 10.89 & 9.19 \\
\hline & & & & 11.87 & 10.89 & 12.09 & & 10.10 & 10.67 & 9.88 \\
\hline & & & Avg. & 11.11 & 11.61 & 12.16 & Avg. & 10.65 & 9.98 & 10.12 \\
\hline \multirow{6}{*}{8} & \multirow{6}{*}{ Fine } & \multirow{6}{*}{8} & \multirow{2}{*}{ Back } & 11.56 & 12.23 & 11.87 & \multirow{2}{*}{ Back } & 11.23 & 10.56 & 10.41 \\
\hline & & & & 11.34 & 11.45 & 12.02 & & 10.94 & 10.27 & 10.27 \\
\hline & & & Avg. & 11.45 & 11.84 & 11.95 & Avg. & 9.88 & 10.45 & 10.56 \\
\hline & & & \multirow{2}{*}{ Front } & 10.34 & 12.32 & 12.23 & \multirow{2}{*}{ Front } & 10.31 & 10.89 & 9.19 \\
\hline & & & & 11.87 & 10.89 & 12.09 & & 10.10 & 10.67 & 9.88 \\
\hline & & & Avg. & 11.11 & 11.61 & 12.16 & Avg. & 9.80 & 8.11 & 8.80 \\
\hline \multirow{6}{*}{9} & \multirow{6}{*}{ Fine } & \multirow{6}{*}{12} & \multirow{2}{*}{ Back } & 9.29 & 9.27 & 9.66 & \multirow{2}{*}{ Back } & 8.77 & 9.66 & 10.00 \\
\hline & & & & 9.09 & 9.02 & 8.11 & & 9.29 & 8.89 & 9.40 \\
\hline & & & Avg. & 9.19 & 8.66 & 8.89 & Avg. & 9.68 & 9.55 & 9.35 \\
\hline & & & \multirow{2}{*}{ Front } & 8.89 & 8.69 & 8.66 & \multirow{2}{*}{ Front } & 9.11 & 9.98 & 8.78 \\
\hline & & & & 9.22 & 9.34 & 9.24 & & 9.40 & 9.77 & 9.07 \\
\hline & & & Avg. & 9.06 & 9.02 & 8.95 & Avg. & 11.23 & 10.56 & 10.41 \\
\hline
\end{tabular}


APPENDIX B. PHASE II MIX DESIGN DATA 
Table B1. Volumetric properties mix design 10: Marshall, 85 percent limestone -15 percent \#9

\begin{tabular}{|c|c|c|c|c|c|c|c|c|c|c|c|c|c|c|}
\hline \multirow{3}{*}{$\begin{array}{c}\text { Sample } \\
\text { No }\end{array}$} & \multirow{3}{*}{$\begin{array}{l}\text { Asphalt } \\
\text { Content } \\
\text { percent }\end{array}$} & \multirow{3}{*}{$\begin{array}{c}\text { Spec. } \\
\text { Thickness } \\
(\mathrm{mm})\end{array}$} & \multicolumn{3}{|c|}{ Mass (g) } & \multicolumn{2}{|c|}{ Specific gravity } & \multirow{3}{*}{\begin{tabular}{|c|}
$\begin{array}{c}\text { Voids } \\
\text { in total } \\
\text { mix }\end{array}$ \\
VTM \\
\end{tabular}} & \multirow{3}{*}{\begin{tabular}{|c|c|}
$\begin{array}{c}\text { Voids in } \\
\text { mineral } \\
\text { aggregate }\end{array}$ \\
VMA \\
\end{tabular}} & \multirow{3}{*}{$\begin{array}{l}\begin{array}{l}\text { Voids } \\
\text { filled }\end{array} \\
\text { VFA }\end{array}$} & \multirow{3}{*}{$\begin{array}{c}\text { Measured } \\
\text { Stability } \\
\text { (N) }\end{array}$} & \multirow{3}{*}{$\begin{array}{c}\text { Corrected } \\
\text { Stability } \\
(\mathrm{N})\end{array}$} & \multirow{3}{*}{$\begin{array}{l}\text { Flow } \\
0.25 \\
\mathrm{~mm}\end{array}$} & \multirow{3}{*}{$\mid \begin{array}{c}\mathrm{P}_{0.075} \text { to } \\
\mathrm{P}_{\mathrm{be}}\end{array}$} \\
\hline & & & Air & Water & Air & Bulk & Maximum & & & & & & & \\
\hline & & & (Dry) & (SSD) & (SSD) & & & & & & & & & \\
\hline 1 & \multirow{4}{*}{6.0} & 59.6 & 1179.2 & 671.8 & 1181.1 & 2.315 & & & & & 12102 & 12894 & 11.0 & \\
\hline 2 & & 62.0 & 1181.4 & 673.1 & 1182.9 & 2.317 & & & & & 11542 & 11821 & 8.0 & \\
\hline 3 & & 61.0 & 1179.6 & 671.4 & 1181.5 & 2.312 & & & & & 12102 & 12598 & 8.0 & \\
\hline Avg. & & & & & & 2.315 & 2.473 & 6.4 & 18.0 & 64.4 & 11914 & 12438 & 9.0 & 1.18 \\
\hline 1 & \multirow{4}{*}{6.5} & 59.0 & 1180.8 & 677.7 & 1182.2 & 2.341 & & & & & 13783 & 14834 & 10.0 & \\
\hline 2 & & 63.0 & 1183.7 & 677.8 & 1185.1 & 2.333 & & & & & 12998 & 13102 & 11.0 & \\
\hline 3 & & 66.0 & 1184.9 & 678.9 & 1186.4 & 2.335 & & & & & 12774 & 12290 & 11.0 & \\
\hline Avg. & & & & & & 2.336 & 2.455 & 4.8 & 17.7 & 72.9 & 13187 & 13409 & 12.5 & 1.07 \\
\hline 1 & \multirow{4}{*}{7.0} & 60.0 & 1188.5 & 682.3 & 1190.4 & 2.339 & & & & & 13783 & 14587 & 12.0 & \\
\hline 2 & & 64.0 & 1190.4 & 683.7 & 1191.5 & 2.344 & & & & & 13447 & 13342 & 12.5 & \\
\hline 3 & & 67.0 & 1191.9 & 684.4 & 1192.1 & 2.348 & & & & & 13335 & 12638 & 15.0 & \\
\hline Avg. & & & & & & 2.344 & 2.437 & 3.8 & 17.9 & 78.8 & 13523 & 13522 & 13.2 & 0.99 \\
\hline 1 & \multirow{4}{*}{7.5} & 59.0 & 1177.2 & 677.1 & 1178.0 & 2.350 & & & & & 12550 & 13507 & 14.0 & \\
\hline 2 & & 67.0 & 1194.4 & 686.4 & 1195.2 & 2.347 & & & & & 12998 & 12319 & 12.5 & \\
\hline 3 & & 66.0 & 1191.1 & 685.7 & 1191.9 & 2.353 & & & & & 13223 & 12722 & 16.0 & \\
\hline Avg. & & & & & & 2.350 & 2.419 & 2.9 & 18.1 & 84.0 & 12922 & 12850 & 14.2 & 0.91 \\
\hline 1 & \multirow{4}{*}{8.0} & 59.0 & 1184.0 & 682.5 & 1185.6 & 2.353 & & & & & 11654 & 12543 & 16.0 & \\
\hline 2 & & 62.0 & 1200.4 & 693.0 & 1200.9 & 2.363 & & & & & 11474 & 11752 & 15.0 & \\
\hline 3 & & 63.0 & 1201.2 & 692.7 & 1202.0 & 2.359 & & & & & 11833 & 11927 & 15.5 & \\
\hline Avg. & & & & & & 2.358 & 2.402 & 1.8 & 18.3 & 90.2 & 11654 & 12074 & 15.5 & 0.85 \\
\hline
\end{tabular}



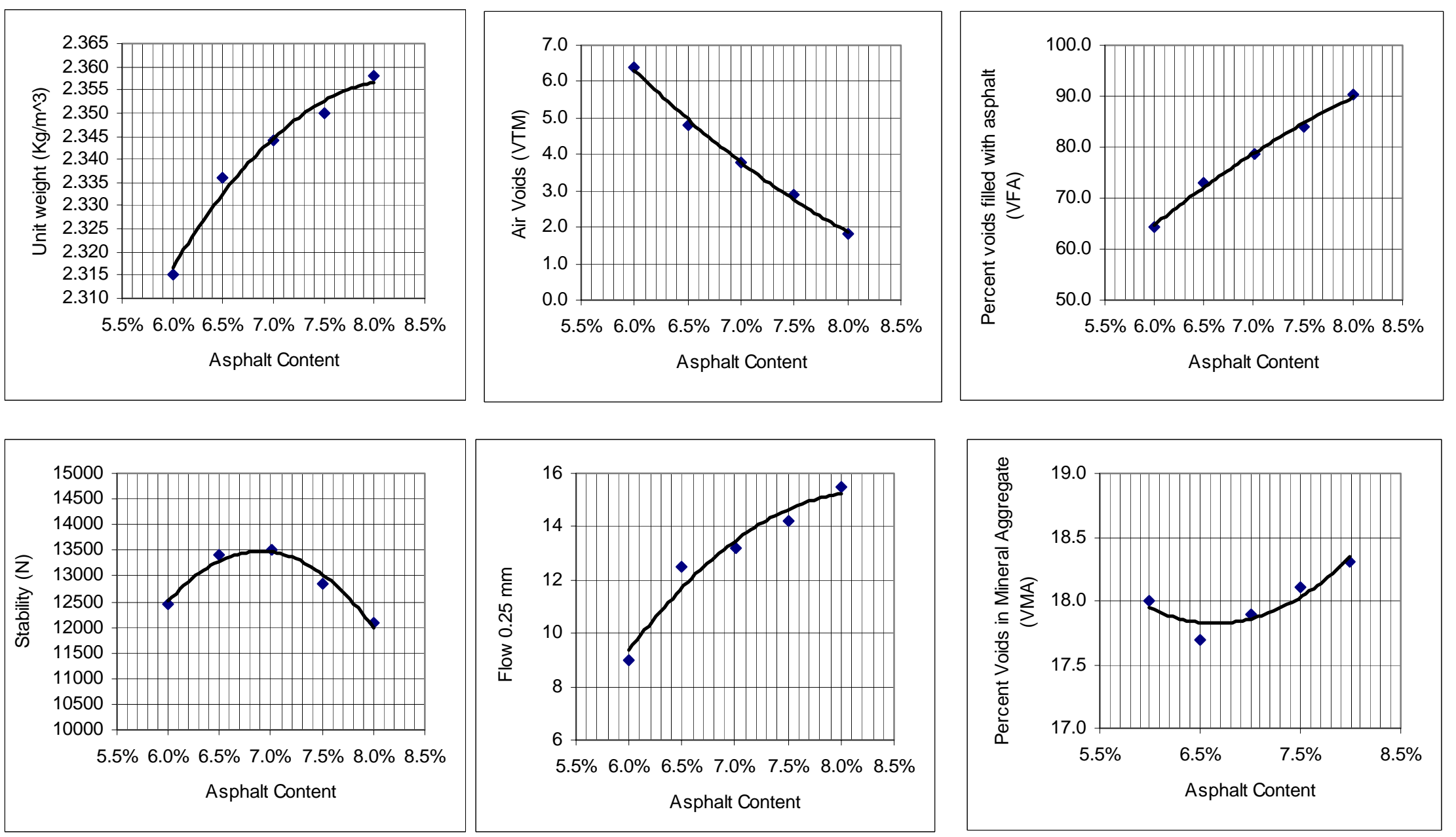

Figure B1. Volumetric properties plots mix design 10: Marshall Mix 10, 85 percent limestone - 15 percent \#9 
Table B2. Volumetric properties mix design 11: Marshall, 55 percent limestone - 45 percent natural sand

\begin{tabular}{|c|c|c|c|c|c|c|c|c|c|c|c|c|c|c|}
\hline \multirow{3}{*}{$\begin{array}{c}\text { Sample } \\
\text { No }\end{array}$} & \multirow{3}{*}{$\begin{array}{l}\text { Asphalt } \\
\text { Content } \\
\text { percent }\end{array}$} & \multirow{3}{*}{$\begin{array}{c}\text { Spec. } \\
\text { Thickness } \\
(\mathrm{mm})\end{array}$} & \multicolumn{3}{|c|}{$\operatorname{Mass}(\mathrm{g})$} & \multicolumn{2}{|c|}{ Specific Gravity } & \multirow{3}{*}{\begin{tabular}{|c|}
$\begin{array}{c}\text { Voids } \\
\text { in total } \\
\text { mix }\end{array}$ \\
VTM \\
\end{tabular}} & \multirow{3}{*}{\begin{tabular}{|c|}
$\begin{array}{c}\text { Voids in } \\
\text { mineral } \\
\text { aggregate }\end{array}$ \\
VMA \\
\end{tabular}} & \multirow{3}{*}{$\begin{array}{l}\begin{array}{l}\text { Voids } \\
\text { filled }\end{array} \\
\text { VFA } \\
\end{array}$} & \multirow{3}{*}{$\begin{array}{c}\text { Measured } \\
\text { Stability } \\
\text { (N) }\end{array}$} & \multirow{3}{*}{$\begin{array}{c}\text { Corrected } \\
\text { Stability } \\
\text { (N) }\end{array}$} & \multirow{3}{*}{$\begin{array}{c}\text { Flow } 0.25 \\
\mathrm{~mm}\end{array}$} & \multirow{3}{*}{$\underset{\mathrm{P}_{0.075} \text { to }}{\mathrm{P}_{\mathrm{be}}}$} \\
\hline & & & Air & Water & Air & \multirow{2}{*}{ Bulk } & \multirow{2}{*}{ Maximum } & & & & & & & \\
\hline & & & (Dry) & (SSD) & (SSD) & & & & & & & & & \\
\hline 1 & \multirow{4}{*}{6.5} & 58.0 & 1187.0 & 662.4 & 1188.7 & 2.255 & & & & & 5379 & 5888.7 & 11.5 & \\
\hline 2 & & 62.0 & 1179.0 & 659.3 & 1180.7 & 2.261 & & & & & 6051 & 6197.4 & 10.0 & \\
\hline 3 & & 60.0 & 1179.4 & 659.9 & 1181.2 & 2.262 & & & & & 4706 & 4980.9 & 12.0 & \\
\hline Avg. & & & & & & 2.259 & 2.435 & 7.2 & 18.9 & 61.9 & 5379 & 5689.0 & 11.2 & 1.14 \\
\hline 1 & \multirow{4}{*}{7.0} & 64.0 & 1181.1 & 662.4 & 1182.5 & 2.271 & & & & & 6723 & 6670.8 & 13.0 & \\
\hline 2 & & 61.0 & 1180.4 & 662.2 & 1181.6 & 2.273 & & & & & 7284 & 7582.1 & 13.0 & \\
\hline 3 & & 58.0 & 1188.2 & 667.5 & 1189.7 & 2.275 & & & & & 7396 & 8097.0 & 14.0 & \\
\hline Avg. & & & & & & 2.273 & 2.417 & 6.0 & 18.8 & 68.1 & 7134 & 7450.0 & 13.3 & 1.04 \\
\hline 1 & \multirow{4}{*}{7.5} & 66.0 & 1181.0 & 668.8 & 1182.4 & 2.299 & & & & & 7620 & 7331.1 & 14.0 & \\
\hline 2 & & 62.0 & 1179.3 & 668.5 & 1180.5 & 2.303 & & & & & 7396 & 7574.6 & 14.0 & \\
\hline 3 & & 60.0 & 1177.2 & 664.4 & 1178.4 & 2.290 & & & & & 8068 & 8538.6 & 15.0 & \\
\hline Avg. & & & & & & 2.297 & 2.400 & 4.3 & 18.4 & 76.6 & 7694 & 7815.0 & 14.3 & 0.96 \\
\hline 1 & \multirow{4}{*}{8.0} & 61.0 & 1180.4 & 674.1 & 1181.1 & 2.328 & & & & & 6723 & 6998.9 & 15.0 & \\
\hline 2 & & 65.0 & 1182.6 & 675.2 & 1183.6 & 2.326 & & & & & 6387 & 6239.8 & 15.0 & \\
\hline 3 & & 61.0 & 1184.0 & 675.5 & 1185.0 & 2.324 & & & & & 6679 & 6952.2 & 16.0 & \\
\hline Avg. & & & & & & 2.326 & 2.383 & 2.4 & 17.8 & 86.5 & 6596 & 6730.0 & 15.3 & 0.80 \\
\hline 1 & \multirow{4}{*}{8.5} & 63.0 & 1178.3 & 671.9 & 1178.9 & 2.324 & & & & & 6275 & 6324.9 & 17.0 & \\
\hline 2 & & 61.0 & 1156.6 & 662.4 & 1157.2 & 2.338 & & & & & 6230 & 6485.6 & 18.0 & \\
\hline 3 & & 63.0 & 1179.3 & 673.9 & 1179.9 & 2.331 & & & & & 4975 & 5014.8 & 16.0 & \\
\hline Avg. & & & & & & 2.331 & 2.366 & 1.5 & 18.1 & 91.7 & 5827 & 5942.0 & 17.0 & 0.83 \\
\hline
\end{tabular}



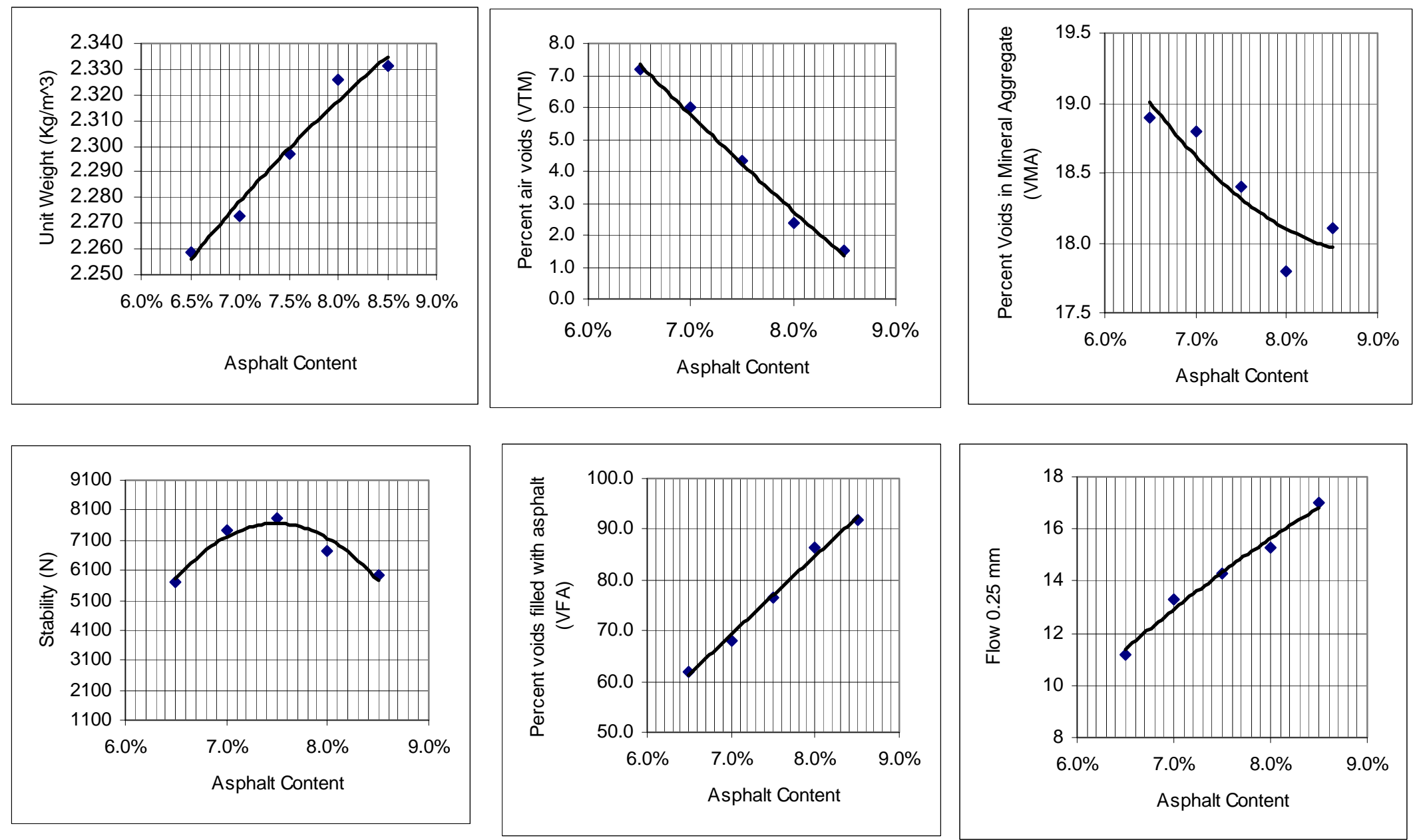

Figure B2 Volumetric properties plots mix design 11: Marshall, 55 percent limestone - 45 percent natural sand 
Table B3. Volumetric properties mix design 12: Marshall, 60 percent limestone -40 percent natural sand

\begin{tabular}{|c|c|c|c|c|c|c|c|c|c|c|c|c|c|c|}
\hline \multirow{3}{*}{$\begin{array}{c}\text { Sample } \\
\text { No }\end{array}$} & \multirow{3}{*}{$\begin{array}{l}\text { Asphalt } \\
\text { Content } \\
\text { percent }\end{array}$} & \multirow{3}{*}{$\begin{array}{c}\text { Spec. } \\
\text { Thickness } \\
(\mathrm{mm})\end{array}$} & \multicolumn{3}{|c|}{ Mass (g) } & \multicolumn{2}{|c|}{ Specific Gravity } & \multirow{3}{*}{\begin{tabular}{|c|}
$\begin{array}{c}\text { Voids } \\
\text { in total } \\
\text { mix }\end{array}$ \\
VTM \\
\end{tabular}} & \multirow{3}{*}{\begin{tabular}{|c}
$\begin{array}{c}\text { Voids in } \\
\text { mineral } \\
\text { aggregate }\end{array}$ \\
VMA \\
\end{tabular}} & \multirow{3}{*}{$\begin{array}{l}\text { Voids } \\
\text { filled }\end{array}$} & \multirow{3}{*}{$\begin{array}{c}\text { Measured } \\
\text { Stability } \\
\text { (N) }\end{array}$} & \multirow{3}{*}{$\begin{array}{l}\text { Corrected } \\
\text { Stability } \\
\text { (N) }\end{array}$} & \multirow{3}{*}{$\begin{array}{c}\text { Flow } 0.25 \\
\mathrm{~mm}\end{array}$} & \multirow{3}{*}{$\mid \begin{array}{c}\mathrm{P}_{0.075} \\
\mathrm{P}_{\mathrm{be}}\end{array}$} \\
\hline & & & Air & Water & Air & \multirow[t]{2}{*}{ Bulk } & \multirow[t]{2}{*}{ Maximum } & & & & & & & \\
\hline & & & (Dry) & (SSD) & (SSD) & & & & & & & & & \\
\hline 1 & \multirow{4}{*}{6.5} & 63 & 1187.0 & 667.1 & 1188.3 & 2.277 & & & & & 11878 & 11972 & 13.0 & \\
\hline 2 & & 61 & 1182.0 & 662.8 & 1180.4 & 2.284 & & & & & 11250 & 11711 & 12.0 & \\
\hline 3 & & 59 & 1179.4 & 661.1 & 1180.2 & 2.272 & & & & & 11161 & 12012 & 10.0 & \\
\hline Avg. & & & & & & 2.278 & 2.439 & 6.6 & 18.4 & 64.1 & 11430 & 11899 & 11.7 & 1.02 \\
\hline 1 & \multirow{4}{*}{7.0} & 61 & 1178.4 & 666.9 & 1179.6 & 2.298 & & & & & 11833 & 12318 & 13.0 & \\
\hline 2 & & 60 & 1182.5 & 669.9 & 1183.5 & 2.302 & & & & & 11116 & 11764 & 13.0 & \\
\hline 3 & & 63 & 1170.4 & 662.9 & 1172.0 & 2.299 & & & & & 10533 & 10617 & 13.0 & \\
\hline Avg. & & & & & & 2.300 & 2.421 & 5.0 & 18.0 & 72.2 & 11161 & 11566 & 13.0 & 0.94 \\
\hline 1 & \multirow{4}{*}{7.5} & 61 & 1179.5 & 672.5 & 1180.3 & 2.323 & & & & & 10264 & 10685 & 13.0 & \\
\hline 2 & & 59 & 1175.4 & 668.9 & 1176.0 & 2.318 & & & & & 9995 & 10758 & 15.0 & \\
\hline 3 & & 66 & 1172.3 & 669.4 & 1175.0 & 2.319 & & & & & 9682 & 9315 & 15.0 & \\
\hline Avg. & & & & & & 2.320 & 2.404 & 3.5 & 17.8 & 80.3 & 9982 & 10253 & 14.3 & 0.87 \\
\hline 1 & \multirow{4}{*}{8.0} & 66 & 1183.4 & 676.7 & 1184.8 & 2.329 & & & & & 10085 & 9703 & 16.0 & \\
\hline 2 & & 63 & 1178.6 & 672.4 & 1179.2 & 2.326 & & & & & 9413 & 9487 & 15.0 & \\
\hline 3 & & 61 & 1180.3 & 673.0 & 1180.9 & 2.324 & & & & & 9099 & 9472 & 16.0 & \\
\hline Avg. & & & & & & 2.326 & 2.387 & 2.5 & 18.0 & 86.1 & 9534 & 9554 & 15.7 & 0.81 \\
\hline 1 & \multirow{4}{*}{8.5} & 59 & 1180.9 & 674.1 & 1181.5 & 2.327 & & & & & 8471 & 9118 & 18.0 & \\
\hline 2 & & 61 & 1182.8 & 676.3 & 1183.1 & 2.334 & & & & & 9278 & 9658 & 19.0 & \\
\hline 3 & & 66 & 1187.2 & 678.7 & 1188.1 & 2.331 & & & & & 8875 & 8539 & 21.0 & \\
\hline Avg. & & & & & & 2.331 & 2.370 & 1.6 & 18.3 & 91.3 & 8875 & 9105 & 19.3 & 0.76 \\
\hline
\end{tabular}



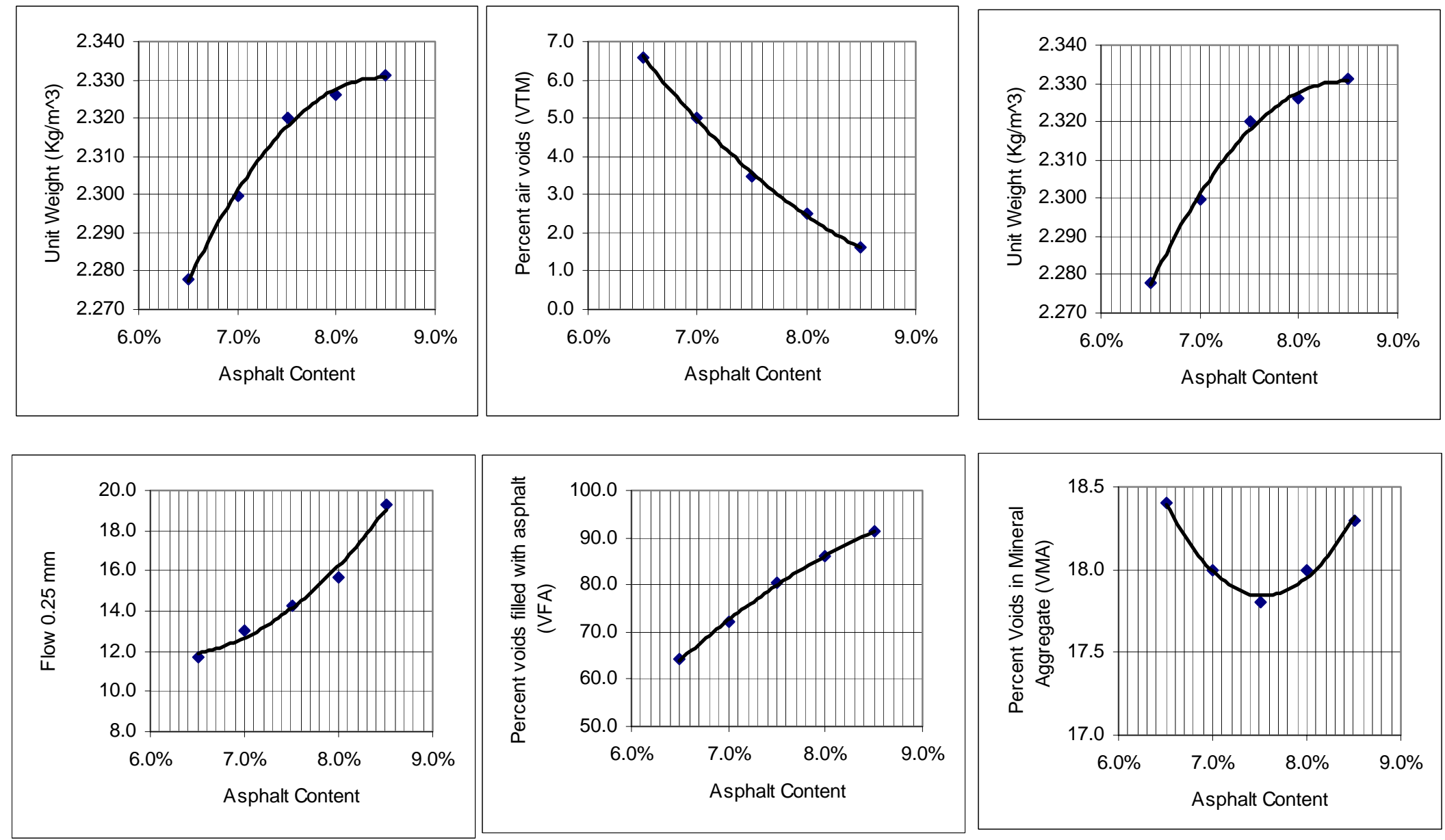

Figure B3. Volumetric properties plots mix design 12: Marshall, 60 percent limestone -40 percent natural sand 
Table B4. Volumetric properties mix design 13: Superpave, 85 percent limestone -15 percent \#9

\begin{tabular}{|c|c|c|c|c|c|c|c|c|c|c|c|c|c|}
\hline \multirow{3}{*}{$\begin{array}{l}\text { Specimen } \\
\text { Number }\end{array}$} & \multirow{3}{*}{$\begin{array}{l}\text { Percent } \\
\text { Asphalt } \\
\text { Content }\end{array}$} & \multirow{3}{*}{$\begin{array}{l}\text { Gyration } \\
\text { Number }\end{array}$} & \multirow{3}{*}{$\begin{array}{c}\text { Specimen } \\
\text { Height } \\
(\mathrm{mm})\end{array}$} & \multicolumn{3}{|c|}{ Weight $(\mathrm{g})$} & \multicolumn{2}{|c|}{ Specific gravity } & \multirow{2}{*}{$\begin{array}{l}\text { Voids in } \\
\text { total mix }\end{array}$} & \multirow{2}{*}{$\begin{array}{c}\text { Voids in } \\
\text { mineral } \\
\text { aggregate }\end{array}$} & \multirow{2}{*}{$\begin{array}{l}\text { Voids } \\
\text { Filled }\end{array}$} & \multirow{3}{*}{$\begin{array}{c}\% \mathrm{G}_{\mathrm{mm}} \\
\mathrm{N}_{\mathrm{ini}}\end{array}$} & \multirow{3}{*}{$\begin{array}{c}\mathrm{P}_{0.075} \text { to } \\
\mathrm{P}_{\mathrm{be}}\end{array}$} \\
\hline & & & & In Air & In Water & (SSD) & Bulk & Maximum & & & & & \\
\hline & & & & A & $\mathrm{C}$ & $\mathrm{B}$ & & & VTM & VMA & VFA & & \\
\hline \multirow[t]{2}{*}{1} & \multirow{5}{*}{$6.0 \%$} & 6 & 128.5 & & & & 2.074 & & & & & & \\
\hline & & 50 & 115.0 & 4648.5 & 2654.3 & 4659.3 & 2.318 & & & & & & \\
\hline \multirow[t]{2}{*}{2} & & 6 & 126.4 & & & & 2.124 & & & & & & \\
\hline & & 50 & 114.9 & 4664.1 & 2702.3 & 4698.4 & 2.337 & & & & & & \\
\hline Avg. & & & & & & & 2.328 & 2.473 & $5.9 \%$ & $17.6 \%$ & $66.5 \%$ & $84.9 \%$ & 1.24 \\
\hline \multirow[t]{2}{*}{1} & \multirow{5}{*}{$6.5 \%$} & 6 & 126.5 & & & & 2.128 & & & & & & \\
\hline & & 50 & 113.1 & 4695.9 & 2750.5 & 4723.6 & 2.380 & & & & & & \\
\hline \multirow[t]{2}{*}{2} & & 6 & 125.4 & & & & 2.142 & & & & & & \\
\hline & & 50 & 114.3 & 4669.7 & 2713.4 & 4700.4 & 2.350 & & & & & & \\
\hline Avg. & & & & & & & 2.365 & 2.455 & $3.7 \%$ & $16.7 \%$ & $77.8 \%$ & $87.0 \%$ & 1.13 \\
\hline \multirow[t]{2}{*}{1} & \multirow{5}{*}{$7.0 \%$} & 6 & 125.0 & & & & 2.136 & & & & & & \\
\hline & & 50 & 112.1 & 4667.3 & 2730.1 & 4689.8 & 2.382 & & & & & & \\
\hline \multirow[t]{2}{*}{2} & & 6 & 124.9 & & & & 2.152 & & & & & & \\
\hline & & 50 & 113.7 & 4699.3 & 2741.3 & 4729.1 & 2.364 & & & & & & \\
\hline Avg. & & & & & & & 2.373 & 2.437 & $2.6 \%$ & $16.8 \%$ & $84.5 \%$ & $88.0 \%$ & 1.04 \\
\hline \multirow[t]{2}{*}{1} & \multirow{5}{*}{$7.5 \%$} & 6 & 124.7 & & & & 2.162 & & & & & & \\
\hline & & 50 & 113.0 & 4697.5 & 2736.0 & 4704.8 & 2.386 & & & & & & \\
\hline \multirow[t]{2}{*}{2} & & 6 & 124.4 & & & & 2.162 & & & & & & \\
\hline & & 50 & 112.7 & 4697.5 & 2736.0 & 4704.8 & 2.386 & & & & & & \\
\hline Avg. & & & & & & & 2.386 & 2.419 & $1.4 \%$ & $16.8 \%$ & $91.7 \%$ & $89.4 \%$ & 0.96 \\
\hline
\end{tabular}



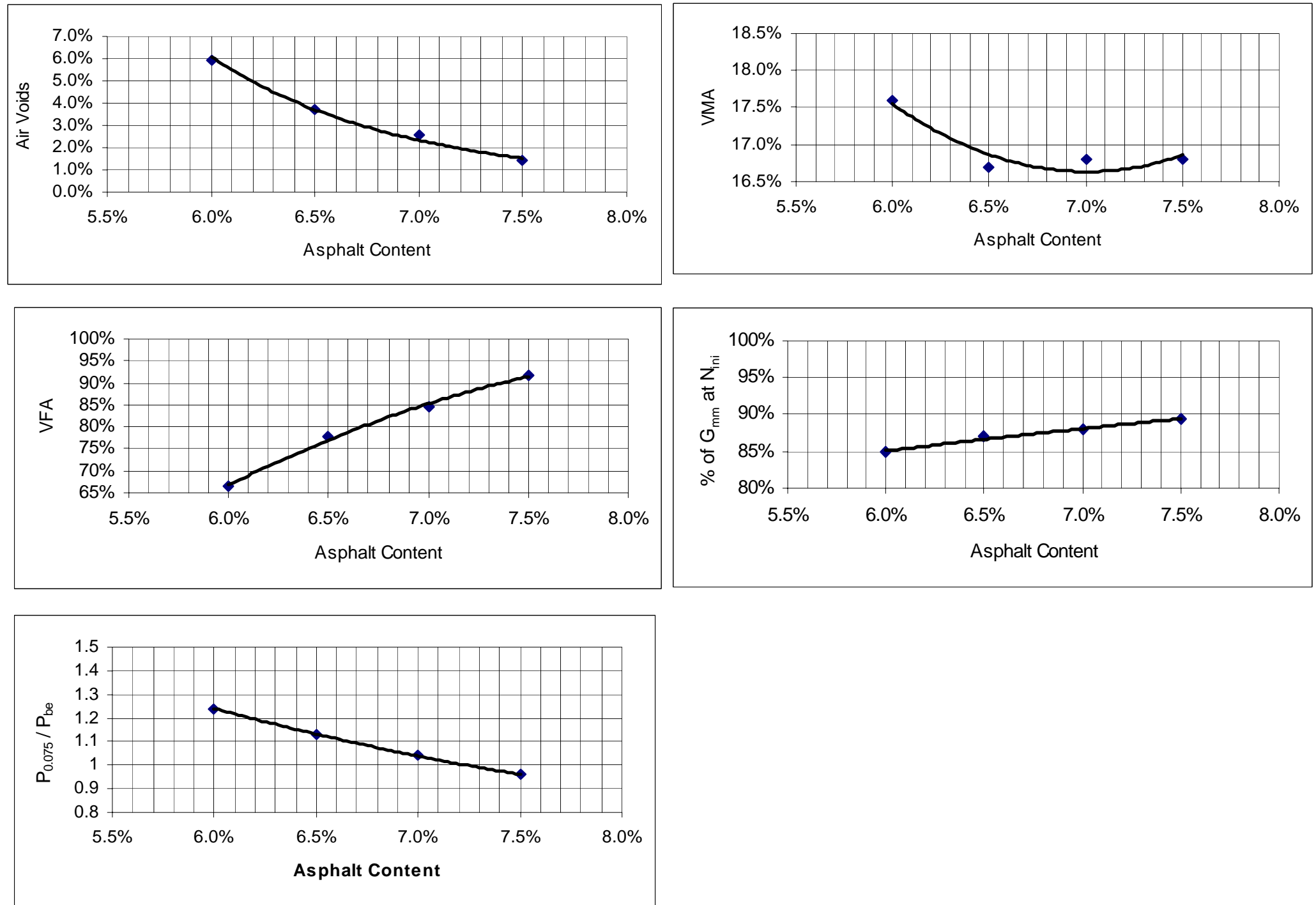

Figure B4. Volumetric properties plots mix design 13: Superpave, 85 percent limestone - 15 percent \#9 
Table B5. Volumetric properties mix design 14: Superpave, 55 percent limestone -45 percent natural sand

\begin{tabular}{|c|c|c|c|c|c|c|c|c|c|c|c|c|c|}
\hline \multirow{3}{*}{$\begin{array}{l}\text { Specimen } \\
\text { Number }\end{array}$} & \multirow{3}{*}{$\begin{array}{l}\text { Percent } \\
\text { Asphalt } \\
\text { Content }\end{array}$} & \multirow{3}{*}{$\begin{array}{l}\text { Gyration } \\
\text { Number }\end{array}$} & \multirow{3}{*}{$\begin{array}{c}\text { Specimen } \\
\text { Height } \\
(\mathrm{mm})\end{array}$} & \multicolumn{3}{|c|}{ Weight $(\mathrm{g})$} & \multicolumn{2}{|c|}{ Specific gravity } & \multirow{3}{*}{\begin{tabular}{|c|}
$\begin{array}{c}\text { Voids in } \\
\text { total mix }\end{array}$ \\
VTM \\
\end{tabular}} & \multirow{3}{*}{$\begin{array}{c}\begin{array}{c}\text { Voids in } \\
\text { mineral } \\
\text { aggregate }\end{array} \\
\text { VMA }\end{array}$} & \multirow{3}{*}{$\begin{array}{c}\text { Voids } \\
\text { Filled } \\
\text { VFA }\end{array}$} & \multirow{3}{*}{$\underset{\mathrm{N}_{\mathrm{ini}}}{\% \mathrm{G}_{\mathrm{mm}}} @$} & \multirow{3}{*}{$\begin{array}{c}\mathrm{P}_{0.075} \text { to } \\
\mathrm{P}_{\mathrm{be}}\end{array}$} \\
\hline & & & & In Air & In Water & (SSD) & \multirow{2}{*}{ Bulk } & \multirow{2}{*}{ Maximum } & & & & & \\
\hline & & & & A & $\mathrm{C}$ & B & & & & & & & \\
\hline \multirow[t]{2}{*}{1} & \multirow{5}{*}{$5.7 \%$} & 6 & 125.5 & & & & 2.149 & & & & & & \\
\hline & & 50 & 116.2 & 4691.6 & 2695.6 & 4717.3 & 2.321 & & & & & & \\
\hline \multirow[t]{2}{*}{2} & & 6 & 124.8 & & & & 2.139 & & & & & & \\
\hline & & 50 & 115.6 & 4636.8 & 2649.4 & 4657.6 & 2.309 & & & & & & \\
\hline Avg. & & & & & & & 2.315 & 2.463 & $6.0 \%$ & $16.2 \%$ & $63.0 \%$ & $87.0 \%$ & 1.58 \\
\hline \multirow[t]{2}{*}{1} & \multirow{5}{*}{$6.2 \%$} & 6 & 124.5 & & & & 2.168 & & & & & & \\
\hline & & 50 & 115.3 & 4698.4 & 2717.5 & 4724.5 & 2.341 & & & & & & \\
\hline \multirow[t]{2}{*}{2} & & 6 & 124.6 & & & & 2.168 & & & & & & \\
\hline & & 50 & 115.4 & 4700.4 & 2719.1 & 4727.1 & 2.341 & & & & & & \\
\hline Avg. & & & & & & & 2.341 & 2.445 & $4.3 \%$ & $15.7 \%$ & $72.6 \%$ & $88.7 \%$ & 1.42 \\
\hline \multirow[t]{2}{*}{1} & \multirow{5}{*}{$6.7 \%$} & 6 & 123.3 & & & & 2.176 & & & & & & \\
\hline & & 50 & 114.3 & 4667 & 2681.5 & 4670 & 2.347 & & & & & & \\
\hline \multirow[t]{2}{*}{2} & & 6 & 124.4 & & & & 2.172 & & & & & & \\
\hline & & 50 & 115.0 & 4703 & 2726.1 & 4727.7 & 2.350 & & & & & & \\
\hline Avg. & & & & & & & 2.3485 & 2.427 & $3.3 \%$ & $15.9 \%$ & $79.2 \%$ & $89.6 \%$ & 1.29 \\
\hline \multirow[t]{2}{*}{1} & \multirow{5}{*}{$7.2 \%$} & 6 & 123.3 & & & & 2.185 & & & & & & \\
\hline & & 50 & 114.3 & 4685.9 & 2700.6 & 4688.6 & 2.357 & & & & & & \\
\hline \multirow[t]{2}{*}{2} & & 6 & 124.6 & & & & 2.179 & & & & & & \\
\hline & & 50 & 115.4 & 4733.8 & 2746.1 & 4757.9 & 2.353 & & & & & & \\
\hline Avg. & & & & & & & 2.355 & 2.410 & $2.3 \%$ & $16.1 \%$ & $85.7 \%$ & $90.5 \%$ & 1.18 \\
\hline
\end{tabular}



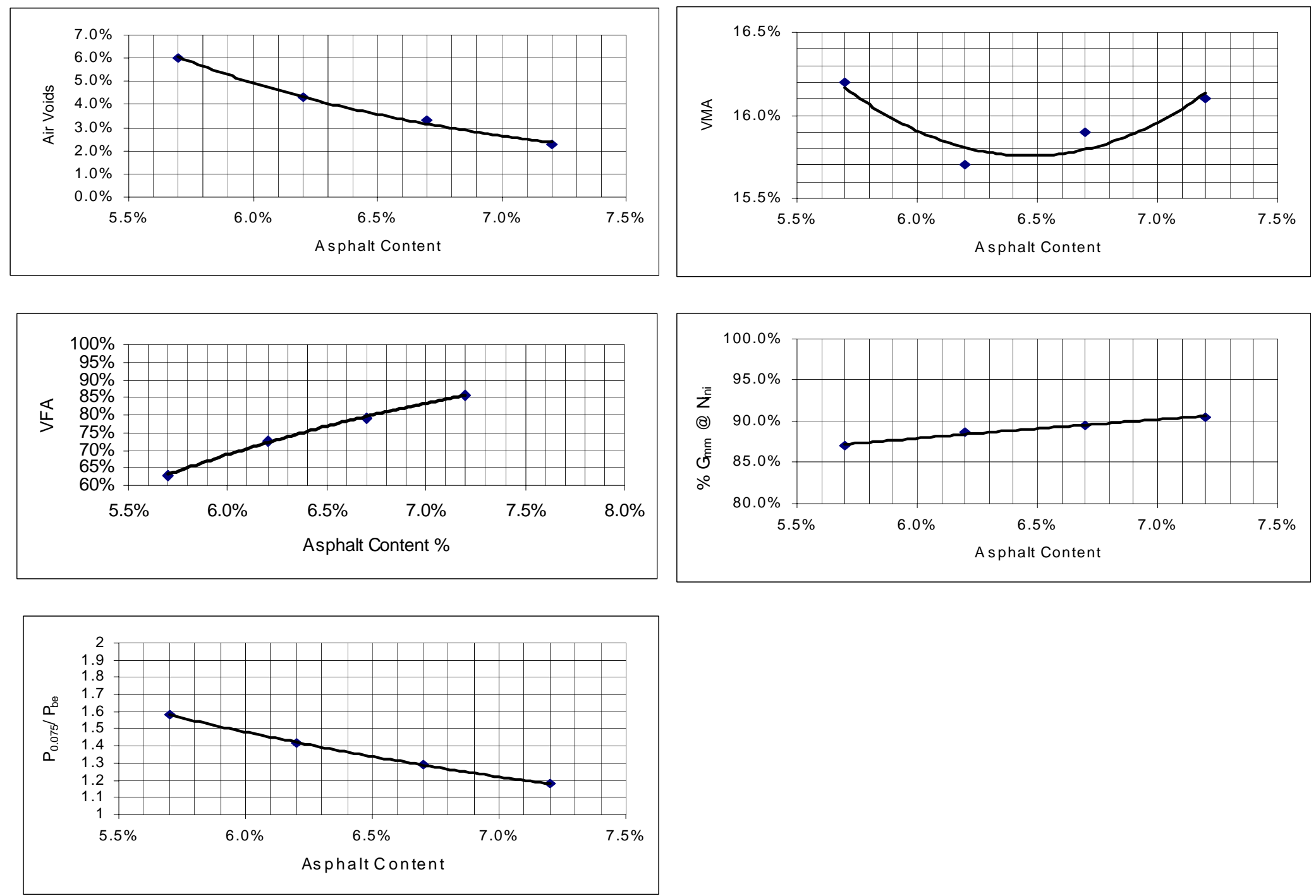

Figure B5. Volumetric properties plots mix design 14: Superpave, 55 percent limestone -45 percent natural sand 
Table B6. Volumetric properties mix design 15: Superpave, 60 percent limestone -40 percent natural sand

\begin{tabular}{|c|c|c|c|c|c|c|c|c|c|c|c|c|c|}
\hline \multirow{3}{*}{$\begin{array}{l}\text { Specimen } \\
\text { Number }\end{array}$} & \multirow{3}{*}{$\begin{array}{l}\text { Percent } \\
\text { Asphalt } \\
\text { Content }\end{array}$} & \multirow{3}{*}{$\begin{array}{l}\text { Gyration } \\
\text { Number }\end{array}$} & \multirow{3}{*}{$\begin{array}{c}\text { Specimen } \\
\text { Height } \\
(\mathrm{mm})\end{array}$} & \multicolumn{3}{|c|}{ Weight $(\mathrm{g})$} & \multicolumn{2}{|c|}{ Specific gravity } & \multirow{3}{*}{\begin{tabular}{|c|}
$\begin{array}{c}\text { Voids in } \\
\text { total mix }\end{array}$ \\
VTM \\
\end{tabular}} & \multirow{3}{*}{\begin{tabular}{|c|}
$\begin{array}{c}\text { Voids in } \\
\text { mineral } \\
\text { aggregate }\end{array}$ \\
VMA \\
\end{tabular}} & \multirow{3}{*}{$\begin{array}{c}\text { Voids } \\
\text { Filled } \\
\text { VFA } \\
\end{array}$} & \multirow{3}{*}{$\begin{array}{c}\% \mathrm{G}_{\mathrm{mm}} \\
\mathrm{N}_{\mathrm{ini}}\end{array}$} & \multirow{3}{*}{$\begin{array}{c}\mathrm{P}_{0.075} \text { to } \\
\mathrm{P}_{\mathrm{be}}\end{array}$} \\
\hline & & & & In Air & In Water & (SSD) & Bulk & Maximum & & & & & \\
\hline & & & & A & $\mathrm{C}$ & $\mathrm{B}$ & & & & & & & \\
\hline \multirow[t]{2}{*}{1} & \multirow{5}{*}{$5.9 \%$} & 6 & 125.9 & & & & 2.115 & & & & & & \\
\hline & & 50 & 115.9 & 4654.6 & 2661.7 & 4687.3 & 2.298 & & & & & & \\
\hline \multirow[t]{2}{*}{2} & & 6 & 125.3 & & & & 2.117 & & & & & & \\
\hline & & 50 & 115.5 & 4636 & 2648.4 & 4667 & 2.297 & & & & & & \\
\hline Avg. & & & & & & & 2.2975 & 2.46 & $6.6 \%$ & $17.2 \%$ & $61.6 \%$ & $86.0 \%$ & 1.47 \\
\hline \multirow[t]{2}{*}{1} & \multirow{5}{*}{$6.4 \%$} & 6 & 124.9 & & & & 2.140 & & & & & & \\
\hline & & 50 & 115.0 & 4653.9 & 2676.3 & 4679 & 2.324 & & & & & & \\
\hline \multirow[t]{2}{*}{2} & & 6 & 124.5 & & & & 2.149 & & & & & & \\
\hline & & 50 & 114.6 & 4676.1 & 2702.9 & 4705.6 & 2.335 & & & & & & \\
\hline Avg. & & & & & & & 2.3295 & 2.442 & $4.6 \%$ & $16.5 \%$ & $72.1 \%$ & $87.8 \%$ & 1.33 \\
\hline \multirow[t]{2}{*}{1} & \multirow{5}{*}{$6.9 \%$} & 6 & 125.6 & & & & 2.141 & & & & & & \\
\hline & & 50 & 115.5 & 4694.8 & 2705.8 & 4722.4 & 2.328 & & & & & & \\
\hline \multirow[t]{2}{*}{2} & & 6 & 124.1 & & & & 2.155 & & & & & & \\
\hline & & 50 & 114.2 & 4675.7 & 2707.4 & 4704 & 2.342 & & & & & & \\
\hline Avg. & & & & & & & 2.335 & 2.425 & $3.7 \%$ & $16.7 \%$ & $77.8 \%$ & $88.6 \%$ & 1.21 \\
\hline \multirow[t]{2}{*}{1} & \multirow{5}{*}{$7.4 \%$} & 6 & 124.6 & & & & 2.163 & & & & & & \\
\hline & & 50 & 114.7 & 4715.4 & 2728.2 & 4734.9 & 2.350 & & & & & & \\
\hline \multirow[t]{2}{*}{2} & & 6 & 124.7 & & & & 2.155 & & & & & & \\
\hline & & 50 & 114.7 & 4707.2 & 2720.2 & 4729.5 & 2.343 & & & & & & \\
\hline Avg. & & & & & & & 2.346 & 2.407 & $2.5 \%$ & $16.7 \%$ & $85.0 \%$ & $89.7 \%$ & 1.12 \\
\hline
\end{tabular}



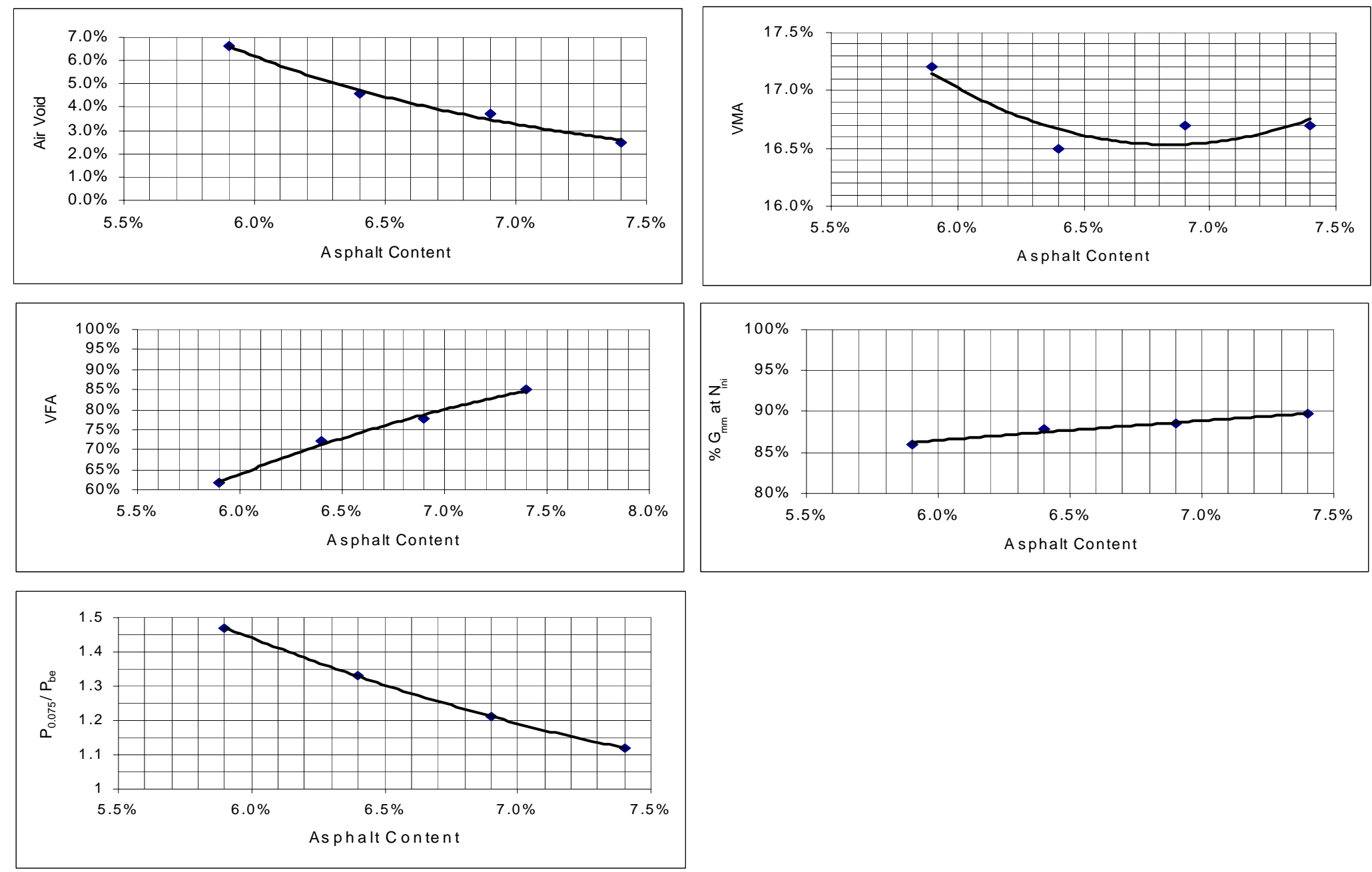

Figure B6. Volumetric properties plots mix design 15: Superpave, 60 percent limestone - 40 percent natural sand. 
Table B7. APA rut depths for Phase II Superpave mixes

\begin{tabular}{|c|c|c|c|c|c|c|}
\hline \multirow{3}{*}{ Design \# } & \multirow{3}{*}{$\begin{array}{l}\text { Gradation } \\
\text { Blend }\end{array}$} & \multirow{3}{*}{$\begin{array}{l}\text { Dust } \\
\text { Content } \\
\text { percent }\end{array}$} & \multicolumn{4}{|c|}{4.0 percent Voids in total Mix } \\
\hline & & & \multirow{2}{*}{$\begin{array}{l}\text { Reading } \\
\text { Position }\end{array}$} & \multicolumn{3}{|c|}{ Pill Position } \\
\hline & & & & Left & Center & Front \\
\hline \multirow{6}{*}{1} & \multirow{6}{*}{$\begin{array}{c}85 \text { percent } \\
\text { limestone } 15 \\
\text { percent } \# 9\end{array}$} & \multirow{6}{*}{4} & \multirow{2}{*}{ Back } & 9.71 & 9.88 & 9.64 \\
\hline & & & & 9.54 & 9.64 & 9.67 \\
\hline & & & Avg. & 9.63 & 9.76 & 9.66 \\
\hline & & & \multirow{2}{*}{ Front } & 8.98 & 9.72 & 9.6 \\
\hline & & & & 9.11 & 9.5 & 9.64 \\
\hline & & & Avg. & 9.05 & 9.61 & 9.62 \\
\hline \multirow{6}{*}{2} & \multirow{6}{*}{$\begin{array}{c}55 \text { percent } \\
\text { limestone } 45 \\
\text { percent } \\
\text { natural sand }\end{array}$} & \multirow{6}{*}{8} & \multirow{2}{*}{ Back } & 23 & 22 & 22 \\
\hline & & & & 23 & 23 & 23 \\
\hline & & & Avg. & 23 & 22.5 & 22.5 \\
\hline & & & \multirow{2}{*}{ Front } & 22 & 23 & 21 \\
\hline & & & & 22 & 21 & 22 \\
\hline & & & Avg. & 22 & 22 & 21.5 \\
\hline \multirow{6}{*}{3} & \multirow{6}{*}{$\begin{array}{c}60 \text { percent } \\
\text { limestone } 40 \\
\text { percent } \\
\text { natural sand }\end{array}$} & \multirow{6}{*}{12} & \multirow{2}{*}{ Back } & 19 & 20 & 20 \\
\hline & & & & 18 & 21 & 22 \\
\hline & & & Avg. & 18.5 & 20.5 & 21 \\
\hline & & & \multirow{2}{*}{ Front } & 19 & 20 & 20 \\
\hline & & & & 19 & 20 & 21 \\
\hline & & & Avg. & 19 & 20 & 20.5 \\
\hline
\end{tabular}

